\title{
Managing Labour in Small Firms
}

This book explores the manner in which the size of the organisation influences the employment relationship with a focus upon small enterprises. The majority of organisations in the UK economy are categorised as small firms, having under 50 employees, and in 2002 such firms were found to provide 43 per cent of jobs within the economy (DTI, 2002). Clearly these organisations make a critical contribution to the British economy, yet - surprisingly - until quite recently very little was known about how such firms managed their labour. Since the 1990s there has been a growing body of evidence which has explored the employment relationship in small firms and this book fulfils an important task by recognising the importance of this literature, and also by moving the debate forward.

Managing Labour in Small Firms also acknowledges that size - whilst influential in shaping firm behaviour - will interact with context to create particular employment relationships. These relationships are examined in chapters covering:

- HRM in the smaller organisation

- The challenge of undertaking research in such firms

- The impact of regulation

- The influence of social embeddedness

- The affect of the national minimum wage

- Training and development

- Pay construction

- Employee representation

These discussions link the key themes and concepts within employment relations, and illustrate how firm size shapes their articulation and consequent management. Written by well respected specialists in the field, this is one of the only books on the market covering this topic, and as such it will be an essential text for researchers and graduates studying business and management, human resource management and industrial relations.

Susan Marlow is Reader in HRM at De Montfort University. She has extensive experience and an international reputation in the field of small firm research, having her work published in leading academic journals such as Entrepreneurship, Theory and Practice. Dean Patton is Senior Enterprise Fellow at the Institute for Entrepreneurship, University of Southampton; he has undertaken research and consultancy within and on behalf of small firms. His current research interests focus on the evaluation of small firm policy, and training and management development within smaller firms. Monder Ram is Professor of Small Business, and Director of Small Business and Enterprise Research Group, at De Montfort University. He has extensive experience of working in, researching, and acting as a consultant to ethnic minority businesses. He is author of Managing to Survive Working Lives in Small Firms, and co-author of Ethnic Minorities in Business. 


\section{Routledge studies in small business \\ Edited by David J. Storey}

1 Small Firm Formation and Regional Economic Development Edited by Michael W. Danson

\section{Corporate Venture Capital}

Bridging the equity gap in the small business sector

Kevin McNally

\section{The Quality Business}

Quality issues and smaller firms

Julian North, Robert A. Blackburn and James Curran

4 Enterprise and Culture Colin Gray

5 The Financing of Small Business

A comparative study of male and female small business owners Lauren Read

6 Small Firms and Network Economies Martin Perry

7 Intellectual Property and Innovation Management in Small Firms Edited by Robert A. Blackburn

8 Understanding the Small Family Business Edited by Denise E. Fletcher

9 Managing Labour in Small Firms Edited by Susan Marlow, Dean Patton and Monder Ram

10 Promoting Informal Venture Capital

Learning from the UK experience

Richard Harrison and Colin Mason 


\section{Managing Labour in Small Firms}

\section{Edited by Susan Marlow, Dean Patton and Monder Ram}


First published 2005 by Routledge

Published 2017 by Routledge

2 Park Square, Milton Park, Abingdon, Oxon OX14 4RN

711 Third Avenue, New York, NY 10017, USA

Routledge is an imprint of the Taylor \& Francis Group, an informa business

Copyright (C) 2005 Susan Marlow, Dean Patton and Monder Ram for selection and editorial matter; individual contributors their contribution

Typeset in Times by Wearset Ltd, Boldon, Tyne and Wear

The Open Access version of this book, available at www.tandfebooks.com, has been made available under a Creative Commons Attribution-Non Commercial-No Derivatives 4.0 license.

British Library Cataloguing in Publication Data

A catalogue record for this book is available from the British Library

Library of Congress Cataloging in Publication Data

A catalog record for this book has been requested

ISBN 978-0-415-31285-1 (hbk) 


\section{Contents}

List of tables vii

List of contributors viii

1 Introduction 1

SUSAN MARLOW

2 The hunting of the snark: a critical analysis of human resource management discourses in relation to managing labour in smaller organisations

SCOTT TAYLOR

3 Researching the employment relationship in small firms: what are the contributions from the employment relations and small business literatures?

ROBERT BLACKBURN

4 Managerial strategies in small firms

RICHARD SCASE

5 Training in smaller firms

DEAN PATTON

6 Breaking out of survival businesses: managing labour, growth and development in the South Asian restaurant trade

MONDER RAM, TREVOR JONES, TAHIR ABBAS AND SARA CARTER 
vi Contents

7 Labour regulation and SMEs: a challenge to competitiveness and employability?

MARK HART AND ROBERT BLACKBURN

8 Small firms and the National Minimum Wage 159

JIM ARROWSMITH AND MARK GILMAN

9 Managing variable pay systems in smaller workplaces: the significance of employee perceptions of organisational justice

ANNETTE COX

10 Representation, consultation and the smaller firm

A L AN R Y A N

Index 


\section{Tables}

3.1 Studies of employment relations in small firms: methods and key points

3.2 Features of small business employment relations

3.4 Size distribution of enterprises in UK with employees (start 2002)

3.5 Number of articles on 'employment relations' and small firms

6.1 Composition of South Asians and total unemployment in the 'Balti Quarter'

6.2 Typology of break-out

7.1 Statutory maximum working week (2000) 136

7.2 Areas of recent legislation on employment rights in the UK 141

7.3 Summary of owner-managers awareness of IERs 144

7.4 Owner-managers' awareness of IERs covered by legislation 145

7.5 Equation for composite awareness of individual employment rights

7.6 Constraints on business performance over last two years 148

7.7 Influence of employment rights legislation on business operations

7.8 Highest negative counts on impact of IERs by sector 151

7.9 Highest negative impact of IERs by female orientation 153

8.1 Typology of response to employment regulation 173

9.1 Firm characteristics 184

9.2 Employee perceptions of fairness of pay level 185

9.3 Percentage of employees believing that pay should be variable 186

9.4 Percentage of employees supporting each potential criterion for variable pay

9.5 Employees believing that poor performers receive less money than good performers

9.6 Earnings of case study company employees compared with national averages

9.7 Employee knowledge of better paying employers in the local area

9.8 Employee perceptions of pay system fairness 


\section{Contributors}

Dr Tahir Abbas is Lecturer in Sociology and Director of the Centre for the Study of Ethnicity and Culture, Department of Sociology, University of Birmingham, Birmingham.

Dr Jim Arrowsmith is Senior Research Fellow and Lecturer in Industrial Relations at Warwick Business School, University of Warwick, Coventry.

Professor Robert Blackburn is Director of the Small Business Research Centre, Kingston University, Kingston upon Thames.

Professor Sara Carter is Professor of Entrepreneurship at the Hunter Centre for Entrepreneurship, University of Strathclyde, Glasgow.

Dr Annette Cox is Lecturer in Employment Studies, Manchester School of Management UMIST, Manchester.

Dr Mark Gilman is Lecturer in Industrial Relations/HRM at Canterbury Business School, University of Kent at Canterbury.

Professor Mark Hart is Professor of Small Business Research at Small Business Research Centre, Kingston University, Kingston upon Thames.

Professor Trevor Jones is Visiting Professor of Strategy and Management at De Montfort University, Leicester.

Dr Susan Marlow is Reader in HRM, Small Business and Enterprise Research Group, De Montfort University, Leicester.

Dr Dean Patton is Senior Enterprise Fellow, Institute for Entrepreneurship, University of Southampton, Southampton.

Professor Monder Ram (OBE) is Professor of Strategy and Management, Small Business and Enterprise Research Group, De Montfort University, Leicester.

Alan Ryan is Senior Lecturer in Employment Relations at De Montfort University, Leicester. 
Professor Richard Scase is Professor of Organisational Behaviour at Canterbury Business School, University of Kent at Canterbury.

Dr Scott Taylor is Lecturer in the Organizational Behaviour, International Management and Organization Group, Birmingham Business School, University of Birmingham. 



\title{
1 Introduction
}

\author{
Susan Marlow
}

In a recent discussion paper pertaining to theoretical shifts and challenges in the study of the contemporary employment relationship, Edwards (2001:3) argues that ignoring emerging sectors of the economy and associated developments in management theory is blinkered and indeed, counterproductive. Whilst arguing that new areas for study and debate must be recognised, Edwards also states that these must be seen to be part of wider, established theoretical analyses in that, 'tools such as the effort wage bargain (are) equally applicable'. Hence, it was suggested that whilst debate upon developments in labour management must have foundations set in fundamental terms and concepts, it must also recognise how particular situations and circumstances, such as firm size, will shape and influence the articulation of these concepts within the organisation. This book demonstrates the manner in which the size of the organisation influences the effort-wage bargain (Burowoy, 1979). Illustrated by the range of issues and arguments included within this text, it is evident that organisation size will affect the manner in which the employment relationship is managed. However, it is also acknowledged that size, whilst influential in shaping firm behaviour, will interact with a number of other extraneous elements such as market constraints, sector, location, age (amongst others). These will, in turn, interact with characteristics such as management styles, family dynamics, skill profiles, owner gender and ethnicity; the outcome of these complex interactions being varied and shifting employment relationships.

So, whilst sensitive to heterogeneity arising from context, the underlying argument within this book is that it is possible to recognise and accommodate difference within labour management in small firms whilst identifying a number of key themes and concepts which will offer an analytical framework and foundation to this work. As such, this book differs from others which focus on contemporary employment relations by considering the manner in which fundamental concepts pertaining to labour management in a market economy, such as the effort-wage bargain, are shaped particularly by the context within which the firm operates. Hence, whilst drawing upon a number of key areas in current debate such as 


\section{S. Marlow}

human resource management (HRM) as a new managerial strategy, employee representation and employment regulation, this collection of essays illustrates how the size of the firm, in conjunction with other influences, such as sector, forms a lens through which specific articulations of the effort/wage concept can be analysed.

When considering the extant literature which explores the employment relationship in small firms, there is a growing sophistication in the material which acknowledges heterogeneity within sector, whilst developing conceptual themes drawn from accepted theory and applying this to the specific circumstance of the smaller organisation. So, whilst the current body of evidence exploring employment relations in small firms is limited, compared to that of larger firms, it is notable for its increasing complexity in unpicking how firm size, in tandem with other contingent factors, will influence the manner in which labour is managed. Indeed, just recently, it has been argued that within the sociological discipline of work and organisations, the growing sophistication of the literature pertaining to labour management in small firms is, 'a key exemplar of analytical advance ... (and) British research has made substantial empirical and analytical progress' (Ram and Edwards, 2003:719). This book will contribute further to this debate through discussion and analysis of the manner in which firm size, in accordance with other factors, impacts upon labour management. To set these current debates in context, a critical evaluation of the extant literature pertaining to this area of study will be briefly outlined after which there will be a consideration of how the contributors to this text advance this debate.

As interest in the experience of small firm ownership grew from the mid-1970s so did a certain myth that labour management in small firms was, in general, 'harmonious' with proof of this assertion evident by the absence of collective dispute (Bolton, 1971). Although the analysis of labour management in small firms commanded little attention during the 1980s (Matlay, 2002), the emergent debate focused largely around dispelling the harmony thesis. Rather, it was argued that industrial relations in small firms was generally defined by autocratic owner prerogative (Rainnie, 1989) leading to highly exploitative labour relations. In his challenge to the 'harmony' thesis, Rainnie argued that the structure of the market economy, founded upon the domination of large capitals ensured that small firms were limited in their operations primarily to subcontracting or within niche areas where it was irrational for large firms to operate. Such market positioning then critically affected the nature of the employment relationship in such firms. In effect, in markets where large organisations dictate supplier relationships small firm owners and managers are largely denied choice regarding the manner in which they manage labour as observing cost constraints and meeting quality targets takes away options for independent decision making. For those firms who locate in niche areas and so do not enter such supply chains, the nature of 
the market, by definition, limits their operational scope and so again, survival under such constraints will lead to specific and exploitative approaches to labour management. This analysis broadened the debate to locate small firms within the wider market environment, arguing that centralised and fragmented capital have a symbiotic relationship, if asymmetrical in terms of power. Hence, large firms dominate markets in such a way as to essentially dictate the employment relationship in both their smaller suppliers and those confined to niche markets.

In expounding this analysis, Rainnie used a series of taxonomies reminiscent of Weberian ideal types to describe how the market positioning of smaller firms would determine their modes of operations and management strategies. To some degree this was a useful device as it challenged the notion of homogeneity based upon size alone. The focus upon market determinism, however, did somewhat narrow the scope to generate further analyses of the employment relationship in small firms whilst the use of taxonomies is constricting. Although this device is useful in recognising degrees of heterogeneity, the nature of the model by necessity, crudely categorises firms on the basis of limited descriptors. In a contrasting consideration of employment relations in small firms, whilst still favouring the taxonomy approach, Goss (1991) based his typologies of labour management on a wider ranges of influences drawing together both market structures and the impact of owner prerogative upon management style. This led to a more sensitive, sociological assessment which recognised the interplay of structure and agency in the dynamic links between the internal and external environment of the firm (Gorton, 2000), thus acknowledging the impact of the social relations of production upon labour management practices.

Indeed, recent work which has advanced the analysis of the employment relationship in small firms recognises the complex interplay between the position of the organisation in the wider economy and the components which make up the 'black box' of the firm itself (Ram, 1994; Holliday, 1995; Moule, 1998). This case study material, gathered in the 1990s, proved to be both sensitive to market constraints whilst acknowledging how the internal dynamics within the firm led to heterogeneity within the sector. This work illustrated how owners actually managed their employees in situ and also, how employees experienced their work in small firms and were in fact able, to differing degrees, to manipulate their own labour process. Reminiscent of the classic case studies of large firms in the 1970s and 1980s (Beynon, 1973; Nichols and Beynon, 1977; Cockburn, 1983) studies of labour management in smaller firms echoed this approach with their intimate portrayals of how the employment relationship was constructed, changed and challenged in such firms. So for example, the study of three small textile firms owned by members of ethnic minorities enabled Ram (1994) to analyse the interplay between sector, ethnicity and gender and then demonstrate how firm size was critical in deciding how these 


\section{S. Marlow}

influences collided to generate a particular employment relationship. In recognition of the negotiated nature of the employment relationship, Ram (1994:150) suggests that the market-based autocracy thesis did not adequately 'convey the bargained nature of life on the shop floor, the extent of mutual dependency between workers and management and the importance of informal accommodation'.

The primary influence of market conditions upon the employment relationship was further challenged by Holliday (1995), who explored the manner in which family ownership structures shaped this relationship and how, in particular, paternalism pervaded labour management. The ensuing employment relationship then developed around notions of deference and mutual dependence, but this also acted to obscure exploitative behaviour as notions of obligation intruded, particularly where family members were also employees.

Developing this focus upon the dynamic interplay between the social relations of production and market imperatives, Moule's (1998) study of a button factory brought together issues of firm size in a context of subcontracting dependence. Just as in the other cases discussed, he observed an employment relationship which was constructed around negotiation, toleration and occasional outbursts of employer prerogative. In this particular study, Moule was a participant observer so was able to observe first hand, and over some time, the manner in which the proximity between the Directors and the employees facilitated a particular employment relationship where mutual dependence was tacitly recognised, if unevenly applied. Within Button Co. this led to a situation where, 'the toleration of certain fiddles, practices [by employees] and unpredictable patterns of behaviours by the Directors did not appear to stem from any other motive other than ensuring workable day to day relations' (Moule, 1998:652). Thus, it was argued that this firm had a complex approach to labour management whereby Directors would ignore certain behaviours if targets were met but levels and degrees of toleration were differentiated dependent on employee status. This debate around the notion of consent and control is well rehearsed (Burowoy, 1979) and the type of behaviour identified by Moule in Button Co. is evident throughout the economy. But what sets this firm and many small firms aside in this debate is that this behaviour is not bounded or underpinned by the bureaucratic rationality of formal management processes, a point which will be explored in more detail below. Instead, the business was based upon an informal, tacit, uneven managerial approach which was negotiated and renegotiated on a frequent basis. This work, as part of the wider evidence to analyse the complexity of employment relations in small firms which emerged in the 1990s (see also, Curran et al., 1993; Matlay, 1999; Ram, 1999) advanced the debate by demonstrating the manner in which firm size facilitates social negotiation between employees and employers around the labour process.

These case studies have been particularly helpful in revealing the inter- 
action between markets, firms, owners, managers and employees which then in turn, shapes the manner in which labour is managed. The findings support the notion that it is somewhat simplistic to argue that the employment relationship in small firms is determined solely by the market and so, from necessity autocracy, not harmony, dominates. It would appear that market influence is critical, but equally, the particularistic social relations of production generated within a context of smallness and proximity will facilitate differentiated degrees of negotiation between employers and employees regarding the terms and conditions of employment. As such, the form and content of the employment relationship in small firms arises from the interplay of these factors rather than either one alone. A critical outcome of this more complex analysis focuses around the importance of informal management approaches in small firms. In this context, informality and formality are presented as opposing constructs where the former is perceived to encompass an approach where labour management is largely emergent, flexible and loosely structured. As such, in the small firm this would appear to be an outcome from a number of factors, of importance amongst these is the preference of owners to manage labour either themselves or delegate this task to a general manager. Consequently, there is an absence of informed professional HR management, this ensures that contemporary and appropriate HR policies and practices are unlikely to be in place plus, management by the uninformed encourages and perhaps even requires the intrusion of personal idiosyncrasies and priorities (Wynarczyk et al., 1993; Marlow, 2002). Formality, however, might usefully be described as where:

terms and conditions of employment are formally contracted so both labour and management have recourse to a set of rules, should they feel it appropriate to use them. Moreover, the presence of HR professionals who can be called upon to formulate policy and apply rules and regulations facilitates a more 'arms length' or anonymous application of formality which emphasises bureaucratic rationality.

(Marlow, 2002:4)

This notion of informality in small firms is a useful construct as a general indicator of difference between the employment relationship in small and large enterprises with empirical evidence, drawn from both fine grained research (Marlow and Patton, 2002) and large surveys (Matlay, 2002) supporting this notion, whilst of course, exception is recognised. So, for example Cully et al. (1999) in WERS did find that smaller firms were likely to have some formal policies in place - particularly regarding discipline issues. It is interesting to note that Marlow (2002), in a qualitative study of labour management in manufacturing firms, also found some degree of co-existence between formality and informality, but upon closer analysis found that whilst policy was in place, owners were reluctant to use 


\section{S. Marlow}

it. This occurred as the close proximity between employer and employee generated a social relationship into which formality could not readily intrude. This social relationship emerged in a number of ways, some of which were highly exploitative, but whether harsh or based around friendships and team working, the resort to formality was unlikely as this in fact 'professionalised' the employment relationship where previously there had been no precedent for this. Matlay (2002), in his survey of 6,000 SME owners, looked for any 'mix' of formality and informality but found little evidence for this and a significant preference for informal approaches to labour management by small firm owners.

However, it is recognised that it is overly simplistic to subscribe to a dichotomy of formality and informality without recognising the dynamic nature of such constructs as noted by Ram et al. (2001:846), who suggested that 'informality is therefore, a matter of degree and not kind' when arguing that the manner in which informality is articulated changes over time and is sensitive to context. Drawing upon a study of the impact of regulatory shock, specifically the introduction of the National Minimum Wage (NMW), Ram et al. argued that informality was not solely an outcome of owner prerogative but is also a necessary response to accommodating fluctuating product and labour market demands. In essence firms were combining flexibility and informality to remain viable.

There can be little dissent, however, from the notion that a defining feature of firm growth is increasing bureaucracy which will, of course, also apply to the employment relationship (Wynarczyk et al., 1993). This is articulated through the development of formal policy and practice administered by a personnel function subject to updating and, where trade unions are recognised, amendment through collective bargaining. Studies of labour management in large firms again demonstrate the co-existence of formality and informality, indicating that whilst the former 'bounds' the employment relationship, the latter underpins it (Nichols and Beynon, 1977; Westwood, 1986). Moreover, despite recent volatile markets, shifts towards greater managerial prerogative and diminishing union power, the informal manipulation of the labour process persists and continues to be tolerated to a greater or less degree (Elger and Smith, 1998; Webb and Palmer, 1998).

So, it would appear that within all firms there is a differentiated degree of co-existence between informal and formal labour management approaches which suggests that it is too simplistic to develop an uncritical correlation between firm size and these concepts. Whilst recognising this, Marlow (2002) draws attention to the fact that within larger firms, the dynamic of control and consent is bounded by formality in that if, and when, line managers have to overtly assert authority, they have the channels by which to do so or indeed, where necessary or preferred, they can even delegate this task to the professional HR function. Equally, the recourse to formal policy and practice is available to employees or their 
trade union representatives should they wish to individually, or collectively, assert their rights within the employment relationship.

From this, it is argued that informality in large firms, although an enduring if changing feature of the employment relationship, is to a degree, a subversive activity. Whilst many informal practices are accepted under the auspices of custom and practice, this is only ever discretionary with both labour and management being able to challenge these practices should the need arise. This is not the case in small firms where formality is less likely to 'police' informality as, even where the former is in place, owner/managers seem reluctant to use it. As noted above, this is supported by survey and case study evidence (Cully et al., 1999; Marlow, 2002) regarding the presence of formal discipline/grievance policies. Yet, as small firms are still overrepresented at Employment Tribunals (Earnshaw et al., 1998) in unfair dismissal cases it would appear that they are either over-selecting litigious employees or failing to apply appropriate policy in the correct manner. The latter scenario would appear more likely. So, whilst the constructs of informality and formality are useful in the debate regarding the association between firm size and employment relations, this is a complex association. Rather, it would appear that formality and informality co-exist in all firms but the degree to which this occurs and the manner in which it emerges will be influenced by firm size. Hence, larger firms are likely to be bounded by formality whereas their smaller counterparts are likely to adopt this approach as an outcome of a range of influences which include, amongst others, owner prerogative, professional ignorance, the need to respond flexibly to market shifts and employer/ employee dynamics. Thus, some degree of difference can be identified between the articulation of formality and informality in large and small firms whilst still acknowledging heterogeneity and change both within firms themselves and within their market context.

Empirical evidence relating to the manner in which regulatory compliance is managed by smaller firms is a good illustration of the impact of external change upon the articulation and accommodation of informality. Regulating the employment relationship through the strengthening of individual rights and, to a lesser degree, collective rights has been a critical element of contemporary Labour government policy (Labour Party, 2001). This has been articulated through the recognition and adoption of European regulation (albeit in a minimal fashion [McKay, 2001]), the enactment of legislation to introduce a National Minimum Wage (NMW) in 1998, plus the Employment Relations Act (1999) and the Employment Act (2002). Overall, the introduction of an increasing tranche of employment regulation has been seen to be particularly problematic for smaller firms. If, as the evidence would indicate, that many such firms rely on differing degrees of informal, flexible, even idiosyncratic labour management, adopting a regulatory approach will be challenging as it is axiomatic that compliance is demonstrated by inclusion within existing, established 


\section{S. Marlow}

policy. There has been considerable resistance to the regulation agenda by pressure groups representing small businesses in particular (FSB, 2000) with dire predictions made regarding the impact of increasing regulation upon the performance of the small firm sector per se (Oldfield, 1999). However, the empirical evidence which has emerged regarding this issue suggests that the impact of compliance has been considerably less disastrous than predicted with negative perceptions outweighing 'experiential effects' (Blackburn and Hart, 2001:764).

Developing an analysis of the challenges surrounding the successful incorporation of NMW regulation into largely informal systems of labour management enables Ram et al. (2001) and Gilman et al. (2002), to unpick the concept of informality in more detail. It was found that whilst informality was positively advantageous in accommodating the NMW as 'the effort bargain was very fluid' (Gilman et al., 2002:65), it was not an outcome solely of owner preference and/or spatial and social proximity with labour. Rather, it was noted in both these papers that the interaction between labour markets, product markets and owner/employee social dynamics generated particular and differing forms of informality which then supported a largely indeterminate approach to pay setting whilst prompting specific responses to pay change. For some firms this meant ignoring the NMW, others were able to adjust fairly easily but the authors of these studies reveal that whilst informality assisted this process, the manner in which it was articulated adapted itself in accordance to changes being introduced. This was in response to both external market conditions and internal approaches to labour management and again, illustrated that informality is not just a product of owner prerogative but an outcome of a number of influences which go beyond the whim of owner choice alone.

This brief overview of some of the critical developments in the literature pertaining to employment relations in small firms serves to demonstrate the growing sophistication of this analysis. Contrary to the belief of Barrett and Rainnie (2002), the literature has moved forward from the generalised dichotomy focused upon notions of 'small is beautiful' or 'bleak house scenarios'. Rather, as evidence has accumulated around analyses which delve into the nature of employment relations in small firms, knowledge has become more detailed and far more sensitive to issues of heterogeneity within the sector as well as the dynamic between these enterprises and their larger counterparts. What has emerged is an argument which suggests that the effort-wage bargain is an outcome of the interaction between the external market positioning of the firm and the internal dynamics of the enterprise. Gilman et al. (2002:54) usefully summarises this commenting that, 'the balance between some form of negotiation and direct employer autocracy and the whip of the market is likely to be determined by employee skill, scarcity value, and the extent to which there are fraternal or familial relationships'. 
Whilst concepts of formality and informality have been applied rather generally, in the light of recent evidence stemming largely from the regulation debate, it has emerged that these constructs have a co-, rather than counter-, existence and should not be seen as simply emerging from the interplay of firm size and owner prerogative. Rather, there is a complex relationship between wider issues such as contemporary market pressures and how these are articulated within the firm. Moreover, it is simplistic to perceive informality as irrational, inappropriate or unprofessional. Work by Ram (1994), Marlow (2002) and Gilman et al. (2002) indicates that informality facilitates a flexible response to changing environments and so is positively advantageous to firm survival and stability whilst recognising that it leaves employees vulnerable to employer prerogative. The manner in which the study of the employment relationship in small firms is a critical element in the contemporary analysis of shifting labour management policy and practice is now clearly acknowledged (Edwards, 2001). This book will advance the debate further through the consideration of a range of critical issues in employment relations and how they are articulated, modified, understood and practised within smaller firms.

So, in chapter 2, Taylor analyses the manner in which HRM theory and practice has been explored in relation to smaller organisations. The discussion is thought provoking in that it explores Townley's (1993) argument which views HRM as a discourse. In so doing, it is suggested that it is necessary to consider how this discourse is introduced into smaller organisations; to undertake this task it is essential to analyse the structural and cultural conditions that influence the introduction of HRM into smaller firms. As such, the notion of HRM as an objective set of policies and procedures strategically linked to performance enhancement is challenged. In many ways, the smaller firm emerges as the 'other' in organisational studies as the normative model is that of the complex, hierarchical enterprise equipped with appropriate systems to apply new managerial strategies such as HRM, to labour management. Taylor explores this notion, critically evaluating the presumptions underpinning HRM which demand sophisticated managerial practices combined with an ideological investment in the concept of HRM to ensure successful adoption. Taylor draws two key conclusions: first, that the culture of the firm, of management, of labour, of HRM and of regulation is a critical mediating influence which must be understood to fully comprehend differing approaches to labour management; second, Taylor draws attention to the manner in which HRM is linked to performance enhancement as it aims to limit indeterminacy between employee effort and output. This approach, however, is not in accordance with the socially embedded and negotiated employment relationship more likely to be found in smaller organisations and so leads to a degree of tension as firms grow and the negotiated stance is gradually replaced by one which is based upon more structured policy and practice. Currently, it is argued, the theory to explore this shift is narrow and so 
should be challenged and developed to add to our conceptual knowledge of the role of HRM.

The discussion by Taylor questions accepted theory and practice regarding new managerial strategies and their articulation in firms of differing sizes, so the next chapter by Blackburn, focusing upon methodological approaches underpinning contemporary knowledge of the employment relationship, complements this debate. Blackburn begins with an exploration of the evolution of employment relations research in small firms; during this analysis the methodological challenges of undertaking such work are considered. Moving on from this general overview, the chapter reviews in more depth the degree to which labour management in small firms has been incorporated into the time series dates captured by the Workplace Industrial Relations survey (now Employment Relations). This survey is seen as a barometer by which labour management strategies, policies and practices can be revealed and evaluated and data from these studies informs a wide range of literatures exploring many different facets of labour management. So in many ways, that which is included in this survey is deemed to be the critical core of what actually constitutes the employment relationship. Given that until the late 1990s, small businesses were excluded from the survey suggests that, regardless of the fact that 99.1 per cent of enterprises in the UK economy are classed as such and these firms employ 43 per cent of the private sector workforce (DTI, 2002), the conditions under which labour is managed in these organisations have only just been considered to be of consequence to the wider debate.

Hence, whilst the survey methodology in itself has been subject to critique (see McCarthy, 1994 for example), this discussion advances the debate further with a consideration of how the adoption of specific methodological parameters can effectively define that which constitutes key issues in a field of study. This chapter reveals the growing integration of small firm labour management research into the mainstream debate and it is noted that the first WERs study to be published in the twenty-first century will have again broadened this particular analysis. This chapter argues that there is now a rich and varied body of research drawing upon diverse methodologies which serve to illustrate the manner in which labour is managed in small firms, and moreover this contribution is critical to the wider understanding of the employment relationship in the contemporary economy.

An important element of the last chapter focused upon the manner in which large firms are taken as constituting the normative model of labour management which leads to a focus upon such organisations to advance developments in theory and illustrate change in practice. However, it is argued that such bias leads to a 'skewed' picture of what is happening in the contemporary employment relationship as it offers only a partial view of events; chapter 4 supports this notion. Traditionally, strategic manage- 
ment was a set of complex practices associated with large, sophisticated firms and so, by its very constitution, is not utilised in small firms. Despite developments in the strategy field and particularly, the emergence of HRM theory with its focus upon the strategic use of labour, smaller firms have been largely excluded from this debate as it is assumed that firm size will preclude the utilisation of such management practices which are associated with complex, large organisations. This notion is critically evaluated by Richard Scase through his analysis of sectoral heterogeneity which draws comparisons between managerial strategies in the traditional manufacturing sector and those in the fast growing creative and professional areas of the economy. From this analysis, it is concluded that the diverse context within which small firms operate ensures that there can be no allembracing operational textbook advice which offers definitive advice upon the 'best' approach to managing small firms. Consequently, strategic management of large firms is informed by very different considerations to those of its smaller counterparts, reflecting this assertion, this discussion draws attention to the way in which firm context shapes the manner in which strategy is devised and articulated.

One facet of effective strategic development is to enhance opportunities for individual and organisational learning and training. However, drawing upon the extant literature, it would appear that smaller firm owners, in general, invest few resources in formally developing either themselves, their managers or employees. Empirical evidence (Patton and Marlow, 2002) would indicate that informal approaches to training and learning are the preferred mode of development and this in itself is considered problematic. There is a presumption that an absence of formally delivered training and development with measurable inputs and outputs will contribute to a general erosion of the national skill base and prevent organisations building strategic capabilities (Harrison, 2002). In chapter 5, Patton explores this area in more detail challenging the generalisation that 'small firms do not train' with an analysis sensitive to issues of formality and informality in issues of learning and development. It is overly simplistic to suggest that training, development and learning which enhances key competencies does not occur in smaller firms, but rather, the manner in which these practices are articulated will be shaped by firm context and so differ from the formal large firm model. However, in his analysis of current arguments Patton considers some of the implications of trying to integrate informal models of training into the mainstream arena, for example, how to 'measure' the extent and impact of training, development and learning upon the individual, the firm and the economy as a whole. If the aim of the government is to improve measurably upon the level of skill and competence in the economy, assessing the contribution of informal training in smaller firms to this agenda would be challenging. It is recognised, however, that engaging small firms in the training agenda has proved to be difficult; as there is little likelihood of regulation in the UK to ensure 


\section{S. Marlow}

training becomes incorporated into firm practice and policy, alternative routes are required to address this issue. Drawing upon the extant evidence, this chapter argues for a more inclusive approach to training and development that recognises the value of informal initiatives whilst sensitivity to the diversity of sectoral needs is key to ensuring that training initiatives are perceived as both relevant and able to add value to the organisation.

So, it is argued that the manner in which teaching, learning and development emerges within firms is linked to context. Developing this concept further, in chapter 6, Ram et al. link the notion of social embeddedness and the employment relationship; Granovettor's (1985) theory of mixed embeddedness argues that economic rationale alone is not sufficient to explain individual choices and actions, rather, action is influenced by social and geographical environments. This thesis is particularly useful in the analysis of the employment relationship where the penetration of the local/social/cultural environment into labour management practices is evident. One area of employment which reflects the mixed embeddedness concept is that of ethnic minority labour; there are notable enclaves of employment which are dominated by different ethnic minority groups, for example, the Indian restaurant sector. This chapter analyses the notion of mixed embeddedness, how this is articulated, what the consequences are for employment issues and, critically, will draw together theories of embeddedness and ethnicity whilst demonstrating how the context of firm size has a fundamental affect upon this relationship. Ram et al. specifically focus upon the notion of breakout - that is moving away from traditional ethnic minority business niches - and the strategies firms might use to achieve this aim. In exploring this process, the chapter finds that reliance on social networks for key assets such as finance and employees is important at start up, but if the firm does not broaden its networks, serious limitations will be placed upon its ability to access alternative sources of human and social capital. Sectoral location was also found to be influential in terms of breakout, so for example, the restaurant sector is currently buoyant but this has attracted growing numbers of enterprises leading to market saturation. This situation, in itself, has motivated greater creativity in product and process differentiation, which has in turn required shifts in labour management strategies to attract new staff with expertise in these particular areas.

From this analysis of embeddedness it appears that a range of influences combine in a dynamic and variable fashion to shape the employment relationship, hence efforts to formalise and regulate labour management will be potentially disruptive to the organic and negotiated nature of this relationship. However, successive Labour administrations, elected since 1997, have focused upon labour market regulation as the most appropriate manner in which to restore 'fairness at work' whilst reflecting the social agenda favoured by the European Union. The Employment Relations Act (1999), which was an amalgamation of new legislation and statutory 
amendments, aimed to establish a floor of individual employment rights, offer some limited new rights to trade unions and place 'family friendly' policies upon the statute book. Attempts to regulate the employment relationship have been resisted by employers' organisations - particularly small-firm pressure groups - who argued that compliance costs threaten firm viability whilst stifling enterprise. Exploring such issues in more detail, in chapter 7, Hart and Blackburn develop an analysis of the labour regulation debate and the degree to which blanket policy imposition, presuming a degree of homogeneity across the economy with a fixed notion of universal best practice, can be effective. To add a new dimension to this debate, the authors also place their arguments in the broader European context of regulation to assess to what degree the UK does suffer under any excessive regulatory burden. Drawing upon empirical evidence, the manner in which regulation and compliance issues are dealt with by smaller firms and consequent implications for policy development, employee rights and firm viability are critically evaluated. From this evidence the authors found that contrary to images portrayed by the media and small business pressure groups, regulation did not emerge as the primary constraint upon business performance. In fact, market competition was identified as the greatest challenge in this respect. What has emerged, however, is that once again, the level of heterogeneity within the sector is influential; so micro firms reported few negative aspects whilst those firms who depended heavily upon female employees were more likely to be affected by new maternity rights. Whilst acknowledging such diversity within the sector, Hart and Blackburn did note a more generalisable negative predisposition regarding regulation even when owner/managers professed to have very little knowledge of the details of such. Overall however, this chapter does not support the notion that currently, new regulation is a significant obstacle to small firm development in the UK, but does draw attention to differences between EU member states regarding SME perceptions and responses to regulation which reflects both the pace and intensity of such change.

Having explored recent shifts in regulatory regimes and the manner in which the context of the firm ensures that unproblematic, informed and complete compliance is unlikely, the impact of a particular element of recent regulation is analysed in more detail. The introduction of a National Minimum Wage (NMW) stimulated wide-ranging debate regarding potential damage to overall economic performance and smaller firms in particular. It was argued that the marginal position of many smaller organisations meant that any extra financial demands upon them would lead to increasing and extensive levels of firm failure (FSB, 2000). Widespread predictions of firm failure, downsizing and constrained performance do not appear to have been borne out in practice and in chapter 8 , Arrowsmith and Gilman analyse this issue in greater detail drawing upon debates pertaining to theory, role, utility and impact of a national 
minimum wage across the economy. Given the level of concern articulated by various interest and pressure groups regarding the potentially damaging effect of this policy upon smaller firms in particular, this issue will be considered in some depth utilising empirical evidence drawn from a recent study of the impact of the NMW in such firms. The findings from this study suggest that notions of fairness were defined using both external benchmarks, such as local market rates, and internal values of flexibility and 'give and take'. Whilst the NMW had raised very low wages without the predicted growth in unemployment, there was a persistence of so called 'stickiness' in pay and conditions such that there appear to be relatively few direct and determinate effects of this regulation.

Arrowsmith and Gilman demonstrate that the manner in which pay is related to effort and productivity is highly complex and subject to a wide range of influences and variations. In chapter 9, Cox develops this analysis of employment reward with a particular focus upon the context of the firm and how this fashions the construction and perception of payment. Analyses of variable pay systems in the UK are mostly dominated by investigations of individual performance-related pay. There is very little work which compares the process of design, implementation and outcomes across different kinds of variable pay systems and even less into the way pay and pay systems are managed in smaller organisations. This chapter is grounded in well established theory pertaining to the significance of employee involvement and consultation practices and the role of procedural and distributive justice perceptions in introducing variable pay schemes.

Drawing from empirical evidence, the debate examines the application of differing types of variable pay systems. Attention is drawn to the way in which the design of pay systems is influenced by the nature and size of the organisations with perceptions of distributive and procedural justice shaping employee responses to the schemes. The chapter concludes by assessing how far the management of variable pay systems is typical of, and dependent upon, the methods used to manage other aspects of the employment relationship in such firms. The implications for the application of organisational justice theory to the study of pay systems within smaller firms are also assessed.

As noted above, employee involvement and consultation are highly significant in the determination and perception of payment. In this final chapter these key elements within the employment relationship are considered at greater length. Until fairly recently there was a presumption that smaller firms were more likely to enjoy close, harmonious employment relations. As noted in this chapter, this thesis has been effectively challenged with evidence indicating that a complex and shifting range of influences will impact upon labour management in small firms leading to varying outcomes (Rainnie, 1989; Ram, 1994; Moule, 1998). Simplistic correlations between size and labour management style have been exposed as 
both inappropriate and inaccurate. However, one area which has remained rather closed - in terms of evidence and investigation - is that of employee representation in small firms. A number of presumptions underpin this stance; trade unions, as the 'norm' of representation are rarely present; firm owners are hostile to union organising; representation is, therefore, fragmented and ineffective leaving many small firm employees without an effective voice.

In this chapter Ryan explores such notions in greater detail. It is certainly true that unions are no longer synonymous with employee voice in the UK economy per se (Towers, 1997) so, as suggested by other contributors, it is no longer appropriate to see small firms as the 'other' as union representation is unusual in this particular area. This chapter explores issues of voice, communication, consultation and representation and how these concepts are articulated in smaller firms. Evidence would indicate that employees in small non-union firms do have informal and negotiated channels by which they can, to differing and varying degrees, influence their conditions of employment (Ram, 1994; Marlow, 2002). Such channels are created and managed by employers and employees reflecting a range of often disparate influences from the market position of the firm to the nature of social and personal relationships and so are potentially discriminatory and do not challenge underlying power disparities dependent as they are upon social ties. Thus, forthcoming regulation - the Information and Consultation Directive - has some potential to challenge this preference and the implications of this are considered in some detail. Hence, this chapter draws out a range of issues around employee voice and representation in small organisations to demonstrate that this situation is not static and can by no means be presumed to be simply atomised and fragmented.

This collection of essays draws upon a number of key elements in the contemporary labour management field and illustrates how the context of the organisation will shape the manner in which they are articulated. Using a 'lens' of firm size, whilst recognising how other variables also intrude into labour management policy and practice, demonstrates how core concepts underpinning employment relations are sensitive to context and so emerge in a shifting and fluid manner.

\section{References}

Barrett, R. and Rainnie, A. (2002) 'What's so special about small firms? Developing an integrated approach to analysing small firm industrial relations', Work, Employment and Society, 16(3):415-33.

Beynon, H. (1973) Working for Ford, Harmondsworth: Penguin.

Blackburn, R. and Hart, M. (2001) 'Ignorance is bliss, knowledge is blight? Employment rights and small firms', Paper to the 24th ISBA National Small Firms Conference, Leicester, November. 
Bolton Committee Report (1971) 'Report of the Commission of Inquiry in small firms', Cmnd. 4811, London: HMSO.

Burowoy, M. (1979) Manufacturing Consent: Changes in the Labour Process under Monopoly Capitalism, Chicago: University of Chicago Press.

Cockburn, C. (1983) Brothers: Male Domination and Technical Change, London: Pluto Press.

Cully, M., O'Reilly, A., Millward, N., Forth, J., Woodland, S., Dix, G. and Bryson, A. (1999) The 1998 Workplace Employee Relations Survey, London: Routledge.

Curran, J., Kitching, J., Abbott, B. and Mills, V. (1993) Employment and Employment Relations in the Small Service Sector Enterprise, Kingston: Centre for Research on Small Service Sector Enterprises.

DTI Small Business Service (2002) www.sbs.gov.uk/content/statistics/stats2001.xls

Earnshaw, J., Goodman, J., Harrison, R. and Marchington, M. (1998) 'Industrial tribunals, workplace disciplinary procedures and employment practice', Employment Relations Research Series 2, London: DTI.

Edwards, P. (2001) 'Industrial relations: from apparently anachronic to analeptic and anaclastic condition', Paper to the Conference on 'Industrial Relations: an Anachronism', University of Tubingen, June.

Elger, T. and Smith, C. (1998) 'Exit, voice and mandate: management strategies and labour practices of Japanese firms in Britain', British Journal of Industrial Relations, 36(2):185-208.

Federation of Small Business (2000) 'FSB Delivers damning "Red Tape" dossier to government', 23 May, www.fsb.org

Gilman, M., Edwards, P., Ram, M. and Arrowsmith, J. (2002) 'Pay determination in small firms in the UK: the case of the response to the National Minimum Wage', Industrial Relations Journal, 33(1):52-68.

Gorton, M. (2000) 'Overcoming the structure - agency divide in small business research', International Journal of Entrepreneurial Behaviour and Research, 6(5):276-92.

Goss, D. (1991) Small Business and Society, London: Routledge.

Granovettor, M. (1985) 'Economic action and social structure: the problem of embeddedness', American Journal of Sociology, 91:481-510.

Harrison, R. (2002) Learning and Development, London: CIPD.

Holliday, R. (1995) Investigating Small Firms, Nice Work? London: Routledge.

Labour Party (2001) Ambitions for Britain: Labour's Manifesto 2001, London: The Labour Party.

McCarthy, W. (1994) 'Of hats and cattle: or the limits of macro-survey research in industrial relations', Industrial Relations, 25(4):315-22.

McKay, S. (2001) 'Between flexibility and regulation: rights, protection and equality at work', British Journal of Industrial Relations, 39:285-303.

Marlow, S. (2002) 'Regulating labour management in small firms', Human Resource Management, 12(3):25-43.

Marlow, S. and Patton, D. (2002) 'Minding the Gap: managing the employment relationship in smaller firms', Employee Relations, 24(5): 523-9.

Matlay, H. (1999) 'Employee relations in small firms: a micro-business perspective', Employee Relations, 21(3):285-95.

Matlay, H. (2002) 'Industrial relations in the SME sector of the British economy: an empirical perspective', Journal of Small Business and Enterprise Development, 9(3):307-19. 
Moule, C. (1998) 'The regulation of work in small firms', Work, Employment and Society, 12(4):635-54.

Nichols, T. and Beynon, H. (1977) 'Living with capitalism: class relations and the modern factory,' London: Routledge and Kegan Paul.

Oldfield, C. (1999) 'Red tape is strangling enterprise', Sunday Times, 31 October, p. 7.

Patton, D. and Marlow, S. (2002) 'The determinants of management training within smaller firms in the UK: What role does strategy play?', Journal of Small Business and Enterprise Development, 9(3):260-70.

Rainnie, A. (1989) Small isn't Beautiful, London: Routledge.

Ram, M. (1994) Managing to Survive, London: Routledge.

Ram, M. (1999) 'Managing autonomy: employment relations in small professional service', International Small Business Journal, 17(2):13-30.

Ram, M. and Edwards, P. (2003) 'Praising Caesar not burying him: what we know about employment relations in small firms', Work, Employment and Society, 17(4):719-30.

Ram, M., Edwards, P., Gilman, M. and Arrowsmith, J. (2001) 'The dynamics of informality: employment relations in small firms and the effects of regulatory change', Work, Employment and Society, 15(4):845-61.

Towers, B. (1997) The Representation Gap, Oxford: Oxford University Press.

Townley, B. (1993) 'Foucault, power/knowledge, and its relevance for human resource management', Academy of Management Review, 18(3):518-45.

Webb, M. and Palmer, G. (1998) 'Evading surveillance and making time: an ethnographic view of the Japanese factory floor in Britain', British Journal of Industrial Relations, 36(4):611-28.

Westwood, S. (1986) All Day, Every Day, London: Pluto Press.

Wynarczyk, P., Watson, R., Storey, D., Short, H. and Keasey, K. (1993) Managerial Labour Markets in Small Firms, London: Routledge. 


\title{
2 The hunting of the snark ${ }^{1}$ \\ A critical analysis of human resource management discourses in relation to managing labour in smaller organisations
}

\author{
Scott Taylor
}

\section{Introduction: universal labour management systems and local order}

Sometimes when I'm with people who are in equivalent positions to me you hear views like, 'well, they're just cheap labour'... they really don't give a shit about the people. They look at a person as, how much have you turned over for me, how much profit, how little can I keep you for, and how bad can I make your conditions before the Health and Safety walk in? The sadness is, bastards often do make a lot of money. I sat recently with [the owner-manager of a] company, a wellknown company, with 1400 employees - and their [staff] turnover in the year is 600 . One of my girls who [worked] there, she said, 'I felt as if I had a job. I walked in and I walked out, and there was nothing in between'. I've had people come to work for me who've come up in that sort of environment, and I've had a terrible job breaking through - if you go up and say good morning you almost see them cower in front of you, it takes quite a bit of bringing them out, because they would feel exposed, they're suspicious. When they've been in the hands of these people, and they're totally helpless to do anything about it because they need the money - that really sickens me. I think they should clear the bloody boardrooms out, because it's not often the people.

(Director and department manager, Zincpipe)

As outlined in chapter 1, Edwards (2001) argues that there is a continually adapting but fundamentally consistent basis for analysing industrial relations (IR) in work organisations, whatever the sector or context. $\mathrm{He}$ suggests that while managerial labels may change and employment environments can be differentiated, a core of critical analytical concepts endures, amongst which we find the notions of conflict, uncertainty and 
tension. Central to this understanding of IR is the pursuit of interests by groups of employees and managers, and the structured antagonism that results. In this chapter, it is argued that we can better understand this dynamic through analysis of the enactment of labour management practices in the context of human resource management (HRM); that is, the accomplishment of people management through recruitment, appraisal and training, within the particular 'way of ordering' (Townley, 1993) that HRM provides. Following Townley, particular attention is paid to the actions of managing labour within the HRM framework. This approach is taken to throw light on the management of indeterminacy in work contracts through changing definitions of formality (Ram et al., 2001; see also chapter 1). In particular, the analysis examines the interstices of organising people management, where managers and employees must negotiate an order that both can work with. 'All activities that affect the provision or utilisation of human resources within the business unit' (Arthur and Hendry, 1990: 233) are open to analysis; however, the symbolism and legitimacy associated with HRM are crucial to understanding people management (Ferris et al., 1999). This chapter develops an analysis that integrates the practical working reality with less visible aspects of the discourse. This approach contrasts with the more common focus on either the individual or organisation in analysing HRM, wherein priority is given to assessing goal achievement and efficiency (Wright and Boswell, 2002). The chapter is informed empirically by a qualitative study of people management practices in four smaller organisations. ${ }^{2}$

The chapter begins with a brief review of the historical development of HRM and its application in British organisational contexts, with a focus on the ideological nature of the discourse. The descriptive nature of mainstream HRM research is noted, and it is argued that this approach has subsequently been adopted in research into HRM in the small business context. The chapter then moves on to consider current research into HRM and performance; it is argued that this strand of research forms the basis of exhortations to small business managers to adopt HRM as a practice and as an ideology in managing people. This dynamic can be seen in a number of studies that seek to apply HRM or test for its existence in smaller organisations, and is further manifest in recommendations to owner-managers to adopt voluntarist state frameworks for people management, such as Investors in People (IiP), that are informed by the HRM discourse. ${ }^{3}$ Recognition of the role of state agencies in legitimating certain practices, and stimulating managerial adoption of them, is often absent from research into HRM (de Kok and Uhlaner, 2001). A number of problematic aspects of the movement of 'HRM-ism' (Keenoy, 1999) are outlined, and the economic basis of the calls to adopt the discourse is noted. The chapter then presents managerial and employee experiences of people management in four smaller organisations, focusing especially on the nature of formality and the changing basis of enactment over time. 
This serves to provide a contrast to surveys that provide a momentary picture of intent (Ram et al., 2001), and to highlight the iterative process of people management enactment and formalisation. It is argued that the HRM discourse is not adopted in the organisations; rather, it forms one aspect of people management processes that are in continual flux and under constant contestation.

Thus, the rationale of this chapter is in part to question the association of smaller organisations and HRM in two contexts. First, the academic, in which HRM practices are presented as the answer to managerial difficulties, particularly during expansion. Second, in the policy area, where the ideology of HRM informs legislation and state sponsored initiatives. The approach taken enables the analysis of both the practices within the HRM discourse, and the ideological underpinnings. It is not the aim of the chapter to simply argue against either the practices or the theory of HRM; rather, the intent is to question the unproblematic application of the discourse to smaller organisations. The chapter is intended as a counterpoint to the numerous calls for managers in smaller organisations to adopt an HRM approach to managing people.

As part of this, two alternative means of understanding the relation between discourses of HRM and labour management in smaller organisations, other than the functionalist or positivist, are explored. First, it is argued that more attention should be given to the role of HRM discourses in seeking to minimise indeterminacy in the management of the labour process (Townley, 1993) in smaller organisations. Such an approach would enable a conceptualisation of power relations within people management processes, and provide an alternative to functionalist studies of HRM-performance links. In addition, it would focus attention on how, why and with what effects people management frameworks are enacted, moving away from mock scientific (Van Maanen, 1995) analyses of the efficiency or effectiveness of techniques and procedures. Second, relatedly, it is suggested that people management practices in smaller, nonmainstream ${ }^{4}$ organisations may be conditioned more by cultural contexts than formalised economic considerations, and that analyses of people management in smaller organisations should recognise this more than currently is the case (de Kok and Uhlaner, 2001). This contributes to the argument that adoption of individual practices and adherence to discourses such as HRM are complex and conditioned by a wider variety of dynamics beyond the economic or functional.

\section{Developing HRM: practice and ideology}

Exploring the nature of HRM can take a number of empirical or theoretical forms. This chapter takes the approach that investigation of how a discourse of HRM emerged and has been legitimated is of more interest than assuming that it reflects an 'external facticity' (Townley, 1994:22) of 
managerial practice. Such an analysis takes into account the many stakeholders involved in developing 'HRM-ism': personnel managers, academics, consultants, professional bodies and state agencies (Keenoy, 1999). Our understanding of HRM as a discourse is thus seen as a complex interplay of practitioner, academic, policymaker and student. ${ }^{5}$ It is also relevant to note at this point that managers in smaller organisations are often argued to be excluded from such processes of discourse formation (Gibb, 1987).

Academically, HRM as a clearly articulated approach to managing labour is rooted in a series of publications emanating from Harvard and Michigan universities (Tichy et al., 1982; Beer et al., 1984; Fombrun et al., 1984). An extended treatment of the shift from labelling people management as 'personnel' to the discourse of HRM was set out by Lundy (1994) where she argues that incorporation of strategy, either as a language or as a practice, is the key indicator in assessing any purported move away from personnel to HRM. Such an understanding of people management emphasises the developing professionalism of both HR managers and labour management itself. Linkages with organisational performance are also central to this process, expanding the managerial role beyond basic functional tasks (Ferris et al., 1999). This argument has been used many times to support the claim that HRM provides an approach to managing labour in large companies that is significantly different from the old personnel approach (Guest, 1987; Boxall, 1992).

In contrast, it is easy to find arguments that support the 'old wine in new bottles' (Armstrong, 1987) criticism that is applied to HRM; the primary contention here is that HRM may be seen as a re-labelling of personnel management more than anything else, as part of the ongoing process of professionalisation that personnel managers are caught up in (Lupton, 1964; Bell et al., 2001). Survey evidence appears to support the contention that personnel managers in the UK have mutated only very slowly into HR managers (Cully et al., 1999), and a number of best-selling textbooks continue to juxtapose personnel management with HRM (e.g. Torrington and Hall, 1995; Bach and Sisson, 2000). Wright (1994) provides a systematic analysis of textbooks under both flags, concluding that there is a clear focus on the same subjects in terms of practical action, while Torrington (1989) argued at length that the concept of HRM was merely personnel management 'moved on a bit'. The newly constituted HR manager does, however, take on a role defined by service to the organisational bottom line, moving away from welfarist roots and the old organisational identity as a social reformer or humane bureaucrat. Responsibility for design and implementation of recruitment and selection, appraisal, payment systems and training is retained, but the ideology underpinning the actions has changed.

This distinction between the practices that HR managers are responsible for, and the linguistic changes that becoming an HR manager rather 
than a personnel manager involves, is central to understanding the construction of HRM as a discourse. The dichotomous representation of the practical 'essences' (Eccles and Nohria, 1992) of people management, and the ideology of HRM, is however only a heuristic to come to an understanding of both sides of the HRM coin. In practice, the two are inseparable (Townley, 1993). At the broadest level, personnel management is traditionally concerned with four basic realms of organising labour: bringing in new staff (recruitment and selection), methods of paying staff (payment systems), performance appraisal (or management), and training or development. It is unlikely that an HRM textbook could be found that would not include substantial sections on each. Clearly, a wide variety of managerial and organisational dynamics can be chosen through which to illustrate and theorise the basic action.

This approach, according to Legge (1995), can be seen as the normative or aspirational model of personnel. ${ }^{6}$ Personnel managers are explicitly advised of the best way to maximise production through efficient use of human resources, in contrast with the descriptive-functional model, in which the regulation of employment relations and discipline are emphasised. This second framework recognises that people, managers and capital owners may not share the same, or even similar, goals. Personnel managers in this perspective are also acknowledged as working within organisational power relations, at a micro-political between-managers level, and at a collective level.

Beyond this is the critical-evaluative model, within which Legge's (1978, 1989, 1995) own work falls. This understanding of the activities of personnel management seeks to incorporate the inequality and power relations that characterise 'working for capital', and to assess activities and associated languages as discourses. This is the rarest analytical perspective taken in seeking to understand personnel management, yet potentially one of the most theoretically fruitful. Townley $(1989,1994)$, for example, explores the ways in which everyday personnel management activities may be seen as means of constituting subjectivity at work. These analyses locate personnel management as just one aspect of the development of a disciplinary society, in which employees may find themselves working within a matrix of power that seeks to define them as individuals to be 'produced' through personnel practices. HRM may thus be seen as providing means to measure the many tangible and subjective dimensions of labour, with the promise of rendering individual behaviours predictable and individual labour calculable (Townley, 1993).

The final category of Legge's (1995) typology is termed the descriptivebehavioural model of personnel. This thread of research takes as its focus the status and role of personnel professionals within large and complex work organisations. As Legge outlines, key issues here include the gendered nature of the personnel profession (which has arguably changed significantly since the advent of HRM), and a number of connotations 
attaching to the function that personnel managers have long sought to discard; bureaucratic, interfering, ineffectual and out of touch with business reality (i.e. not always focused on economic outcomes), for example. This approach to understanding HRM is an enduring concern of practitioners and the professional body that regulates personnel and HR management, the Chartered Institute for Personnel and Development (CIPD), and it is a dynamic that will be echoed later in this chapter.

The next section assesses a recent development in the discourse of HRM that provides a category on its own: the performative model. The academic study of HRM is currently much concerned with attempting to construct models of labour management that show causal (or at least correlative) relations between individual or bundled people management practices and performance. The section focuses on two issues: first, whether the proxy measures that are used to indicate whether an 'HRM approach' is being enacted are appropriate to smaller organisations, and second, the ideological aims of this strand of labour management research. It is argued that this conceptualisation of labour management practices is more appropriate in a large firm context both in terms of practice, and in relation to the discourse employed to legitimate it. The defining feature of this project, it is suggested, relates to supporting HR managers in contexts where micro-political battles must be fought to ensure their own and the department's status.

\section{HRM and performance: individual and collective}

In addition to seeking to link personnel management with organisational strategy and corporate performance, the systematic focus within HRM discourse on individual performance, on exploiting the labour resource more fully (Storey, 1992), distinguishes it from previous ideas of people management. This emphasis was embedded within HRM from the outset, and has provided academics and consultants with a research agenda since; to prove, using positivist methods, what is an article of faith within the profession and aspirational how-to books. This section explores the progress so far in this endeavour, and questions whether this approach to HRM research should also inform analysis of people management practices in smaller organisations in the manner in which it has done so.

Studies in the area of HRM and performance have become so numerous, particularly in the UK and the US, that it is more practical to review summary articles that gauge progress towards demonstrating correlations between HRM and performance (see, for example, Paauwe and Richardson, 1997; Guest, 2001; Wright and Boswell, 2002). It has proven consistently difficult to show clear causal relations between HR practices and corporate performance; hence, more effort is currently being expended on classifying HR practices under broader categories that summarise an organisation's approach to labour management (Wright and Boswell, 
2002). Thus, we find the 'skills' approach that focuses on attracting and developing highly skilled employees, the 'motivational' approach with emphasis on stimulating performance, and the 'empowerment' category, that seeks to enable employee voice and influence.

Studies seeking to demonstrate causal links ${ }^{7}$ between managerial practice and performance are being conducted with increasing frequency. However, despite the breadth of empirical data and the range of propositions that are emerging from this work, linkages remain stubbornly difficult to demonstrate. Certainty or even reliability is elusive, and conclusions continue to be highly contingent or tentative. In a recent effort to dispel the fog and confusion around this area, Guest (2001) assesses the state of the field in depth from a methodological perspective. The recognition that 'abstracted empiricism' may be the result of too little theory development and too much emphasis on collecting data is central to this review. This extended reflection is worth examining in detail, as Guest (1997, 1999; see also Guest and Conway, 1999; Guest et al., 2000a) is a leading exponent of empirical research in the UK assessing relations between HRM and performance, and as such is a key figure in the construction of the discourse of HRM that is being applied to or recommended for managers in smaller organisations.

Guest (2001) argues that three conceptual areas remain unclear in seeking to assess relations between labour management practices and performance: the relationship between HRM and performance, what performance measures are to be used, and the nature of HRM itself. For the nature of HRM, it is argued that researchers should make use of one of two strategies: either adopt one of the normative 'listing' models proposed (e.g. Storey, 1992; Pfeffer, 1998), or adapt the high-commitment or high-performance models of HRM. In order to measure the implementation of the practices, Guest acknowledges that relatively crude proxies to indicate managerial uptake of practices are used.

This approach has been taken by studies that test for HRM in smaller organisations (e.g. Duberley and Walley, 1995; Bacon et al., 1996). Although these studies take a more sensitive approach, engaging more with the world and interpretations of the owner-manager, extensive use is still made of indicators of people management 'sophistication' such as psychometric testing, delayering or culture change programmes. As might be expected in organisations employing fewer than 200 people, with three or perhaps four hierarchical levels and an approach to recruitment and selection that relies on friends and family, scores on such measures are often low. Such results would suggest that an alternative approach to understanding the people management policies or practices in smaller organisations might be more meaningful, both academically and in practice.

The relevance of such research can also be questioned at other levels. Ferris et al. (1999) argue that researchers are no longer driven by the con- 
cerns or problems of managers. Instead, the primary concern appears to be the development of a scientifically robust or respectable theory of HRM, becoming more methodology or data driven, and ultimately lacking practical implications or even meaningfulness for those working in organisations. Research becomes relevant only to the academic community producing it 'academic' in the worst sense. In addition to this criticism, it might be argued that the scientific approach also lacks relevance in seeking to understand the fundamental terms and concepts of the labour management debate (see chapter 1). The implications of such 'disconnects' (Buckley et al., 1998) are varied, and explored further in the final section of this chapter.

In addition, Guest (2001) seeks to take the analysis of the HRMperformance literature further through exploring the measurement of outcomes which are examined for reliability and objectivity. Unfortunately, little evidence of either is found; nor can subjective measures (such as selfreporting - managers estimating organisational performance according to their perceptions) be relied upon. Guest acknowledges that access to outcome measures (such as absence or turnover) is often problematic at two levels: in deciding which metric to use, and in gauging the relationship between measures. As Shenhav et al. (1994) note, the notion of performance is characterised by conceptual confusion and operational pragmatism. They suggest that this undermines the claims of positivistic management research to 'normal science' status, casting doubt on the potential of the HRM-performance research to make sense to either academics or practitioners even on its own terms.

Finally, Guest (2001) also suggests that the involvement of economists in researching the linkage of people management techniques and performance is a positive and key theoretical development. This is reflected in the work of US-based HRM researchers, such as Ulrich (1997), who argues that HRM must respond to a 'new mandate' that is defined quantitatively, using econometric measurement techniques. It is this core contention that this chapter seeks to question. It underlies the discourse of HRM as represented by the professional body of personnel managers, the Chartered Institute of Personnel and Development (CIPD), ${ }^{8}$ and the promotion of HRM-related state initiatives such as Investors in People (Bell et al., 2001). This area of research seeks above all to prove the intuitive feeling of personnel professionals - that people management practices can make a difference to measurable organisational outcomes. The approach taken by studies that take practices such as psychometric testing as indicative of HRM sophistication, or define organisational performance through variables such as absence, however, may not be the best means through which to understand managerial practice or approach in smaller organisations. Notwithstanding, empirical research into HRM in smaller firms has often taken this approach, and managers in such enterprises are encouraged to implement HRM practices as a route to improved performance; the next section provides a brief review of research that adopts this approach. 


\section{Bringing smaller organisations in: seeking HRM in smaller organisations}

A number of studies focusing on growth in smaller organisations propose adoption of professionally legitimated HRM frameworks as the answer to problems in managing people. Amba-Roe and Pendse (1985), for example, argue that if managers fail to formalise personnel management procedures as employee numbers increase, the number of personnel-related problems will increase; in a similar vein, Mazzarol (2003) presents a model in which formalisation of HRM policy and practice is located as an integral aspect of growth. In contrast to these prescriptive recommendations, descriptive research has consistently found that owner-managers in smaller organisations retain personal control over HR planning and implementation for longer than most other managerial functions (Ardichvili et al., 1998). Accounting functions, for example, are released to other staff at a much earlier point. This paradox highlights two aspects of people management that are central to the analysis presented in this chapter: control and indeterminacy. It might be argued that owner-managers retain control over personnel or HR issues for longer due to a perception of control over employees, or perhaps that control is only reluctantly released as a result of the inherent indeterminacy of managing people - better to have that indeterminacy on one's own desk where it can be seen. The overall picture is of owner-managers who find it at best difficult to address HR issues (Wilkinson, 1999), expressing scepticism about formalising methods of managing labour (Carroll et al., 1999) and reluctant to employ people management professionals (de Kok and Uhlaner, 2001). Thus, it is frequently argued that the implementation or avoidance of HR policies in smaller organisations is dependent on the personal attitude or beliefs of the owner-manager (Matlay, 1999; Mazzarol, 2003). Such a finding is wholly consistent with understandings of larger organisations, where the relevance of the values, beliefs and personal approach of the dominant coalition of managers to strategic decision-making is well established (Child, 1972).

This area of research focuses on managerial agency within the smaller organisation, and how actions might be influenced by encouraging the introduction of more formal policies or practices. A crucial omission, however, is the lack of recognition of the nature of culture in managerial decision-making (de Kok and Uhlaner, 2001). In common with other areas of social science (Archer, 1988), debates on the nature of employment relations in smaller organisations have focused on the interplay of agency and structure (e.g. Rainnie, 1989; Ram, 1994; Barrett and Rainnie, 2002). However, the notion of small business culture invoked as a backdrop to analysis is often homogenising, not least in defining the field as different from large organisation research. As Archer (1988) argues, the notion of culture in social research has traditionally prioritised two strands of analy- 
sis: the idea of a unified, coherent patterning of meaning, and uniformity of activity within the cultural context. These can exist independently of each other; thus, meaning may be patterned across contexts, but this may not always be accompanied by uniformity of action (cf. Ram et al., 2001). Approaches to understanding the management of people that are based on 'size determinism', underpinned by an assumption of integration of action within a unified cultural system of small business management, may underestimate the range and diversity of practice and experience.

Elements of this homogenising approach are evident in UK-based studies of HRM in smaller organisations, such as Bacon et al. (1996) and Duberley and Walley (1995). These studies are sensitive to incorporating the ideological elements of HRM analytically; however, they also reproduce the approach of studies from the US that seek normative HRM. Thus, Duberley and Walley (1995) sought evidence of HRM in small and medium sized business units (i.e. not all independent companies). The research was conducted in 16 organisations employing between 120 and 425 people; interviews were conducted with a selection of managers and employees to gauge the presence of Storey's (1992) 27 indicators of HRM. A number of features of this study are worth noting. First, the definition of what constitutes a small firm is flexible, to the point of losing meaning, both in terms of number of employees and in relation to more qualitative aspects of definition (such as ownership). Second, the application of a framework developed through research in very large organisations in the expectation that comparisons can be drawn to 'the small business sector' is problematic.

A second study conducted at a similar time (Bacon et al., 1996) investigated 'independent' organisations (i.e. not subsidiary business units), employing fewer than 200 people; almost half of the sample consists of companies that fall into the 15 to 24 employees category. In this study, eleven indicators of the 'new management agenda' were tested for through telephone surveys with managers, and 13 companies were chosen for follow-up visits to interview the owner-managers. A number of conclusions from this study further illustrate the difficulty of using this approach. First, it is suggested that the standard of management, measured against the HRM norms being tested, is 'higher' than might be expected. It is further noted that managers interviewed were often unaware of the existence of HRM as a 'management theory', while simultaneously implementing many of its practical components. This is taken to indicate that small business managers may not be as far behind as is sometimes presumed. However, this argument implies that HRM is much more than a set of new practices within a changing discourse of people management; it suggests that it is an aspiration, something that should be aimed for. This in turn assumes that managers in smaller organisations need the legitimated version of HRM in order to manage effectively and efficiently. This is, to say the least, questionable. As noted above, the ability of HRM as practice 
or ideology to improve either individual or organisational performance remains in question (Dyer and Reeves, 1995; Becker and Gerhart, 1996). Second, this study works with an understanding of employment relations in small firms that focuses exclusively on the 'bleak house' scenario advanced by Rainnie (1989). This ignores more sophisticated understandings of the negotiated order that characterises management-labour relations (Ram, 1994; Holliday, 1995). Incorporation of these conceptualisations of employment relations in small firms might aid in understanding the nature of people management practices, as less emphasis is placed on formal procedures and processes, while more insight is gained into the everyday working reality of managers and employees.

In sum, while such studies increase our understanding of managerial attitudes and the implementation of specific practices from within the HRM discourse, a number of difficulties exist with drawing conclusions about a homogeneous 'small firm sector' from them. HRM is a profoundly influential discourse that conditions the management of employment relations, academically, in practice, and ideologically. It has both stimulated and reflected attitudes towards management and the experience of being managed. Previous studies that report on the incidence of HRM in smaller firms have not, however, reflected the complexity of employment relations within the context. In addition, hunting for 'the HRM' through testing for the existence of codified practices, as indicators of adherence to contemporary discourses of employment relations, without incorporating analysis of the structural or cultural conditions of labour management, provides only a small part of the picture.

The next section consists of an empirically informed outline of employee management practices in four smaller organisations. The analytical focus centres on the practical actions that managers and employees experience in managing and being managed, in relation to recruitment and selection, training and development, and performance appraisal. The effort-wage bargain in the form of payment systems forms a thread that runs through the experience of people management, conditioning the employment relationship as formulated through the managerial practices. Finally, this next section provides further discussion of the potential that the HRM discourse and people management activities in smaller organisations have to inform each other.

\section{Making context concrete: tensions between HRM and managing labour in smaller organisations}

This empirical section focuses then on the management of labour in four smaller organisations in the northwest of England. Each firm employs around 50 people; two are in the light manufacturing sector, two in business services. Of the four firms, three are independently owned and one is a wholly owned subsidiary of a Danish parent. In total, more than 60 inter- 
views were conducted across the four organisations; data were also collected through periods of non-participant observation, from firm documentation, and through unrecorded conversations.

The four enterprises represented here are Diamondcom, Bodywork, Zincpipe and Gearbox. Diamondcom provides telecommunications services to organisations and individuals, and is the second firm founded by the four friends who own it; they decided to found the business after selling their first business when it became too big (at around 200 employees) to manage between them. Diamondcom has been trading for around eight years. The three main departments are sales, customer relations and technology development. Bodywork also provides a service, providing temporary workers to larger organisations. The enterprise was founded in the late 1980s by two friends, one of whom subsequently left 'to spend more time on the golf course' (as one of the current ownermanagers put it). The firm is now owned by the remaining founder and his wife, the finance manager. Zincpipe is a light engineering firm, supplying parts to the chemical and drug industries. Again, it was founded in the late 1980 s, as a result of one of the founders developing and patenting an innovative method of extruding plastic. Since then, the organisation has changed hands numerous times, sometimes being independently owned, sometimes owned by a larger parent; at the time of the empirical work, it had recently been the subject of a management buy-out led by four people external to the firm, funded by venture capitalists. Finally, Gearbox provides gearing parts to the motor manufacturing industry; at the time of the research process, it was in the process of being sold by a German parent to a Danish multinational. This sample of organisations provided a means of exploring people management practices in three structural contexts: independently owned, independently managed but owned by venture capitalists, and owned by a parent company. The enactment and experience of the core activities of personnel management was however broadly comparable across the four firms.

As Curran and Blackburn (2001) note, and as is explored in depth elsewhere in this collection, issues of definition are central to much research that is located within the 'small business' field. It is important to recognise that this research is located within a size band (20-49 employees) that constitutes only 1.3 per cent of the total number of businesses in the UK and 6.9 per cent of employment. Thus, the analysis presented here does not claim to represent managerial dynamics in all small and medium-sized enterprises; rather, it is intended to provide a picture of the everyday experience of management and being managed within organisations that are neither very small nor very large (cf. Bresnen and Fowler, 1996). The empirical work presented here was guided by a number of methodological dynamics and primary amongst these was the need to gain access to gather qualitative data through a slow, relatively long process. This involved extensive negotiation with individuals, both before data collection 
(organisational access) and during it (permission to interview employees and maintain a presence in work areas). This, in turn, generated an opportunistic approach to selecting the organisations to be studied (cf. Holliday, 1995); ultimately, analytical insight rather than statistical representativeness was sought. A commitment to represent the many voices within the organisations was maintained throughout. Thus, the organisations selected for study share some characteristics, and in other respects may be differentiated. More importance is placed on contextualisation and complexity of representation (Mead, 1953), to provide a rich description of practice and meaning, from which to extract analytical commonalities.

\section{Knowledgeable recruitment}

Recruitment and selection is the HRM activity most highly regulated by the state; it is also commonly represented as crucial to firms, the first step in constructing a useful employee (Jacques, 1996). As such, it is also central to the employee experience of work organisations, as the first impressions and initial contact with 'how things are done' can be part of the mutual selection process. Analysis of recruitment and selection in smaller organisations tends to focus on the role of friends and family and the social embeddedness of the process (Holliday and Letherby, 1993; Ram and Holliday, 1993), and this is a prominent aspect of the processes at the four case study companies. However, this section also explores the power relations of such recruitment and selection procedures, and the tensions between the empirical evidence presented here and normative HRM.

Both employees and managers play an active part in the recruitment process, suggesting family and acquaintances for vacancies, or sometimes canvassing for a vacancy to be created for an unemployed friend. Many relate their application to domestic circumstances; some were born and brought up in the area of the organisation, others had moved to the area to join a partner. Such stories demonstrate the importance of real and 'fictive' kin (Rose-Ebaugh and Curry, 2000), and the rights that attach to membership of such a network. Responsibilities also attach to membership; however, those recruited through this method often go on to recommend friends and family for recruitment, and the proposer takes some responsibility for the recruited. Managers at the firms recognise that this could place employees in an invidious position, making the sponsor responsible for the performance and behaviour of the kin recruit. Another aspect of these highly effective networks of recruiters and prospective recruits is the speed with which people could be found and put to work. Many spoke of coming in to see either the owner-managers or departmental manager, filling out a short application form, and starting work days later.

This results in highly localised employee populations; one manager at 
Zincpipe travels forty miles to work there, a distance seen by colleagues as exceptional. The three independently owned companies are located within a short distance of the locale where the owners grew up and live. Managers recognise this as problematic when they speak of being in the sticks'; the location of the four firms is seen as restrictive in relation to the pool of potential employees. However, they also emphasised the disciplinary advantages of employing people who are less likely to 'rip us off' (owner-manager, Diamondcom) because they and the firm are an integral part of the local economic community.

This also means that siblings, parents and children, and close friends work together, a dynamic that affects the employment relationship. At a basic level, managers and employees are able to make recruitment and selection decisions on the basis of high levels of knowledge, unmediated by scientific selection tools such as psychometric tests. Information is collected from friends and family, within the firm and in the local community, to inform the decision. However, once the local person has been recruited, this information network continues, according to one employee at Zincpipe, to operate in local pubs, clubs and other 'non-work' social locales, where behaviour may be monitored and reported back to managers - effectively, an informal appraisal network that extends beyond the workplace and job tasks to include normative judgements of character.

However, managerial reliance on these methods may also be seen as fragile. All four businesses are on the edge of the accepted definition of small, and employees recognise this as making a difference to the experience of work. The firms are perceived to be less embedded in local communities than previously, during start-up, and less rewarding to work in. This process of 'estrangement' from the local community is reflected in the introduction of more formal, rational methods of managing labour (Taylor, 2003), generating tensions in how work and the role of the organisation are understood. A number of employees told how they no longer recommend kith and kin to managers, as the organisations are either no longer secure or 'family-ish' any more.

These processes can be contrasted with managerial accounts of recruitment and selection. Managerial interviewees describe this aspect of HRM in quite different terms to their employees. In particular, a manager at Bodywork presented a highly formalised, complex process involving adverts in newspapers, repeated visits to the firm by the prospective employee, and a series of selection exercises such as role-playing and intelligence testing. This narrative was not supported by accounts of the process from employees in his department. In addition, an owner-manager at Diamondcom objected strongly to a question relating to recruitment of employees through kinship networks, arguing that such practices may have been used during the start-up phase but had since been replaced by a more formal selection procedure. She went on to describe this process, reflecting both formalisation and the retention of social embeddedness: 
I had to bring in half a dozen people like that [snaps fingers]. I asked Harry [to help] - we always have Harry, he's like a consultant - suits him, suits us, works fine. I like to interview my own people, I handpick them, and I'm an unorthodox interviewer as well, which will go down like a ton of bricks [laughs and points to tape recorder]. Anyway, Harry did all the legwork, sifted [the applications], listed them with attributes. I told him the sort of person I was looking for women have got to have balls, they've got to be over twenty or at least mature in outlook, because they're dealing with our customers and I can't afford any slip-ups. If they can't use a computer I can teach them that, but they've got to be the right sort of character - I'm going for personality. I sat there for two days [in the hotel where interviews were conducted], came down the morning after with the photographs and how the analysis of the very simple test came out ... and they're all sat out there now, all happy. And it's a tough job to learn, it's a hard slog and it was hard on the original ones 'cause they had to keep the work moving plus teach someone else.

Here, limited formalisation is combined with 'finger in the air' decisions, personal control of the process is retained at all stages (through the use of a friendly 'outsider'), and objective methods such as testing are used alongside a judgement as to whether candidates have 'balls'. Such combinations of method and process are common across the four firms; candidates either walk in speculatively or come through recommendation from an existing employee, some testing or interviewing is done (primarily to ensure that the candidate will 'get on' with the existing employees), and the person is taken on. When such rituals are not followed, however, conflict can be the result. Employees at Gearbox spoke without enthusiasm of how the site manager brought both of his sons into the factory as summer holiday trainees without any due process at all.

It may be that these contradictory accounts reflect a desire on the part of managers not to be seen as recruiting through informal methods. A number of reasons might underpin this: the legal implications of managing in this way, the interview situation itself in which managers perceive themselves being 'tested' as to their managerial competence, or perhaps a desire to provide an account that conforms to 'good practice' as represented in managerial frameworks. Whatever the reason, such contradictions and tensions are indicative of the tensions inherent to managing people in such organisations, and the variety of discourses that affect managerial decisions.

\section{Developing appraisal: watching and learning}

If recruitment and selection are seen as the managed processes that bring new employees into the organisation, training and development is the 
means through which the individual is made into a useful, productive member. It is cited as the part of labour management in small firms that is most problematic, particularly during expansion (Greening et al., 1996), yet paradoxically it is traditionally the area about which we know least, qualitatively (Pettigrew et al., 1990).

Training and development in all four firms begins with induction, usually by the individual with nominal responsibility for 'personnel', focusing on health and safety, buildings layout, use of machinery or computers, and any quality management procedures - as an employee at Bodywork put it: 'You don't just put your bum on a seat, there's a certain way of doing it and you have to meet certain standards in doing it.' Beyond this, many employees experience an 'in at the deep end' initial period in the firms, as managers are out of the office or off ill - perhaps indicating that the speed of the recruitment process may also be related to a need for someone to fill in quickly.

After induction, employees are expected to pick up both job tasks and enterprise norms from watching and learning in the environment. Managers emphasised that the physically small nature of the enterprises enables this process, particularly at Bodywork. The finance manager there noted that if her department takes on more staff, desks would have to be hanging from the ceiling; even the toilet on that floor of the building is converted to house filing cabinets. However, as well as employees picking up technical skills and behavioural norms from each other, this method of localised training enables managers to keep an eye on new employees. Performance appraisal is not difficult, as managers noted, if the person is sitting in the same room as you or even across a shared deskspace. Identifying training needs is also less subject to formal procedures in this context, as managers observe working practices and form assessments of performance.

These methods of training are presented as 'first-class' (owner-manager, Bodywork) or 'highly effective' (owner-manager, Diamondcom); employees however, can find them more problematic. Responsibility for transferring skills and knowledge is placed on the individual employee seeking training, and his/her colleagues with the knowledge. This results in continual negotiation between employees, often over-ridden by demands of customers or production. Trainers express frustration at being 'landed' with someone to teach, and employees express unhappiness with the lack of formal qualifications available. Training is presented as the first casualty when there is a need to 'get stuff out the door' (employee, Gearbox). In addition, the introduction of a formal timesheet system (at Zincpipe) to inform performance appraisal means that there is even less incentive to take time out of productive work to train employees. Finally, payment systems based on employee skills levels measured by the range of functions that can be performed are undermined by lack of formal training procedures, and the ad-hoc provision of skills development. 


\section{S. Taylor}

It has been argued that owner-managers may be reluctant both to support training financially and to release employees during work time, as there is a fear that the newly skilled employee will leave for another organisation. This has been related to the lack of 'vertical complexity' (Daft, 1986) within smaller organisations, as employees are unable to move up through a status and financial hierarchy. This lack of a 'bureaucratic climbing-frame' to symbolise progression (Scarbrough and Burrell, 1996) stimulated a number of employees in the four firms to leave for local competitors (many of whom subsequently returned), and one outlined how he became active in the trade union as a result of frustration at lack of progression. ${ }^{9}$

The final aspect of training and development relates to managerial competence. This is treated in more detail elsewhere as part of negotiating managerial legitimacy (Taylor et al., 2002), but it may also be seen as a means of understanding power relations through personnel procedures. Within all four firms, four levels of hierarchy were clearly defined: lower level employees, supervisors, departmental managers, and senior or owner-managers. A high proportion of the departmental and senior managers interviewed had little or no managerial training, often having 'become' managers through length of service. Others, however, are new to the organisation, and this group may be split into two categories: skilled and unskilled. Skilled managers are perceived by employees as having the ability to do the jobs employees do, while unskilled have come from other industries or sectors. Employees are not slow to remind managers that they have less understanding of production processes, often through 'banter' with a sharp edge to it. In return, managers deride the level of skill needed to perform basic job tasks such as metal cutting or customer cold calling, telling employees that 'monkeys' (production manager, Zincpipe) could be taken on to replace them. Ultimately, however, managers retain the prerogative to set payment levels, performance targets, or enable more formal training, demonstrating that the labour management process, formalised or not, will be conditioned by power relations.

\section{HRM in smaller organisations: organisational and cultural barriers}

This brief exploration of some aspects of labour management in four smaller organisations is intended to illustrate the arguments of the chapter. These arguments are founded on approaching HRM from a different perspective to that previously taken in studies of personnel management in small firms. It is of crucial importance that HRM is understood not only as a set of codified practices, a basis for professional managerial practice, or as an aspiration that might lead to improved performance. Rather, the analysis presented in this chapter suggests that in order to understand the dynamics of managing employees in smaller organisations, 
and the interplay of managerial agency, legislative structure and culture that surrounds the employment relationship in smaller organisations, HRM must be treated as a discursive formation that rests on concepts of (economic) rationality, measurement and assessment (Townley, 1993).

The employment relationship also exists within structural and cultural frameworks. Managers in smaller firms are notoriously resistant to regulation, valuing their own agency above wider social ideals represented in such legislation as the National Minimum Wage Agreement (see chapter 8) or the Employment Relations Act (Atkinson and Taylor, 2003). If managers in smaller firms are able to resist both voluntarist initiatives (such as Investors in People) and state labour regulation, then there can be little hope that they will take up HRM good practice, no matter how much they are exhorted to by the CIPD or business advisors. This potentially leaves firms to fall into the 'black hole' of labour management unmediated by trade unions, legislation or cultural norms. A number of cultural barriers are also cited when commentators suggest how to 'improve' managerial practice within smaller organisations. Lack of resources to train specialists, lack of complexity to employ specific functional managers, lack of familiarity with management theory, disinclination to seek or take advice on management - all are raised as issues that mitigate against the adoption of modern best practice in analysing why managerial practice in smaller organisations remains stubbornly rooted in an alternative way of thinking and acting. This chapter is concerned to question such analysis, for a number of reasons.

First, the smaller organisation is cast as lacking. Whether the lack is financial or in expertise, managers of smaller firms are presented as not doing enough or trying hard enough to catch up with cutting edge practice. This fails to acknowledge the difference in context and aims that smaller organisations embody. Second, a significant proportion of the proxy measurement of whether HRM is being practised (such as psychometric testing for selection, culture change programmes or delayering) are either inappropriate or highly problematic to implement in smaller organisations. The inflexibility of the hunt for HRM in smaller organisations is demonstrated by implying that directly transferred practices are indicative of sophistication in people management. Third, the dynamic process of managerial adoption of new practices (or new discursive formations) is absent from such a mode of analysis, something which is more evident in smaller organisations where managers may have little contact with the institutions that produce such discourses as HRM. Practices and ideologies may be partially understood or applied, rather than firmly implemented and adhered to. Finally, the construction of HRM as something that can be hunted for and found in smaller organisations leaves our understanding of employment relations as the 'black box of production' (Townley, 1993). Inside the box, personnel management is conceptualised as a set of tools that enables managers to select, train, pay and appraise employees more 
effectively in the service of maximising labour efficiency. The alternative means of conceptualising HRM presented in this chapter, and the outline of practice in four smaller organisations, serves to support the argument that managerial practice and HRM in smaller organisations exist within a complex set of dynamics that are not all reducible to a simple hunt for a recognisable and easily identified animal.

\section{Conclusions}

This chapter has sought to provide an analysis of the relationship between the contemporary discourse of HRM and the management of employees in smaller organisations in the UK. Following Townley's (1993) suggestion to treat HRM as a discourse constituted through micro-technologies of practice and language, the chapter has focused on a number of aspects of HRM that are rarely raised in assessing its relevance to, and impact on, managers in smaller organisations. In particular, the structural and cultural conditions that surround the introduction of the HRM discourse into smaller organisations, the consequences of implementing the discourse, the institutional sites from which legitimacy is drawn, and the position in which it places subjects (both managers and others), have all been raised as worthy of analysis. It has been argued that HRM should not be seen as a stable and scientifically established set of procedures that must be implemented in response to economic conditions or changing institutional conditions, which will inexorably lead to higher levels of individual and organisational performance.

HRM has long been recognised as a significant managerial and cultural discourse, it is increasingly manifest in state regulation of the employment relationship (Bacon and Storey, 2000), and, through Investors in People (Bell et al., 2001) and the Employment Relations Act (Atkinson and Taylor, 2003), the language and ideology of HRM are further promoted within frameworks for practice in smaller organisations. However, this chapter has questioned the relevance and appropriateness of the HRM discourse and such frameworks to order employee relations in smaller organisations. If, as this chapter contends, the discourse of HRM is potentially neither appropriate nor meaningful in smaller organisations, how should the employment relationship be mediated? A number of potential routes have been suggested. Gibb $(1983,1997)$ repeatedly argues for management development that is more relevant, informed by research that engages more fully with the lived experience of managing smaller organisations. Rainnie (1989), in contrast, calls for more legislation that can be implemented in a directive way. The CIPD calls for more management education, while IiP UK suggests quality initiatives in people management that are minimally bureaucratic. All of these proposals are potentially worthwhile; however, this chapter has sought to provide two more that relate specifically to labour management dynamics and the context of the 
smaller organisation as defined in this collection. They involve going beyond the profit calculation, to a more rounded culturally informed understanding of people management practices.

The first is based on the notion of culture. Debates around the role of small business managers in defining people management strategies have emphasised the amount of employee and manager agency in shaping employment relations, but perhaps a wider question relates to the culture of small business management as it is currently understood. Both analysis of the labour process and policy formation might be informed by theory that conceptualises the interplay of the cultures of smaller organisation management and labour, and the cultures of HRM and regulation of the employment relationship. These dynamics are enacted within structures, undoubtedly, but the ability and will of managers in smaller organisations to resist such structural imposition is well established. An understanding of the mediating role of cultures might enable a more informed approach to understanding approaches to labour management in this area.

The second is concerned with the notion of HRM as a system of powerknowledge based on producing individual employees, a system that claims to be accurate and objective (Townley, 1993). Because of the inherent indeterminacy of the employment contract underpinning the labour exchange process, there is a managerial need to reduce indeterminacy between promise and performance. Thus, we might also see individuals as produced by HRM through the construction of knowledge (mainly psychological), whereas the more common approach in smaller organisations is to see labour management as socially embedded. The two approaches to labour management may be seen as existing in tension, so the analytical interest lies in the shift from one to the other. As enterprises grow or pass from one owner to another, from socially ordered to more 'scientifically' or psychologically ordered, an information gap may arise; more formal people management processes seek to fill or bridge this gap, in part through redefining power relations between managers and managed, and in part through providing a more scientific, more systematic knowledge base. This shift is little understood, and will not be made clearer by recommending that managers in smaller organisations adopt pre-existing frameworks, that are then researched from within an academic context that over-emphasises the development of a very narrow kind of theory.

\section{Notes}

1 This chapter is in part guided by a conceit, referred to in the title, that searching for HRM in smaller organisations is analogous to hunting the snark. In Lewis Carroll's poem (Carroll, 2000), the Bellman leads a diverse crew in the search for a mysterious animal, the snark. Each crew member brings his own particular set of doubts and distractions that hinder the hunt; in particular, the Baker brings the knowledge that while snarks are harmless, some of their number transform into boojums, an altogether more dangerous animal. If the snark turns 
out to be a boojum, then the hunter is likely to vanish and 'never be met with again'. This chapter might be seen in part as an assessment of how the hunt for the HRM-snark in smaller organisations has progressed, and in part as an analysis of the potential that the HRM discourse has to become a boojum for managers and employees.

2 See Taylor (2001), Taylor et al. (2002), Atkinson and Taylor (2003) and Taylor (2003) for more details.

3 IiP is an initiative that was developed initially in the UK, financially and ideologically supported by successive governments. However, the initiative structure is now being licensed to a number of European countries, as well as further afield in South Africa, Australia and Canada.

4 Non-mainstream in terms of academic research discourse; as Bresnen and Fowler (1996) point out, it might be argued that the large, prestigious organisations that form the core of much academic research are non-mainstream, and that smaller or medium sized companies are the context in which most people experience work and management.

5 As Alvesson and Sköldberg (2000) note, researchers must acknowledge the notion that research subjects read and interpret research, which in turn informs practice, which is then in turn researched to inform the production of further texts ... and so on.

6 Storey (1992) uses the label 'prescriptive' to map the same territory, which is essentially 'universalistic' (Ferris et al., 1999) - no matter what the organisational context, there are certain practices or combinations of practice that will produce improved individual and company performance.

7 The term most often used is 'positive association', to define results from statistical tests that indicate that use of a technique is positively associated with, for example, an increase in productivity. However, presentation of research results, in the academic forum and in practitioner-oriented publications such as People Management, often elide the distinction between positive associations and causal relations. For this reason, in this chapter the term causal relations is preferred as it is more widely used in constructing the discourse of HRM.

8 The CIPD funds a significant amount of academic research into HRM and performance (see, for example, Guest et al., 2000b).

9 At Gearbox, the only company of the four with collective union representation.

\section{References}

Alvesson, M. and Sköldberg, K. (2000) Reflexive Methodology: New Vistas for Qualitative Research, London: Sage.

Amba-Roe, S. and Pendse, D. (1985) 'Human resources compensation and maintenance practices', American Journal of Small Business, Autumn:19-29.

Archer, M. (1988) Culture and Agency: The Place of Culture in Social Theory, Cambridge: Cambridge University Press.

Ardichvili, A., Harmon, B., Cardozo, R., Reynolds, P. and Williams, M. (1998) 'The new venture growth: functional differentiation and the need for human resource development interventions', Human Resource Development Quarterly, 9(1):55-70.

Armstrong, M. (1987) 'Human resource management: a case of the emperor's new clothes', Personnel Management, August:28-35.

Arthur, M. and Hendry, C. (1990) 'Human resource management and the emergent strategy of small to medium sized business units', International Journal of Human Resource Management, 1(3):233-50. 
Atkinson, C. and Taylor, S. (2003) 'Personnel management in smaller companies: the implementation of policy structures within a negotiated order', paper presented at the 21st International Labour Process Conference, Bristol.

Bach, S. and Sisson, K. (eds) (2000) Personnel Management, 3rd edn, Oxford: Blackwell.

Bacon, N. and Storey, J. (2000) 'New employee relations strategies in Britain: towards individualism or partnership?', British Journal of Industrial Relations, 38(3):407-27.

Bacon, N., Ackers, P., Storey, J. and Coates, D. (1996) 'It's a small world: managing human resources in small businesses', International Journal of Human Resource Management, 7(1):82-100.

Barrett, R. and Rainnie, A. (2002) 'What's so special about small firms? Developing an integrated approach to analysing small firm industrial relations', Work, Employment and Society, 16(3):415-31.

Becker, B. and Gerhart, B. (1996) 'The impact of human resource management on organisational performance: progress and prospects', Academy of Management Journal, 39(4):779-801.

Beer, M., Spector, B., Lawrence, P., Quinn Mills, D. and Walton, R. (1984) Managing Human Assets, New York: The Free Press.

Bell, E., Taylor, S. and Thorpe, R. (2001) 'Investors in people and the standardisation of knowledge in personnel management', Management Learning, 32(2):201-19.

Boxall, P. (1992) 'Strategic human resource management: beginnings of a new theoretical sophistication', Human Resource Management Journal, 2(3):60-79.

Bresnen, M. and Fowler, C. (1996) 'Professionalisation and British management practice: case evidence from medium-sized firms in two industrial sectors', Journal of Management Studies, 33(2):159-82.

Buckley, M., Ferris, G., Bernardin, H. and Harvey, M. (1998) 'The disconnect between the science and practice of management', Business Horizons, 41:31-8.

Carroll, L. (2000) The Hunting of the Snark, London: Methuen.

Carroll, M., Marchington, M., Earnshaw, J. and Taylor, S. (1999) 'Recruitment in small firms: processes, methods and problems', Employee Relations, 21(3):236-51.

Child, J. (1972) 'Organisational structure, environment and performance: the role of strategic choice', Sociology, 6:1-22.

Cully, M., Woodward, S., O'Reilly, A. and Dix, G. (1999) Britain at Work, London: Routledge.

Curran, J. and Blackburn, R. (2001) Researching the Small Enterprise, London: Sage.

Daft, R. (1986) Organisational Theory and Design, St. Paul, Minn: West.

de Kok, J. and Uhlaner, L. (2001) 'Organisation context and human resource management in the small firm', Small Business Economics, 17:273-91.

Duberley, J. and Walley, P. (1995) 'Assessing the adoption of HRM by small and medium-sized manufacturing organisations', International Journal of Human Resource Management, 6(4):891-909.

Dyer, L. and Reeves, T. (1995) 'Human resource strategies and firm performance: What do we know and where do we need to go?', International Journal of Human Resource Management, 6(3):656-70.

Eccles, R. and Nohria, N. (1992) Beyond the Hype: Rediscovering the Essence of Management, Boston, Mass.: Harvard Business School Press. 
Edwards, P. (2001) 'Industrial relations: from apparently anachronic to analeptic and anaclastic condition', Paper presented to 'Industrial relations: An anachronism?' conference, University of Tübingen, June.

Ferris, G., Hochwarter, W., Buckley, M., Harrell-Cook, G. and Frink, D. (1999) 'Human resources management: some new directions', Journal of Management, 25(3):385-415.

Fombrun, C., Tichy, N. and Devanna, M. (1984) Strategic Human Resource Management, New York: Wiley.

Gibb, A. (1983) 'The small business challenge to management education', Journal of European Industrial Training, 7(5).

Gibb, A. (1987) 'Enterprise culture - its meaning and implications for education and training', Journal of European Industrial Training, 11(2).

Gibb, A. (1997) 'Small firms' training and competitiveness: building upon the small business as a learning organisation', International Small Business Journal, 15(3):13-29.

Greening, D., Barringer, B. and Macy, G. (1996) 'A qualitative study of managerial challenges facing small business expansion', Journal of Business Venturing, 11:233-56.

Guest, D. (1987) 'Human resource management and industrial relations', Journal of Management Studies, 24(5):503-21.

Guest, D. (1997) 'Human resource management and performance: a review and research agenda', International Journal of Human Resource Management, 8(3):263-76.

Guest, D. (1999) 'Human resource management: the workers' verdict', Human Resource Management Journal, 9(3):5-25.

Guest, D. (2001) 'Human resource management: when research confronts theory', International Journal of Human Resource Management, 12(7):1092-1106.

Guest, D. and Conway, N. (1999) 'Peering into the black hole: the downside of the new employment relations in the UK', British Journal of Industrial Relations, 37(3):367-89.

Guest, D., Michie, J., Sheehan, M. and Conway, N. (2000a) Employment Relations, HRM and Business Performance: An Analysis of the 1998 Workplace Employee Relations Survey, London: CIPD.

Guest, D., Michie, J., Sheehan, M., Conway, N. and Metochi, M. (2000b) Effective People Management: First Findings from the Future of Work Study, London: CIPD.

Holliday, R. (1995) Investigating Small Firms: Nice Work?, London: Routledge.

Holliday, R. and Letherby, G. (1993) 'Happy families or poor relations? An exploration of familial analogies in the small firm', International Small Business Journal, 11(2):54-63.

Jacques, R. (1996) Manufacturing the Employee, London: Sage.

Keenoy, T. (1999) 'HRM as hologram: a polemic', Journal of Management Studies, 36(1):1-23.

Legge, K. (1978) Power, Innovation and Problem Solving in Personnel Management, Maidenhead: McGraw-Hill.

Legge, K. (1989) 'Human resource management: a critical analysis', in Storey, J. (ed.) New Perspectives on Human Resource Management, London: Routledge.

Legge, K. (1995) Human Resource Management: Rhetorics and Realities, London: Macmillan. 
Lundy, O. (1994) 'From personnel management to strategic human resource management', International Journal of Human Resource Management, 5(3):687-720.

Lupton, T. (1964) Industrial Behaviour and Personnel Management, London: IPM.

Matlay, H. (1999) 'Employee relations in small firms: a micro business perspective', Employee Relations, 21(3):285-95.

Mazzarol, T. (2003) 'A model of small business HR growth management', International Journal of Entrepreneurial Behavior and Research, 9(1):27-49.

Mead, M. (1953) The Study of Culture at a Distance, Chicago: The University of Chicago Press.

Paauwe, J. and Richardson, R. (1997) 'Introduction', International Journal of Human Resource Management, 8(3):257-62.

Pettigrew, A., Arthur, M. and Hendry, C. (1990) Training and Human Resource Management in Small- to Medium-Sized Enterprises: A Critical Review of the Literature and a Model for Future Research, Sheffield: Training Agency.

Pfeffer, J. (1998) Competitive Advantage through People: Unleashing the Power of the Workforce, Boston, Mass.: Harvard Business School Press.

Rainnie, A. (1989) Industrial Relations in Small Firms, London: Routledge.

Ram, M. (1994) Managing to Survive: Working Lives in Small Firms, Oxford: Blackwell.

Ram, M. and Holliday, R. (1993) 'Relative merits: family culture and kinship in small firms', Sociology, 27(4):629-48.

Ram, M., Edwards, P., Gilman, M. and Arrowsmith, J. (2001) 'The dynamics of informality: employment regulations in small firms and the effects of regulatory change', Work, Employment and Society, 15(4):845-61.

Rose-Ebaugh, H. and Curry, M. (2000) 'Fictive kin as social capital in new immigrant communities', Sociological Perspectives, 43(2):189-210.

Scarbrough, H. and Burrell, G. (1996) 'The axeman cometh: the changing roles and knowledges of middle managers', in Clegg, S. and Palmer, G. (eds) The Politics of Management, London: Sage.

Shenhav, Y., Shrum, W. and Alon, S. (1994) 'Goodness concepts in the study of organisations: a longitudinal survey of four leading journals', Organization Studies, 15(5):753-76.

Storey, J. (1992) Developments in the Management of Human Resources, Oxford: Blackwell.

Taylor, S. (2001) 'Managing people in smaller organisations', Unpublished thesis, Manchester Metropolitan University.

Taylor, S. (2003) 'The spatial estrangement of smaller firms through personnel management practices', Paper presented to the 19th EGOS Colloquium, Copenhagen.

Taylor, S., Thorpe, R. and Down, S. (2002) 'Negotiating managerial legitimacy in smaller organisations', Journal of Management Education, 26(5):550-73.

Tichy, N., Fombrun, C. and Devanna, M. (1982) 'Strategic human resource management', Sloan Management Review, 23(2):47-61.

Torrington, D. (1989) 'Human resource management and the personnel function', in Storey, J. (ed.) New Perspectives on Human Resource Management, London: Routledge.

Torrington, D. and Hall, L. (1995) Personnel Management: HRM in Action, London: Prentice Hall.

Townley, B. (1989) 'Selection and appraisal: Reconstituting "social relations"?', in 


\section{S. Taylor}

Storey, J. (ed.) New Perspectives on Human Resource Management, London: Routledge.

Townley, B. (1993) 'Foucault, power/knowledge, and its relevance for human resource management', Academy of Management Review, 18(3):518-45.

Townley, B. (1994) Reframing Human Resource Management, London: Sage.

Van Maanen, J. (1995) 'Style as theory', Organisation Science, 6(1):133-43.

Wilkinson, A. (1999) 'Employment relations in SMEs', Employee Relations, 21(3):206-18.

Wright, M. (1994) 'A comparative study of the contents of personnel and human resource management textbooks', International Journal of Human Resource Management, 5(1):225-47.

Wright, P. and Boswell, W. (2002) 'Desegregating HRM: a review and synthesis of micro and macro human resource management research', Journal of Management, 28(3):247-76. 


\title{
3 Researching the employment relationship in small firms
}

\author{
What are the contributions from the \\ employment relations and small \\ business literatures?
}

\author{
Robert Blackburn
}

\section{Introduction}

This chapter will discuss the evolution of knowledge on employment in small firms by exploring both the employment relations and small firms' literatures. The discussion will also examine the methodological and practical issues facing those seeking to collect and analyse data and provide interpretations of labour management and employment relations in the small enterprise. Overall, it will demonstrate that although researching the employment relationship in small firms is not easy, there has been steady progress in our understanding of this relationship. Some of the reasons for this progress will be explored.

From a researcher's perspective, one of the perennial challenges in small business research is the absence of a rigorous or comprehensive empirical foundation to provide a sound basis for knowledge building, conceptualisation and theory development. Most government sponsored surveys, for example, have tended to avoid small firms on the grounds of expense and the bureaucratic burden this places on owner-managers. As a result, the small business literature is littered with piecemeal surveys, and the occasional secondary analyses of existing data sets, seeking to answer specific questions, some of them having statistical validity, others not, but generally tending to be distinctive by their methodological inadequacies rather than rigour. Of course, not all data sets are appropriate for helping answer some of the research avenues we seek to pursue. Yet, this absence of either appropriate sampling frames, or data sets for secondary analyses, does mean that small business researchers have additional challenges to those studying larger organisations. It also underlines the need to engage with the methodological debates within business and management and the social sciences more broadly (see Curran and Blackburn, 2001; Grant and Perren, 2002 for further discussion). Serious investigations of the employment relationship in small firms are no exception to this challenge. 
Ostensibly, one of the fundamental weaknesses in the study of labour management in small firms is the lack of attention paid to small firms by mainstream employment relations specialists. All disciplines and areas for study have their own methodological approaches, disciplinary origins, subject inclinations and agenda 'baggage'. Yet, for some time it appeared that the recognition of small firms as key employers was denied by the corpus of mainstream industrial relations which, throughout the latter part of the twentieth century, continued to focus on formality, the industrial relations framework, trade unions, collective bargaining and conflict at work. This has led to expressions of frustration by small business researchers and was evidenced in numerous introductions to articles seeking to analyse the employment relationship and is one of the major reasons for this book (see, for example, Marlow, 2002).

A key argument in this chapter will be that whilst there has been a growing understanding of the employment relationship in small firms, a great deal remains to be understood. Early analyses of labour management approaches in small firms tended to draw from established analyses of large organisations rather than construct appropriate concepts based upon evidence drawn from smaller enterprises themselves. These approaches also failed to question dominant institutional approaches, leading to a diversion from the richness of issues which could be investigated (such as the role of the family home as a workplace, e.g. Baines et al., 1997; Baines and Wheelock, 1998). Instead, for decades this potential was swamped with a relatively sterile agenda obsessed with comparing employment conditions by workplace size, based on measurable factors such as the existence of formal systems and trade union density. With time, the situation has improved but much remains to be done if we are to understand the employment relationship in small firms. This chapter suggests that although there is scope for more baseline data on small firms, including contributions from the Workplace Employee Relations Survey (WERS), ${ }^{1}$ this should not be to the detriment of more exploratory approaches and further qualitative research. Indeed, it is argued that our knowledge levels on the process of employment relations in small firms has developed irrespective of WIRS (Workplace Industrial Relations Survey) or WERS. The need for case study approaches, it is argued, will greatly add to our growing body of knowledge and theorisation on the employment relationship in small enterprises.

\section{Employment relations in the small firms' literature}

As background to understanding our knowledge base on the employment relationship in small firms, it is important to recognise the cumulative development of research in both the employment relations and small firms' literatures. In addition to the chapters in this book, a summary of some of the significant research studies on small firms is shown in Table 3.1. As can 


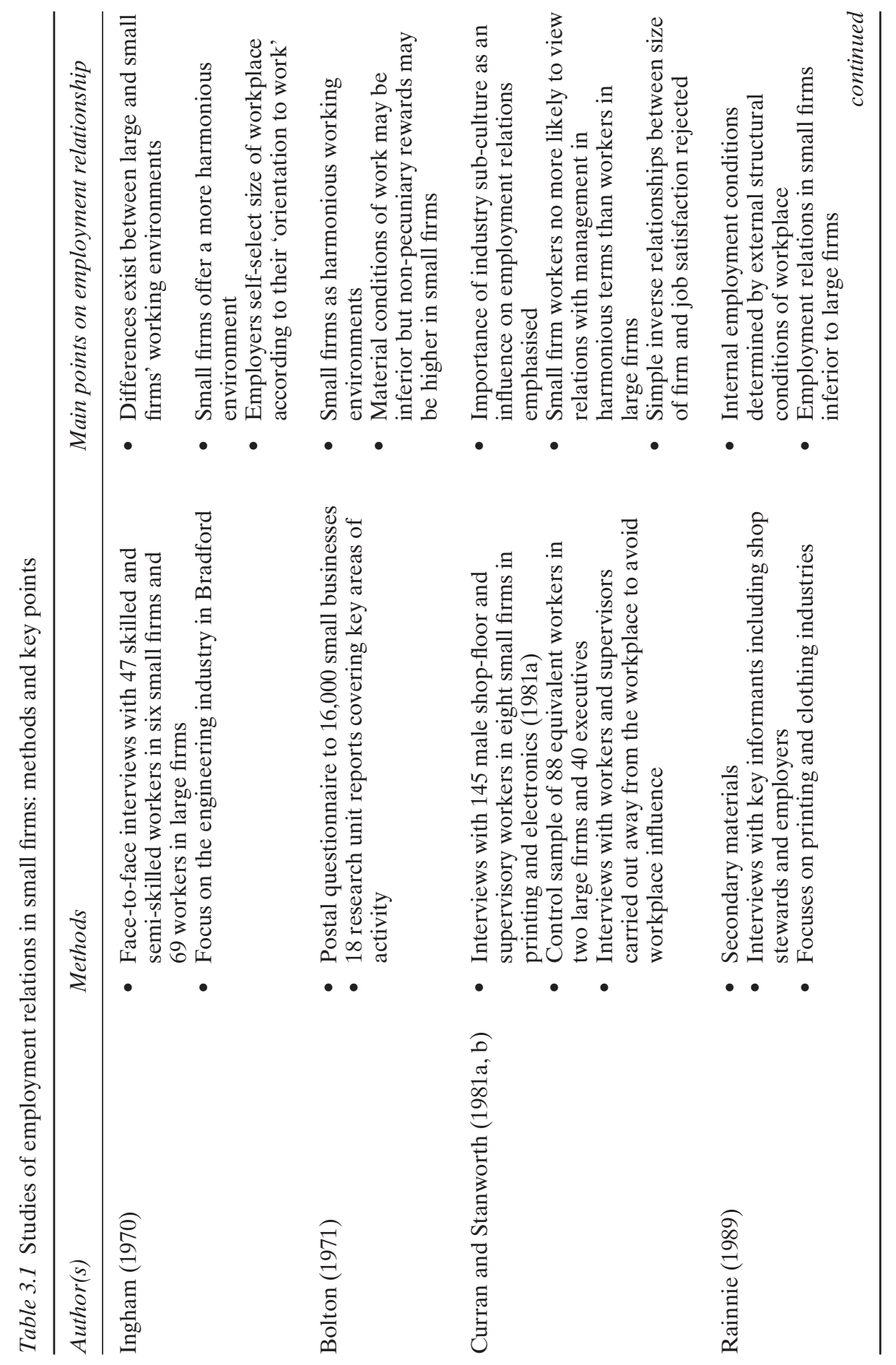




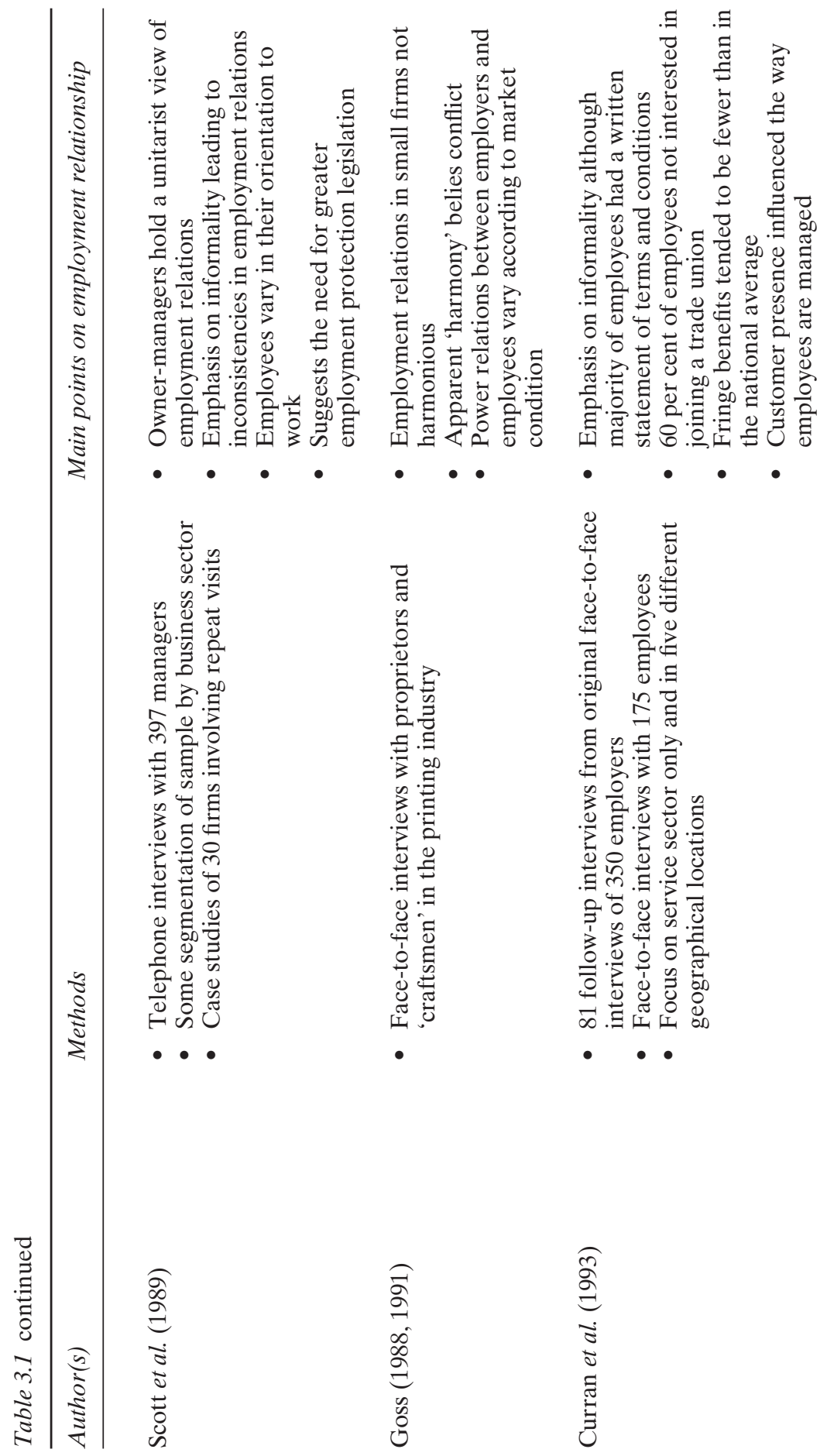



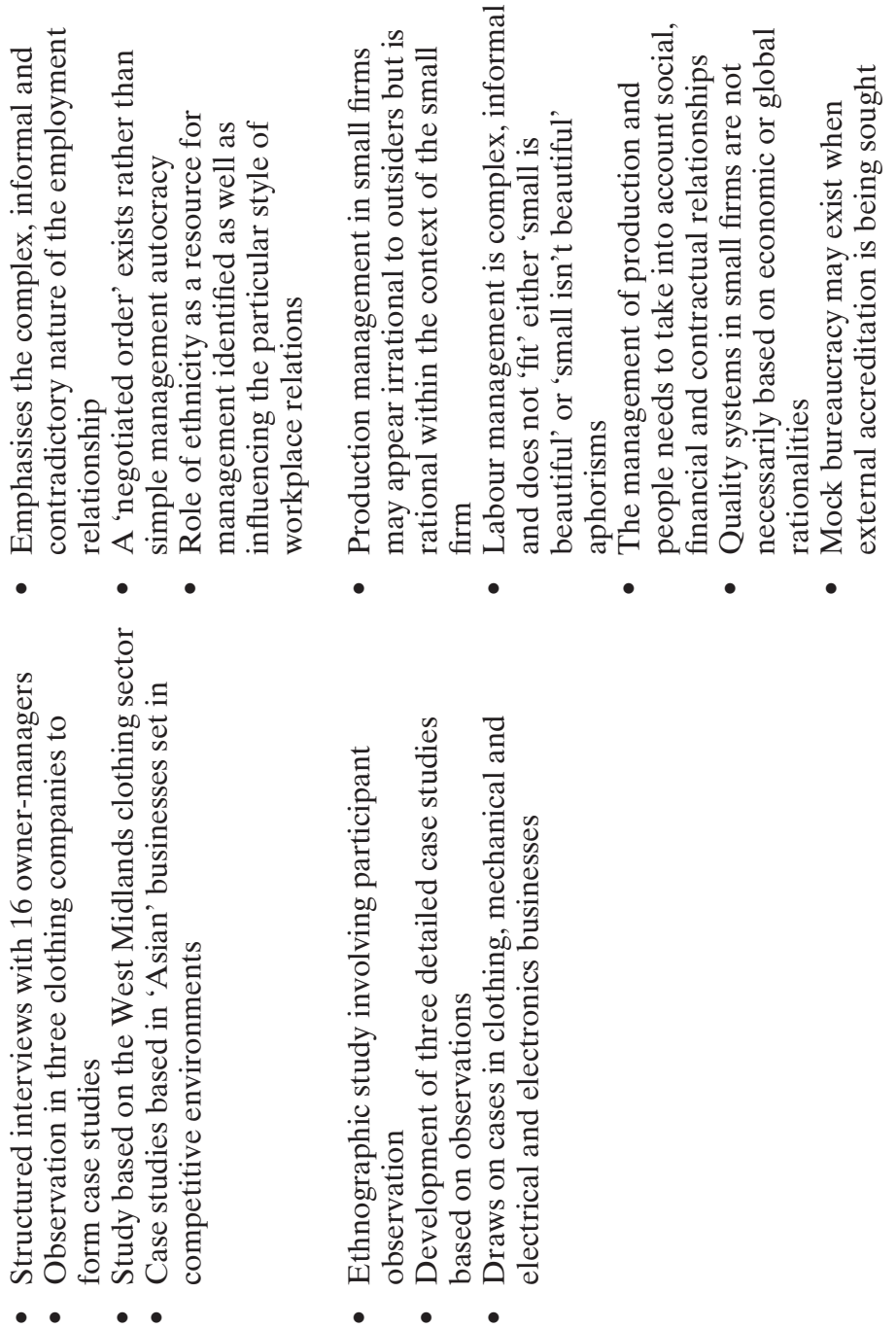

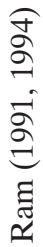

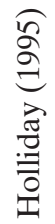


be seen, this is not a new area of research within the field of small business studies although it could be argued that the area itself is relatively new compared with the study of the employment relationship. ${ }^{2}$

A key foundation stone for the study of smaller firms in the UK was the Bolton Report (1971). The Committee commissioned a main report plus 18 research reports focusing on different aspects of activity. Employment relations were considered significant enough only to merit attention in the main report. Its position on employment relations was, with the benefit of hindsight and subsequent research, rather naïve and tended to fit into a recurring, if not tedious, theme of comparing small firms with large firms.

In many respects the small firm provides a better environment for the employee than is possible in most large firms. Although physical working conditions may sometimes be inferior in small firms, most people prefer to work in a small group where communication presents few problems. The employee in a small firm can more easily see the relation between what he (sic) is doing and the objectives and performance of the firm as a whole.

(Bolton Report, 1971:21)

This rosy view of employment relations in small firms tended to be the prevailing position of early studies. Ingham (1970) had also offered a more theoretically sophisticated explanation for the apparent relatively harmonious employment relationship in small firms. His theory suggested that employees in small firms held a 'non-economistic expressive orientation' to work and instead were more interested in the intrinsic aspects of work and the social relations within the workplace. In contrast, workers in large firms were more likely to hold an 'economistic instrumental orientation' to work, with an emphasis on material rewards. The thesis inferred that employees actually self-select whether they want to work in a large or small firm depending on their work orientation. ${ }^{3}$

This early view of the employment relationship was developed in a series of research projects and publications, many critical of Ingham and the Bolton Report's 'harmony' thesis. Sociologists in the small business field, Curran and Stanworth $(1979,1981 \mathrm{a}, 1981 \mathrm{~b})$ pioneered what was to become a steady deconstruction of the harmony view. ${ }^{4}$ In essence, the position advocated by Curran and Stanworth was one based on the heterogeneity of small firms emanating from their economic market context which would, as a consequence, lead to variations in employment conditions, social relations and labour stability within small firms. By implication, Curran and Stanworth suggested that it was too simplistic to pursue a generalised picture of employment conditions in small firms. Methodologically, they also pointed out that the overwhelming bulk of research on employment in small firms had, in fact, been undertaken using evidence from employers, rather than employees giving a rather one-sided view of 
accounts of the employment relationship. Subsequent studies built on the notion of heterogeneity, unpacking the management styles of ownermanagers (Goffee and Scase, 1982), linking what goes on within the enterprise explicitly with the external environment (Rainnie, 1989) and developing a typology of employers' control strategies (Goss, 1991).

Using case study material from printing and electronics it was Rainnie who argued most forcefully against the 'harmony view' (see also Barrett and Rainnie, 2002). Rainnie attempted to position his argument within a broader Marxist framework of combined and uneven development. Within this, it was argued that small firms play different roles within the economy (dependent, dominated, isolated and innovative) with implications for different employment relations and conditions within the enterprise. In his argument, Rainnie offered a 'bleak house' picture of employment relations in small firms as hosts of an autocratic management style and poor terms and conditions. This emanated from their subcontract relations with larger firms or the occupation of low-wage, low profitability industry sectors. Although criticised for suffering from structural determinism and an unclear research methodology (see Ram and Edwards, 2003), the work did represent an attempt to link the position of small firms within a broader theoretical context and pave the way for subsequent conceptual development.

Scott et al. (1989) provided one of the first major empirical studies focused on labour management in small firms. The research comprised a mixed method approach, with interviews of almost 400 owner-managers and three follow-up interviews with employers and employees for the development of 30 case studies. The follow-up visits allowed the eliciting of material not normally found in previous 'snapshot' approaches of employment relations. The advantage of this approach was that it allowed a focus on the processes of employment relations rather than mere outcomes. This study was also significant in that it tried to break away from the comparisons and agendas found in the study of large organisations and sought to build-up a picture of the employment relationship in small firms. The study emphasised the role of informality and the importance of personal relations as a means of managing labour within the enterprise. Employers, it was argued, held a unitarist view of the enterprise, and they pursued various non-bureaucratic strategies to achieve their objectives. It was argued that the absence of formality can have costs and benefits but caused particular problems when disciplinary matters arose.

Goss $(1988,1991)$ building on earlier classifications of employment relations typologies proposing that three employers' strategies were possible in small firms: fraternalism, paternalism, benevolent autocracy. These were contingent on the external conditions of the enterprise and internally, the bargaining power of employers and employees. Goss sought to explore why, on the assumption that there is disagreement between employers and their employees, there is a perception of harmony. Drawing on data from 
the general printing industry, he argued that there is a power asymmetry between labour and capital with employers having the upper hand. This relationship is also influenced by the external conditions within which the business operates and under favourable market conditions, employees will be in a stronger negotiation position. This study continued the theme that small businesses do not necessarily have a harmonious employment relationship but also that the social relations of production change and are influenced by the structural conditions within which the enterprise operates. Hence, the apparent harmony in small firms concealed the unitary perspective of owner-managers and in times of conflict it was the employee who had to accept the perspective of the owner-manager rather than vice versa.

A significant event in small business as a field of research enquiry was an initiative sponsored by the Economic and Social Research Council (ESRC) in 1990 (for overview see Storey, 1994). This initiative spawned three research centres of excellence as well as 16 projects on small firms. The study of employment in small firms formed an important component of the initiative and the main contributions were reported in an edited volume (Atkinson and Storey, 1994). The methodologies utilised in the volume were diverse, ranging from quantitative analyses of secondary data (Rees and Shah, 1994) to the analysis of primary data collected in interviews (Curran et al., 1991; Kitching, 1997). Probably because of the prevailing agendas of the time, the nature of the projects and the expertise of the researchers involved, there was little explicit link with the employment relations literature. Curran et al.'s (1993) analysis of the workforce construction policies of employers, their use of part-time, temporary, selfemployed and freelance workers, provided significant insights into the recruitment practices of employers and of all the ESRC's initiative research has the closest links with the mainstream employment relations literature. Atkinson and Meager's (1994) commentary, on the small firm in the labour market, highlighted the changes in small firms as they expanded and used the then popular notions of functional and numerical flexibility. What the book tended to confirm was that the employment relations agendas and literatures of interest to researchers in small firms were generally remote from mainstream debate.

Subsequent studies from the small business literature have become more conceptually sophisticated emphasising the diversity of employment conditions, unpacking notions of 'informality' and taking us away from the overly structural determinist positions in earlier studies (Ram, 1994). Here it is argued, the employment relationship is dynamic, fluid and often contradictory, rather than following any owner-managers' strategic position. Ram's contribution shows that the external structural conditions of an enterprise will not determine actual internal employment relationships. The latter, it is shown, goes beyond the material, cash nexus (which had been the focus of attention for so many previous studies) and often requires mutual dependency between employer and employees for sur- 
vival and involved social mores. One significant argument here was that informality was not necessarily an inferior form of employment relationship but was often necessary and advantageous for the prosperity of the enterprise and those engaged within it.

Holliday's (1995) ethnographic study of manufacturing in clothing, mechanical and electrical and electronics businesses has contributed to opening up what has been described as the 'black box' of the employment relationship: that is the precise types of employment relations in smaller firms and the factors influencing the relationship. Holliday shows that the logic of production organisation and the accompanying employment relations are influenced by familial ties. To the 'objective' outsider, these may appear unjustifiable on 'business rationality' grounds, but for the business owner they were eminently sensible, the strength of this argument is based on the soundness of her methodological approach and ability to unearth the multifaceted influences on the employment relationship. Holliday (1995:174) concludes with a critique of quantitative studies:

The emphasis on multiple rationalities at work in small firms mitigates against the positivistic reasoning of much production research, which places all its emphasis on an unproblematic rationality.

Clearly, for Holliday (1995:174) the search for generalisable statements about small firms and the use of quantitative approaches to verify these 'truths' is highly problematic:

Only a qualitative approach responds to the differences within and between firms with the necessary sophistication to begin the task of helping us understand exactly how these rationalities are played out to create the organisations which we study.

This case-study approach has been employed elsewhere highlighting that even within a close sub-contracting relationship, employment relations within the enterprise cannot merely be 'read-off' from the external conditions of the business:

if Button Co.'s relationship with M\&S (Marks and Spencer), and the need to complete orders quickly in general impacted upon life on the shopfloor, it did so not in a static way which implies the imposition of control, but through a dynamic (socio-political) process which rendered control a more fluid outcome. For the emphasis on completing orders quickly, especially in the case of $M \& S$, meant that directors were to some extent dependent on workers. This, in turn, created space for workers to re-interpret, or modify, control through the process of negotiation.

(Moule, 1998:642) 
These more recent qualitative approaches to understanding the employment relationship in small firms have the advantage of seeing how workplace norms and practices are executed rather than relying on second hand accounts of what happens from key informants. These methodological approaches, it could be argued, are also much more appropriate when studying small firms because of the informal, contradictory and ad hoc nature of the employment relationships reported in macro-surveys.

Of course, not all the key studies of employment relations in small firms deriving from the small business literature are able to be covered in one chapter. Yet, this short, overview has revealed that this area of the literature is making serious attempts at understanding the employment relationship in small firms. It reveals a shift from structurally deterministic approaches (Ingham, 1970; Rainnie, 1989; Barrett and Rainnie, 2002) to more complex attempts to embrace in-firm factors such as ownermanagerial style and family and kinship ties. What is also noticeable in this short review is the variety of methodological approaches used by small firms researchers: statistical analyses of primary data, case studies, personal interviews and work shadowing.

\section{Small firms in the employment relations' literature}

If the development of an understanding of the employment relationship in small firms within the 'small firms literature' can best be described as experiencing a steady evolution, that within the mainstream literature may be depicted as coming from a position of absence, to marginal interest and more recently, growing awareness. An examination of the industrial relations literature of the 1970s and 1980s reveals a poverty of studies on small firms, much to the exasperation of some small business researchers (see Marlow, 2002; Matlay, 2002; Scase, 2003). Marlow sums this up quite succinctly 'Labour management practices and policies in smaller firms have been somewhat ignored by mainstream industrial relations academics and those with an interest in the sector as a discrete area of study' (2002:39). Indeed, it could be argued that it was researchers from other disciplinary areas - industrial sociology, economics, geography and small firms researchers themselves - who were carrying the mantle of this area of investigation within the traditional field of industrial relations.

Although the reasons for this are debatable, it could be argued that this was a result of the attraction of other major topics of interest for researchers in the field of industrial relations (industrial conflict, trades unions, the wage-effort bargain and institutional approaches). These interests were also reflected in the prevailing broader mass media and analytical discourse on industry and commerce by industrial correspondents. Marlow (2002) suggests that this heightened in the 1980s because of the sustained attack on collective institutions and processes that were the very basis of the academic industry and corpus of knowledge of the employ- 
ment relationship. For academics in this field, studying employment relations in small firms may simply not have had the intellectual appeal of building on previous studies of workplace relations in large firms. To this is the added difficulty of conducting research in small firms: business owners are often antithetical to academics undertaking research in their enterprise, a position which may be hardened further when this comes to investigating employment relations. For many business owners employing people constitutes a problematic exercise on which they may have difficulty in volunteering to be researched.

\section{A dominance of large-scale surveys?}

In addition to the above disincentives to studying small firms, it has been argued that the absence of serious analyses of the employment relationship in small firms is a consequence of the predominant methodological paradigms of the mainstream employment relations' literature: sometimes called the 'Donovan legacy'. As Marginson suggests 'WIRS and other large-scale employer-based surveys now constitute a distinctive and important strand in the tradition of industrial relations' (1998:362). Analyses of the methodological approaches of studying employment relations suggested, at first sight, that there has been a shift away from case study, inductive methods, towards multivariate, deductive approaches (Whitfield and Strauss, 2000). Given the absence of readily available data sets on small firms, perhaps the study of employment relations in small firms was one of the casualties in this move.

\section{From WIRS to WERS: The role of small firms?}

One of the touchstones of the study of the contemporary employment relationship in Britain is undoubtedly the Workforce Industrial Relations Surveys (WIRS) and from 1998, renamed the Workforce Employee Relations Surveys (WERS). ${ }^{5}$ Students of employment relations, lecturers, researchers, post-graduates and undergraduates, analysts in the private sector, trade unions and government bodies will be aware of, if not influenced by, the surveys and their results.

It has been argued that the introduction of the WIRS (subsequently WERS) series demonstrated the rise of large-scale variable-centred surveys and the need to consider sampling methods and appropriate analytical techniques. Although these surveys were complex, and collected material from managers and employee representatives in telephone interviews, the criticism levelled at the outputs was profound (McCarthy, 1994). In his blistering criticism of WIRS, McCarthy argued that macrosurveys of this kind cannot capture the essence of labour management in the workplace. Not only are such research approaches, with a reliance on closed and standardised questions amenable to statistical manipulation, 


\section{R. Blackburn}

flawed, they failed to pick-up on the causes of the patterns found in the results. Some of the findings from WIRS were regarded as obvious: the decline in trade union membership and collective bargaining for example. Moreover, WIRS was criticised for influencing the research agenda because of its ease of access and analysis by other senior researchers and academics. Thus McCarthy (1994:319) pointed out:

It seemed a way of providing standardised and easily processed responses, delivered by respondents themselves, a part-time labour force from commercial agencies. Armed with the results desk-based academics could feed them into their newly acquired terminals, running them against a wide variety of readily available statistical series.

What followed, it is argued, was an avalanche of material using the data set and similar surveys in other countries (Millward et al., 2002). ${ }^{6}$ In his disquiet, although McCarthy did not argue for the total abandoning of WIRS, it was argued quite forcefully that there needed to be a shift away from this '. . . flight towards what is often nothing more than second-order desk-top research' (1994:312). Such a dominant methodology, it was argued, displaces the efforts of researchers from undertaking research of a kind which would generate '. . imaginative insights with possible practical consequences' (1994:321). WIRS it was argued, was not only influencing the employment relations literature through the publication of the results, it was also considered significant as setting subsequent research agendas and methodological approaches.

Millward and Hawes (1995) provided a robust response to McCarthy's critique of WIRS (see also Marginson, 1998). In relation to the research methods appropriate to understanding the employment relationship they accepted the relevance of 'the full range of social science research methods as appropriate to the subject' (Millward and Hawes, 1995:71). WIRS, it was argued, had a variety of roles to play including mapping changes, comparing matched units, the exploration of relationships between variables, the generation and testing of hypotheses both within the survey and for other research projects, and the derivation of implications for individuals and interest groups (see Millward and Hawes, 1995:71-2). It was argued that WIRS was not taking over the dominant methodology for studying employment relations, citing numerous alternative paradigms evident in the literature and that anyway they, as the original authors, could not be held responsible for those who had misused the data set, in secondary analyses. The defence of WIRS was concluded with an acceptance that '... the survey design must move on to reflect the changing realities of employment relationship' (1995:72). Of particular interest here is the growing non-union 'sector' and the authors accepted the need for both analyses of existing data sets as well as intensive case studies. 
The debate between McCarthy and Millward and Hawes was as revealing for what was omitted as much as what was included. Clearly, the debate shows evidence of concerns regarding what is meant by employment relations, the appropriate methodologies to investigate the field of study and who are the audiences for the research results. Yet, in the whole discussion there was little mention of the need to include smaller enterprises and whilst it was noted that newer businesses tended to be less unionised, even the reflective critical debates around WIRS appeared to be fixed in an historical time warp of the industrial framework and agendas of the 1960s and 1970s.

As WIRS developed into WERS, a number of areas were identified for development (Cully, 1998; Cully et al., 1999). Amongst these was an acceptance of the need to include smaller workplaces in recognition of their significance (as well as a separate employee questionnaire). As a result, WERS98 lowered the minimum size threshold of establishments for inclusion in the survey from 25 to 10 employees and included 250 'stand alone' businesses in this size band. ${ }^{7}$ The results were reported on specific variables which allowed a depiction of what employment conditions were like in small firms, also enabling comparison with larger and multiestablishment organisations. Table 3.2 shows some of the baseline characteristics of employment in small firms (employing between 25 and 100 people). The survey found that although employees had relatively high levels of job satisfaction, low pay and industrial tribunal applications were high (see Cully et al., 1998:26-7).

The results on small firms were also discussed elsewhere and presented similar comparative analyses. In one of the main outputs of WERS98, a chapter was dedicated to small firms (Cully et al., 1999). Here comparisons were made between small workplaces and larger organisations as well as stand-alone small firms and small organisations (i.e. establishments of 10-99 employees which are part of a larger organisation). The chapter concluded:

Organisation size and patterns of ownership proved to be clearly associated with the incidence of formal structures and practices within small workplaces. Overall, small businesses - especially those with

Table 3.2 Features of small business employment relations

\begin{tabular}{lc}
\hline Small businesses & Workplaces (\%) \\
\hline No 'new' management practices of employee involvement & \\
schemes & 8 \\
Five or more of these practices and schemes & 28 \\
Joint consultative committee at workplace & 17 \\
One or more equal treatment practices & 24 \\
\hline
\end{tabular}


working owners - had a less formal approach than small multiples to regulation of employment relationship. Compared to other small workplaces, they were less likely to have significant personnel expertise in-house or the more sophisticated personnel systems such as performance appraisal, incentive pay systems, or family friendly working practices.

(Cully et al., 1999:273)

There was, unfortunately, no disaggregated analyses within the 10-99 size band category even though most official classifications of small firms use a 49 employee upper size band cut-off. A major problem here was the low number of single plant small firms available for analysis. Thus, although the inclusion of firms employing 10 to 24 people did represent something of a breakthrough in bringing the survey in line with changes in the economy, the outcome was somewhat disappointing. The actual research-based output appears to have added very little if anything to existing knowledge on smaller firms. The bulk of publications reported, for example, in Millward et al. (2002) shows a continued focus in the literature on the effects of trade union membership on performance and workforce representation.

Despite the reduction of the size threshold, the inclusion of smaller establishments (i.e. those employing 10-24 people) however, still meant that the largest and most expensive investigation of employment relations in Britain has missed out on the biggest employer size band (Table 3.3). A review of WERS98 highlighted this weakness:

larger organisations ( 25 or more employees) were given a markedly greater chance of selection than their smaller counterparts because of a preponderance of the latter. This represents a slight qualification to claim the WERS is a nationally representative sample of workplaces.

(Lorretto, 2001:87)

Table 3.3 Size distribution of workplace establishments, GB

\begin{tabular}{crrrr}
\hline Establishment size & Population numbers & $(\%)$ & \multicolumn{2}{c}{ Initial sample numbers } \\
\cline { 5 - 5 } & & & WERS98 sample & $(\%)$ \\
\hline $5-9$ & 311,360 & 43.5 & 0 & \\
$10-24$ & 233,150 & 32.6 & 362 & 11.3 \\
$25-49$ & 91,250 & 12.8 & 603 & 18.9 \\
$50-99$ & 44,135 & 6.2 & 566 & 17.7 \\
$100-199$ & 20,435 & 2.9 & 562 & 19.6 \\
$200-499$ & 11,260 & 1.6 & 626 & 14.8 \\
$500+$ & 3,840 & 0.5 & 473 & 100.0 \\
Total & 715,430 & 100.0 & 3,192 & \\
\hline
\end{tabular}

Source: National Centre for Social Research (2002). 
This weakness is made even more stark when set against the background of the size distribution of enterprises in the UK economy (Table 3.4) of those with employees, 64.9 per cent employ less than 5 people and 82.5 per cent less than 20 people. Given that the number of establishments in the economy is higher than the number of enterprises and a proportion of the establishments employing less than 25 people will be part of larger organisations, the bias against studying small firms is reinforced. On the other hand, the majority of employees are in firms of 500 or more (53.4 per cent), offering some justification for the focus on larger enterprises.

An often cited defence for continuing to omit smaller firms is made on the grounds of the 'original purpose' of WIRS in 1980 (Millward and Hawes, 1995). The WIRS surveys were a response to the demise of '... national agreements and procedural arrangements of the kind given to the then standard sources. There was a clear consequential need for systematic and extensive data describing arrangements at workplace level' (Millward and Hawes, 1995:69-70). As a result, the surveys were commissioned to '... focus on the structures and practices of management trade union relationships and their outcomes' (1995:70). In other words, WIRS sought to understand formal industrial relations between management and workers at the level of the workplace rather than at the national level.

However, the world of work by the turn of the century had changed dramatically and, in 2002, only 26.6 per cent of the workforce are trade union members and 35.6 per cent of employees are considered to be covered by collective agreements (Labour Market Trends, 2003). The composition of industry has also changed significantly with a continued

Table 3.4 Size distribution of enterprises in UK with employees (start 2002)

\begin{tabular}{|c|c|c|c|c|}
\hline \multirow[t]{2}{*}{ Size band ${ }^{a}$} & \multicolumn{2}{|l|}{ Number } & \multicolumn{2}{|l|}{$(\%)$} \\
\hline & Enterprises & $\begin{array}{l}\text { Employment } \\
\text { (O00's) }\end{array}$ & Enterprises & Employment \\
\hline $1-4$ & 796,880 & 2,332 & 64.9 & 9.4 \\
\hline 5-9 & 215,855 & 1,537 & 17.6 & 6.2 \\
\hline 10-19 & 119,145 & 1,660 & 9.7 & 6.7 \\
\hline $20-49$ & 56,515 & 1,746 & 4.6 & 7.1 \\
\hline 50-99 & 19,255 & 1,340 & 1.6 & 5.4 \\
\hline 100-199 & 8,370 & 1,181 & 0.7 & 4.7 \\
\hline $200-249$ & 1,845 & 411 & 0.2 & 1.6 \\
\hline $250-499$ & 3,740 & 1,310 & 0.3 & 5.3 \\
\hline 500 or more & 4,470 & 13,178 & 0.4 & 53.4 \\
\hline All enterprises ${ }^{a}$ & $1,226,075$ & 24,695 & 100.0 & 100.0 \\
\hline
\end{tabular}

Source: adapted from SBS (2003) Table 1.

Note

a Tables excludes 'with no employees' which comprise sole proprietorships, partnerships comprising only the self-employed owner-manager(s), and companies comprising only an employee director. 
decline in manufacturing employment and a shift to the non-unionised service sector. The defence of continuing to exclude smaller enterprises of establishment on the grounds of continuity and facilitating comparison appeared very weak indeed.

As well as offering only confirmation of what is already known it could also be argued that WERS has intrinsic limitations on helping develop an understanding of the employment relationship, let alone those in small firms. Methodologically, such large-scale, deductive approaches tend to offer descriptions of situations based on 'facts', with clear-cut patterns and associations within the data all lending themselves to researcher assessments for their clients seeking to grasp the 'bottom-line' and develop key action points. At best, survey-based approaches, such as WERS, provide high quality baseline data drawn from a range of key 'actors' in the workplace. At worst, such surveys are methodologically inadequate to unearth the real nature and processes of employment relations in the workplace. By offering 'bottom-line' assessments of certain spheres of work activities, it may be argued that such surveys offer an overly-simplistic picture of the complexities of employment relations in the workplace.

If we set aside the inherent limitations of the research methodology of WERS98, there remains fundamental weakness in its contribution to the knowledge-base of employment relations in small firms. First, the variables for analysis continue to be driven by a 'formal' employment relations framework which simply does not encapsulate the bulk of employment practices in small firms. It could be argued further that the WERS approach is even less amenable to understanding the employment relationship in small firms. The small firm has less bureaucratic and 'recorded' information than larger firms and thus 'ready-made' data sources are much less likely to be available. Nor are the ready-made contacts (trades union representatives, personnel managers etc.) often available in large firms evident in smaller enterprises, thus rendering the research approach unsuitable. Second, there appears to be an underlying, related, assumption that 'formality' is the norm, the benchmark against which specific groups of organisations, large-small, sector by sector are analysed. This adds very little to our appreciation of the types of informality so prominent in small firms and the potential benefits or drawbacks which informality may embrace to the employment relationship. Finally, the simple comparison with larger organisations approach provides little opportunity for comparisons between small firms and reinforces an already discredited stereotype (see earlier discussion of for example Holliday, 1995) of the type of employment relations in small firms.

Inasmuch as the original WIRS was a response to the deficiencies of relying on descriptions of national agreements, which were declining in the 1970 s and 1980s, there needs to be a response on the relevance, or otherwise, of the WERS research approach to contemporary employment practices. This is particularly so when the shift from collectivism to 
individualism in the employment relationship (Brown et al., 2000) and the dominance of smaller workplaces is now so clearly obvious. In sum, whilst a further reduction in the size-band of workplaces (to five employees) to be included in WERS2006 is to be welcomed, this should not be taken as a panacea for understanding the employment relationship in small firms.

\section{Divergence or fusion?}

One possible barrier to the development of a more direct connection between the employment relations and small firms literatures is that they are both applied areas of study drawing on core disciplines such as economics, psychology and sociology. The study of small firms, as a discrete area, is relatively new compared with that of employment relations which has developed from the early part of the twentieth century (Edwards, 2002). This relative newness and accompanying lower levels of academic esteem may have not been attractive research territory for the more able researchers seeking to raise their academic profile. Whitfield and Strauss (2000) for example suggest that the shift towards quantitative and deductive approaches may be attributed to '... a desire among some employment relations researchers to gain greater respectability among their academic peers' (2000:147). Similarly, debates within the small business literature have suggested that the small business domain is only recently proving itself to rank with other applied areas of study. A survey of small business researchers showed that they perceived their area of study to have relatively low academic esteem and, within this, qualitative research is regarded as having the lowest academic status (Perren et al., 2001). More recently, the small firms literature has been influenced by the 'entrepreneurship' literature, which does not appear to consider the employment relationship at all. Instead, new agendas have been injected into the literature with an underlying advocacy and accompanying absence of critical approach to studying small firms. ${ }^{8}$

Is there a division in the mainstream employment relations and small

Table 3.5 Number of articles on 'employment relations' and small firms

\begin{tabular}{ll}
\hline British Journal of Industrial Relations (1997-2003) & 1 \\
Industrial Relations Journal (1997-2003) & 3 \\
Employee Relations (1992-2003) & 7 \\
Journal of Enterprise and Small Business Development (1997-2003) & 6 \\
International Small Business Journal (1997-2003) & 2 \\
\hline Note & \\
The words 'small firms' or 'small establishments' were used in this search and had to appear \\
in the title of the paper in the IR journals. The word 'employment' was used in the search of \\
the small business journals. Papers included focused on industrial or employment relations, \\
HR strategy and procedures. Papers covering state regulation and the evaluation of govern- \\
ment initiatives were not included.
\end{tabular}


business literature? At first sight, it may appear that the literatures studying labour management in the employment relations and small business literatures operate in isolation. Each literature has its own diverse origins, epistemological foundations, audiences and objectives. In reality, however, research is undertaken by individuals and groups of researchers who span disciplinary boundaries.

A summary of the articles on employment relations in key employment relations and small business journals (Table 3.5) reveals that there has been a similar number of published papers in the two academic domains. This could be taken to infer that mainstream employment researchers do pay some attention to small firms and journal editors are prepared to publish papers in this field of study. However, a more detailed investigation reveals that in both domains, where the numbers of papers are high these are a result of 'special editions' rather than a steady flow of papers over the time period investigated. The papers are also dominated by researchers deriving from a small business rather than an employment relations background, partly justifying the allegations of some researchers that small firms have been ignored by employment relations researchers. Yet, there does appear to be a core of researchers in this area, as in 2001, the register of BUIRA members, for example, shows that 17 (out of around 500) record an interest in small firms (BUIRA, 2001). Similarly, a database of abstracts compiled by ISBA and the SBRT for the Department of Trade and Industry had a specific section on Employment Relations in the Small Firm, showing a body of interest from the small business researchers' perspectives.

More recently, there has been a new vibrancy in the area with interdisciplinary researchers studying, for example, the effects of government interventions, such as individual employment rights (Blackburn and Hart, 2002; Marlow, 2002; Ram and Edwards, 2003) and the impact of the minimum wage (e.g. Gilman et al., 2002; Arrowsmith et al., 2003). These studies have also utilised a variety of methodological approaches demonstrating that the study of the employment relationship in smaller firms is attracting attention from researchers across the social sciences.

\section{Conclusion}

This chapter has sought to explore our understanding of the employment relationship in small firms, the contributions from the small firms and employment relations literatures and the methodological approaches used by researchers. It is crucial that an understanding of labour management in small firms is advanced if we are to raise our knowledge levels on the world of work in the bulk of the economy. This has both theoretical and practical implications.

The analysis has revealed a number of significant issues. First, research on small business has often been described as a 'cinderella activity' - 
coming late to the study of business and management in the social sciences. This view could not be more salient when examining the study of small firms by mainstream employment relations' researchers. It may be argued that the contribution to understanding the process of employment relations in small firms by the mainstream researchers in the past 30 years has been negligible. The focus of these researchers on formal labour management institutions, industrial conflict and collective bargaining has meant that our understanding of employment relations in small firms has been underdeveloped. Instead, the most significant contributions to knowledge have derived from small business researchers linking into the employment relations literature. More recently, however, the two domains have undergone some 'fusion' and within the employment relations literature itself the study of smaller firms is now more mainstream.

Second, within the small business literature there appears to have been a steady accumulation of knowledge on the employment relationship. This has moved from a strongly general, structural determinist approach to a more sensitised understanding which takes into account both structural and agency perspectives. Early structural analyses vacillated between 'small is beautiful' to 'small is ugly' positions offering little room for varying depictions of employment relations within small firms. With time this structural-determinist perspective has been steadily dismantled and it is now recognised that there is a diversity of employment relations between and within small firms. There also appears to have been a recognition that comparing large and small firms' employment practices by the same 'yardstick' can be misleading. The informality inherent in the small business employment relationship is now recognised as worth investigation as a process per se rather than a mere 'variable' for comparison with large organisations.

Third, the methodologies used for studying both smaller firms and the employment relationship have continued to excite controversy and debate. WERS, for example, has the strength of being longitudinal, capturing views of employers, managers and employees and covers a broad range of locations and industry sectors. However, from the small business research perspective, WERS has two broad limitations. First, the scale of the survey is inadequate to draw meaningful investigations. Even the reduction in the lower size threshold of WERS to establishments of 10 employees (and as proposed to five in WERS, 2006) has contributed little to what is already known. The statistical approach and limitations in the sample base of WERS to date renders its contribution to little more than a poor baseline. Whether or not the inclusion of firms employing 5-9 employees will help overcome the statistical deficiencies outlined remain to be seen. Second, WERS has its own limitations, intrinsic to most quantitative studies, but these are amplified when it comes to the study of smaller firms. The statistical analyses and subsequent interpretations of such large-scale data sets lend themselves to misleading generalisations on small firms, which appear 
to be more appropriate to government bodies seeking to monitor and design policy, rather than raise our appreciation of the processes within the employment relationship in small firms.

More recently, however, the literature appears to offer a richness of diversity in the methodologies adopted. As a corollary, accounts of the employment relationship show diversity not only between firms but within enterprises having similar external structural and market conditions. The recent emphasis on case study approaches is to be welcomed (Perren and Ram, 2004) and, from the evidence presented here, provides a way forward for developing further our understanding of the employment relationship in small firms. At the same time it is important that there needs to be a greater transference of ideas between 'small business' and 'employment relations' researchers. In short, the literature on the employment relationship in small firms, therefore, has moved slowly forward over the past 30 years. If this progress is to continue, it is important that a diversity of research approaches is embraced.

\section{Notes}

1 Formerly the Workplace Industrial Relations Survey (WIRS) (see Marginson and Wood, 2000).

2 When an area of study 'began' is of course open to debate and the small business area is no exception. There are some studies which are tangential to the area under study but did influence some of the early studies on small firms (e.g. Newby, 1977).

3 Ingham's thesis focused on male employees in the engineering industry.

4 It is notable that in this series of articles, they were able to publish in the British Journal of Industrial Relations (Curran and Stanworth, 1981a), one of the mainstream industrial relations journals.

5 Formerly the Workplace Industrial Relations Survey (WIRS). This was changed in 1998 to WERS.

6 Millward et al. (2002) provide a comprehensive list of books, book chapters, articles and other media deriving from WERS from 1983 to 2002. For example in 2001, there was 39 publications based on WERS material. WERS has also formed the basis for 10 doctoral theses (between 1985 and 1997).

7 This doubled the number of workplaces covered to over 3,000 and increased the proportion of employees covered by 15 per cent to 30,000 (see Marginson and Wood, 2000).

8 Take, for example, The Blackwell Handbook of Entrepreneurship (Sexton and Landström, 2000) and Advances in Entrepreneurship (Westhead and Wright, 2000) which provide key readings for many undergraduate and postgraduate courses but do not embrace any of the literature seeking to explore the employment relationship in small firms.

\section{References}

Arrowsmith, J. M., Gilman, P., Edwards and Ram, M. (2003) 'The impact of the National Minimum Wage in small firms', British Journal of Industrial Relations, 41(3):435-56. 
Atkinson, J. and Meager, N. (1994) Running to stand still: the small firm in the labour market, in Atkinson, J. and Storey, D. (eds), Chapter 2, Employment, The Small Firm and the Labour Market, London: Routledge.

Atkinson, J. and Storey, D. (eds) (1994) Employment, The Small Firm and the Labour Market, London: Routledge.

Baines, S. and Wheelock, J. (1998) 'Reinventing traditional solutions: job creation, gender and the micro-business household', Work, Employment and Society, 12(4):579-601.

Baines, S., Wheelock, J. and Abrams, A. (1997) 'Micro-businesses ownermanagers in social context: household, family and growth or non-growth', in Deakins, D., Jennings, P. and Mason, C. (eds) Small Firms, Entrepreneurship in the Nineties, London: Paul Chapman Publishing.

Barrett, R. and Rainnie, A. (2002) 'Industrial relations in small firms: the case of the Australian information industry', Work, Employment and Society, 16(3):415-31.

Blackburn, R. and Hart, M. (2002) 'Small firms' awareness, knowledge and access to information on individual employment rights', Department of Trade and Industry, Research Monograph No. 14, DTI, August.

Bolton Report (1971) Report of the Committee of Enquiry on Small Firms, Chaired by J. E. Bolton, Cmnd. 4811, London: HMSO.

Brown, W. A., Deakin, S., Hash, D. and Oxenbridge, S. (2000) 'The employment contract: from collective procedures to individual rights', British Journal of Industrial Relations, 38(4):611-30.

BUIRA (2001) Register of Members, British Universities Industrial Relations Association, Warwick University.

Cully, M. (1998) 'A survey in transition: the design of the 1998 workplace employee relations survey', London: Department of Trade and Industry, September.

Cully, M., O'Reilly, A., Millward, N., Forth, J., Woodland, S., Dix, G. and Bryson, A. (1998) 'The 1998 workplace employee relations survey, first findings', London: DTI.

Cully, M., Woodland, S., O'Reilly, A. and Dix, G. (1999) Britain at Work: As Depicted by the 1998 Workplace Employee Relations Survey, London: Routledge.

Curran, J. and Blackburn, R. A. (2001) Researching the Small Enterprise, London: Sage.

Curran, J. and Stanworth, J. (1979) 'Self-selection and the small firm worker: a critique and alternative view', Sociology, 13(3):427-44.

Curran, J. and Stanworth, J. (1981a) 'Size of workplace and attitudes to industrial relations in the printing and electronics industries', British Journal of Industrial Relations, 19(1):14-25.

Curran, J. and Stanworth, J. (1981b) 'A new look at job satisfaction in the small firm', Human Relations, 34(5):343-65.

Curran, J., Blackburn, R. A. and Woods, A. (1991) Profiles of the Small Enterprise in the Service Sector, ESRC Centre for Research on Small Service Sector Enterprises, Kingston upon Thames: Kingston Business School.

Curran, J., Kitching, J., Abbott, B. and Mills, V. (1993) Employment and Employment Relations in the Small Service Sector Enterprise - A Report, ESRC Centre for Research on Small Service Sector Enterprises, Kingston upon Thames: Kingston Business School. 
Edwards, P. K. (ed.) (2002) Industrial Relations, Theory and Practice, 2nd edn, Oxford: Blackwell.

Gilman, M., Edwards, P., Ram, M. and Arrowsmith, J. (2002) 'Pay determination in small firms in the UK: the case of the response to the National Minimum Wage', Industrial Relations Journal, 33(1):52-67.

Goffee, R. and Scase, R. (1982) 'Fraternalism and paternalism as employer strategies in small firms', in Day, G. (ed.) Diversity and Decomposition in the Labour Market, Aldershot: Gower.

Goss, D. M. (1988) 'Social harmony and the small firm: a reappraisal', Sociological Review, 36(1):114-32.

Goss, D. (1991) Small Business and Society, London: Routledge.

Grant, P. and Perren, L. (2002) 'Small business and entrepreneurial research: meta-theories, paradigms and prejudices', International Small Business Journal, 20(2):315-36.

Holliday, R. (1995) Investigating Small Firms: Nice Work? London: Routledge.

Ingham, G. K. (1970) Size of Industrial Organisation and Worker Behaviour, Cambridge: Cambridge University Press.

Kitching, J. W. (1997) 'Labour regulation in the small service sector enterprise', unpublished PhD thesis, Kingston University.

Labour Market Trends (2003) 'Labour market spotlight: trade union membership', LMT, July:338.

Lorretto, W. (2001) 'Review of Britain at work', Industrial Relations Journal, 32(1):87-8.

Marginson, P. (1998) 'The survey tradition in British industrial relations research: an assessment of the contribution of large-scale workplace and enterprise surveys', British Journal of Industrial Relations, 36(3):361-88.

Marginson, P. and Wood, S. (2000) 'WERS98 special issue: Editors' introduction', British Journal of Industrial Relations, 38(4):489-96.

Marlow, S. (2002) 'Regulating labour management in small firms', Human Resource Management Journal, 12(3):25-43.

Matlay, H. (2002) 'Employee relations in small firms: a micro-business perspective', Employee Relations, 21(3):285-95.

McCarthy, W. (1994) 'Of hats and cattle: or the limits of macro-survey research in industrial relations', Industrial Relations Journal, 25(4):315-22.

Millward, N. and Hawes, W. R. (1995) 'Hats, cattle and IR research: a comment on McCarthy', Industrial Relations Journal, 26(1):69-73.

Millward, N., Woodland, S., Bryson, A., Forth, J. and Kirby, S. (2002) 'A bibliography of research based on the Workplace Industrial Relations Survey Series', National Institute of Economic and Social Research, London, September [http://www.niesr.ac.uk/niesr/WERS98].

Moule, C. (1998) 'The regulation of work in small firms', Work, Employment and Society, 12(4):635-54.

National Centre for Social Research (2002) Sampling Issues for a Fifth WERS, prepared for the Department of Trade and Industry, Nat Cen, London, December.

Newby, H. (1977) The Deferential Worker, Harmondsworth: Penguin.

Perren, L. and Ram, M. (2004) 'Case-study method in small business and entrepreneurial research', International Small Business Journal, 22(1):77-93.

Perren, L., Blackburn, R. A. and Berry, A. (2001) 'The UK small business 
community and its publication channels: perceptions and ratings', Journal of Small Business and Enterprise Development, 8(1):76-90.

Rainnie, A. (1989) Industrial Relations in Small Firms: Small Isn't Beautiful, London: Routledge.

Ram, M. (1991) 'The Dynamics of Workplace Relations in Small Firms', International Small Business Journal, 10: 1, October-December, 44-53.

Ram, M. (1994) Managing to Survive: Working Lives in Small Firms, Oxford: Blackwell.

Ram, M. and Edwards, P. (2003) 'Praising Caesar not burying him: what we know about employment relations in small firms', Work, Employment and Society, 17(4):719-30.

Rees, H. and Shah, A. (1994) 'The characteristics of the self-employed: the supply of labour', in Atkinson, J. and Storey, D. (eds) Employment, the Small Firm and the Labour Market, London: Routledge.

Scase, R. (2003) 'Employment relations in small firms', in Edwards, P. K. (ed.) Industrial Relations, Theory and Practice, Oxford: Blackwell.

Scott, M., Roberts, I., Holroyd, G. and Sawbridge, D. (1989) 'Management and industrial relations in small firms', Research Paper No. 70, London: Department of Employment.

Sexton, D. L. and Landström, H. (eds) (2000) The Blackwell Handbook of Entrepreneurship, Oxford: Blackwell.

Small Business Service (2003) SME Statistics for the UK, 2002, Sheffield: SBS, August.

Storey, D. (1994) Understanding the Small Business Sector, London: Routledge.

Westhead, P. and Wright, M. (eds) (2000) Advances in Entrepreneurship, Volumes I-III, Cheltenham: Edward Elgar.

Whitfield, K. and Strauss, G. (2000) 'Methods matter: changes in industrial relations and their implications', British Journal of Industrial Relations, 38(1):141-51. 


\title{
4 Managerial strategies in small firms
}

\author{
Richard Scase
}

\section{Introduction}

Studies of the employment relationship in small firms have tended to explore the work orientations of those employed in small firms and draw comparisons between these and their colleagues in larger corporations (Marlow, 2002). This has also been the basis for comparisons in terms of employee motivation and moral as well as for explanations of differences in rates of absenteeism and industrial unrest. This was very much the focus of small business research more than thirty years ago and this has, in many ways, set the agenda for large areas of academic debate ever since (Ingham, 1970). Indeed, the preponderance of discussion continues to surround issues of the small industrial or manufacturing enterprise rather than 'knowledge-based', professional service businesses that make up a growing percentage of the small business sector.

In this chapter, the emphasis is rather different. It is to discuss the managerial strategies found in different types of small firm and to make rather more explicit some of the differences that exist in these strategies in those businesses trading in the traditional manufacturing sector compared to those in the fast growing 'creative' and professional areas of the economy. It goes without saying that it is conceptually simplistic to collapse a diversity of proprietorial and managerial styles into a single generic category of 'small business'. The characteristics of skill, product and market are inevitably determining factors that shape features of the management process within any firm. 'Low-skill', 'manual', or 'craft' enterprises will be organised according to different principles compared to those prevailing in the professional services, high technology and science sectors of the economy. In order to highlight these, strategies in 'traditional' small firms are first discussed, followed by an exploration of management processes in 'knowledge-based' businesses.

\section{Management processes in traditional small firms}

In these firms, it is possible to distinguish between the self-employed, craft employers and entrepreneurs (Scase and Goffee, 1987). For many, self- 
employment is the ultimate goal of business proprietorship and, essentially, the self-employed undertake all tasks. They may make use of unpaid family labour or, at best, others on a part-time basis, but they employ no staff on a regular basis. Such businesses are usually set up on the basis of specific craft skills which are then used for the purposes of trading in a particular local market niche. These are the carpenters, plumbers, hairdressers, electricians, window cleaners, secretaries, car mechanics and many others who sell to customers their personal skills of one kind or another. It is their detailed knowledge of trading opportunities within a particular locality that often motivates craft workers to start on their own. Their enterprises are based upon the delivery of goods and services to customers on a regular and personal basis. In this way, they have immediate feedback from the market in terms of response both to the quality of their services and to the prices which they charge.

Such traditional traders, however, often lack basic business management skills, since their overriding goal is to provide services to customers on the basis of their craft skills. For this reason they may under-charge, confuse turnover with profits, have high but hidden overheads and generally neglect the book-keeping and general administration of the business. It is weaknesses in these areas that lead to their high failure rates, particularly during recession as in the 1990s, rather than deterioration in the quality of services or products.

Self-employed enterprises often have precarious futures because they are entirely dependent upon the talents and energies of their proprietors, a feature which is reinforced by their reluctance to employ others. The latter is a function of their lack of management skills and training and also because of their underlying motive for business start-up - the need for personal independence (Goffee and Scase, 1995).

\section{Craft employers}

The self-employed often find that they are unable to meet the demands of their customers on the basis solely of their own skills, resources and time. It is necessary for them to hire employees on a more-or-less regular basis. Normally only two or three staff are employed, but it can be as many as twenty, depending upon the ability of the proprietor to manage as well as to work alongside them as a team member. In these businesses there is the emergence of a management function, since their proprietors have to organise the work process so that there are regular cash flows to pay wages and other costs associated with the employment of staff.

It is in businesses of this kind that the two basic principles of any organisation become apparent; those of integration and differentiation. For selfemployed proprietors the integration and division of work tasks is undertaken within the context of their own time management. Craft employers, by contrast, are faced with the need to break down and to 
differentiate business activities into specific job tasks and then integrate these through modes of personal supervision and control. How is this undertaken within businesses which employ no more than five or six people? If in large organisations some type of division of labour is moreor-less taken for granted, and is embedded within structures of authority and responsibility, this is less so in small businesses, with the result that the allocation of duties is always more uncertain, variable and problematic. Accordingly, the division of tasks and the specification of jobs is the outcome of a process of mutual adjustment (Goffee and Scase, 1995). The division and integration of the work process is based upon the interdependence of employees undertaking duties in a flexible and broadly defined manner. This can be a source of employee work satisfaction because the delineation of job duties through mutual adjustment offers task variety which may not be available within the more bureaucratised structures of many large organisations. Mutual adjustment also binds individuals into teams, with the result that a high premium is attached to personal compatibilities between employer and employees as well as among employees themselves. Equally, there is the need for high-trust relations since, without these, mutual adjustment as an organising process is unlikely to generate productive and profitable business performance. Recruitment is often a compromise between competence and compatibility and it can be a source of considerable tension within many small businesses. Rarely are personal compatibilities and expert skills perfectly matched and the former may be given priority over the latter in the small business proprietor's recruitment process.

A feature of traditional craft-based enterprises managed on the basis of mutual adjustment is the absence of a distinctively separate management function and the exercise of authority through formal hierarchical control. Relatively low profit margins prevent proprietors withdrawing from the performance of productive work tasks and becoming full-time managers and supervisors of others. They, themselves, are part of the process of mutual adjustment and as such, they are members of teams working alongside their employees. It is through this involvement that they fulfil the managerial function. Instead of issuing instructions, they determine the criteria for quality and quantity of employee performance through personal example. As such, proprietorial authority is exercised within rather than superimposed upon the work process. This reaffirms the need for personal compatibility between employers and employees and the vital importance of high-trust relationships. Within these, proprietors have to maintain a delicate balance between their identification with employees' interests, and the distance needed to fulfil the proprietorial function.

Small businesses, organised on a basis of such informal mechanisms, have to undergo a process of organisational restructuring if they are to grow. It is generally necessary for proprietors to cease working alongside their staff and instead to become more fully occupied with the administra- 
tion of their businesses. As a result, the management function is undertaken by proprietors through various face-to-face mechanisms of direct control.

\section{Entrepreneurs}

These owner-managers exercise control over their businesses through directly imposed but mostly unwritten guidelines and instructions. They may employ up to fifty or sixty staff, but it can be far more, depending on the ability of proprietors to exercise control through informal, face-to-face processes rather than according to formalised structures and job descriptions. Unlike craft employers, they do not rely upon establishing performance criteria through personal example. Although in the larger of these enterprises there may be supervisors and managers, the exercise of authority and responsibility is concentrated in their proprietorial hands. By dint of ownership, proprietors possess legitimacy to impose business decisions, often in a more-or-less arbitrary manner. They may consult with key employees, but typically they retain almost total control and remain at the centre of the decision-making web (Churchill and Lewis, 1983).

In these enterprises a high premium is attached to nurturing strong but informal cultures and employee integration tends to be on the basis of personal allegiance to proprietors. Such enterprises are, generally, structured around the 'personalities' of their owner-managers and their growth potential is highly dependent upon proprietors' preferences, energies and plans. Accordingly, rational decision-making within entrepreneurial enterprises is often bounded by, or contingent upon, a range of sentimental and pesonal factors (Birley, 1989).

Within the context of direct, face-to-face relations with staff and in the absence of formalised rules and procedures, owner-managers develop a number of strategies for cultivating employee commitment. The most common of these is the appeal of charisma. Some proprietors nurture business cultures which serve to exaggerate their own extraordinary qualities and, through this, they link their own achievements with those of their business and, equally important, with their employees. In this way, proprietors appeal to their staff to exercise exceptional commitment and output in return for generous financial rewards. Sometimes this can be in the form of overtime or, more usually, through year-end bonuses, sales commissions, and profit-related payment systems. Since these rewards are offered within the context of highly personalised, informal face-to-face relations in sharp contrast to the working procedures of large bureaucratic organisations - they serve to reinforce employee allegiance to, and their dependency upon, their employers. In the deliberate absence of formalised rules and guidelines, such rewards are always discretionary and may be seen as an attempt by proprietors to legitimate their control through the maintenance of dependency relations. This can be particularly effective if 
employees are low skilled and have competences which are only relevant within the context of their proprietors' enterprises. In lacking transferable skills, they become excessively dependent upon their continuing personal compatibility with their employers.

An alternative for proprietors is to exercise control through more paternalistic methods. As such, they attach considerable importance to the social as well as the economic responsibilities of being 'local' employers who share the long-term interests of their staff. As with charismatic strategies, the intended outcome is a high level of employee dependency, underwritten by employers' discretionary use of material rewards and fringe benefits.

Alongside these two proprietorial styles, there is the classic autocratic approach, whereby entrepreneurs manage their staff in a more impersonal, calculative and instrumental manner. Owners stress the purely economic character of their businesses and the fact that, in order to survive, and for jobs to be preserved, wage costs must be kept to a minimum. As a result, working conditions are often poor, rates of pay are low and there is a high level of staff turnover. This autocratic style tends to be found where the nature of the product or service requires very low employee skills and where labour market conditions enable staff to be readily hired and fired as well as being employed irregularly or on a part-time basis. It is a method of management which leads to low employee trust and which exploits and reinforces the vulnerability and dependence of unskilled labour. Such a proprietorial style is often found in the hotel and catering, cleaning, textile and clothing, and subcontracted low-skill, machine tool industries (Scase, 2003).

Although the above styles - charismatic, paternalistic and autocratic can be considered as distinctive, they are often juxtaposed with each other within the same small business. Proprietors will often use a variety of interpersonal techniques, drawing upon each of them in relation to different categories of employees. For example, the paternalistic style may be applied to long-term, relatively indispensable employees, whilst the autocratic approach may be reserved for temporary, less skilled workers.

Within such enterprises, there is often greater clarity and specification of work tasks than is found within smaller craft employer businesses. If in the latter, processes of mutual adjustment determine the allocation of job duties, the proprietors of entrepreneurial firms manage through mechanisms of direct control, devoting more attention to setting up explicit systems of responsibility and control (Moule, 1998). Even so, the division of work and associated job descriptions remain relatively loose compared with those found in many larger organisations. Further, by managing through direct face-to-face supervision, owners are able to monitor employee performance closely, and to exercise tight controls over operating costs. However, the potential of these strengths can be untapped because of other inherent weaknesses associated with the indispensable 
roles of their proprietors. Even if there are managers and others who undertake some of the supervisory tasks, systems of delegation in terms of responsibility, authority and decision-making usually remain underdeveloped. This is often because of the predominant power cultures of these businesses (Goss, 1991). In the absence of formalised systems, the management function is exercised by owners developing networks of personal allegiance. Within cultures which stress the importance of employee compliance, decision-making is rarely queried or subject to detailed employee scrutiny. Employees may be powerless as their employers take decisions which can jeopardise the future viability of the business. Proprietors' reluctance to delegate may lead to the under-development of management skills among staff and the under-utilisation of their talents and skills. This can be a deliberate strategy which facilitates the retention of tight control over business operations with little challenge to proprietorial authority. However, businesses become over-dependent upon proprietors and, at the same time, staff may become disaffected and de-motivated. Further, little attention is often given to management succession, with the effect that the longer-term future of such businesses is uncertain (Aston Business School, 1991).

\section{Creative and professional small firms}

Growing numbers of managers, technologists, highly qualified specialists and professionals are leaving the relative security of the corporation to risk starting up their own businesses (Scase, 2002). Many of them feel that their personal talents and skills are not being fully utilised. Middle-aged managers often accept redundancy and experiment with entrepreneurship, often with initial financial support from their previous employers (ibid.). Younger managers, on the other hand, who have been encouraged to expect opportunities for creativity, challenge and self-fulfilment in their jobs, are often disappointed. Consequently, they are increasingly convinced that entrepreneurship may offer an alternative route for the achievement of such goals (Scase and Goffee, 1989).

What kinds of businesses do former corporate managers set up? It is often in their capacity as corporate specialists of one kind or another that they have been able to identify market trends and to determine, within these, niches for trading opportunities. It is not unusual for managers to negotiate deals with their previous employers' customers to give them their first trading opportunities and with these, to raise finance. In common with traditional craft entrepreneurs, their businesses are often highly dependent upon their own particular talents and skills. It is with these that products and services are traded.

The growth of these businesses has been most pronounced in those economic sectors where there has been corporate fragmentation, down-sizing and associated processes of outsourcing (Scase, 2002). The media offer 


\section{R. Scase}

many examples of these trends, with more than one half of those working in this sector being freelance, self-employed or the proprietors and partners of small business enterprises. Television broadcasting companies, for example, now purchase programmes from producers and directors who in turn hire, on a project and temporary basis, freelance sound engineers, camera crews and other staff. The television industry, once integrated on the basis of large corporations with both in-house production and broadcasting functions, has become an example of the 'virtual' corporation, fragmented around a network of broadcasters who are little more than commissioning agents of programmes made by small-scale enterprises (Davis and Scase, 2000).

A similar process is occurring within other media sectors such as newspaper, magazine and book publishing, advertising and the performing arts. Out-of-house freelance specialists are commissioned to contribute to specific projects which are co-ordinated by their clients. Areas of London, New York, Paris and other capital cities are taking on the features of closely knit occupational districts where networks of independent specialists are constantly grouping and re-grouping to offer contractual services to commissioning clients. Equally, the financial services sector has become fragmented around a core of major insurance companies, finance houses and other banking institutions. Self-employed consultants and advisers, operating from home-based work stations, increasingly 'interface' between the purchasers and suppliers of corporate services and establish partnerships and small limited companies, offering specialist financial services within precisely-designated market niches (Castells, 1996).

Increasing affluence and the greater disposable income of the middle classes in Europe and the United States offer opportunities for business start-up among corporate managers and others with specialist skills in finance, investment and accountancy (Scase, 2000). There are also growing business opportunities for those occupying middle-level management positions possessing specialist skills associated with new technology, telecommunications and information systems. Demands for software and computer packages have generated a sector of small-scale providers who prefer to be self-employed rather than to work in large corporations. Many university graduates with such skills obtain work experience in large companies (ibid.) before moving on to smaller software houses or setting up their own businesses, often in partnership with like-minded others. Similarly, more sophisticated consumer markets have led to the growth of public relations, promotion and marketing functions which, instead of being undertaken in-house, are outsourced to freelance specialists who often pool their personal talents (Scase, 2002). What are the management characteristics of these businesses?

The organisation of work on the basis of specialist and changing customer needs tends to produce 'flexible' work roles, duties and responsibilities. Instead of the performance of routine tasks, adaptiveness and job 
variety are the predominant characteristics of these enterprises. Equally, their small-scale nature means that little can be offered to employees in the form of conventional promotion prospects. If these are important sources of motivation for managers in large organisations, they are generally absent within small firms. In the latter, psychological rewards are obtained through personal self-fulfilment and individual recognition (Davis and Scase, 2000). This has ramifications for management styles, interpersonal relations between proprietors and employees, business cultures and structures, and growth strategies. Work roles tend to be broadly defined with high levels of discretion and responsibility. Professional employees working in these small businesses are assumed to prefer personal autonomy, responsibility and recognition and, indeed, these are typically their motives for moving from employment in large organisations. Staff are encouraged to develop close working relationships with clients so that, in a relatively autonomous manner, they can exercise particular expert, creative and technical skills.

Personal recognition is also an important reward because of the significance of broader 'professional' reference groups. In advertising, television, film, the performing arts and public relations, there are numerous rewards and other tokens of recognition that constitute important motivators for those working in these industries (Fletcher, 1990). Equally, professional bodies stipulate standards of conduct and criteria for terms of trade which shape relationships between the buyers and sellers of services. It is only in the consideration of these factors that it is possible to understand the internal dynamics and the management processes of these creative and professional businesses.

Even though the creative energies of employees are the major asset of such businesses, and the need for self-fulfilment must be addressed, there must also be suitable financial rewards. However, the discretionary nature of work means that pay and performance can rarely be precisely measured (Fletcher, 1990). Further, the organisation of work activities around clientdetermined projects can entail the cultivation of long-term relationships with financial returns accruing over relatively lengthy periods of time. Employees, then, often expect to have a financial stake in the future of their businesses, since the assets are largely comprised of their own and their colleagues' expert skills. Hence, enterprises that trade with creative and expert skills are often set up as partnerships rather than as sole proprietorships. A further reason for the partnership form is that previously disaffected colleagues may, together, possess complementary skills for start-up. Similarly, partnerships offer support systems and shared competences which reduce the risks inherent in business start-up. But more important is the fact that such partnerships enable individuals whose skills are indispensable for business success to have a stake in ownership. Although partners may pay themselves relatively low wages in the short term, they enjoy longer-term benefits in the incremental increases in the 
value of their businesses. Ownership stakes are often extended to those employees who demonstrate high commitment and performance; equally, new staff are often attracted by this promise (Scase, 2002). In these ways participation in ownership is a means for incentivising colleagues in enterprises where staff skills provide the basis for value-added trading. Without such arrangements, tensions can easily emerge, leading to staff resenting the fact that their talents and skills are being exploited by others for personal gain.

If the underlying principles of any organisation, whether large or small, are those of integration and differentiation, within these businesses tendencies to differentiation can dominate. Again, partnerships offer an appropriate solution, since sources of individualism, division and segmentation within work processes are compensated by the integrative mechanism of joint ownership. But the tendency to differentiation makes these businesses prone to break-up, with partners selling their stakes to set up their own ventures, often with some of their colleagues. 'Spin-offs' of this kind account for the growing proliferation of small businesses in the media and creative sectors (Granger et al., 1995). In the absence of methods of direct managerial control, of the kind found in some traditional craft enterprises, there is little in the form of explicit control mechanisms which function to integrate work processes. Even methods of supervision whereby proprietors work alongside their staff may be inappropriate, since they offend 'professional' notions of personal autonomy and discretion. Further, the exercise of proprietorial control through the adoption of various charismatic, paternalistic or autocratic management styles is of limited value. Highly motivated employees are likely to feel patronised rather than motivated by such managerial appeals.

In creative, professional and high technology small businesses, the work process is broken down into 'projects', 'jobs' and 'accounts'. In this way, activities are organised according to client needs, for which particular individuals or groups within the enterprise will be responsible. Partners and employees organise their own and colleagues' work tasks according to the job requirements of their own projects, leading to an overall work process which, although highly fragmented, is dependent upon partners' relationships with clients (Davis and Scase, 2000).

There is little need for more direct forms of management control since workflows are constantly adapted according to client preferences. In this sense clients manage the work process and as such, there is little need for explicit management control. Just as the division between owners and employees is dissolved through the setting-up of these businesses as partnerships, any distinction between managerial and non-managerial functions is virtually non-existent. There are no managers and rarely are there partners with solely managerial responsibilities; it is unnecessary when the management of work is built into the professional-client relationship.

A further reason why the management function lacks specificity in 
these firms is because of the nature of their core competences. Creative, expert and professional employees obtain qualifications, training and work experiences that inculcate them with codes of practice and ethics which are designed to control standards and shape the nature of professional-client relations. As such, these function as modes of internalised control, rendering redundant the need for external managerial controls. Insofar as behaviour is regulated, it tends to be built into collegial relationships and expressed as professional ethics within 'training', 'induction' and 'shared experiences'. If there are explicit managerial controls these are applied to support staff such as secretaries, technicians, bookkeepers and other assistants. It is in handling these relationships that there are likely to be more workplace tensions, since hierarchical controls are contrary to the predominant culture of these enterprises. Attempts to exercise formal management over support staff may cause resentment because this contrasts vividly with the apparently ill-defined interpersonal relations between experts and professionals within the 'operating core'. Such divisions may be compensated by various office rituals; for example, the celebration of birthdays, office parties and after working hours drinks, when all employees are invited to socialise. Although embedded in personal networks, support staff are not partners and rarely have a stake in the wealth-creation potential of the business. Their jobs offer only limited opportunities for personal discretion and there are few other rewards in the form of personal recognition, challenge or self-fulfilment. They have few chances of promotion as they lack the professional qualifications and/or creative, technical or expert skills necessary to become members of the operating core. The absence of formalised management can also create job dissatisfaction since the work process is organised around specific projects, support staff are often subject to conflicting demands, yet are rarely trained to handle such interpersonal relations. For some, then, loosely structured organisations may be a source of frustration and friction rather than job satisfaction.

If the cultures of traditional small firms are strongly shaped by their proprietors, this is less likely to be found in professional and creative small businesses. The ethos of these reflects a strong 'individualism' and the professional desire for personal autonomy. As a result, business-based cultures tend to be less influential than the ethos of the profession. To compensate for this, proprietors and/or senior partners often give explicit attention to the development of business-based shared values. This may be achieved through appeals to 'customer service', the 'traditions' of the business and 'pride in the product'. Such values are inculcated through induction programmes, socialising, and various in-house rituals and ceremonies which reinforce 'core' attitudes, beliefs and practices. But despite such attempts, the work process fundamentally orientates staff towards clients, an attitude which is reinforced by their identification with broader reference groups such as professional associations. As a result, professionals 
tend to view their employing organisations as resources which can be used for delivering services to clients and for enhancing personal reputations (Davis and Scase, 2000). How, then, can commitment to the business be obtained?

Essentially, such enterprises are integrated on the basis of informal social networks and work teams. In staff recruitment, it is often difficult to assess in any precise manner a person's skills because of the indeterminate nature of creative, expert and professional tasks. Alongside references and job histories, knowledge of job applicants through networks of personal contacts is often considered important in the recruitment process. Since work activities are project-driven, as in television production or advertising campaigns, it is important that specialists are able to work together, pooling their talents and skills in a creative and productive manner. Hence, trust relations are important, and ever-forming and temporary work teams are the chief means whereby these can be nurtured. In these teams, work roles are often stretched beyond specific personal, technical and creative competences and, hence, colleagues become interdependent upon each other for the success of their own goals. It is this interdependence of skills that is the key integrative mechanism which - because of their external client and professional orientations - might otherwise be excessively fragmented (Mintzberg, 1983).

A key managerial issue for these enterprises is how to build teams and recruit colleagues who can fill appropriate team-member and leadership roles. Team leadership requires the exercise of delicate interpersonal skills because of the 'professional sensitivities' of colleagues. The ability to be both a team or project leader and a close working colleague is an essential component of successful organisational integration. Without this, individualism, division and segmentation can become pronounced as colleagues refuse to work together, withhold ideas and 'role play', with the effect that the potential for creative synergy is lost. Clearly, project teams which consist of highly talented but often individualistic members may be reluctant to share and build upon each other's ideas (Belbin, 1986).

\section{Growth and management control}

Among traditional craft employers there is a reluctance to move beyond the size at which it is possible to manage employees on a face-to-face basis by working alongside them within a process of mutual adjustment. In such working relations they can remain in control of staff by managing through example. To shift from this to a management style that requires the ability to trust staff in a hands-off manner so that systems of delegation can be established requires a fundamental change in proprietorial attitude and competence. Equally, the ability to manage according to rules, procedures and impersonal monitoring mechanisms requires entrepreneurs to develop management competences. This is particularly the case for those who have 
started their businesses on the basis of specific manual and technical craft skills. This can also apply to those who have managerial experience in large organisations since their skills are usually associated with specialist functional competences rather than more general, all-round abilities. It is such factors which are likely to hinder business growth, rather than lack of market opportunity or the inability to raise additional finance (Scase and Goffee, 1987).

A major constraint limiting small business growth is the process of mutual adjustment which characterises the work processes of small businesses. The organisation of duties on this basis incorporates both proprietors and their employees within an interdependent division of tasks, out of which individual skills and competences become defined. Although staff may be recruited according to their own particular specialist skills, these do not constitute the sole basis upon which work tasks are performed. By working closely with others, individuals develop flexible and more broadly defined skills which enhance the overall performance of the business. But business growth can destroy this process and therefore the motivation, morale and the competitive advantage committed staff give to an enterprise. Business expansion can lead to the restructuring of relationships, both between the employer and employees as well as among work colleagues. It is often necessary for proprietors to withdraw from their direct involvement in work processes and, instead of exercising managerial control through working alongside employees, to exercise authority in a much more hierarchical manner. A dimension of managerial control is introduced whereby there is a separation between managerial and operational activities. As proprietors become less involved in day-to-day operational matters, more of their time is devoted to negotiation with customers, suppliers, financial backers and other external agents. In this way, strategic and operational decision-making becomes separated from the execution of work tasks. If, at an earlier stage of the business, proprietors discuss business plans with their employees, this now becomes less evident, and with hierarchical control there can be the emergence of staff resentment as they perceive their employers to be 'non-productive'. This may threaten processes of mutual adjustment because employees become preoccupied with their own duties and thereby reduce the operational flexibility of the business as a whole. There can also be the deterioration of trust relations between employer and employees, and among work colleagues. As a result, forces emerge within the business whereby work procedures become more formalised according to rules, regulations, job descriptions, duties and responsibilities. This, in turn, reinforces the need for a separate management function with proprietors devoting more time to staff supervision or to their appointing managers, chargehands and others who can perform this task. Either way, there is generally an increase in management overheads, with ramifications for the competitive advantage of the business. 
Because of these internal organisational forces, associated as they are with the dynamics of business growth, many proprietors choose not to expand. Growth requires such a fundamental shift in the nature of their businesses, and of their own managerial role within them, that many proprietors often feel unable to handle expansion. This is certainly the case with many manual craft owners who, for reasons of work experience and business background, do not possess the skills for setting up effective management systems. Equally, they are unlikely to possess the required competences for appointing staff who could take on managerial responsibilities required of a growing business.

The problems of growth associated with creative and professional small businesses can be even more complex and difficult to overcome. Again, these often arise from a lack of expert management competence but they can also be related to the job needs and work aspirations of employees. People with creative talents usually have little desire to exercise managerial control over others. They are more inclined to be interested in exercising their personal talents, to deliver professionally-determined quality services to their clients and to enjoy personal recognition (Davis and Scase, 2000).

Of course, there are a variety of management functions to be undertaken within professional-based small businesses; tasks have to be supervised, co-ordinated and controlled. But this leads to the emergence of a management process without specialist management roles. In other words, professional and other highly qualified staff undertake managerial tasks as part and parcel of their particular competences. Managerial identities remain latent to those of a more professional or technical kind and the only explicit management functions which they perform are undertaken in relation to support staff that provide administrative back-up.

Those businesses which do grow may do so in a variety of ways. Some do so by what may be described as 'confederate' structures. Such firms operate on the basis of a number of separate profit centres, each focused upon a particular service, geographical location or market sector. Colleagues are designated with responsibilities for each of these and when the point is reached at which the volume of trade requires the input of a specialist management function, a part of the growing business is hived off as a newly created profit centre that again becomes the responsibility of a colleague. In this way, not only do these businesses reduce the need for a formalised full-time management function and associated overheads, but they also meet the personal autonomous work needs of colleagues. They are able to enjoy continuing self-development through new challenges, enhancing their specialist and technical competences without increasing excessively the burden of managerial and administrative responsibilities. In a sense, then, these businesses achieve growth without managers; the managerial function is incorporated within the day-to-day exercise of professional, technical and specialist skills (Slatter, 1992). 
Confederate structures often have tensions associated with forces of centralisation and decentralisation. Although these may not be evident within each of the operating units - functioning as separate profit and loss centres - they can be apparent within the business as a whole. How and according to what procedures is performance of the separate units to be monitored? How much autonomy are they to have in the pursuit of their own growth strategies? To what extent are the separate strategies likely to weaken the synergy of the business as a whole? Decisions about these issues have to be taken, but by whom? In owner-managed businesses this is likely to be less of a problem, bearing in mind the legitimacy which the ownership function bestows upon proprietors' decision-making. But even so, there are severe constraints on the decision-making autonomy of owner-managers because of the quality of information that is available to them. Operational competences are located within the separate business units and information to proprietors is often 'filtered' by those who are responsible for these units and who are stakeholders in decision-making processes. As a result, proprietors are likely to rely excessively upon their own judgement and have insufficient consultation with their senior staff about strategic issues. There can, in other words, be problems of communication, information flows and decision-making within confederate structures (Scase, 2002).

In professional partnerships there are similar problems in strategy formulation. Decision-making for the business as a whole will often be subordinated to the interests of the separate operating units because each professional colleague's primary interest is directed towards the needs of their own particular clients. Overall strategy will be decided at infrequent meetings of those responsible for each of the profit centres. They may be concerned to protect their own vested interests, rather than to consider the overall interests of the business. Strategy formulation will be the outcome of bargaining between interested parties and there will be little in the form of a coherent 'core' which can integrate these into a long-term business plan. The outcome is for professional-based small businesses to be reactive to market demands, rather than to have explicit business strategies derived from detailed analyses of market forecasts and longer-term economic trends. Only after significant growth is it usually possible for such businesses to devote the resources necessary for strategic planning. If there is the nurturing of management skills associated with business growth, these are more likely to be in operational rather than strategic planning, derived from their own and their colleagues' technical capabilities.

The precise organisational characteristics of small-scale confederate structures are variable; some are extremely loose-knit, with the operating units trading in a very autonomous manner, others will be more tightly integrated through a variety of mechanisms. Sometimes these will be to do with the management or leadership styles of senior partners who may choose to 'arbitrarily' intervene in the decision-making processes of the 
separate operating units. In this way, the business is integrated by shared values expressed and embodied by the attitudes and behaviour of senior partners or owner-managers. This is particularly likely to be the case in those businesses in which there are founder-owners who are able to impose their opinions upon all aspects of their businesses, ranging from acceptable standards of performance, to preferences of personality 'types' in staff selection, to day-to-day working procedures. This is less likely in professional small businesses where highly qualified staff are more inclined to shape the culture of their enterprises according to criteria of professionalism. Such businesses may grow through the generation of autonomous operating units, the control of which is more likely to be exercised through financial rather than managerial processes. Monitoring of performance will be undertaken mainly through standardised output measures - such as monthly management accounts - rather than according to forms of direct supervisory control.

Despite the tendency to achieve growth through decentralisation and fragmentation, some professional and high-tech small businesses are compelled to develop more clearly defined management functions. The need to integrate the day-to-day activities of professional colleagues and to coordinate these within strategic business plans becomes more explicitly acknowledged. How, then, is growth to be managed so that professionals continue to feel in control and yet, at the same time, are prepared to accept the need for separate managerial mechanisms that will integrate and co-ordinate their different activities? (Gibb and Scott, 1985). This is a key issue, the resolution of which will shape the direction of business growth. Increasingly, it seems, those enterprises producing high valueadded products and services take the view that growth through fragmented and confederate devolved structures is the more preferable option.

It is not only in 'high value-added' businesses that growth is managed through the development of decentralised structures. In those firms trading in more traditional sectors, the approach to growth through sustaining highly centralised entrepreneurial forms is also under review. The outcome may be reflected in the setting-up of functional structures according to which businesses are organised on the basis of a number of specialist spheres of responsibility. But staff can resent the imposition of procedures through which they are then compelled to communicate with managers and/or proprietors. As they perceive it, hierarchical and impersonal systems erect boundaries between the managerial and operational functions of the business. The imposition of rational monitoring mechanisms designed to measure output and productivity may, in fact, lead to demotivation. Cultures of 'informality' and 'indulgence' become superseded by those characterised by suspicion, resent and interpersonal friction. But even so, the setting-up of more formalised functional structures can fail to tackle the central issue facing these businesses: namely, the exercise of 
proprietorial authority. In practice, the imposition of functional structures can reinforce the highly centralised nature of these businesses, with owner-managers continuing to be overburdened with operational and strategic responsibilities and with managerial staff remaining underdeveloped (Joyce et al., 1996).

To develop organisational structures and managerial strategies continues to be a major challenge for both traditional and knowledge-based small firms. To resolve the tensions between the 'need' for formal control mechanisms and employee expectations for 'autonomy' produces negotiated outcomes that are both the defining and distinctive features of each and every small firm. This is why there can be no operational textbooks for small business management of the kind that shape the philosophies and practices of the managers of large, bureaucratised organisations. Equally, from an academic point-of-view, it is difficult to envisage the development of an all-embracing theory that focuses on the management of the small firm. The cluster of both internal and external variables that impinge upon their characteristics is too diverse, particularly bearing in mind the role of the founding partners or entrepreneurs. Their personal agendas, motives and philosophies of how 'businesses should be run' are bound to be major determinants of management practices in their businesses and how they treat their staff. Indeed, as research has shown, whether or not owners have children that want to come into the business can have strategic significance for the future of the business. By comparison, the strategies of large publicly quoted corporations are shaped by rather different considerations.

\section{References}

Aston Business School (1991) Constraints on the Growth of Small Firms, Department of Trade and Industry, London: HMSO.

Belbin, M. (1986) Management Teams. Why they Succeed or Fail, London: Heinemann.

Birley, S. (1989) 'Corporate strategy and the small firm', in Bowman, C. and Asch, D. (eds) Readings in Strategic Management, London: Macmillan.

Castells, M. (1996) The Rise of the Network Society, Oxford: Blackwell.

Churchill, N. C. and Lewis, V. L. (1983) 'The five stages of small business growth', Harvard Business Review, 61(1).

Davis, H. and Scase, R. (2000) Managing Creativity: The Dynamics of Work and Organisations, Milton Keynes: Open University Press.

Fletcher, W. (1990) Creative People: How to Manage Them and Maximise Their Creativity, London: Century Hutchinson.

Gibb, A. and Scott, M. (1985) 'Strategic awareness, personal commitment and the process of planning in the small business', Journal of Management Studies, 22(6).

Goffee, R. and Scase, R. (1995) Corporate Realities: The Dynamics of Organisations Large and Small, London: Routledge.

Goss, D. (1991) Small Business and Society, London: Routledge. 


\section{R. Scase}

Granger, B., Stanworth, J. and Stanworth, C. (1995) 'Self-employment career dynamics: the case of "unemployment push" in UK book publishing', in Work, Employment and Society, 9(3).

Ingham, G. (1970) Size of Industrial Organisation and Worker Behaviour, London: Cambridge University Press.

Joyce, P., Seaman, C. and Woods, A. (1996) 'The strategic management styles of small businesses', in Blackburn, R. and Jennings, P. (eds) Small Firms' Contributions to Economic Regeneration, London: Paul Chapman Publishing.

Marlow, S. (2003) 'Formality and informality in employment relations: the implications for regulatory compliance by smaller firms', Government and Policy, 21:531-47.

Mintzberg, H. (1983) Structures in Fives: Designing Effective Organisations, Englewood Cliffs, New Jersey: Prentice Hall.

Moule, C. (1998) 'The regulation of work in small firms', Work, Employment and Society, 12(4).

Scase, R. (2000) Britain in 2010: The Changing Business Landscape, Oxford: Capstone Publishing.

Scase, R. (2002) Living in the Corporate Zoo, Oxford: Capstone Publishing.

Scase, R. (2003) 'Industrial relations in small firms', in Edwards, P. (ed.) Industrial Relations in Britain, 2nd edn, London: Macmillan.

Scase, R. and Goffee, R. (1987) The Real World of the Small Business Owner, London: Croom Helm.

Scase, R. and Goffee, R. (1989) Reluctant Managers, London: Routledge.

Slatter, S. (1992) Gambling on Growth, Chichester: Wiley. 


\title{
5 Training in smaller firms
}

\author{
Dean Patton
}

\section{Introduction}

A critical element of the contemporary employment relationship is training, learning and development. This activity is vital to improve the general stock of skills within an economy but also forms a key part of the 'employment package' for individuals. The opportunity to engage with appropriate and effective training and development not only enables employees to add value to their own stock of human capital, it also contributes to the notion of being valued by the organisation. Consequently, firms which offer employees opportunities to develop themselves, their skills and competences are more likely to retain key workers, be more attractive as employers and become more productive (Harrison, 2002).

Hence, as is argued by the CBI (2003), a skilled and adaptable workforce for firms of all sizes is an essential ingredient in the competitiveness of UK business. A view supported by the Small Business Council (SBC, 2003) in a recent report which highlighted that Britain has relatively poor labour productivity and low economic performance which can be attributed to a low skills base. These two reports do not identify anything new; the link between training and competitiveness has been made several times in the literature (see for example Finegold and Soskice, 1988; Keep and Mayhew, 1999) and successive governments have sought means by which the take-up of training by UK business could be more effectively facilitated. In particular, there has been a focus upon smaller firms because the evidence indicates that they provide less training than larger firms (see Blackburn and Hankinson, 1989; Cambridge Small Business Research Centre, 1992; Curran et al., 1997) and are reluctant to engage with training and development initiatives instigated by governments, regardless of the incentives offered (Stanworth and Gray, 1992; Jennings and Hawley, 1996; Maton, 1999; Matlay, 2000). A number of critical issues have been suggested that limit smaller firm engagement in training and development initiatives, in particular a lack of time, inadequate finance, and ignorance of benefits and/or available schemes (Westhead and Storey, 1997; Marlow, 1998). 
This is not to suggest that training does not take place in smaller firms, the extant literature indicates (Hendry et al., 1995; Curran et al., 1997) that the owners of smaller firms rely upon more informal approaches to training and development and appear more sceptical of the formal training process and its presumed benefits (Atkinson and Meager, 1994; Curran et al., 1997; Matlay, 1999). The reliance upon informal training within the smaller firm makes the documentation and analysis of such activity more problematical and issues related to the timing, duration, frequency, numbers involved, and quality of training provider are all more ambiguous within the remit of an informal training intervention. Such activity may also be under-reported as owner-managers, governments and researchers often adopt very narrow definitions when documenting the training provision within a firm (Ross, 1993; Kitching and Blackburn, 2002). This does not necessarily mean that such training is of less value, only that it is more difficult to track the process and consequences of any intervention.

Curran et al. (1997) point out that research on training has led to the inference that smaller firms, for whatever reason, require special assistance in raising the skill levels of their workforce. In order to address this problem, successive UK governments have invested considerable resources in attempting to encourage greater take up of mainly formal training and development initiatives which lead to some recognised qualification. Policies thus far have sought to broaden the range and scope of agencies offering training schemes and develop new standards to recognise both corporate and individual achievement, such as the National Vocational Qualifications (NVQs) and Investors in People (IiP) awards. In addition, firms have been encouraged to develop support structures for those employees who seek external training opportunities, whilst employees themselves have been offered incentives to develop skills, for example from the now defunct Individual Learning Accounts initiative. Furthermore, the structure through which such initiatives are implemented has undergone significant change. National Training Organisations (NTOs), the successor to Training and Enterprise Councils (TECs), are themselves now to be replaced by Sector Skills Councils (SSCs). The speed with which NTOs, designed to impose some coherence upon a chaotic structure of skills training, have been discarded does not engender a great deal of confidence, especially in the aftermath of the discredited Individual Learning Accounts. The network of 23 SSCs, as opposed to 73 NTOs, is expected to provide employers with greater influence in their dealings with government and the improvement in budget from $£ 8 \mathrm{~m}$ for NTOs to $£ 40 \mathrm{~m}$ for SSCs should also provide the resource to help drive the initiative forward (Guardian, 2003).

As noted above, despite the efforts made by government to date, the general take-up of training and development initiatives remains low, particularly in smaller firms, and it is not possible to overestimate the difficulties in developing a set of policies and structures that could improve 
the current situation. There is clearly no shortage of advice and the subject has recently been the recipient of a number of reports, two reports from DfES (Kitching and Blackburn, 2002 and IFF Research, 2002), a report from the SBC (2003) and finally the CBI (2003). The IFF (2002) report is the third annual report on learning and training at work which suggests that the generic provision of training by businesses of all categories had changed very little since 1999 and, if anything, has slightly declined. The need to improve the propensity to train would still appear to be an important issue. As indicated, the UK government has, to date, continued to focus upon the provision of subsidised formal training initiatives that are linked to some external verification/qualification supported by campaigns to persuade smaller firms, in particular, of the benefits of training. The CBI (2003) and the SBC (2003), taking their lead from the Kitching and Blackburn (2002) report, both promote the suitability and benefits of a more informal approach to the training process in the smaller firm community and identify the limited relevance and disproportionate cost of more formal initiatives to the smaller business. This chapter investigates the role of training in smaller firms and provides a review of the extant literature to highlight a number of salient issues relating to the take up of training initiatives, the barriers and motivations that exist, the role and importance of informal and formal practices, the influence of size, sector and structure, and the implications of these issues for policy.

\section{Training take-up rates in smaller firms}

Training activity within smaller firms will almost certainly be influenced by the owner-manager; writers have indicated that there are differences in the performance of smaller firms that relate to the characteristics of the owner (Birley and Westhead, 1990; Ram and Sparrow, 1993; Marlow, 1998; Moran, 1998). It has also been suggested that the business strategy of a firm is often intimately linked to the personality of the owner-manager reflecting their priorities and characteristics (Welch, 1996; Moran, 1998; Perry et al., 1998) and again, it is not untenable to suppose that an element of strategy would be the employment of training to develop strengths and reduce perceived weaknesses in the firm. Matlay (1997) and Watson et al. (1998) indicate that the background, experience, growth orientation and motivation of the owner are critical when making decisions to commission training and also in the way in which it is used and disseminated throughout the organisation. The characteristics of the owners and their perceptions of the value of training are clearly important to the decision to train, the areas in which training will be undertaken and how the training is then deployed within the firm.

Research evidence has also consistently shown that the take up of training is strongly associated with employer size (Blackburn and Hankinson, 1989; Cambridge Small Business Research Centre, 1992; Storey, 1994), but 
in reaching this conclusion the emphasis inevitably falls, as a consequence of government predisposition, upon more formal training practices. This evidence is clearly borne out in the IFF survey (2002) which indicates that SMEs are less likely to undertake training than larger firms; a trend which is more evident for off-the-job training, especially that type which leads to qualifications. However, they also indicate that some 75 per cent of firms employing 5-24 employees provide on-the-job training and 57 per cent provide off-the-job training, indicating that those smaller firms that do not train are in a minority and showing a smaller firm preference for more informal approaches to training. The report by Kitching and Blackburn (2002) also identifies the limited take up of formal training by smaller firms and highlights that this is more so when government training initiatives are involved; excluding NVQs only 13 per cent of responding businesses reported current involvement in government training initiatives. NVQs were slightly more popular with some 11 per cent of firms reporting that at least one worker had achieved an NVQ during the year prior to interview and a further 13 per cent reporting that someone was currently working towards an NVQ. The popularity of NVQs may be related to the increased awareness of the initiative relative to other government schemes as identified in reports by both the IFF (2002) and Kitching and Blackburn (2002).

The above, while supporting the fact that smaller firms are less likely to train than larger firms, also highlight that other underlying trends within the sector could be obscured by such a generic statement. For example, Deloitte et al. (1989:25) indicated that "when smaller establishments train they provide as many, and often more, days of training per employee as larger establishments', signifying that not all smaller firms are poor trainers. Furthermore, the CBI's Employment Trends Survey (2002) indicates that SMEs are more likely than larger firms to rate workforce skills as a major factor in their competitiveness, refuting the suggestion that SMEs do not value their staff and offering a compelling reason for smaller firms to undertake training. Similarly, it says little about the qualitative reasons for variations in the training provision between firms of different sizes, in particular the significance which employers attach to training, motives for providing (or not providing) training, and the type of training they consider relevant to their needs. Questions of this nature are important if a realistic attempt is to be made to improve the level of training provision among smaller businesses. Cosh et al. (1998) indicate that there are significant differences in the characteristics of firms which provide training compared to those which do not and that the determinants of training could include industrial sector, past innovation, size, growth, skill ratio and recruitment problems.

The general conclusion from the literature investigating the training needs of small business owners (see Stanworth and Curran, 1989; Goss and Jones, 1992; Curran et al., 1997) would seem to indicate that such needs are highly variable, and reflect the diversity of background and experience pos- 
sessed by individuals in this field. It seems likely therefore, that understanding the training provision in smaller firms, and avenues to improve it, will need to recognise diversity such that future research needs to draw firmer conclusions on the influence of variables, including size, sector and growth patterns on the decision to train. Those responsible for policy must also be familiar with and understand the diversity of needs among small firms and be able to match this to training initiatives if smaller firms are to increase their training provision. The next sections will, therefore, review the literature that has investigated the barriers to training in smaller firms and the motivations that exist for those firms that do undertake training.

\section{Motivations to train}

In discussing training in smaller firms the actual motivations that underpin the decision to train are often overlooked; the axiomatic argument that training per se is beneficial to the business is assumed to be enough justification to develop initiatives and expect firms to adopt them. As indicated in the next section, since evidence identifying such benefits is limited, the decision by smaller firms to engage in limited formal training may be derived from sound reasoning. It should also be noted that the motivation to train will also be dependent upon the type of training being offered and the position of the recipient within the firm. Motivations to offer induction training to new staff may be very different from those motivations that lead to investments in continuous training by owner-managers or managers. Some generic statements on the motivations to train are, however, offered in the literature.

The Nottinghamshire Research Observatory (2002) identified three main factors which motivated the decision to train in smaller businesses. First, firms were motivated to train because they viewed such activity as good for business through the improvement of customer service, company standards and supporting competitiveness. Second, it was thought to keep staff motivated and made them more productive through improvements in flexibility and professionalism. Finally, training was undertaken as a result of legislative requirements.

Kitching and Blackburn (2002) in their study indicated that workforce training had two purposes: technical, to equip new recruits with sufficient knowledge and skills to enable them to perform their new work roles to some minimum standard; and social, to secure new recruits' co-operation with the employer's aims and the working relations into which they enter. This latter objective was particularly important for new recruits. In summary, employers provided workforce training to provide workers with skills required in their current jobs and to improve business performance. Within the Kitching and Blackburn study these two motives accounted for 71 per cent of the most important reasons for respondents undertaking training activity. Goals such as training in order to introduce new equipment 
or software, or to meet legal obligations such as health and safety regulations, were also perceived as important. Other objectives such as providing workers with skills required in future jobs or to provide qualifications were much less important and approximately 10 per cent of employers felt that training offered no benefits whatsoever.

In discussing motivations to undertake training, the SBC report (2003:4) suggests that there is a clear link between such activities and business strategy, they go on to state, 'employers do not train for the sake of it, or for paper qualifications, but because there is a business need; skills are a means to an end, rather than an end in themselves'. The report then identifies the key drivers for investment in training as recruitment of staff, new products and services, changes in technology and work organisation, and new regulation.

\section{Barriers to training in smaller firms}

There are a number of supply and demand factors that could limit the take up of training in smaller firms and this section will review these factors and then interrogate the empirical evidence to look at their perceived impact on smaller firms. In their review of the literature on barriers to training take-up by SMEs, Westhead and Storey (1997) identify two explanations, 'market forces' and 'ignorance'. The market forces explanation refers to the different factors that influence the supply and demand of training and rests on the view that smaller businesses offer a less than optimal level of training due to their expectations that the returns to training will not exceed the costs of its provision. Market forces explanations highlight the problems of organisational constraints such as lack of time, costs of training and the dominance of short-term survival issues, the limited internal labour market and the geographical location of the business. In essence, it is suggested that the market context in which firms are embedded would affect their skill needs. On the supply side, there are also a number of issues pertaining to the delivery of programmes to a heterogeneous sector that have their decision-making processes compromised by a variety of factors as identified above. Ignorance explanations refer to a lack of awareness by small business owners of the importance of training for skills development and indicate that smaller firms are less likely to provide training because owner-managers are unaware of training initiatives and/or the benefits that such training can provide.

\section{Issues linked to market forces}

\section{Greater uncertainty}

Westhead and Storey (1997:18) indicate that the 'small firm experiences considerably greater external uncertainty than a large firm, primarily 
because of its lack of power in the market place'. As a consequence of greater external uncertainty and lower survival rates smaller firms are more inclined to take a short-term view of investment decisions and this will include training decisions. Therefore smaller firms, because of the context in which they operate, may be acting more rationally by undertaking proportionately less training than that undertaken by larger firms.

\section{Mobility/poaching of trained employees}

It would normally be expected that training would enhance the human capital of those involved. Human capital theory argues that individuals will invest time and effort in adding to their own capital in order to enhance careers, or obtain greater rewards for their efforts. It has been established that smaller firms, on average, offer poorer terms and conditions of employment than large firms (Rainnie, 1989: Storey, 1994) and that career progression may also be limited because of the absence of internal labour markets (Wynaczyk et al., 1993). These two factors increase the possibility that those that have undergone training in smaller firms would be more likely to seek alternative employment outside the firm, to take advantage of enhancement in their human capital. In these circumstances it may be expected that smaller firms would be more sceptical about investments in training, and particularly that type of training that is generic to all firms which may be then used by the individual to gain employment elsewhere, a situation documented by Westhead and Storey (1997). However, the Kitching and Blackburn (2002:xiii) report suggests that a relatively low proportion of employers (2 per cent of respondents) perceive the threat of poaching trained employees as a barrier to training.

\section{A failure to associate training with performance}

The problems faced in identifying positive causal relations between investment in training and development initiatives and enhanced performance have been identified by a number of commentators (Westhead and Storey, 1997; Patton et al., 2000). Smaller firms may be more reluctant to invest in training because there are no clear indicators that even coherent and integrated training initiatives reap a tangible return.

\section{Diseconomies of scale}

As Vickerstaff (1992) suggests, in practice within smaller firms, there will be relatively few trainees per firm but such firms will generally require bespoke training due to the diverse nature of requirements within the sector. Not being able to spread the cost of training across a number of employees significantly raises the cost involved. This was identified by 
respondents in the Kitching and Blackburn report as the second most important reason for not providing more training.

\section{Significant loss of output}

The high associated opportunity costs of providing time away from work has been identified as a key reason for not releasing employees for training. The cost relates not only to the loss of productivity, which can be very significant within a smaller firm, but also the associated cost of hiring someone else who is likely to be less efficient or competent (see Blackburn and Hankinson, 1989; Atkinson and Meager, 1994; Curran et al., 1997). Kitching and Blackburn (2002:57) note that, 'lost working time while workers were being trained was the third most important reason, among respondents, for not providing more training'. The extent of this problem is highlighted by the SBC (2003) when they suggest that the proposal to pay an employer 150 per cent of the worker's wage under the Employer Training pilots will not be sufficient to replace the experience and knowledge of the person given leave to train.

\section{Suitability of the training available}

There have been a number of studies that have suggested that the supply of training to small firms in the UK may be inappropriate (see for example Vickerstaff, 1992; Westhead and Storey, 1997; CBI, 2003). A main concern being that the training available is based upon what can be supplied, not what is required/demanded and as a consequence, provision does not recognise the true needs of the sector. In addition, owner-manager awareness and confidence has not been helped by the fact that previous training programmes introduced by the government have not had a particularly long shelf life (Jennings et al., 1992). Small firms have also indicated that the training provision has not been conveniently provided either in terms of timing and/or location and that, in general, too little consultation has been made by those providing training with the recipients of that training (Kirby, 1990; Cambridge Small Business Research Centre, 1992; CBI, 2003).

\section{Perceived quality of the training provider}

Criticism has been made of the quality of those involved in providing the training to smaller firms. It has been indicated that providers lack both the essential skills and knowledge to deal with the heterogeneity that exists within the smaller firm context (Cambridge Small Business Research Centre, 1992; Johnson and Gubbins, 1992; CBI, 2003). 


\section{Issues linked to ignorance}

\section{Problems in understanding the need to train}

Micro and small firms, in particular, are less likely than larger firms to have a training and development plan or training budget established from some formal assessment of needs. For example, Keogh and Stewart (2001), report that SMEs often lack the capacity to undertake skills forecasting and strategic analysis that would enable them to plan future training interventions. Consequently, smaller firms often do not have in place the systems that could highlight skill deficiencies. At this level the ownermanager is critical in the decision to train and convincing them that business performance can be improved through the skill enhancement of employees is crucial to raising the demand for training. Curran et al. (1997) also indicate that many owner-managers hired people already fully trained and this probably contributes to the perception that training is not required. The study by Kitching and Blackburn (2002:57) offers some supporting evidence for this, indicating that two of the most important reasons for not providing more training to established workers were 'sufficient training is provided after workers are recruited' (31.8 per cent identified this as the most important reason) or 'staff are all fully trained before they are recruited' (11.2 per cent).

\section{Awareness of opportunities}

Ignorance of available opportunities is also a critical issue regarding the degree of commitment to existing schemes and the IFF (2002) report indicates that awareness of all training initiatives increases as the size of the firm increases. Fuller et al. (1991) have previously suggested that trainers do not provide sufficient information about training programmes and as a consequence owner-managers are unaware of courses available and this may explain some of the difference in awareness between size of business. This point was also emphasised in the study of the Small Firms Training Loan Scheme (Maton, 1999), where the main reason indicated for the low take-up rate of the scheme was a lack of awareness on behalf of respondents.

It is probable that all of these criticisms contribute to a negative perspective on behalf of owner-managers leading to mental barriers against training because previous experiences have not lived up to expectations (Kirby, 1990; Vickerstaff, 1992). So, any solutions in developing the propensity of smaller firms to train may need to start with redressing the negative perceptions that have been instilled within owner-managers as a consequence of antecedent factors. 


\section{The role and importance of informal and formal training}

When reviewing the training process within smaller firms it is important to identify the differentiations that have been made within the literature and provide some commentary on the reasons for such distinctions. Training has been essentially subdivided into three categories: informal and formal training, induction and continuous training, and management and employee training. If a generalisation from the literature were to be made then it could be suggested that smaller firms will tend to utilise informal, induction training for employees; larger firms will also use these techniques but, in addition, offer formal, continuous training to employees and managers. Furthermore it would, normally, be assumed that the majority of continuous training, especially that which related to management, would be delivered formally by external providers (Kitching and Blackburn, 2002).

The term, formal training and development refers to initiatives which can be identified by both recipients and deliverers as an intervention which has a structured mode of delivery, where the aim is to impart new awareness or knowledge of a workplace process or activity. After the training experience, the recipient should be able to demonstrate new skills and/or competencies. Formal training would normally result in a qualification or other form of recognition and is often divided into three distinct groups.

- Professional and job specific skills training which is required to do the job or is a necessary part of improving a person's ability to do the job.

- Training that is a legal requirement for the position, often done as a rolling programme or on an annual basis as part of continuing professional development.

- Training undertaken for an individual's personal development.

In contrast informal training and learning is a far more diffuse process and occurs throughout the organisation as individuals observe, imitate and learn from others on a fragmented and flexible basis. The extent to which this occurs is dependent on the environment of the organisation, the nature of the tasks in hand, the propensity of individuals to learn, imitate and innovate etc. As a consequence of its informality training of this nature has often been described in rather negative language, for example, undertaken on an ad hoc basis, unstructured and/or unplanned. Such language can lead to the mistaken assumption that it is of a lower value than formal training. This perception has led researchers, for example Curran et al. (1996), to question the emphasis placed upon formal training in a smaller firm context. They go on to suggest that in smaller firms the nature of the labour process combined with owner-manager concerns regarding time and financial resources ensure that informal training is preferred and 
this preference should be considered as a valuable source of new skills and knowledge. In particular, diffuse forms of knowledge and skill accumulation should not be dismissed because they are outside the measurable template of formality.

The SBC (2003:4) suggest that 'training is often distinguished by its formality, but all these types of training are equally valid and those that are less formal are more suited to the needs and demands of small employers and should be recognised as such by the Government'. In addition, it should be pointed out that an individual in a firm may undertake some form of formal training and then utilise this to provide informal training for those employees within the firm to whom it is relevant. In a smaller firm this would probably be regarded as an effective and efficient use of resources where some skill gap had been identified. In a recent article, Storey (2002) suggested once more that smaller businesses were not scaled-down versions of large ones and that, 'While smaller companies provide less formal training than large ones, they are nevertheless substantial providers of informal training, encapsulated in the phrase "sitting by Nellie".' It is argued that a better understanding of the diversity that exists within smaller firms and the contexts under which they operate is required to inform the policy agenda.

The IFF report (2002:99) suggests the proportion of employers providing off-the-job training increases with increasing size of employer. In the 2001 study, just over a quarter (29 per cent) of the smallest firms did so, rising to half (49 per cent) amongst those with 5-24 employees and to three-quarters (77 per cent) amongst those with 25 employees or more. When looking at those employees who had received off-the-job training in the previous 12 months, the average number of days provided by different sizes of firm does not follow a regular pattern and does not vary by size of employer in a uniform manner. Around half of the smallest firms had provided on-the-job training. The proportion amongst those with five or more employees was higher. Whilst the provision of on-the-job training increases with increasing size of employer, the variation is not as great as it is with off-the-job training

Curran et al. (1997) also suggested that it was important to distinguish between induction training and continuing training; previously Johnson and Gubbins (1992) had highlighted the significance of induction training within smaller firms. Induction training is normally associated with more informal practices, generally offered to new or recently promoted staff and corresponds to the type of training most often offered by smaller firms. The content of induction training in most sectors, as Curran et al. (1997) have suggested, is closely tailored to the employee's needs in relation to the work role, instruction on pay and conditions, health and safety and workplace practices. The findings from their study indicate that 'almost 80 per cent of owner-managers reported providing induction training for at least some employees' (1997:93). Kitching and Blackburn (2002:83) 
support this conclusion and indicate that some 82 per cent of respondents from the telephone survey provided initial training and that for at least 16 per cent of firms this was the only form of training offered. The findings from this report (2002:12) also support the notion that such training is most often delivered using more informal practices and examples include initial training being delivered through 'learning on the job' (84 per cent of respondents), informal conversations (74 per cent) and tours of the workplace (66 per cent).

Continuing training is offered to existing employees in an attempt to improve the existing skill base and improve work performance. This type of training has, recently, become associated with the notion of workforce development defined by the Cabinet Office, Performance and Innovation Unit (2001:3) as consisting of ' $\ldots$. activities which increase the capacity of individuals to participate effectively in the workplace, thereby improving their productivity and employability'. Such training has, in the main, been linked with more formal practices, as identified earlier and consequently with larger firms, the content of which typically includes issues related to quality, product knowledge, working methods, computing and IT.

The study by Curran et al. (1997:94) indicated that just over 80 per cent of owner-managers reported providing continuing training for at least some employees during the previous 12 months. Kitching and Blackburn (2002:7) take the analysis a little further and look at the training of established staff in terms of the incidence of training and the 'intensity' of such training based upon an index created to give an approximate measure of the proportion of staff that had received training in the previous year. The findings indicate that some 59 per cent of respondents had undertaken training initiatives for established staff and the index would suggest that approximately half ( 47 per cent) of the workforce in those firms that offered training to established staff had been involved in such initiatives in the year prior to interviews being undertaken.

There has also been a distinction made in the literature between training which is offered to managers, including owner-managers, and training offered to non-managers or employees. Abbott (1993) has suggested that the type of training normally undertaken by professional and managerial employees was much more likely to have been of a formal nature than for any other groups of workers. It may be the case that management training is more likely to be formal and external to the workplace simply because the new skills that managers are seeking to acquire could not be found within the workplace. For this reason it is less likely that management training will be undertaken by smaller firms, and why it is more prevalent within the large firm sector. The distinction between managerial and nonmanagerial training is often made on the implied assumption that the training offered to managers may have a greater impact upon firm performance. For example, Atkinson and Storey (1994) identified the low quality of management as a major problem facing the survival and internal 
efficiency of small firms. In addition, McRae (1991) indicates that a distinguishing feature between high growth and low growth firms is the training and experience of senior management, whilst the Bank of England (1998) makes specific reference to the need for improved management skills in small firms.

Evidence on the characteristics of management and non-management training and its relative take-up within smaller firms is limited. The Kitching and Blackburn (2002:7) study indicates that owner-managers were less likely to report undertaking any training themselves (40 per cent) and suggest that this is probably related to one of two factors. First, ownermanagers were more likely to adopt a narrow view of training that limited the inclusion of informal practices and, second, training may be perceived as more problematical as their absence within the workplace would be more acutely felt.

The different approaches to training within smaller firms partly reflects distinctive size-related characteristics, which affect the ability of firms to identify their skill and training needs and also their capacity to respond to them. However, they may also reflect different requirements, particularly with respect to the greater need for multi-skilling and functional flexibility in organisations where it is a necessity that workers are able to turn their hands to several tasks. Furthermore, while some of the differences in approach stem from differences in management resources that affect the ability of managers to define and organise training, management attitudes can also be a factor. A lack of 'professional' management training is often associated with practices that fail to recognise the full potential value of training or the more general potential contribution of human resources to a firm's competitiveness. In addition, behavioural characteristics that stem from the coalescence of ownership and management mean that the ownermanager's attitudes towards and experience of education and training are, in themselves, a major influence on the training and wider HRM culture within the firm. Financial resource constraints may also contribute to expenditure on training being viewed as a cost to be justified in terms of its contribution to solving an immediate problem or undertaking a particular task, rather than as an investment for the future development of the firm through upgrading its human resource base.

\section{Characteristics that influence the decision to train and training typologies}

Having determined that size is a significant variable in the decision to train and the type of training activity undertaken, this section reviews some of the factors that could account for the diversity that exists within size bands. A number of writers have suggested segmenting the smaller firm sector by the propensity of individual firms to train and early examples include the Training Agency (1989) and Blackburn and Hankinson (1989). 
Goss and Jones (1992) built on these examples to identify three distinct training patterns within smaller firms 'Sophisticated training', 'Instrumental training' and 'Restricted training'. Restricted trainers are defined as providing only informal on-the-job training, or no training at all. Instrumental trainers are defined as those who provide only training of a directly vocational or technical nature, for example apprenticeships for young workers and retraining for more established employees, the latter usually being related to the demands made by the installation of new technology. Sophisticated trainers are defined as those who provide, in addition to Instrumental training, programmes of a more developmental and innovative nature, for example leadership and supervisory skills, graduate or postgraduate sponsorship and management development.

Goss and Jones (1992) indicate that when these training categories are put against size rank a distinct clustering pattern is apparent whereby Sophisticated training is predominant in higher size rank (i.e. largest firms), Instrumental in the mid-range, and Restricted training in the lower size ranks (i.e. smallest firms). However, to offer a more meaningful explanation they found it necessary to use the managerial role structure of the organisation to explain differences in attitudes towards training.

It has already been indicated that some of the difference in attitudes may be as a result of the undoubted influence that the owner-manager can have on training decisions. Goss and Jones (1992), however, take this a stage further and investigate the influence that more sophisticated organisational structures can have upon the decision to train. The authors offered three types of organisational structure that might exist within smaller firms:

- Monarchic structures, where no managers or supervisors, other than the owner-manager(s) were employed.

- Diarchic structures, where, beneath the owner-managers, there was a single line-manager level.

- Polyarchic structures with usually two, but possibly more, managerial levels beneath senior/owner-managers.

Employing this typology Goss and Jones (1992) find that a significant relationship existed between structures and training patterns within smaller firms with the sophistication of training activity increasing as organisations became more complex. In addition, as might be expected, the simpler monarchic and diarchic structures show less formality in terms of the identification of training needs, the designation of training budgets and functional responsibility than that displayed by polyarchic structures.

The Curran et al. (1997) study investigated 4,000 enterprises from three sectors, those of manufacturing, services and construction. While not identifying any specific typology, the study did report differences in training determined by the sector in which the firm operates. Their findings indi- 
cated that firms in the service sectors were most likely to have a training plan and budget, followed by manufacturing firms and finally, construction firms. The low performance of construction was, in part, explained by the use of sub-contractors on short-term contracts hired only if they could demonstrate the skills required. The relatively high levels of training that existed in service businesses was suggested to be linked to the high proportion of businesses in new, knowledge-based and professional services. Curran et al. (1997) suggests that the owner-managers of such firms are more likely to exhibit positive attitudes towards training. The vagaries and diversity that exists within business sectors are also highlighted in the Kitchen and Blackburn (2002) report, which indicates that the sectors found to be high trainers included 'other services', 'business and professional services' and 'primary and construction'. The last grouping, in some part, contradicting the findings made in the Curran et al. (1997) study.

Kitching and Blackburn (2002) also sought to categorise employers based upon the extent to which they varied in their orientation to train, but their analysis of the differences identified advances as based upon responses to questions concerning attitudes towards training and the existence of a training budget; they segmented the sample into 'strategic' (30 per cent of firms), 'tactical' (55 per cent) and 'low' (15 per cent) trainers. Such segmentation shows the variation in small employers' approaches to training and acts as a possible basis for explaining differences in training activities. In summary, Kitching and Blackburn (2002) suggest that a relationship existed between a firm's orientation towards training and both the incidence of training provision and training index values. Strategic trainers were more likely to report training for all three types of recipient identified in the study (new recruits, established staff, owner-managers) than tactical trainers who, in turn, reported a higher incidence of training than low trainers. Furthermore, 'strategic trainers' offered additional training to twice as many established staff as tactical trainers and to seven times as many staff as low trainers during the previous year. The fact that strategic trainers reported a higher number of benefits of training, were more likely to measure the effects of training, were more convinced of the value of training, and also likely to have a more favourable view of qualifications, probably underpins the propensity of training activity.

Similar to Goss and Jones (1992), Kitching and Blackburn (2002) indicate firm size is important and that strategic trainers tended to be larger than other businesses. However, they also indicate that such firms tend to be located in 'other services' rather than other sectors, to operate in slightly more competitive product market conditions than low trainers, and to compete on the basis of non-price factors more commonly than low trainers. Other differences highlighted include the fact that strategic trainers were more likely than tactical and low trainers to report employment growth over the previous two- and five-year periods, to anticipate employment growth over the next two years, to have experienced real sales 
growth over the previous two years, and to expect real sales growth over the next two years.

Finally, strategic trainers were also more likely to report genuine barriers to further training such as financial cost, lost working time and a failure to find suitable training opportunities. Low trainers, in contrast, were more likely to give reasons reflecting the lack of a perceived need for further training. Instead, they claimed that staff were fully trained before they arrived at the firm and that training would not produce any benefits for their businesses. Tactical trainers were more evenly divided on their reasons for not providing additional training.

Consequently, there are some similarities between sophisticated and strategic, instrumental and tactical, and restricted and low trainers, but Kitching and Blackburn (2002) have highlighted significantly more issues other than size that differentiate the various categories. It is important for policy makers to understand when developing new initiatives that firm characteristics, such as organisational structure, market sector, growth aspirations and the perceptions of barriers, can affect future training decisions within smaller firms.

A further point to note from the Kitching and Blackburn (2002) study is the reported differences in training patterns by occupational group; in particular, professional and technical workers were more likely to receive training than other occupational groups. Moreover, it is likely that some relationship exists between the propensity of certain occupational groups to receive training (professional, technical and managerial) and the propensity of certain sectors to exhibit higher levels of training (business and professional services).

\section{The implications for government policy on training in smaller firms}

Storey (2002) indicates that UK public policy-makers have, over the last two decades, attempted to deal with the limited take-up of training in smaller firms in three ways. The first has been a focus upon making smaller firms aware of the benefits and the added value that training can offer to the operations process. Second, and often in association with the first, subsidies and grants have been offered on the assumption that once smaller firms were able to experience the benefits of training, they would continue to use such initiatives even if subsidies were removed. Finally, and probably least effective, has been the attempts to coerce smaller firms to train as a consequence of verbal rebukes and reprimands issued through government bodies and the media. It is Storey's opinion (2002) that these attempts have not been effective in that smaller firms continue to undertake less formal training than their larger counterparts. The Kitching and Blackburn (2002:xiv) study offers empirical support for this view indicating that, unlike smaller firms, 'larger employers were more likely to be 
involved in at least one government training initiative'. The same study, which focused specifically on firms with less than 50 employees, suggested that the great majority of employers were indifferent to government initiatives, finding them irrelevant to their training needs or perceiving little need for any further training per se. However, it should be noted that, those employers who had received funding and/or were involved in the Investors in People initiative expressed general satisfaction with the intervention.

Consequently, Storey (2002) argues that a radical rethink of policy is required to change the current scenario and this should commence with a broadening of the definition of training to include more informal approaches. This greater recognition of more informal approaches to training is required as such practices are more applicable and cost effective within the smaller firm context. So, it is argued that smaller firms cannot be amalgamated with larger businesses within a 'one size fits all' method as such policies fail to address the nuances that exist within the smaller firm community. In fact, policies may actually have to be redesigned to include the informal approaches to training favoured by smaller firms and the link between training and qualifications may have to be broken.

Kitching and Blackburn (2002) offer a number of suggestions on how this radical rethink in policy might be enacted, in particular a key policy implication from the study refers to the targeting of training initiatives at particular types of employer and within enterprises at particular members of the workforce. The advantages of such segmentation are suggested to be a clearer identification of needs and improved targeting of initiatives through, most importantly, the use of relevant delivery mechanisms. The case for segmentation is based upon differences in the type of employer and differences in the training recipient. In the first instance, it is suggested that those firms that had previously undertaken training and exhibited what was described as a strategic orientation to train would be likely to increase their training activity if perceived barriers were alleviated. The barriers identified are the monetary costs and time constraints associated with training. However, they are less optimistic about those firms that have not trained previously and exhibit a low orientation to training. In these circumstances it is suggested that business owners do not perceive the need for training or any potential benefits, in fact, the reverse is the case with training perceived as a drain on resources that could be better allocated elsewhere. As a consequence it is suggested that these firms are unlikely to train unless, somehow, they can be persuaded of the advantages such activity can bring. Even in the former case the report suggested that take-up would only be improved if initiatives also built upon the existing provision which was generally delivered at the workplace either inhouse or by external providers. Kitching and Blackburn (2002) link perceptions in this cohort with the product strategies currently pursued and therefore, suggest that the take-up of training might be improved if 
measures are taken to shift product strategies which are combined with more traditional inducements to train.

Training could also be targeted at different groups of staff within an enterprise; Kitching and Blackburn (2002) make the distinction between new recruits, established staff and owner-managers. With reference to the former, initial training is viewed as often being firm specific but it is suggested firms may be more prepared to engage with NVQs and apprenticeships for new recruits. Once staff are 'established' the barriers to training are similar to those identified for employers; government training initiatives may have the greatest opportunity to interface with this group when there is a technical or product change in the enterprise. Of the three groups, increasing the propensity to train of owner-managers is thought to be most difficult. The main reasons suggested for this are the limited time that owner-managers have and the concern that their knowledge and skills cannot be covered in their absence. The main route forward for this cohort is thought to entail linking training to broader business strategy relating to product, technical or process developments. This may enable governments to embed training of this nature into existing initiatives which are product or market focused, and this approach could be favourably received as it more closely follows the owner-managers line of thinking in that training is not undertaken for its own sake, but reflects wider developments in the business.

The SBC (2003) has used the information developed in the Kitching and Blackburn (2002) study, which they commissioned, to inform their recommendations on future government initiatives. Consequently, the SBC support the recognition of all forms of learning within smaller firms and, in particular, the value offered by informal training. It is suggested furthermore, that governments should concentrate on providing 'effective advice and quality provision rather than passing prescriptive legislation' (2003:6). The SBC are critical of recent government initiatives and suggest that 'Employer Training Pilots' requiring compulsory time off for training or 'the Licence to Practice' that necessitates compulsory qualifications are not compatible with smaller firms. The main reasons for this are that such initiatives fail to address the smaller firm requirements of accessibility, quality and relevance.

The CBI (2003) suggests that both the government and the various training agencies need more understanding of the training requirements of smaller firms, training is not something that can be improved by coercion or force and take-up must be internally driven, originating from the motivation that exists amongst employers and employees. As a consequence, the CBI identifies four areas that they perceive to be key to improving the take-up of training initiatives by smaller firms. In the first instance, it is suggested that such firms have to be convinced that investments in training will improve business performance and productivity. To achieve this, governments should assist SMEs to identify the means of improving business 
performance, including the improvement of skills. The CBI suggests that one way this could be achieved is through the Business Improvement Tool for Entrepreneurs (BITE), which encourages owner-managers to think about the broader problems their businesses face and new ways in which these could be addressed.

Second, the CBI argues that it is important to recognise the role of informal learning and the benefits this can bring to the firm, particularly in the area of management training. Using evidence from NSTF (1999) and CEML (2002) it is noted that the UK has a limited supply of skilled managers and that improving the take-up rate of training initiatives by ownermanagers who have previously had limited involvement in such activity has proven problematic. It is suggested that this may be because ownermanagers prefer to learn from experience, their peers and authentic examples rather than formal courses. Take-up, therefore, might be improved if learning was offered through mentoring and coaching, which owner-managers may view as more flexible and relevant to their needs, and the 'Beacon Company Scheme', which involves visits to 'exemplar' businesses, is identified as one way forward. Nevertheless, it may also be necessary to assist owner-managers to make the link between change that is going on within the enterprise and the need to undertake training activity that could help manage that process.

A third area regarded as important by the CBI is the provision of qualitative information which would help smaller firms differentiate between initiatives and find suitable training interventions. Simply for employers to know the various types of training initiative that exist is insufficient to make informed decisions. The CBI have proposed that more qualitative information is made available to employers and that the government takes responsibility for providing an evaluation of various training interventions and make available to SMEs a guide which highlights this assessment.

Finally, it suggested that government must ensure that smaller firms can access training that is flexible and relevant. The CBI (2003) indicate that the early findings from the Basic Skills Pathfinder Projects and Employer Training Pilots highlight that the most important factor that encouraged firms to participate was the availability of appropriate training delivered in a way that meets the business and individual's needs in terms of timing, location and course content. In essence the CBI advocates that training providers should investigate methods by which training programmes could be tailored to specific needs.

\section{Discussion}

The training agenda in smaller firms has been dominated by two issues, the sector's relative dependency upon informal approaches and the subsequent limited take-up of more formal training interventions, especially 
those offered by government. As a consequence, government efforts regarding training in smaller firms have been led by an assumption that such firms need 'special help and support in raising the skill levels of their workforces' (Curran et al., 1997:90). Successive governments have sought to address this issue either by introducing new formal training programmes, or by encouraging the take-up rates on existing formal courses with little reference to, or consultation with, the small firm sector. Curran et al. (1997:99) argue that 'public policy needs to recognise more clearly that small business owners rather than government (or even other experts) may be best placed to plan employee training in the small enterprise'. In essence, smaller firms may require special assistance but the method and direction of assistance should originate, more often, from smaller firms and their representatives. This change of emphasis and direction of input has obvious problems for any government that is trying to deal with the level of heterogeneity that exists within the smaller firm sector, but acknowledging and understanding this level of diversity should facilitate potential improvements in the training agenda.

\section{Antecedent factors}

Before investigating how the recognition of diversity may offer solutions, it is critical to recognise the difficulties that any new policy on training will face as a consequence of negative antecedent factors built up from a plethora of previous initiatives that have not managed to deliver take-up rates to levels considered acceptable to governments. The range of bodies and initiatives that have been and gone within the last two decades is well documented and the accusation of short-termism, levelled by Jennings et al. (1992) still needs to be addressed. As previously indicated, the initiatives themselves have also been criticised (see Vickerstaff, 1992) for being less than appropriate to the smaller firm context, delivered at inconvenient times and by providers that may not be those best informed to offer advice. The introduction of any new initiative, therefore, has the problem of gaining the confidence of a smaller firm sector that has become somewhat cynical of the commitment and motives of government policymakers and those charged with implementing the initiatives that underpin such policies. So, an immediate area that needs to be addressed is the restoration of confidence in the training agenda, one possible way this may be achieved is with reference to the SBC that has been established to represent the needs and concerns of small businesses to the government.

The recent report by the SBC (2003), however, has potentially uncomfortable conclusions given that it criticises the more prescriptive approach taken by the government and suggests that recent initiatives, for example the Employer Training Pilots and Licence to Practice, are not compatible with small business needs. The SBC (2003:6) go on to state that the 'government should work with small firms to recognise the training they 
do and encourage them to enhance their training in a way that works for them, rather than trying to impose prescriptive and at times, irrelevant training provision'. As such, the SBC concur with previous findings by Curran et al. (1997) and Kitching and Blackburn (2002), and are also supported by the recent CBI report (2003). If the government were to accept the recommendations of the SBC and the findings of the extant literature then they will need to equate informal training practices that are more appropriate/acceptable to the smaller firm sector with the requirement to foster tangible, transferable skills and prevent the more unscrupulous firm from adopting a 'free rider' approach and opting out of the training agenda. It is suggested that there are two strands to the training agenda which need to be addressed: one that recognises and fosters informal practices bespoke to the firm, and one that addresses particular contexts and antecedent factors that have limited the take-up of more formal training initiatives. In the former case the emphasis needs to be placed on the recognition and fostering of training initiatives internal to the firm that improve employee productivity. In the latter case the accent is upon training initiatives that are more meaningful and bespoke in that they segment either by sector, training recipient, or perhaps type of enterprise. These latter initiatives would not deliberately set out to provide information at the level of the firm, rather the final application of skills/advice appropriated would be applied to the firms by the recipients themselves.

\section{Raising the profile of informal training}

The SBC (2003) have suggested that a 'skills passport' could both encourage the development of informal training and improve its standing relative to its more formal counterpart. The 'skills passport' would effectively be a record of both formal and informal training that an individual has undertaken and provide verification of the skills and competencies accumulated via participation with initiatives that took place within the firm, in addition to more formally recognised qualifications. A process of this nature could assist in both the employability and productivity of the workforce providing each employee with employer-validated transferable skills along with more formal qualifications that offer an external verification of an individual's ability to learn. Providing a record of externally verified courses would not prove a problem but putting a value upon informally delivered internal training, often conducted on the job, would prove to be more so. The SBC (2003) offer a number of solutions to the measurement of such training using criteria that includes the number of hours involved, the number of hours involved multiplied by the employee's hourly rate, or the increase in an employee's remuneration. Each criteria has problems that would need to be addressed, and arriving at a common standard is more likely to result from an experiential process of trial and error, but this can only take place if there is a political will, in the first instance, to develop such an initiative. 


\section{Increasing demand for training}

One of the issues that segmentation highlights is the need to create greater demand for training initiatives within the smaller firm sector; there are enterprises that do not perceive the need to train, established employees that find it difficult to justify access to continuing training, and ownermanagers/managers who are concentrating more on short-term issues within the firm rather than devoting time to train to meet future development needs or unexpected challenges. In all cases, for training initiatives to be adopted, governments need to investigate approaches which will recognise specific needs from particular segments of the sector as well as smaller firms in general.

A number of approaches have been suggested that might improve participation in training initiatives, perhaps the most important is to develop schemes that offer smaller firms the opportunity to contribute to the design and implementation of new initiatives. As indicated earlier, previous initiatives have been criticised for their lack of relevance and flexibility; governments have also failed to recognise the contribution and significance of informal activity. Increasing the representation of smaller firms on bodies that design and develop initiatives would, perhaps, generate/restore confidence, create more appropriate schemes and be the first stage in a continuing dialogue that needs to be developed with the sector as one element in the process of increasing demand for training.

Kitching and Blackburn (2002) also suggest that one route by which enterprises may be encouraged to train is through the promotion of changes to product or market strategies that, in effect, lead ownermanagers to seek assistance in what, for them, are uncharted waters. However, the authors are also quick to point out that it may be as difficult to encourage firms to move into more innovative products and markets as it would be to improve the take-up of training in smaller firms. Nevertheless, this is an area where the SBC (2003) feel the government should take a greater interest and become more actively involved.

The demand for training could also be encouraged if more smaller firms were prepared to undertake skills audits. As the CBI suggest (2003), SME owner-managers have to be convinced that raising employees' skills will benefit business performance and productivity before investing in training. The CBI recommend the Business Improvement Tool for Entrepreneurs (BITE); the SBC (2003), while not as prescriptive, would advocate a skills audit which assisted a firm to benchmark its skills and develop future training initiatives based upon planned objectives. Once more it may be as difficult to convince smaller firms of the value of such audits as it is to encourage them to engage in training per se, and audits may be perceived as simply highlighting limitations internal to the firm rather than contributing to a plan of action. Establishing policy that creates activity of this nature cannot, however, be viewed as a short-term goal but should be 
undertaken as part of an ongoing long-term strategy that builds relevance and engagement into the training agenda for the smaller firm sector.

\section{Improving the quality of training and its signposting}

Encouraging skills audits and motivating employers and individuals to improve skills could be counterproductive if they cannot access relevant, high quality, training. So, government policy should also focus on improving the signposting and quality of available training initiatives. Indeed, a key issue identified by recent reports is that of signposting; there is a need to provide a critical assessment of what is available rather than simply identifying the various types of training provision that exist. Smaller firms are able to access training from a variety of routes, but it is the intention of the government that there should be 'no wrong door' whatever route is used to access training. Such an initiative could be facilitated by the introduction of a new guide to training provision that goes beyond stating simply what is available and instead offers an evaluative assessment of the quality of training provided (CBI, 2003). Smaller firms and their intermediaries could, therefore, use a guide of this nature to inform training decisions and reduce the trial and error often associated in contracting with training providers external to the workplace.

Recent reports (SBC, 2003 and CBI, 2003) were also keen to promote the use of professional intermediaries that already offer services to smaller firms, for example accountants, management consultants, lawyers and other peer intermediaries, who are often small business owners in their own right. The expectation is that such individuals will be accredited to a high standard and, consequently, able to match firms to appropriate training initiatives. The term 'appropriate training' is important as it refers to the content, quality, timing and location of training being offered and to this end any recommendation should encompass both informal and formal initiatives.

Engaging smaller firms in the training agenda has proven difficult for successive governments and the limited success of previous initiatives would suggest the need for a radical rethink of policy intervention. In other countries training has prospered under a more prescriptive regime where regulation makes training an integral and compulsory element of business practice. In the UK such initiatives, in the current business environment, are unlikely to win very many supporters and it is up to government to find more representative methods to encourage smaller firms to invest in training. This chapter has suggested that a more inclusive approach to the design and implementation of initiatives, recognition and support of existing informal practices and the segmentation of initiatives by type of business and training recipient may offer a more logical and cohesive set of policies. 


\section{References}

Abbott, B. (1993) 'Training strategies in small service sector firms: employer and employee perspectives', Human Resource Management Journal, 4(2):70-87.

Atkinson, J. and Meager, N. (1994) 'Running to stand still: the small firm in the labour market', in Atkinson, J. and Storey, D. (eds) Employment, the Small Firm and the Labour Market, London: Routledge.

Atkinson, J. and Storey, D. (1994) 'Small firms and employment', in Atkinson, J. and Storey, D. (eds) Employment, the Small Firm and the Labour Market, London: Routledge.

Bank of England (1998) Finance for Small Firms: A fifth report, London.

Birley, S. and Westhead, P. (1990) 'Growth and performance contrasts between “types” of small firms', Strategic Management Journal, 11:535-57.

Blackburn, R. and Hankinson, A. (1989) 'Training in the smaller business', Industrial and Commercial Training, 21:27-9.

Cabinet Office, Performance and Innovation Unit (2001) In Demand: Adult Skills for the 21st Century, London: Cabinet Office.

Cambridge Small Business Research Centre (1992) The State of British Enterprise, Cambridge: Department of Applied Economics, Cambridge University.

CBI/Mercer (2002) Employment Trends Survey, London: Human Resources, CBI Office.

CBI (2003) 'Informality works: a new approach to training for SMEs', Human Resources Brief, April, London: CBI Office.

CEML (2002) Raising Our Game: Government Response to the Report of the Council for Excellence in Management and Leadership, London: DTI.

Cosh, A., Duncan, J. and Hughes, A. (1998) Investment in Training and Small Firm Growth and Survival: An Empirical Analysis for the UK 1987-95, DfEE Research Report RR36, London: HMSO.

Curran, J., Blackburn, R., Kitching, J. and North, J. (1996) Establishing Small Firms Training Practices, Needs, Difficulties and Use of Industry Training Organisations, Research Studies RS 17, Department for Education and Employment, London: HMSO.

Curran, J., Blackburn, R., Kitching, J. and North, J. (1997) 'Small firms and workforce training: some results, analysis, and policy implications from a national survey', in Ram, M., Deakins, D. and Smallbone, D. (eds) Small Firms: Enterprising Futures, London: Paul Chapman Press.

Deloitte, Haskins and Sells (1989) IFF Research Ltd. Training in Britain: Employers' Activities, London, HMSO.

Finegold, D. and Soskice, D. (1988) 'The failure of training in Britain: analysis and prescription', Oxford Review of Economic Policy, 4(3):21-53.

Fuller, M. F., Murphy, M. P. and Vickerstaff, S. A. (1991) 'Training in the Kent economy: present and prospect', Regional Studies, 25:563-9.

Goss, D. and Jones, R. (1992) 'Organisational structure and SME training provision', International Small Business Journal, 10(4):13-25.

Guardian (2003) 'British agents with a licence to skill', 17 May, pp. 18-19.

Harrison, R. (2002) Learning and Development, 3rd edn, London: CIPD.

Hendry, C., Arthur, M. B. and Jones, A. M. (1995) Strategy Through People: Adaptation and Learning in the Small-Medium Enterprise, London: Routledge. 
IFF Research (2002) Learning and Training at Work 2001, Department for Education and Employment, Research Report RR334, London: DfEE.

Jennings, P. L., Richardson, B. and Beaver, G. (1992) 'Improving the role of accreditation in the training and development of small business owners/managers', 15th National Small Firms Policy and Research Conference, Southampton: Southampton Institute.

Jennings, P. and Hawley, D. (1996) 'Designing effective training programmes', 19th ISBA National Small Firms Policy and Research Conference, Birmingham: Enterprising Futures, November.

Johnson, S. and Gubbins, A. (1992) 'Training in small and medium-sized enterprises: lessons from North Yorkshire', in Caley, K., Chell, E., Chittenden, F. and Mason, C. (eds) Small Enterprise Development: Policy and Practice in Action, London: Paul Chapman.

Keep, E. and Mayhew, K. (1999) 'The assessment: knowledge, skills and competitiveness', Oxford Review of Economic Policy, 15(1):1-15.

Keogh, W. and Stewart, V. (2001) 'Identifying the skill requirements of the workforce in SMEs: findings from a European social fund project', Journal of Small Business and Enterprise Development, 8(2):140-9.

Kirby, D. A. (1990) 'Management education and small business development: an exploratory study of small firms in the UK', Journal of Small Business Management, 28:78-87.

Kitching, J. and Blackburn, R. (2002) The Nature of Training and Motivation to Train in Small Firms, Small Business Research Centre, Kingston University, Research Report RR330.

McRae, D. (1991) 'Characteristics of high and low growth small and medium sized enterprises', Paper presented to 21st European Small Business Seminar, Barcelona, September.

Marlow (1998) 'So much opportunity - so little take up: the use of training in smaller firms', Journal of Small Business and Enterprise Development, 5(1):38-48.

Matlay, H. (1997) 'The paradox of training in the small business sector of the British economy', Journal of Vocational Education and Training, 49(4):573-89.

Matlay, H. (1999) 'Vocational education and training in Britain: a small business perspective', Education and Training, 14(1):6-13.

Matlay, H. (2000) 'Training and small business', in Carter, S. and Jones-Evans, D. (eds) Enterprise and Small Business, London: Addison-Wesley.

Maton, K. (1999) Evaluation of Small Firms Training Loans, DfEE Research Report No. 97, Sheffield: DfEE.

Moran, P. (1998) 'Personality characteristics and growth orientation of the small business owner-manager', International Small Business Journal, 16(3):17-38.

National Skills Task Force (1999) The Market Value of Generic Skills, Research Paper No. 13, London: DfEE.

Nottinghamshire Research Observatory (2002) 'Barriers to Training in Small and Medium Sized Enterprises', Nottingham Trent University, www.theobservatory.org.uk.

Patton, D., Marlow, S. and Hannon, P. (2000) 'The relationship between training and small firm performance: research frameworks and lost quests', International Small Business Journal, 19(1):11-27.

Perry, C., Meredith, G. and Cunningham, H. (1998) 'Relationship between small 
business growth and personal characteristics of owner-managers in Australia', Journal of Small Business Management, 26(2).

Rainnie, A. (1989) Small Isn't Beautiful, Industrial Relations in Small Firms, London: Routledge.

Ram, M. and Sparrow, J. (1993) 'Issues in supporting enterprise and training in Asian SMEs: a case from the inner city', in Chittenden, F., Robertson, M. and Watkins, D. (eds) Small Firms Recession and Recovery, London: Paul Chapman Publishing, pp. 229-41.

Ross, K. (1993) 'Training and evaluation in SMEs: manufacturing enterprises in the West Midlands', Local Economy, 8(2).

Small Business Council (2003) 'Measuring Training in Small Firms', London: Small Business Council.

Stanworth, J. and Curran, J. (1989) 'Education and training for enterprise: some problems of classification, evaluation, policy and research', International Small Business Journal, 7(2):11-22.

Stanworth, J. and Gray, C. (1992) 'Entrepreneurship and education: action based research with training policy implications in Britain', International Small Business Journal, 10(2):11- 24.

Storey, D. (1994) Understanding the Small Business Sector, London: Routledge.

Storey, D. (2002) 'Why Nellie still has the answers', Financial Times, 26 September.

Training Agency (1989) Training in Britain, Sheffield: Training Agency.

Vickerstaff, S. (1992) 'The training needs of small firms', Human Resource Management Journal, 2:1-15.

Watson, K., Hogarth-Scott, S. and Wilson, N. (1998) 'Small business start-ups: success factors and support implications', International Journal of Entrepreneurial Behaviour and Research, 4(31):217-38.

Welch, B. (1996) 'Developing managers for the smaller business: a report on training and development needs', Institute of Management Research Report, London.

Westhead, P. and Storey, D. (1997) Training Provision and the Development of SMEs, Research Report No. 26, London: HMSO.

Wynarczyk, P., Watson, R., Storey, S., Short, H. and Keasey, K. (1993) Managerial Labour Markets in Small and Medium Sized Enterprises, London: Routledge. 


\title{
6 Breaking out of survival businesses
}

\author{
Managing labour, growth and \\ development in the South Asian \\ restaurant trade
}

\author{
Monder Ram, Trevor Jones, Tahir Abbas and \\ Sara Carter
}

\section{Introduction}

Despite the statistical problems of cross-national comparison, it is safe to say that the rise of ethnic minority business ownership is an international trend, being especially strong in relatively deregulated Anglo-Saxon economies (see Light and Rosenstein, 1995, on the USA; Ram and Jones, 1998, on Britain; Razin and Langlois, 1996, on Canada), but also discernible in some mainland European nations such as the Netherlands (Rath and Kloosterman, 2000) and France (Ma Mung, 1999). Much of the recent literature endeavours to explain the presence of ethnic minority enterprise in particular sectors, localities and communities. For example, Werbner $(1984,1990)$, has demonstrated how Pakistani clothing manufacturers in Manchester (UK) draw on an array of 'ethnic resources' to initiate and sustain their businesses. These include: a supply of willing, flexible and cheap labour from the family and co-ethnic community; interest-free credit offered on trust by fellow Pakistani suppliers; and preferential outlets among co-ethnic wholesalers and retailers. From a radically different 'mixed embeddedness' perspective, Kloosterman et al. (1999) and Rath and Kloosterman (2000) locate immigrant entrepreneurship in its social, economic and institutional context rather than reducing it to a pure 'ethno-cultural' phenomenon.

Yet despite a burgeoning research interest, the concrete ways in which ethnic minorities attempt to grow and develop their business remains a neglected issue, with comparatively few attempts to identify what distinguishes the relative handful of fast trackers from the broad mass of survivalists.

Rarer still is any considered assessment of the 'people-dimension' of ethnic minority firms that have attempted the transition from survivalism to growth. While realism demands an insistence on the marginal nature of 
many ethnic minority enterprises, greater attention now needs to be directed at entrepreneurial success and the exceptional factors that underpin it. In comparison to the prevailing approaches in the field, the present chapter is distinct in three respects. First, we directly address the experiences of growing and developing firms, as well as survival-orientated enterprises, using as a framework the concept of 'break-out' (Ram and Hillin, 1991; Ram et al., 1998). This term was introduced to underline the constricted nature of much ethnic minority enterprise within narrow and highly competitive market segments and the need to escape into more high yielding markets. Here, a key argument is that the success of such a transition is contingent upon the availability of 'class resources' (Light and Bonacich, 1988), together with a commitment on the part of the entrepreneurs to modernisation, especially with regard to labour relations. Informal working methods like the use of uncosted family labour and paternalistic relations with co-ethnic employees work very well as an insurance for survival but are less appropriate for expanding firms in mainstream markets (Bates, 1993). As Scase (1995:584) argues, the study of small business growth tends to focus on issues like the capacity to raise finance and the nature of market opportunities. Yet, the substantive growth of small enterprises often rests upon the capacity of entrepreneurs to manage the altered dynamics to negotiated orders that are often necessary in small organisations undergoing transition. In essence, the 'human dimension' is often neglected in the prevailing discourse on small business growth.

Second, we focus upon the sectoral as well as the ethnic context, through an investigation of South Asians operating in Birmingham's independent restaurant sector. Such a focus is consistent with the recent literature's recognition of the social and economic embeddedness of ethnic minority business activity, its determination by external forces as well as by its internal family and community dynamics (Kloosterman et al., 1999; Rath, 1999; Rath and Kloosterman, 2000). This perspective is also in line with the firm-in-sector approach to the study of employment relations. In the context of small firms, this requires an acknowledgement of the importance of market relations, which at its most extreme has been advocated by Rainnie (1989; see also Barrett and Rainnie, 2002). Importantly though, market relations are not accorded a determinate role in shaping shop floor dynamics; of greater significance is the way in which the market is actually interpreted in the workplace. A key aim of the present study is to demonstrate a wide range of responses to market pressures, even in a comparatively narrow sectoral and spatial milieu.

Finally, our preference is for a qualitative methodology, drawing in this instance on 23 case histories to illuminate the processes involved in growth and development. Arguably, this approach is more conducive to an exploration of the meaning and content of business development than the quantitative orientation hitherto dominant in this field (Aldrich et al., 1981; 
McGoldrick and Reeve, 1989; Jones et al., 1992; Metcalf et al., 1996; Basu, 1998). Further, as the broader literature on industrial relations suggests, more subtle forms of control will emerge only through intensive methods (Edwards, 2001).

\section{Breaking out: the development of ethnic minority businesses}

For all its rapid quantitative proliferation, it remains almost universally true that ethnic enterprise remains qualitatively limited, its scope largely restricted to a narrow range of activities in the least rewarding areas of the economy. Numerous British studies remark on the pronounced overrepresentation of South Asian firms in low order retailing and catering, and their under-representation elsewhere in the economy (Rafiq, 1985; Jones et al., 1989, 1992; McGoldrick and Reeve, 1989). Essentially, the new wave of self-employed South Asians, many of them displaced from manual labour, have gravitated towards sectors with low entry thresholds, usually those requiring little start-up capital, specialised expertise or formal credentials. Moreover, the low returns intrinsic to these sectors are often compounded by over-dependence on a limited South Asian clientele and by all the classic disadvantages of operating in an inner city location (Jones et al., 1989; Rafiq, 1985, 1992). Significantly, this sectoral skewedness, far from an isolated British instance, is widely reported internationally. In Germany, for example, 20 per cent of 'foreign' entrepreneurs are in retail businesses and a further 26 per cent in catering, 'an example of an area that has become unattractive for Germans because of the long hours involved and the small profit in exchange' (Wilpert, 1999:10). Here, Wilpert echoes the long-running theme of racialised minorities as replacement entrepreneurs, moving into the void created by the exodus of mainstream business owners from markets increasingly seen as undesirable (Aldrich et al., 1984; Light, 1984). In cases such as Italy, where for cultural and economic reasons, independent retailing and catering continue to be highly valued activities, even this low quality market space is largely absent and immigrant entrepreneurs are driven to the extreme margins of irregular street trading and hawking (Quassoli, 1999). Strictly speaking, however, these international variations are a matter of degree rather than kind, and it would seem that the ubiquitous processes of racialised exclusion, so well documented in other spheres of life, extend also into the realm of enterprise.

However, in the British case at least, these unpromising market circumstances have to be set against two complementary developments, which presage an interest in the potential of more economically sustainable and viable ethnic minority firms. First, as a small number of empirical studies indicate, there are signs that some well established entrepreneurial minorities such as South Asians are gradually diversifying into the kinds of 


\section{M. Ram et al.}

economic sectors that can support flourishing businesses above the microscale (Jones et al., 1989; Ward, 1991; Basu, 1998; Ram et al., 2003). Operating in these fields also represents a move away from the labour-intensiveness and the arduous toil to which so many owners are subject. While such businesses continue to represent only a tiny minority of the total, they might be taken as role models for some of the broad mass of micro-scale 'trundlers' and 'strugglers' (to use Storey's, 1994 terminology). Second, at a more conceptual level, there has been some theoretical interest in the general processes by which some ethnic minority firms emerge from their often-straitened market circumstances. For example, Ram and Hillin (1991) have coined the term 'break-out' to capture the need to escape from the stereotypical activities in which most businesses are confined and the need for an outward reorientation towards new and more expansive market space. Building upon this, Jones et al. (2000) argue that such repositioning ought to take the form of a shift away both from dependence on fellow South Asian customers and from corner shop retailing and other activities aimed at a local neighbourhood clientele. Where possible, Asian entrepreneurs need to aim at higher-level activities - manufacturing, wholesaling, producer services and high order retailing and consumer services - whose markets are in principle spatially and ethnically unbounded.

By the use of such strategies, the South Asian firm can release itself from overcrowded and hyper-competitive niches, where labour-intensive toil usually provides only lean pickings. Where this hypothesis has been applied to real world conditions as in Jones et al.'s (2000) study of two sets of South Asian firms in Britain and Canada, it has tested positive, with those firms operating in higher order sectors with expansive market potential clearly performing better than those operating in low level bounded markets.

Having the will to break new ground, however, is not the same as having the wherewithal, and whether or not the ethnic minority firm can tap into such market potential depends upon three further considerations. First, it is likely that any significant re-orientation of the firm's market position will require radical changes in the management process, particularly with regard to management roles and the use of labour. At a minimum, it is likely to require a redirection of the proprietors' efforts, if not a more substantial change in their role, a significant undertaking since many ethnic minority businesses operate on a tight budget with little paid assistance. As Jones et al. (1994:195) point out,

one of the major weaknesses of the ethnic minority enterprise economy is the great preponderance of micro-firms, taking onerous toll of the owner's own labour and further impeding efficiency by leaving little opportunity for planning, information-gathering or any other activity which might be designated 'managerial'. 
The widely noted characteristic of utilising predominantly co-ethnic labour may further inhibit break-out since such workers are in effect recruited on the basis of ethnic loyalty and other paternalistic considerations rather than for their skills, qualifications and experience. Although family/co-ethnic labour is conventionally portrayed as a crucial resource, whether the presentation has emphasised consensus (Werbner, 1990), or exploitation (Hoel, 1984), the reluctance to enlist 'outside' labour (Jones et al., 1994; Ram, 1992; 1994) works directly against all rational management principles. Highly functional in the corner shop context, such ethnic informalism becomes increasingly uneconomic past a certain level of scale and sophistication.

Second, although the discourse of promoting 'growth' firms or 'picking winners' is well established in the small business field (Hakim, 1989; Storey, 1994; Freel, 1998), it is vital to recognise that most small businesses do not have such aspirations. 'Fast-trackers' driven by goals of profit maximisation and expansion are in a very small minority, irrespective of their ethnic origin. For the most part, small business owners are guided more by a cluster of values related to a desire for independence (Bechoffer and Elliott, 1978; Scase and Goffee, 1982; Curran, 1986, 1991; Storey, 1994; Baines and Wheelock, 1998), an outlook that cannot be dismissed as irrational or backward. Equally, it should be recognised that break-out can be a risky and daunting option. To penetrate the more fruitful markets of the mainstream is by definition to venture out into contested territory. This highly desirable market space is the preserve of firms owned by the majority population, in fields where demands on capital, management, technology, knowledge, expertise, information, labour skills and customer relations are likely to be much greater than in the abandoned niches, where ethnic minority businesses generally reside. Ram's (1994) investigation of small South Asian-owned clothing firms underlines this point and warns that, in certain circumstances, such reorientation can be positively misplaced. The owners in Ram's study, who relied heavily on very basic machinery, family and co-ethnic labour and 'informal' working practices, were exhorted by local business support agencies to 'go up-market', a course requiring investment in new machinery, adopting 'enlightened' labour management policies, and utilising more 'efficient' production methods. However, many firms following this advice became victims of fierce competition; whilst the seemingly 'irrational' firms remained sufficiently flexible to cope with the vagaries of a turbulent marketplace.

Finally, the growth and restructuring capabilities of ethnic minority firms and indeed small businesses per se (Storey, 1994) will be contingent upon their access to class resources. In their extensive treatment of this concept, Light and Rosenstein (1995) observe that 'a defining feature of class resources is universality'. Unlike ethnic resources, which derive very specifically from membership of an ethno-cultural fraternity, they emanate from an individual's class position, occurring irrespective of national or 


\section{M. Ram et al.}

ethnic origin. In practice, of course, the two categories are by no means mutually exclusive and one fairly common pathway for 'rags-to-riches' South Asian entrepreneurs in Britain (still a comparatively rare category) has been to start by using ethnic resources, such as family labour or a loan from community religious and cultural organisations. Subsequently, sufficient class resources in the form of wealth, property and credit-worthiness are accumulated to launch out into higher-level spheres (Jones et al., 1994). Often class resource accumulation is an intergenerational process, as when the business generates sufficient income to support the owner's offspring through advanced education and training to acquire vocationally relevant expertise and credentials (Ram, 1994). This fits well with Light and Rosenstein's (1995) definition of class resources, which they see as including both tangible financial wealth and intangible assets such as human capital in the form of educational credentials.

From this we can appreciate that, even where ethnic minority businesses are in a position to pursue growth, rather than survival, they still nonetheless face major obstacles. Apart from the organisational implications and the need for 'class' as well as 'ethnic' resources, the growth option is almost always a high-risk proposition. Moreover, there are other key entrepreneurial decisions to be taken about such considerations as the location of the enterprise (Rekers and van Kempen, 2000) and the negotiation of official regulations, an issue normally ignored in the informal economy. These issues will now be explored in the case of South Asians operating in Birmingham's independent restaurant sector.

\section{Methodology, rationale and context}

The methodology for the current research was informed by three key guiding principles: a sectoral emphasis; an exclusive focus on the experiences of South Asians; and a qualitative orientation. Since, as we have seen, growth opportunities for small firms are decisively influenced by economic sector (Storey, 1994; Smallbone et al., 1995; Rath and Kloosterman, 1999), a sectoral focus must be central. Our choice of the independent restaurant sector is influenced, among other criteria, by its potential for growth, which stands in sharp contrast to most other historic Asian entrepreneurial specialisms. There is a long-term trend for consumers to spend more on eating out which has continued in recent years, with turnover in the British restaurant market (including takeaways) reaching $£ 11.71$ billion in 1996, an increase of 5.1 per cent at current prices on the previous year. With the increasing popularity of eating out and a widening choice of outlets and menus, it is estimated that the restaurant market is likely to achieve $£ 15.11$ billion sales by 2001 (MINTEL, 1997).

Within the restaurant industry, South Asian businesses providing South Asian cuisine are a growing presence, expanding even more rapidly than the total sector itself. Throughout advanced western society, the independ- 
ent restaurant sector is a highly popular activity for ethnic minority entrepreneurs (see for example Bailey, 1985, on the case of New York; Herman, 1979, on Toronto; Kesteloot and Mistiaen, 1997, on Brussels; Kloosterman et al., 1999, on Amsterdam), and Britain is no exception with an ethnic restaurant market valued at around $£ 3$ billion in 1997, thus accounting for over a quarter of total sales. Within this highly diverse ethnic sub-total, South Asian (Indian, Pakistani, Bangladeshi) outlets accounted for 55 per cent of sales (MINTEL, 1998).

The qualitative orientation of the study is the third principle underpinning the current research. There were two dimensions to this, which stem from the multiple case logic outlined by Eisenhardt (1991) and Eisenhardt and Bourgeois (1988). First, in order to develop a picture of how South Asian firms were faring in the restaurant sector, it was important to involve a broad range of businesses and to this end the participation of 23 restaurants was secured from the Bangladeshi (eight), Pakistani (eight) and Indian (seven) communities. Second, we were anxious to avoid the occasional misconceptions and the superficiality that sometimes results from the use of the standard questionnaire method. The questionnaire approach has tended to reduce complex and often convoluted entrepreneurial decision-making to rigid one-dimensionality (see Ram and Jones, 1998 for critique). By contrast, in recent years a small but growing number of studies have gained deeper insights into the processes of ethnic business development through an in-depth case history approach (Jones et al., 1989; Ram, 1994; Dhaliwal and Amin, 1995). Following this method, our respondents were tape-recorded and encouraged to discourse at length on a comprehensive range of issues relating to entrepreneurial attitudes and behaviour, the interviews consisting in effect of lengthy and detailed conversations prompted by a check list rather than confined by a questionnaire format. To ensure thoroughness of coverage this procedure was used with each business owner on at least two separate occasions, while to achieve a more rounded coverage at least two employees from each firm were also interviewed. As intended, this form of investigation has generated a rich accumulation of findings across a broad spectrum, but for the purposes of the present paper it is the respondents' relationship to the market and their strategies to negotiate this which form the core of the analysis.

Essentially then, this study is predicated upon a methodologically distinct case history approach, with sufficient participants to be broadly representative of South Asians in the sector and multiple interactions with multiple respondents in each firm to permit qualitative assessment of business development processes, taking into account their full complexity. Although we include sufficient firms to capture the breadth of South Asian involvement in the restaurant sector, the canons of statistical notions of representation and generalisation are not of primary significance here. Of more importance is an interest in the illumination of processes in action, 
and analytical modes of generalisation (Stake, 1994; Yin, 1994). The qualitative case history approach permits scrutiny of the processes by which restaurants survive and develop and, in so doing, highlights the integration of social and economic forms of embeddedness (Rath, 1999).

\section{Research setting}

In Birmingham, there are 23,599 service sector companies, of which 16,176 are service sector businesses with fewer than 10 employees (Birmingham Economic Information Centre, 1998:92). Of these, approximately 350 are both licensed and unlicensed restaurants with less than 10 employees. Precise figures on ethnic minority firms are not recorded; but in the case of South Asian restaurants, as many as 70 are to be found in the Sparkhill and Sparkbrook areas of inner city Birmingham. A concentration which has led the area to be dubbed the 'Balti Quarter', after the special version of South Asian cuisine prevalent in this area. As Table 6.1 indicates, this area has a significant South Asian (particularly Pakistani) presence.

A familiar pattern of disadvantage accompanies the minority ethnic community concentrated in this area. For example, unemployment in the 'Balti Quarter' is higher than the city average (Table 6.1). High unemployment levels are exacerbated by the general dilapidation of the local environment, a widespread fear of crime, and the often-hazardous traffic flow in and out of the area. Ten of the outlets (eight Pakistani and two

Table 6.1 Composition of South Asians and total unemployment in the 'Balti Quarter'

\begin{tabular}{|c|c|c|c|}
\hline Population & Small Heath & Sparkbrook & Sparkhill \\
\hline Ward population & 31,617 & 25,896 & 26,251 \\
\hline Indian (No.) & 1,832 & 1,969 & 3,796 \\
\hline Indian (\%) & 6 & 8 & 15 \\
\hline Pakistani (No.) & 11,764 & 7,926 & 9,145 \\
\hline Pakistani (\%) & 37 & 31 & 35 \\
\hline Bangladeshi (No.) & 1,846 & 2,136 & 594 \\
\hline Bangladeshi (\%) & 6 & 8 & 2 \\
\hline \multicolumn{4}{|l|}{ Unemployment rates ${ }^{a}$} \\
\hline Male (No.) & 1,339 & 1,693 & 1,242 \\
\hline Male (\%) & 20 & 31 & 20 \\
\hline Female (No.) & 359 & 413 & 342 \\
\hline Female $(\%)$ & 10 & 14 & 9 \\
\hline Total (No.) & 1,698 & 2,106 & 1,584 \\
\hline Total (\%) & 16 & 25 & 16 \\
\hline
\end{tabular}

Source: Population Census (Office of National Statistics, 1991) and Birmingham Economic Information Centre (2000).

Note

a These unemployment rates easily exceed that for Birmingham as a whole, where rates of male, female and total unemployment are, respectively, $13 \%, 5 \%$ and $9 \%$. 
Indian) investigated in the current research were located in the 'Balti Quarter'. Promisingly at first sight, the customer base for these restaurants is predominantly white young professionals with high disposable incomes (Warde et al., 1999) and students, the professionals of tomorrow. As we shall see, however, the pervading problem of operating in the 'Balti Quarter' is market saturation, an over-supply of restaurant outlets leading to intense competition, in itself the archetypal condition of Asian business in Britain in general and a perfect demonstration of the commercial trap from which they need to escape. By contrast the remainder of our sample represent those who have escaped, spatially at least. All eight Bangladeshi-owned restaurants, and three with Indian proprietors, were geographically dispersed, presenting themselves as 'up-market' establishments with a largely white middle-aged and middle-class clientele.

The following sections examine how the sampled restaurants have adapted to the distinctive market environment of Birmingham's independent restaurant sector. ${ }^{1}$ Four approaches are discussed: survival, which essentially refers to those unwilling or unable to break out and hence compelled to come to terms with an unsatisfactory market environment; and three versions of proactive breakout strategy - multiple business ownership; product differentiation; and geographical relocation. As Table 6.2 reveals, these ostensibly different modes of operating and developing restaurant businesses are not necessarily mutually exclusive. For example, it is possible for a business owner who is intent on survival to have more than one food outlet; and restaurateurs who are located in 'up-market' settings may similarly stress the 'authenticity' of their cuisine. Rather, case comparison logic has been followed, which involves an assessment of the similarities and differences between the firms. Hence, on the basis of a detailed reading of respondents' transcripts, firms have been assigned to categories that best capture their market approach.

\section{Survivalists}

During the 1980s, the pervasive discourse of 'enterprise' fuelled an interest in small business ownership as a means of promoting economic prosperity, both for the nation and for the individuals involved. Empirical studies, however, have noted that the outcome is often more akin to 'survival selfemployment' than dynamic enterprises capable of significant growth (Macdonald, 1996; see also Storey, 1994; Baines and Wheelock, 1998). Even the ostensibly buoyant market conditions enjoyed by the restaurant trade offer no cast-iron guarantee of success and, in the current research, eight of the 23 firms could be described as survival- rather than growthorientated. One of the most notable features of these eight restaurateurs was their almost uniform lament of the spiralling competition from other South Asian restaurants based in the same locality. As noted earlier, these restaurants were located in the city's 'Balti Quarter', where supply outlets 


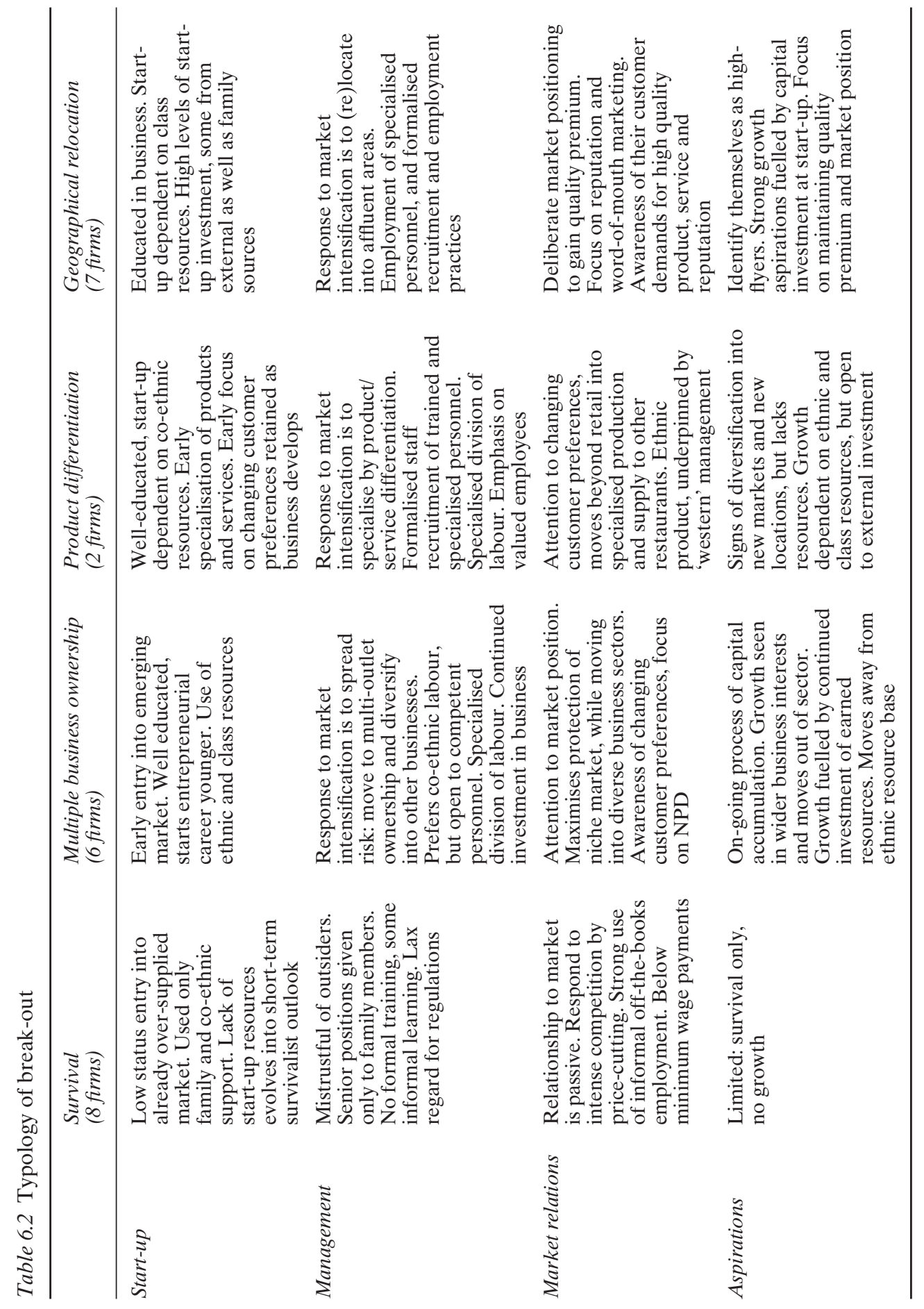


have multiplied even faster than growing consumer demand; resulting in the over-population of this market niche (Ram et al., 2003).

Extreme price-cutting was a common means of coping with this competition, as one owner commented,

Well, there are too many. People ... get a business and they try and make a go of it and if they can't make a go of it they get cornered ... So what they do is drop their prices down, so they kill the market. You know, they have got 20 per cent off, or 50 per cent off or have one free. You buy one and get one free, you know, its just killing the market.

(Javed, Punjab Delight, Pakistani)

This business owner was clearly aware of the contradictory forces operating in this market. On the one hand, a concentrated swarm of 'Baltihouses' had beneficial cluster effects, 'because you are getting more people into the area' and picking up passing trade, but past a certain threshold, diminishing returns set in. Alongside this were complaints about the alleged laxity of planning regulations, with many owners berating local authority officials for granting permission for the establishment of excessive numbers of Balti-houses.

Consistent with previous studies of immigrant restaurants (Herman, 1979; Bailey, 1987), family and co-ethnic support was crucial in initiating and sustaining the business, especially through intensive use of familial labour. Family members tended to occupy senior positions within the firm, primarily because they could be 'trusted' and the fear of losing staff in these pivotal roles was removed. In such family-oriented firms, informality is the keynote throughout, with face-to-face personalised relationships prevailing over textbook management practices. Accordingly, recruitment of workers is almost entirely via word of mouth and formal training is almost non-existent, the preference being for on-the-job coaching by experienced employees. Similarly informal is pay determination, with many interviewed workers disclosing significant 'off the books' working and pay levels well below the National Minimum Wage. In a labour market offering pitifully few openings for unqualified workers, these arrangements provided workers with an opportunity for employment, while employers benefited from the 'flexibility' of these work methods, which was often vital to their own competitiveness. As is so often the case, meaning depends upon context and in this instance 'mutual benefits' must be judged against the employees' utter lack of choice.

In the light of labour-intensive working methods and the harshly competitive market environment, the notion of 'success' was viewed in a modest way by most respondents in this category. As one commented, 'if you can ... pay the bills and make a living and that's it. That's a success'. This same respondent had to bring in at least ' $£ 600$ a month' in order to 
'cover the debt' incurred in an earlier failed business venture. Employers enmeshed in such a hostile trading milieu were often cautious about further expansion. A second-generation respondent stated,

My father said, 'Did I want to [expand]?' But I said to him, 'Listen, you are going to take out that loan for $£ 40,000, £ 50,000$ for another shop, you have got to do it up, it is going to cost you at least $£ 25,000-£ 30,000$ to do the place up, right. It just makes it awkward; you are going to end up paying seven or eight hundred pounds for over three years or four years to pay the mortgage off. What's the point. And you are going to have to get more staff.'

(Jamil, Desi Cuisine, Pakistani)

In summary then, survivalists are characterised by limited aspirations and short-termism, a present rather than a future orientation. Their approach to market relations is largely passive, with few proactive strategies to counter hyper-competition apart from self-destructive price competition. As is widely characteristic of small Asian firms throughout Britain, their operating methods are highly traditional, with an intense reliance on family members and low cost labour-intensive practices to cushion their survival (cf. Jones et al., 1994). While family/co-ethnic labour has been repeatedly presented as a highly advantageous competitive asset for ethnic minority business, it ought more properly to be viewed as a safety net for low-level survival rather than a developmental resource.

\section{Multiple business ownership}

Despite the barriers, however, other restaurants are deploying a variety of strategies designed to elevate them above the survivalist basement. One of the striking features of the sample is the comparatively high incidence of multiple business ownership, with eight employers owning more than one outlet. One of our Bangladeshi respondents perfectly exemplifies the benefits of this multi-outlet approach. A highly successful and self-fulfilled operator, he confidently declared, 'yes, my business has improved. I am quite happy with the way things are going'. This respondent was the sole owner of a restaurant in a relatively affluent part of the city, and a partner in another three others dispersed over the West Midlands, in prosperous small town locations. To a certain extent, the key to success in this case was the owner's very early entry into the field before its eventual saturation. Arriving in Manchester in 1967 as a student, the respondent supplemented his income by working for fellow Bangladeshis in the restaurant trade, developed an interest in the business, abandoned his studies and started his own 'curry house'. At that time, competition was minimal, 'people were queuing outside, but not any more you know, this does not happen now', virtually guaranteeing the success of his initial venture. 
As competition increased, he kept ahead of the field by buying up and maintaining a string of restaurants, thereby spreading his risks, diversifying and geographically expanding his customer base, and in some cases selling them off as valuable going concerns. It was an on-going process of capital accumulation over a thirty-year period and a classic example of the important role of class resources in ethnic business development. From another perspective, he might be seen as exemplifying the principle of selfsustaining growth, with continually increasing scale and diversity permitting ever more plough-back investment. Pertinently for the present argument, this expansion has obliged him to dispense with time-honoured working practice and to shift towards a more modern approach, central to which is a specialised division of labour. Even though his preference is for co-ethnic workers because, 'I can trust them', practical requirements have required a preparedness to recruit any suitable candidates via job agencies and advertising. Unlike the more typical hands-on South Asian firm, relying as it does on the owner's own heavy work load (Jones et al., 1994), this respondent was a genuine owner-manager (Scase and Goffee, 1982), whose headquarters restaurant is managed by his nephew and whose own role is defined as customer care, 'I personally welcome most of my customers and they love it'.

Another illuminating example of multiple business ownership was provided by the manager of an Indian-owned restaurant, who commented on how the proprietor, an economics graduate from Cambridge, expanded from one outlet in 1966 to the current number of five. He had observed the shortage of 'authentic Indian restaurants', and duly opened up his first establishment in London, subsequently seizing the opportunity to expand his operations. The manager from the restaurant described how

he looked at about seven or eight sites all over the country. He wanted to expand in a big way and he started off with Cheltenham ... Cheltenham was chosen because of his brother-in-law and his sisters. His two sisters were married and he had manpower. So, he arranged all the finance with the bank. He had a huge house in London which he put down as collateral to raise the finance and he had two brother in laws who were there to sort of help him and that did very well.

(Mohinder, Raj Palace, Indian)

The managers employed in this chain of restaurants were either relatives or 'recruited through the ranks'. It was clear from this account that growth was largely contingent upon the interplay of a variety of factors: educational credentials, financial resources, familial and co-ethnic networks.

These respondents demonstrate the importance of a number of factors which have been documented in broader debates on 'growth' in small firms: attention to market position, appropriate niches, new product development, and the management of human resources (Smallbone et al., 1992; 
Storey, 1994). Interestingly, the characteristics of these respondents, such as their relative youth at start-up, also replicate characteristics found in other studies of multiple business owners (Kolvereid and Bullvag, 1992). However, the extent to which this model of growth is feasible for others is highly questionable. Given the expense of acquiring and equipping premises, the multi-outlet strategy noted above is virtually impossible without access to class resources, particularly financial capital. The paucity of financial resources necessary for expansion has often been highlighted as a major barrier for many ethnic minority businesses (Jones et al., 1992; Deakins et al., 1994; Ram and Jones, 1998). Hence, for two of the firms in the category of multiple business owners, the development of their enterprises had been a much more incremental, ad hoc and prosaic process.

For example, one respondent owned a commercial property that was currently up for sale. In the case of his own restaurant, it was clear that his wife's income from a full-time job, and her informal labour in the restaurant was vital to the survival of the business,

My wife has got a full time job. She works during the day time and helps us whenever she can in the evening ... To tell you the truth I am struggling now more than I was struggling seventeen years ago ... I am keeping afloat by working seven days a week with no days off.

(Kalvinder, Seven Spices, Indian)

In a discussion on the changes and developments in the business, the respondent commented,

We have not been able to do any changes ... because you need a lot of money for that ... I am just paying my bills ... debts and things like that, just trying to survive ... You can only change the décor when you are making a lot of money.

(Kalvinder, Seven Spices, Indian)

\section{Product and service differentiation}

By its very nature a creative activity, the restaurant trade offers obvious opportunities for any individual firm to blunt the hard edge of competition by promoting its own uniqueness through product and service differentiation. This is a theme exemplified in the current research by the Sikh owner of a sweet centre also offering restaurant and takeaway services. This respondent had consciously based his appeal on the 'rediscovery' of a genuine regional cuisine, with no concessions to what is assumed to be the European palate, 'we only do traditional Punjabi dishes ... anybody who comes through that door and comes out with a fancy name, we tell them we don't do it'. Uncompromisingly traditional and ethnic though his product may be, his working methods are at odds with the labour-intensive 
practices commonly associated with ethnic minority firms. He pointedly eschewed familial and co-ethnic approaches to business, and attributed his business approach to his westernised upbringing (he had been in England since the age of five),

Well we are changing pretty dramatically, I would say, because a lot of the things we are tending to do are more westernised than anything else ... we don't employ family members ... I couldn't work with them all day ... [my children] are not involved in the business ... they have a choice, they can do what they want.

(Baljit, Eastern Delight, Indian)

Significantly, this firm also operates a distinct division of labour, with ownership and management functionally separated from employees. At the time of interview, the restaurant employed four staff, including two highly trained chefs cooking to the specifications of the two partners, husband and wife, both of whom are able to devote their entire energies to supervisory functions and customer care. His wife's status and contribution were formally acknowledged in the form of a legal partnership, which contrasts sharply with many accounts of the unrecognised role of women in ethic minority firms (Phizacklea, 1990; Ram, 1992). Equally significant was the formalised method of staff recruitment through advertising and the job centre rather than the ethnic network.

Differentiating products based on 'authenticity', however, was not the only way in which respondents attempted to create a niche in a competitive marketplace. For instance, a Pakistani owner operating in the crowded 'Balti quarter' saw little scope for development in the existing business. Rather, he was actively pursuing a franchise arrangement with a fast-food company specialising in fried chicken,

We are concentrating on the Southern fried side, on the franchise ... It is working out very well for us ... for the whole of Birmingham ... With that we are going to do Southern fried chickens and things like that so we are going to give it a ... brand new concept.

(Bilal, Mogul Palace, Pakistani)

In another case, a Pakistani restaurateur was attempting to develop a supplementary trade by supplying neighbouring restaurants with starter dishes. According to the owner this sideline was 'picking up gradually', but it also entailed the kind of labour-intensive practice and small margins which are part of the ethnic minority business trap and as such can hardly be considered as an example of successful growth at this stage. Significantly, this respondent continued to operate on the back of traditional practices such as a heavy personal workload with a close hands-on approach, exclusive use of family and co-ethnic workers, and little external funding. 
Attention to customer care and direct engagement with customers, a key feature of this group, enabled these restaurant owners to become quickly aware of on-going and incremental changes in their customer preferences. This, in turn, enabled this group to offer enhanced levels of service, which provided an element of differentiation, as well as make amendments in their product offerings.

\section{Locational break-out}

Locational break-out refers to conscious (re)location in potentially rewarding areas, such as middle class suburbs and affluent city centre spaces not yet colonised by competitors (there were seven firms in this category). Often, this form of business development went hand-in-hand with the kind of discourse of 'exclusivity' and 'authenticity' noted in product differentiation. Highlighting this point, a Bangladeshi respondent, the owner of 'a very high class restaurant' had chosen to distinguish himself by going 'up-market', placing a premium on 'quality' and the salubrious nature of the surroundings. He combined this with a highly distinctive cuisine and asserted, 'I don't copy anyone at all. Therefore, I don't see anybody as my competitor'. Yet, once again the acquisition and fitting out of this restaurant had been extremely capital-intensive, 'a few hundred thousand pounds', and was heavily dependent on his class resources; an entrepreneurial father, who was both a mentor and a financial backer for his initial entry into the trade; and a business studies degree which attuned him in a formal way to the world of enterprise.

Two Indian-owned restaurants were also to be found in this niche of spatial and product exclusivity. Both were located in expensive parts of the city centre, and both claimed to have developed 'national' reputations for the quality of their cuisine. For example, one of these proprietors commented,

if people come to [my restaurant], it's because we are very innovative. We don't take things for granted, we are very experimental in the restaurant and it shows in the way the word has grown in the last 20 years ... It's a small restaurant but we have won national recommendations many, many times.

(Kalra, Taj Mahal, Indian)

The nature of work relations was a revealing feature in both restaurants. In each case, the proprietors had recruited highly experienced chefs from India; they had been with the firms for over fifteen years. These chefs had developed their own reputations; as one commented, 'in this career you can go very high in this job. You can make your own future'. Perhaps reflecting the discretion that these highly skilled operators enjoyed in their work, employees in these firms enjoyed considerable autonomy, as stated 
by one chef, 'I control the kitchen area ... I am left alone ... [The manager] is not worried about the kitchen'. Moreover, owners in both establishments appeared to exhibit the kind of management style revealed in the more benign depictions of 'human resource management'; illustrating this point, one employee commented,

In industry in general, ... staff are regarded as ... expendable commodities, not valued or appreciated. Here I think it is different ... The proprietor of the restaurant he regards us and customers more as friends and family as opposed to employees and he doesn't look at the staff as expendable. He values the staff and I am sure he likes to have his staff value the establishment, so people do stay on.

(Bovinder, Kohinoor, Indian)

Both owners made a point of stressing their 'on the books' employment practices; and compared this with the more informal modus operandi of the 'Balti' restaurants. However, it is important to look again at the wider context, particularly the market relationships, to explain this apparent contrast. For example, one of the respondents was a manager of a restaurant that was part of a chain of five establishments. He elaborated,

Because we're part of a large organisation ... [The owner] has put a system in ... Everything has to go through the till; everything is registered ... We only do 15 per cent cash turnover ... the rest is through credit cards ... There is no scope [for informal practices] ... How can they [Balti restaurants] survive on those prices ... Their biggest overhead is staff. They compromise on VAT, PAYE, and anything else that they can get away with.

(Nirinder, Raj Palace, Indian)

\section{Discussion and conclusions}

The continuing proliferation of ethnic minority businesses in advanced industrial economies reflects these ethnic groups' resilient mining of fringe economic activities. Extant studies have drawn upon different theoretical traditions to document the presence of ethnic minorities in business; these range from cultural approaches (Hardill and Raghuram, 1998; Werbner 1990), to the recent articulation of a 'mixed embeddedness' perspective (Kloosterman et al., 1999). Still neglected though, is an appreciation of the ways in which ethnic minority businesses may be developing, and the dynamics that underpin the growth of such enterprises. Working within a contextualist approach to ethnic minority enterprise, this chapter has sought to shed light on the actual process of 'break-out' and especially the entrepreneurial strategies employed to this end. A key aim has been to demonstrate the importance of employment relations to the management 
of growth in South Asian firms operating in a particular sectoral spatial setting. A variety of responses were evident, even in firms operating in a comparatively narrow segment of the market. The variation in patterns of response owed much to the external context as well as the particular 'informal' characteristics of employment relations in the restaurants. An important lesson is that the pressures stemming from the product and labour market are not easily predictable in advance; they are mediated internal dynamics within the firm.

Using the empirical context of South Asian in Birmingham, a number of other propositions may be advanced that might apply more broadly to small family firms aiming to move beyond traditional business practices.

\section{Excessive reliance on social networks can inhibit the capacity of firms to break-out}

The experiences of the survivalists highlight both the opportunities and constraints of relying primarily on informal insider social networks. Such networks (in the form of family and co-ethnic ties) were important to the processes of business start-up, recruitment and management. Moreover, the ensuing nature of social relations within the enterprise provided employers with an important means of coping with fierce competition, with social networks utilised to operate 'flexibly', which often means operating informally (and on the margins of legality) by avoiding regulations. Yet, although this provided employers with room for manoeuvre in highly pressurised circumstances, it also limited the scope for more substantial development of the enterprise, since over-reliance on social networks is likely to place serious limitations on access to financial and human capital. In addition, the circulation of new information and material resources is also limited in tight groups and so consequently are the chances of business success (Rath, 2002). Having said this, we should also reiterate that lack of capability is often compounded by lack of will. As suggested previously, entrepreneurs of this type tend to define success less in terms of growth and more in terms of economically 'irrational' criteria such as personal autonomy and self-satisfaction. In line with the mass of the entrepreneurial petty bourgeoisie irrespective of ethnicity they are 'steady state survivalists' (Blackburn et al., 1990), whose agenda is dominated by staving off threats to their very existence rather than by prospects of dynamic expansion.

\section{Economic sector has an influential, but not determinate, effect on the capacity of firms to break-out}

On the face of it, there are good reasons for arguing that ethnic minority firms' prospects are decisively shaped by their sectoral location (Jones et al., 1994). In Britain, the great bulk of Asian businesses are concentrated 
in retailing, a conspicuously unpromising area, where the number of independent operators has been shrinking throughout the entire post-war period and declining with particular rapidity in the last two decades, their markets largely wiped out by the invasion of super- and hyper-markets (Jones et al., 2000). By complete contrast, the restaurant sector could hardly be more buoyant, with ethnic restaurants taking an increasing share of rapidly increasing consumer expenditure (Mawson and Fearne, 1997). Yet, as the present research insists, this has to be severely qualified, since in many localised cases such as Birmingham, the perceived attractiveness of the restaurant trade has caused the supply of Asian entrepreneurs to out-run even a vigorously expanding demand, resulting in market saturation. In consequence, our respondent firms face intense competitive pressures, mostly from fellow Asians. Even so, simply because the city-wide and regional markets are expansive, entrepreneurs are granted some scope to shape the trajectory of the business. As we have seen, some developed new markets, adapted existing niches, and re-oriented working practices. This clearly illustrates that markets are not given, but are the products of human actions, and that their emergence involves economic and social determinants (Rath, 2002:15). Even in the highly competitive ethnic restaurant market, the findings illustrate that there is scope for business growth and development. The market relationships documented in the firms that had grown, through multiple business ownership, product differentiation, and locational breakout, highlight the variety of strategic responses open to these operators. Overall then we can conclude that, although nothing can be simply 'read off' from sectoral location, nevertheless some sectors certainly do offer ethnic entrepreneurs a more favourable opportunity/constraint mix than others. What appears to be decisive is the way in which individual firms adapt to this and the way their strategic response is conditions by access to business resources (see below).

\section{Effective break-out requires a combination of financial, human and cultural resources}

Essentially it is the possession and proactive deployment of financial, human and cultural resources (or class resources) that distinguishes the break-out businesses in our sample from the survivalists. Such resources were crucial in helping to acquire additional businesses, locate in more auspicious market settings and invest in work relations that would produce the 'authenticity' required to differentiate the business from its competitors. Enterprises with locational and multiple outlet strategies were better endowed with these resources than other firms. Hence they were in a position to pay much closer attention to market trends, have more 'open' practices to recruitment and management, observe employment regulations, and adopt more innovative approaches to new product development. 
Firms in the product differentiation category tended not to have as many of these resources; but nonetheless, they possessed sufficient human and social capital to engage in a selective re-working of their ethnic resources. Hence rather than investing in new premises, these firms concentrated their efforts on refining their products and developing relationships with key staff that would nurture 'authenticity'.

\section{Acknowledgements}

We are grateful to the Economic and Social Research Council for funding this study (Award Number L130241049), and to Balihar Sanghera for his work on the project. We also appreciate the comments of Mike Wright on an earlier version of this paper.

\section{Note}

1 In addition to the market environment, the city of Birmingham also provides an important setting for the study. With a very significant ethnic minority population (21.5 per cent), the city is seen as an important, test case for the future of race relations in British society (Back and Solomos, 1992:329). Of the city's ethnic minority population, South Asians represent a substantial component, with Bangladeshis comprising 1.3 per cent of the city's population, Indians 5.3 per cent, and Pakistanis 6.9 per cent (Birmingham Economic Information Centre, 1992). Settling mainly from the late 1950s to the early 1970s, Birmingham's ethnic minority communities have tended to form distinct spatial clusters; 'Sparkbrook became a largely Pakistani area, the Handsworth area became the Caribbean centre of Birmingham, alongside the Soho area which was overwhelmingly Indian' (Rex, 1987:104).

\section{References}

Aldrich, H., Cater, J., Jones, T. and McEvoy, D. (1981) 'Business development and self-segregation: Asian enterprise in three British cities', in Peach, C., Robinson, V. and Smith, S. (eds) Ethnic Segregation in Cities, London: Croom Helm, pp. 170-90.

Aldrich, H., Jones, T. and McEvoy, D. (1984) 'Ethnic advantage and minority business development', in Ward, R. and Jenkins, R. (eds) Ethnic Communities in Business, Cambridge: Cambridge University Press, pp. 189-210.

Back, L. and Solomos, J. (1992) 'Black politics and social change in Birmingham, UK: an analysis of recent trends', Ethnic and Racial Studies, 15:327-51.

Bailey, T. (1985) 'A case study of immigrants in the restaurant industry', Industrial Relations, 24:205-21.

Bailey, T. (1987) Immigrant and Native Workers, Boulder: Westview Press.

Baines, S. and Wheelock, J. (1998) 'Reinventing traditional solutions: job creation, gender and the micro-business household', Work, Employment and Society, 12:579-601.

Barrett, R. and Rainnie, A. (2002) 'What's so special about small firms? Develop- 
ing an integrated approach to analysing small firm industrial relations', Work, Employment and Society, 16(3):415-32.

Basu, A. (1998) 'An exploration of entrepreneurial activity among Asian small businesses in Britain', Small Business Economics, 10:313-26.

Bates, T. (1993) Banking on Black Enterprise, Washington: Joint Center for Political and Economic Studies.

Bechoffer, F. and Elliott, B. (1978) 'The voice of small business and the politics of survival', Sociological Review, 26:57-88.

Birmingham Economic Information Centre (1992) 1991 Census topic reports: ethnic groups in Birmingham. Birmingham, UK: Birmingham City Council.

Birmingham Economic Information Centre (1998) Economic Review. Birmingham, UK: Birmingham City Council.

Birmingham Economic Information Centre (2000) Economic Review. Birmingham, UK: Birmingham City Council.

Blackburn, R., Curran, J. and Jarvis, R. (1990) 'Small firms and local networks: some theoretical and conceptual explorations', Paper presented at the 13th National Small Firms and Policy Research Conference, Harrogate, November.

Curran, J. (1986) 'The survival of the petite bourgeoisie: production and reproduction', in Curran, J., Stanworth, J. and Watkins, D. (eds) The Survival of the Small Firm: Employment, Growth Technology and Politics, Aldershot: Gower.

Curran, J. (1991) 'Foreword', in Burrows, R. (ed.) Deciphering the Enterprise Culture: Entrepreneurship, Petty Capitalism and the Restructuring of Britain, London: Routledge.

Deakins, D., Hussain, G. and Ram, M. (1994) Ethnic entrepreneurs and commercial banks: untapped potential. Birmingham, UK: University of Central England Business School.

Dhaliwal, S. and Amin, V. (1995) Profiles of Five Asian Entrepreneurs, London: Asian Business Institute.

Edwards, P. K. (2001) “"Industrial relations": from apparently anachronic to analeptic and anaclastic condition', Paper presented at the conference on Industrial Relations: An Anachronism? University of Tübingen, June. Available at http://users.wbs.warwick.ac.uk/irru.

Eisenhardt, K. (1991) 'Better stories and better constructs: the case for rigor and comparative logic', Academy of Management Review, 16:620-7.

Eisenhardt, K. and Bourgeois, L. (1988) 'Politics of strategic decision making in high-velocity environments', Academy of Management Journal, 31:737-70.

Freel, M. (1998) 'Policy, prediction and growth', Journal of Small Business and Enterprise Development, 5(1):19-32.

Hakim, C. (1989) 'Identifying fast growth firms', Employment Gazette, January, pp. 29-41.

Hardill, I. and Raghuram, P. (1998) 'Diasporic connections: case studies of Asian women in business', Area, 30:255-61.

Herman, H. (1979) 'Dishwashers and proprietors: Macedonians in Toronto's restaurant trade', in Wallman, S. (ed.) Ethnicity at Work, London: Macmillan, pp. 71-90.

Hoel, B. (1984) 'Contemporary clothing sweatshops: Asian female labour and collective organisation', in West, J. (ed.) Work, Women and the Labour Market, London: Routledge and Kegan Paul, pp. 80-98. 
Jones, T., McEvoy, D., de Silva, P. and Cater, J. (1989) Ethnic Business and Community Needs, London: Commission for Racial Equality.

Jones, T., McEvoy, D. and Barett, G. (1992) Small Business Initiative: Ethnic Minority Business Component, Swindon, UK: Economic and Social Research Council.

Jones, T., McEvoy, D. and Barett, G. (1994) 'Labour intensive practises in the ethnic minority firm', in Atkinson, J. and Storey, D. (eds) Employment, the Small Firm and the Labour Market, London: Routledge, pp. 172-205.

Jones, T., Barett, G. and McEvoy, D. (2000) 'Market potential as a decisive influence on the performance of ethnic minority business', in Rath, J. (ed.) Immigrant Businesses: The Economic, Political and Social Environment, London: Macmillan, pp. 35-53.

Kesteloot, C. and Mistiaen, P. (1997) 'From ethnic minority niche to assimilation: Turkish restaurants in Brussels', Area, 29:325-34.

Kloosterman, R., van der Leun, J. and Rath, J. (1999) 'Mixed embeddedness: (in)formal economic activities and immigrant businesses in the Netherlands', International Journal of Urban and Regional Research, 23:252-66.

Kolvereid, L. and Bullvag, E. (1992) 'Novices versus experienced business founders: an exploratory investigation', in Birley, S., MacMillan, I. and Subramony, S. (eds) Entrepreneurship Research: Global Perspectives, London: North-Holland.

Light, I. (1984) 'Immigrant and ethnic enterprise in North America', Ethnic and Racial Studies, 7:195-216.

Light, I. and Bonacich, E. (1988) Immigrant Entrepreneurs: Koreans in Los Angeles, Berkeley: University of California Press.

Light, I. and Rosenstein, C. (1995) Race, Ethnicity, and Entrepreneurship in Urban America, New York: Aldine de Gruyter.

Ma Mung, E. (1999) 'A brief summary of the development of immigrant entrepreneurship in France and its informal aspects', unpublished paper presented to the Launching Conference, Working on the Findings: Immigrant Business, Economic Integration and Informal Practises, Amsterdam, April.

Macdonald, F. (1996) 'Welfare dependency, the enterprise culture and selfemployed survival', Work, Employment and Society, 11:431-47.

Mawson, E. and Fearne, A. (1997) 'Organisational buyer behaviour: a study of UK restaurant chains', British Food Journal, 99:239-43.

McGoldrick, C. and Reeve, D. (1989) Black businesses in Kirklees: a survey of Afro-Caribbean and South Asian businesses in the Kirklees Metropolitan District. Report to employment development unit, Kirklees Metropolitan Council: Huddersfield Polytechnic: Department of Geographical Sciences.

Metcalf, H., Modood, T. and Virdee, S. (1996) Asian Self-employment: The Interaction of Culture and Economics in England, London: Policy Studies Institute.

MINTEL (1997) Ethnic Foods, London: Mintel International Group.

MINTEL (1998) Ethnic Restaurants, Leisure Intelligence, London: Mintel International Group.

Office of National Statistics (1991) Census of Population, London: ONS.

Phizacklea, A. (1990) Unpacking the Fashion Industry, London: Routledge.

Quassoli, F. (1999) 'Migrants in the Italian underground economy', International Journal of Urban and Regional Research, 23(2):212-31.

Rafiq, M. (1985) Asian Businesses in Bradford: Profile and Prospect, Bradford, UK: Bradford Metropolitan Council. 
Rafiq, M. (1992) 'Ethnicity and enterprise: a comparison of Muslim and nonMuslim owned Asian businesses in Britain', New Community, 19:43-60.

Rainnie, A. (1989) Industrial Relations in Small Firms: Small Isn't Beautiful, London: Routledge.

Ram, M. (1992) 'Coping with racism: Asian employers in the inner city', Work, Employment and Society, 6:601-18.

Ram, M. (1994) Managing to Survive: Working Lives in Small Firms, Oxford: Blackwell.

Ram, M. and Hillin, G. (1991) 'Achieving "break-out": developing mainstream ethnic minority business', Small Business Enterprise and Development, 1:15-21.

Ram, M. and Jones, T. (1998) Ethnic Minorities in Business, Milton Keynes: Small Business Research Trust.

Ram, M., Sanghera, B., Abbas, T. and Barlow, G. (1998) 'Facilitating "break-out": ethnic minority business development in an inner city context', unpublished paper presented to the Ethnic Minority Entrepreneurship Seminar. University of Central England Business School: Enterprise Research Centre (22 September).

Ram, M., Smallbone, D., Deakins, D. and Jones, T. (2003) 'Banking on break-out: finance and the development of ethnic minority businesses', Journal of Ethnic and Migration Studies, 29(4):663-81.

Rath, J. (1999) 'A game of ethnic musical chairs? Immigrant businesses and the formation and succession of niches in the Amsterdam economy', in Body-Gendrot, S. and Martineiello, M. (eds) Minorities in European Cities: the Dynamics of Social Integration and Social Exclusion at the Neighbourhood Level, London: Macmillan.

Rath, J. (2002) 'Needle games: mixed embeddedness of immigrant entrepreneurs', Rath, J. (ed.) Unravelling the Rag Trade: Immigrant Entrepreneurship in Seven World Cities, Oxford: Berg Publishers.

Rath, J. and Kloosterman, R. (2000) 'Outsiders' business: research of immigrant entrepreneurship in the Netherlands', International Migration Review, 34(3):656-80.

Rath, J. and Kloosterman, R. (1999) 'A critical review of research on immigrant entrepreneurship', International Migration Review, 34(3):657-81.

Razin, E. and Langlois, A. (1996) 'Metropolitan characteristics and entrepreneurship among immigrants and ethnic groups in Canada', International Migration Review, 30:703-27.

Rekers, A. and van Kempen, R. (2000) 'Location matters: ethnic entrepreneurs and the spatial context', in Rath, J. (ed.) Immigrant Businesses: the Economic, Political and Social Environment, London: Macmillan.

Rex, J. (1987) 'Life in the ghetto', in Benyon, J. and Solomos, J. (eds) The Roots of Urban Unrest, Oxford: Pergamon, pp. 103-110.

Scase, R. (1995) 'Employment relations in small firms', in Edwards, P. (ed.) Industrial Relations in Britain. Oxford: Blackwell.

Scase, R. and Goffee, R. (1982) The Entrepreneurial Middle Class, London: Croom Helm.

Smallbone, D., Leigh, R. and North, D. (1995) 'The characteristics and strategies of high growth SMEs', International Journal of Entrepreneurial Behaviour and Research, 1:44-62.

Smallbone, D., North, D. and Leigh, R. (1992) 'Managing change for growth and survival: the study of mature manufacturing firms in London during the 1980s', Middlesex Polytechnic: Planning research centre, Working paper no. 3. 


\section{M. Ram et al.}

Stake, R. (1994) 'Case studies', in Denzin, N. and Lincoln, Y. (eds) Handbook of Qualitative Research, California: Sage, pp. 236-47.

Storey, D. (1994) Understanding the Small Business Sector, London: Routledge.

Ward, R. (1991) 'Economic development and ethnic business', in Curran, J. and Blackburn, R. (eds) Paths of Enterprise: the Future of the Small Business, London: Routledge, pp. 51-67.

Warde, A., Martens, L. and Olsen, W. (1999) 'Consumption and the problem of variety: cultural omnivorousness, social distinction and dining out', Sociology, 33:105-27.

Werbner, P. (1984) 'Business on trust: Pakistani entrepreneurship in the Manchester garment trade', in Ward, R. and Reeves, F. (eds) Ethnic Community in Business, Cambridge: Cambridge University Press, pp. 166-88.

Werbner, P. (1990) 'Renewing an industrial past: British Pakistani entrepreneurship in Manchester', Migration, 8:17-41.

Wilpert, C. (1999) 'A review of research on immigrant business in Germany', Paper presented to the launching conference, Working on the Findings: Immigrant Business, Economic Integration and Informal Practises, Amsterdam (April).

Yin, R. (1994) Case Study Research, London: Sage. 


\title{
7 Labour regulation and SMEs \\ A challenge to competitiveness and employability?
}

\author{
Mark Hart and Robert Blackburn
}

\section{Introduction}

Since the adoption of the Single European Act, European Community priorities have shifted from the task of harmonisation to the definition and implementation of minimum requirements in the area of working conditions. The encouragement of high labour standards, through legislation, as part of a competitive Europe is a central objective of the priorities in the social field of European Union policy. At the centre of the argument is the belief that the labour market is just as much a social institution as an economic one (Solow, 1990) and that ideas of fairness, motivation and morale imbue the labour market. However, without regulation such principles rarely emerge, and the result is a set of labour standards erroneously designed to serve the economic imperatives of growth. All forms of regulation, therefore, must be resisted in order to pursue greater levels of economic prosperity. Companies can more profitably respond to signals from the market place if they can reduce their core workforce and 'hire and fire' contract and/or part-time workers with the minimum of contractual complication. Such is the thinking of the economics of the new right which came to dominate much of the rationale behind labour market policy in the US and the UK.

A counter-argument, however, would suggest that attention to the social aspects of the employment contract would also provide important contributions to economic growth by delivering higher productivity and high-quality jobs. The elimination of discriminatory wage practices and a reassessment of the attitude towards traditionally low-paid groups would also contribute to the stated objectives of achieving economic and social cohesion within the EU. Such developments, driven through necessity by a legislative framework at national level, would also enhance the employability of the discouraged worker who also tends to be among the more marginalised groups in society.

In short, the European Commission's twin objectives of competitiveness and employability may not be at odds with an increase in the regulatory framework governing employment relations and employment rights 
across the EU. This chapter has two themes. First, to assess the extent to which such claims are valid by looking at recent evidence from the UK where there has been an increase in the volume and complexity of employment legislation on the statute book (DTI, 2000). This legislation covers a variety of individual employment rights including working time, maternity and parental leave, wage rates and discrimination. These rights are enshrined in a number of pieces of legislation, including the Employment Relations Act (1999), the Working Time Directive (1998) and National Minimum Wage (1998).

Second, the discussion seeks to explore a range of issues in relation to the development of labour regulation in the EU and the impact of this regulation upon small firms. So, to what extent are owner-managers aware of the new employment regulations? What, if any, are the different awareness levels and effects within the small business population? What have been their adjustments to it? How has it affected their business performance? The rationale for this focus on the small firm sector is that employment legislation has excited a great deal of debate and comment from the media and pressure groups with employers' representatives expressing concern about the effects on their enterprise (see The Daily Telegraph, 2000; Financial Times, 2001). In theory, it has been argued that small firms are disproportionately affected by legislation and regulation because of the fixed costs of compliance which are more difficult for them to absorb in terms of time and resources afforded to these tasks (Better Regulation Task Force, 2000a).

\section{EU social policy, employment relations and individual employment rights}

\section{Flexibility and regulation - some aspects of the debate}

The move towards Economic and Monetary Union (EMU) has, according to the Commission (CEC, 2000), helped create a more co-operative employment relations climate as a result of shared macro-economic objectives. The social partners have, albeit slowly, responded to the farreaching structural changes affecting industry, which has resulted in an expansion of flexible forms of employment in European labour markets. In the early 1990s, European labour markets were increasingly deregulated, albeit from very different starting points. However, recent developments at European level towards the increased protection for atypical workers (e.g. part-time workers) indicate the initial signs of the reconstruction of labour market 'institutions'. Such trends are treading a fine line between the increased need for working time flexibility in many sectors and firms and employee protection. This is clearly the case concerning the labour market experience of women who, unlike men, are more likely to experience flexible employment conditions throughout their working lives (Rubery et al., 1999). The EU's Part-time Workers' Direc- 
tive in 1997 provides an indication of the attempt to ameliorate some of the disadvantages confronting women in the labour market.

Arising out of the Social Charter, which was adopted by all the Member States except the UK in 1989, the EU's Social Affairs Council adopted the Working Time Directive (WTD) in 1993 which was designed to limit maximum hours of working (48 hours), and establish minimum entitlements to rest periods and paid annual leave for most workers in the EU. The objective and appeal of the policy was simple. The reduction of working time would reduce unemployment without tinkering with Welfare State regimes or affecting worker interests (Marimon and Zilibotti, 2000). But can the WTD be an effective employment policy to translate the volume of work into an increase in the number of individuals employed to deliver that volume? Even if positive employment effects are found there is always the difficulty of separating out the causal relationships from cyclical trends. It should be noted that the debate on the efficacy of working time reductions as an important tool in employment policy has its origins in the late 1970s when countries such as Belgium, Germany, Denmark and the Netherlands introduced a number of statutory or collectively agreed reductions in working time (Bosch and Lehndorff, 2001).

There was a great deal of debate over the introduction of the WTD within the EU with resistance coming particularly from the UK Government, who were more inclined to present the counter-argument that competitiveness would suffer as a result of higher employers' unit labour costs arising out of working time restrictions. According to orthodox economic theory most individuals will be working at their utility level maximising number of hours conditional on the wage they receive (Addison and Seibert, 1979). Working time restriction has the effect of lowering workers' utility and hence employers' unit labour costs rise. Another way of looking at this is that when the working time of an individual worker is cut, unit costs can be affected by the negotiated rise in wages to compensate for the reduced hours worked (e.g. raising the hourly wage). However, part of that negotiation may also involve effects on productivity and changes in operating hours which, in turn, can have an effect on unit costs (Bosch and Lehndorff, 2001). Further, there is an implicit assumption in this theoretical position that the total amount of work to be done remains constant. Finally, the way in which the total package is negotiated between the employer and the employee will determine whether or not the outcomes are cost neutral. For example, a reduction in the number of working hours may be compensated by a wage increase but this in turn may be offset by a lower annual pay rise.

\section{A closer look at working time directives across the $\mathrm{EU}$}

The duration of working time has remained at the centre of discussions on the employment relationship in the last two years across the EU. With the 
exception of the UK, the move towards the regulation of working time has been covered by domestic industry specific or national collective agreements. However, the move towards major cuts in the working week through collective bargaining appears to have stalled in 2000 although they are still on the agenda of many trade unions in Greece, Portugal and Spain, or governments such as in Belgium (European Industrial Relations Observatory (EIRO), 2001). France remains the stark exception within the EU, where legislation introducing the 35-hour working week was introduced in January 2000 for firms with more than 20 employees. In January 2002, firms employing less than 20 employees were required to reduce their working week to 35 hours. ${ }^{1}$ Within the EU this represents by far the strongest policy initiative on WTD and is in no small way related to a long-standing trade union goal within France.

Table 7.1 illustrates the statutory maximum working week across the EU. In short, the countries can be divided into two groups. First, those that have set their maximum weekly hours at 48 hours (as set out in the EU WTD). France is included in this group but as noted above they have set their statutory working week at 35 hours. For these countries this maximum is well above the level of the average collectively agreed weekly working hours and indeed of actual average weekly hours. What seems to be happening here is that the 48 hours acts as some sort of a 'safety net' for workers. Second, those countries which operate a lower limit of 40 hours, which is much closer to the actual or agreed weekly hours, reflect a much more effective legislative framework for 'policing' working time.

However, despite the impression of the universality of these legislative changes, employees with 'autonomous decision-making powers' (i.e. managers and executives), or those who work in excluded sectors (e.g. trans-

Table 7.1 Statutory maximum working week (2000)

\begin{tabular}{ll}
\hline Country & Hours \\
\hline France & 48 \\
Germany & 48 \\
Greece & 48 \\
Ireland & 48 \\
Italy & 48 \\
Luxembourg & 48 \\
Netherlands & 48 \\
UK & 48 \\
Austria & 40 \\
Finland & 40 \\
Portugal & 40 \\
Spain & 40 \\
Sweden & 40 \\
Belgium & 39 \\
\hline
\end{tabular}

Source: EIRO (2001). 
port or hospital services), or where they have negotiated an agreement at the level of the firm to restrict the application of the WTD, are exempt from the directive. In short, large groups of workers are clearly not covered by the directive and what is perhaps more worrying is that there exists the ability for workers to 'self-select' themselves as possessing 'autonomous decision-making powers'. The incentive to do this will reflect the preferences of individual workers who are more likely to be motivated by more earnings rather than fewer working hours (OECD, 1998). With these opt-outs, the ability of the WTD to be an effective tool in an overall employment policy is somewhat weakened. To reiterate, there is a threefold tension between the increase in flexible working practices, a need to create jobs across the EU and the development of regulatory frameworks designed to reduce the discriminatory processes in the labour market.

\section{What has been the impact of working time reduction on employment?}

Although it is perhaps too soon to assess the employment effects of the EU WTD, due to its very recent introduction into national legislative frameworks, the earlier moves to reduce working hours in many European countries do allow some attempt to reflect on the impact on employment. Bosch and Lehndorff (2001) show that these early working time reductions have impacted upon the trends in working time. For example, in Germany and Denmark the average weekly working time has fallen markedly for full-time workers over the period 1983 to 1993: 1,808 to 1,739 hours and 1,833 to 1,747 hours, respectively. By contrast, data from the European Industrial Relations Observatory (EIRO, 2001) indicates that in the UK, annual hours for full-time employees have increased. But has the absolute fall in annual working time hours resulted in increased employment? Bosch and Lehndorff review existing empirical studies which have used a variety of techniques to isolate estimates of the employment effects of reductions in working time. The difficulty, as noted above, is the ability to separate out the effects of reduction in collectively agreed or statutory working hours from broader effects of growth and productivity gains on employment.

In summary, and notwithstanding the weaknesses associated with each technique, Bosch and Lehndorff (2001:227) conclude that 'most empirical studies confirm that collective working time reductions can be expected to have positive employment effects'. For example, in France the Ministry of Labour, using data on the performance of companies introducing a reduction in working hours compared to those that had not, estimated that the overall employment gain over the period 1996-99 preparatory period for the legislation was around 100,000 jobs.

What emerged from many of these studies was the need to recognise the importance in understanding the 'employment gain' which was not just 
a reduction in working hours per se, but also the actions taken by the company, the social partners and the state in the period after the reduction was implemented. In other words, to understand the conditions that are necessary to ensure that working time reductions do actually lead to positive employment effects, which can best be summarised as follows:

- Agreement over the compensatory pay increases and productivity gains (importance of incremental progress on the wage-time tension initial two-year agreements as in the case of France).

- Ensuring that the supply side of the labour market can respond to the new opportunities.

- A sensitivity between working time, the total volume of work in the company (operating hours) and the organisation of work.

- Ensuring job security in the growth of flexible working time systems.

- The role of the state in supporting a collective working time policy through subsidised measures such as lower social security contribution in the case of France.

One of the important debates concerning the WTD has been the differential effect that the legislation might have on the ability of small businesses to maintain their competitive position in the market place. For example, the French Government decided not to go ahead in January 2002 and introduce the 35-hour working week for businesses employing less than 20 employees in the face of some quite forceful lobbying on the part of the small business sector. More generally, it is important to assess the extent to which the raft of legislation within the generic framework of 'individual employment rights' may have a greater impact on small firms compared to larger firms. One might argue, a priori, that the introduction of Individual Employment Rights (IERs) might have a disproportionate effect upon micro-enterprises (less than 10 employees) and small firms (between 10 and 49 employees) for a number of reasons. We take a closer look at these reasons in the next section within the context of a detailed assessment of the impact of the increased scale of IERs in the UK since 1997.

\section{Individual employment rights in the UK}

When the Labour Government in the UK came to office in May 1997, one of its first actions was to sign up to the European Social Chapter in an acceptance of the existence of a social dimension to the process of European integration. However, rather than signalling a full acceptance of European social policy the reality in the detail of the legislation has been to accept the proposals and directives in a minimalist fashion, never exceeding what was required by European legislation (McKay, 2001). The following section probes in more detail the way in which the regulatory 
framework in the UK has undergone a relatively dramatic change since 1997 and seeks to assess the impact of this change on the small firm sector.

\section{The context: employment legislation and small firms}

Employment legislation is amongst the most commonly applicable aspects of regulation in the workplace. Over the past 10 years or so, employment legislation has increased and since coming to power in 1997, the Labour Government has added to the amount of legislation with the aim of providing more protection and rights for individuals in the workplace. This new legislation is broadreaching and complex. Surprisingly, there has been very little research undertaken on owner-managers' awareness and knowledge levels of employment rights. Instead, the bulk of attention has tended to look at the impact of employment legislation. The research that does exist on awareness levels tends to focus on firms employing five or more people (Callendar et al., 1999; Hogarth et al., 2001). However, the volume of new employment legislation raises the question of the extent to which smaller employers are aware of, and have detailed knowledge of, these new rights. Government has attempted to communicate to employers through various media, but little is known about its success in reaching owner-managers. Evidence suggests that owner-managers are generally aware of the rise in legislation. Research conducted by MORI, commissioned by the Small Business Service (SBS) on 1,500 firms with 0-249 employees, found that over two-fifths of SMEs considered that the amount of Government regulations had increased since the election of the Labour Government in 1997 (Small Business Service, 2001).

Whilst research on basic awareness and knowledge levels is scarce, that on the impact of employment legislation is more readily available. A number of small business membership bodies and lobby groups have been vociferous in their criticism of new employment regulations. Studies have shown the new employment legislation to be expensive for employers and constrains the flexibility in their employment practices, ultimately affecting their competitiveness (see British Chambers of Commerce, 1999; The Daily Telegraph, 2000). Some surveys (e.g. Forum of Private Business, 2000; NatWest SBRT Quarterly Survey, 2000) have attempted to measure the costs of compliance by asking employers to estimate the time taken to deal with regulations. For example, a survey for the Small Business Service survey reported that, of the regulations employers' mentioned, complying with Health and Safety legislation was considered to take the most person hours, followed by the Working Time Directive ( 8 per cent) and the National Minimum Wage (6 per cent) (Small Business Service, 2001:61-3). A survey of small business advisers has also provided estimates of the financial costs of compliance with regulations amongst micro and small firms and found that government regulation has become a more 
important factor in employers' perceptions upon the constraints on business performance (ICAEW, 2000).

In principle, the compliance costs of legislation are relatively higher in small firms because of a poorer level of resources in comparison to larger enterprises (Stanworth and Gray, 1991; Van de Horst et al., 2000). These costs include learning the legislation, adjusting administrative procedures to meet the new legislation, paying the relevant taxes or benefits and absorbing the effects within the enterprise. In relation to employment legislation it is likely that small firms are at a relative disadvantage because of the absence of a personnel specialist and the greater proportionate contribution of individual employees to output. Academic research which does exist on the impact of recent employment legislation tends to present a more limited effect than the more popular accounts, with this evidence drawing attention to owner-managers' 'fire fighting' management style (Marlow and Strange, 2000). One of the main effects of the new legislation has been a rise in the search for external advice by employers (Better Regulation Task Force, 2000b; Harris, 2000). However, compared with the amount of legislation it can be argued that the volume of research is disproportionately low.

A research focus on employment regulations and small firms is, however, not new. Over 20 years ago, following the introduction of a series of employment rights, employers' representative groups voiced concerns and research was commissioned by government. The results of the research found that only two per cent of small employers cited employment legislation as the single main difficulty in running business. The biggest perceived constraint was on being unable to sack unsatisfactory workers; and that the expense and time involved in compliance were of secondary importance (Clifton and Tatton-Brown, 1979:Ch.11; Employment Gazette, 1979; Westrip, 1982). The report concluded that the legislation may have involved expenses to employers and that, as a result, the latter were being more careful about whom they employ.

In this section of the chapter we focus on three main areas of this legislation (Table 7.2). The Working Time Directive is one of the major new developments in employment legislation during the past decade. Introduced in 1998, the legislation seeks to regulate employees amount of time at work and provide certain break entitlements whilst at work. It has been argued elsewhere that the WTD is a key element of employment rights' legislation in terms of both its range and depth (IRS, 2000). Certainly the WTD has received a number of criticisms because it has improved the terms and conditions of workers at a cost to employers in addition to the compliance costs of understanding and administering new regulations (Forum of Private Business, 2000:22).

A further thrust of Government legislation has been on developing 'family friendly' employment regulations through the extension of maternity leave and pay and parental leave. The rights to reinstatement after 
Table 7.2 Areas of recent legislation on employment rights in the UK

Working time (Working Time Directive, 1998)

Covers rights on maximum average hours (48) compelled to work; right to four weeks paid leave (after 13 weeks); right to one day off per week; right to Statutory Sick Pay; right to rest periods

Family friendly (Employment Relations Act, 1999)

Covers rights on: Maternity Leave; Additional Maternity Leave; Parental Leave; Emergency Family Leave

National Minimum Wage (National Minimum Wage Act, 1998)

Sets minimum wage rates for workers in the UK.

Currently $£ 4.10$ per hour (from 1 October 2001 ); $£ 3.50$ per hour for workers aged 18-21 and workers aged 22 and above during their first six months in a new job with a new employer and who are recently accredited training

childbirth and protection from unfair dismissal on the grounds of pregnancy were introduced in June 1976 and maternity pay in April 1977. Under the 1976 regulations, all pregnant women who met continuous service requirements had the right to return to their previous jobs before the end of 29 weeks after childbirth. ${ }^{2}$ These rights were reinforced under the Trade Union Reform and Employment Rights Act (1993) which introduced the 'Pregnant Workers' Directive. Women who were expecting a baby on, or after, October 1994 had the right to take 14 weeks off work, regardless of their hours of work or length of service and those with 2 years service were entitled to 29 weeks leave. More recently, the rights for maternity and parental leave have changed as a result of the Employment Relations Act 1999 and the Maternity and Parental Leave Regulations 1999. Initial reactions from employers' groups to the new rights have been critical and there have been suggestions that small firms should be exempt from some of the provisions (British Chamber of Commerce, 1999). However, there is no reason to assume that this emphasis will lose momentum in the near future. There has, however, been an absence of comprehensive and reliable evidence of employers' knowledge levels of the existing and new maternity and parental rights. ${ }^{3}$

A final area of study in this chapter is on the National Minimum Wage (NMW). This has received a great deal of publicity and has been subject to scrutiny by the Low Pay Commission of Inquiry which reports on the impact on the NMW and makes recommendations on the rate to Government (e.g. Low Pay Commission, 2000). Arguably, because of the relative simplicity of the NMW and its high profile this may be one of the most clearly understood areas of legislation. It is also the area where most recently the bulk of research has been conducted (see for example, chapter 8). The overall aim of this section, therefore, is to provide: an analysis of employers' awareness of employment rights; to establish any differences in small employers' awareness of employment rights; and to analyse the effects, real or perceived, of employment rights on their business. 
It is likely that some areas of legislation may be better known to employers than others because of the length of time on the statute books, the amount of effort put into publicity campaigns and the perceived relevance by employers to their enterprise. We also expect that knowledge levels of specific rights would be very much influenced by 'a need to know' basis. Size of enterprise was expected to be a strong influence on awareness and knowledge levels because of the increased likelihood of having to understand the range of employment rights with a larger workforce and the ability of employers to devote more time to a personnel specialism. It was also expected that industry sector and the composition of the labour force would be important determinants in awareness and knowledge levels.

\section{Methodology}

The analysis in this chapter draws on a telephone survey of 1,071 small business owners conducted in Autumn 2000 throughout Great Britain by the Small Business Research Centre at Kingston University for the Department of Trade and Industry (DTI). This was a survey stratified by enterprise size, sector and location and then weighted back to reflect their true proportions in the overall GB economy using the Inter Departmental Business Register (IDBR). This ensured that a sufficient number of firms having certain characteristics were interviewed. This was especially important since one of the main weaknesses in other surveys is that they often omit, or simply fail to attract, responses from owners of very small firms. The mean size of firms in the sample was 7.2 employees (median six employees), the minimum two employees and the maximum 49 employees. The response rate of the survey was 53.8 per cent, calculated as the number of successful interviews $(1,071)$ expressed as a percentage of total valid firms contacted (i.e. including refusals and aborted interviews). The results in the following analysis are based on the weighted sample and therefore can be said to reflect the GB business population.

Interviewing business owners about employment legislation posed a range of special problems. For example, who should we address our questions to when there was a division of labour between owners in the enterprise? How could we approach the key informant to discuss our research questions and how detailed could our questioning of their awareness and knowledge of rights go? Prior to the telephone interview, 18 face-to-face interviews were conducted in order to help the researchers understand the attitude of business owners and see how they responded to answering questions and discussing employment rights. This helped shape the main fieldwork instruments and design of the telephone questionnaire. In the final questionnaire, on the core questions covering employment rights, we started by asking employers' awareness of a particular right such as maternity leave, and only if they said that they were aware of such a right did we 
then ask detailed questions. This helped us focus on those rights which employers were able to discuss as well as avoid alienating the employer. This also helps raise the validity of the research when asking the perceived impact of particular employment rights on their enterprise, something which, we would argue, has been weak in other studies.

For businesses, individual employment rights constitute government regulation. For small businesses, in particular, it is often argued that there is a compliance burden which is regressive because of the economies of scale required in meeting or administering the regulations. The Better Regulation Task Force (2000a) for example, found that the absence of an in-house expert on legislation did mean that legislation did have a disproportionate effect on small firms. There are also suggestions that this legislation is having the effect of deterring employers from recruiting and expanding their workforce because of a regulatory burden. The last major government research undertaken on this issue was carried out over 20 years ago following protests from employers' groups over the adverse impact of the employment legislation introduced in the 1970s (Clifton and Tatton-Brown, 1979).

The next two sections present evidence on the owner-managers' actual awareness and knowledge of regulations, together with the perceived impact of employment legislation on small firms' business performance. A number of questions are relevant here. For example, to what extent is contemporary legislation promoting IERs inhibiting the performance of small firms? What are the perceptions of business owners of the effect of IERs on their businesses? To what extent are these based on actual experiences or based on perceptions? How important a factor are IERs on business performance in the context of other influences such as product market conditions, availability of finance and so on? Which specific IERs do employers perceive as having the greatest and least impact on their business? What are the effects of these IERs?

\section{Awareness and knowledge of IERs}

Although there is a great deal of publicity surrounding the impact of regulation on firms, there is relatively less understanding of owner-managers' actual awareness and knowledge of regulations. Employment legislation establishing the legal rights of workers is no exception. However, this is important to investigate, particularly in a period of growing IERs. If employers are relatively unaware of the IERs then this has implications for how government communicates to SMEs. The awareness and knowledge levels of employers are also important to understand since they will also help determine whether the reports of the effects of IERs are perception or experientially based.

Employers were presented with a sequence of questions to explore different levels of awareness and knowledge. The first question collected 
information on respondents' self-assessed knowledge of employment rights. This was followed by questions designed to test awareness of particular rights. Those respondents who knew a particular right was covered by legislation were then routed to a series of further questions, to test their detailed knowledge of the provisions. In the sequence of questions on awareness and knowledge, three fictitious employment rights were included. The rationale for this was to see if owner-managers were merely claiming awareness to every right mentioned, which may be a socially desirable response, or whether they were prepared to state no awareness.

A number of major themes have emerged from this analysis of the awareness and knowledge of IERs amongst respondents. First, generally, owner-managers claimed to be aware of the major pieces of legislation in relation to IERs (Table 7.3). Whilst this awareness was 'claimed awareness' and in a telephone survey, every effort was made to ensure that employers were able to reveal their understanding or ignorance on IERs. Second, awareness varied according to particular IERs. Highest levels of awareness were amongst both new (the NMW) and older pieces of legislation (maternity rights). However, lowest levels of awareness were amongst new pieces of legislation, with the right for parental leave being the least well known. Third, employers' detailed knowledge was much lower than their claimed awareness on all issues covered. This suggests that ownermanagers had some basic notion that legislation existed but they were not able to provide many accurate responses on the details of legislation. It is suggested that employers' awareness and knowledge was raised when they had to deal with a matter rather than any prior strategic knowledge acqui-

Table 7.3 Summary of owner-managers awareness of IERs

\begin{tabular}{lll}
\hline & & $\begin{array}{l}\text { Per cent aware that } \\
\text { this is covered by } \\
\text { legislation }\end{array}$ \\
\hline Highest & National Minimum Wage & 98.7 \\
& Maternity Leave & 95.6 \\
& Right to rest break & 94.1 \\
& Right to paid holidays & 91.1 \\
& Written statement of employment terms & 89.7 \\
& Maximum number of hours worked & 85.2 \\
& Application of employee rights to part-timers & 83.7 \\
& Right to Maternity Pay & 82.7 \\
& Right to a whole day off per week & 68.4 \\
& Right for time-off to deal with emergencies & 57.7 \\
Minimum size of enterprise for disability rights & 50.1 \\
to be applicable & 48.8 \\
\hline
\end{tabular}

Source: SBRC IER Survey (2000). 
sition. These were small business owners and they dealt with information on employment rights on a need-to-know basis.

Fourth, the size of enterprise proved to be the most consistent discriminator in picking out sub-sample variations when the sample was disaggregated. It is argued that the major reason behind this relationship is that employers in the larger small firms (rather than the micros) will encounter a wider range of employment rights issues merely because they employ a wider diversity of staff. It is also likely that the smaller enterprises were less able to dedicate resources to keeping up-to-date with employment legislation. Fifth, business sector and labour force composition (such as proportion of females and part-time workers) proved influential on awareness levels on specific issues. Being taken to an employment tribunal also proved highly influential on knowledge levels: this not only raised detailed knowledge about unfair dismissal and compensation levels but it also sensitised employers to the wider range of IERs.

At the outset, it is expected that awareness and knowledge will vary according to employers' need to know. It is assumed that the particular explanatory factors will include the size of enterprise, business sector, employment composition and experiences during the running of the enterprise. However, the extent to which these factors are important remain hitherto unexplained. In order to provide an overview of the awareness and knowledge of IERs, a composite variable was created using the employer's responses to 21 questions asking them to indicate whether the current legislation covered a list of possible employee rights. Table 7.4 indicates the number of questions asked under each area of the legislation.

A maximum score of 21 could have been obtained for correct answers to all of the questions. Overall, a mean score of 16 was recorded for all the small firms in the sample indicating a less than perfect awareness of all the

Table 7.4 Owner-managers' awareness of IERs covered by legislation: nature of the composite variable

Area of the legislation

Number of questions included

Maternity provisions (Q14a-Q14c)

Time off for dependents (Q14d)

3

Terms and conditions of employment (Q14e-Q14f)

WTD (hours per week) (Q14g)

WTD (rest and holidays) (Q14h-Q14k)

NMW (Q14l)

Part-timers (Q14m)

Discrimination (Q14n-Q14o)

Unfair dismissal (Q14p-Q14r)

Total

Source: SBRC IER Survey (2000). 
areas of the legislation. How does this score vary across sub-groups within the sample? In order to understand the complexities of awareness and knowledge across the diversity of the small businesses in the sample, a multi-variate approach was adopted for the analysis of the composite variable. An OLS regression was undertaken with the dependent variable specified as the composite awareness variable with a possible score in the range $0-21$. The results of the analysis are presented in Table 7.5.

In this model, what could be classified as three types of variable are included: contextual (Size of firm, Age of firm, Sector, Location); internal firm characteristics and experience (Sex of employer/respondent, Workforce composition I and II, Ethnic minorities in the workforce, Major occupational grouping, Businesses taken to an employment tribunal); and perception of the Impact of employment legislation (impact of IERs). The last may in fact have two-way causality, but this is included because it is

Table 7.5 Equation for composite awareness of individual employment rights

\begin{tabular}{|c|c|c|}
\hline Variable & Coefficients & t statistic \\
\hline Constant & 14.785 & 38.985 \\
\hline $\begin{array}{l}\text { Size of firm } \\
\text { (log of employment) }\end{array}$ & 0.544 & 3.861 \\
\hline $\begin{array}{l}\text { Age of firm } \\
\text { (logged) }\end{array}$ & -0.207 & -3.007 \\
\hline $\begin{array}{l}\text { Sector } \\
(1=\text { Primary, manufacturing and construction; } \\
0=\text { Services })\end{array}$ & 0.495 & 2.584 \\
\hline $\begin{array}{l}\text { Location } \\
(1=\text { South East; } 0=\text { Rest of GB })\end{array}$ & -0.364 & -2.169 \\
\hline $\begin{array}{l}\text { Sex of employer/respondent } \\
(1=\text { Male; } 0=\text { Female })\end{array}$ & 0.598 & 3.429 \\
\hline $\begin{array}{l}\text { Workforce composition I } \\
\text { (\% Part-time workers) }\end{array}$ & $-1.362 .10^{-2}$ & -4.230 \\
\hline $\begin{array}{l}\text { Workforce composition II } \\
\text { (\% Female workers) }\end{array}$ & $1.006 .10^{-2}$ & 2.943 \\
\hline $\begin{array}{l}\text { Ethnic minorities in the workforce } \\
(1=\mathrm{Yes} ; 0=\mathrm{No})\end{array}$ & -0.407 & -1.707 \\
\hline $\begin{array}{l}\text { Major occupational grouping } \\
(1=\text { Operatives; } 0=\text { All others groups })\end{array}$ & 0.431 & 2.033 \\
\hline $\begin{array}{l}\text { Business taken to an employment tribunal } \\
(1=\mathrm{Yes} ; 0=\mathrm{No})\end{array}$ & 0.425 & 1.478 \\
\hline \multirow{2}{*}{$\begin{array}{l}\text { Impact of employment legislation } \\
(1=\mathrm{A} \text { burden; } 0=\text { Other responses })\end{array}$} & 0.673 & 4.082 \\
\hline & $\begin{array}{l}R^{2}=0.073 \\
n=1,058\end{array}$ & $F=8.575$ \\
\hline $\begin{array}{l}\text { Critical values } \\
F(11,1,047)_{0.05}=1.79 \\
t(1,058)_{0.05}=1.645\end{array}$ & & \\
\hline
\end{tabular}

Source: SBRC IER Survey (2000). 
significant. The $R^{2}$ is low but the equation is statistically significant and all but one variable (employment tribunal) is significant.

The interpretation of the results of the model suggests that there is a clear relationship between firm characteristics and awareness of IERs with size, age and sector being significant. In detail, the larger the enterprise the more knowledgeable employers are of the legislation, while greater knowledge is associated with younger businesses. If enterprises are in the primary, manufacturing or construction sectors (i.e. not in services), then the employers are more knowledgeable of the legislation. Connected to this, if operatives are the main occupational group in the business, the employers are more knowledgeable of the legislation. Knowledge levels increase outside the South East suggesting that in 'tight' labour markets employer knowledge is weak, perhaps due to the confidence that recruitment of workers is a relatively easy process.

Perhaps surprisingly, given the 'family friendly' nature of much of the IER legislation, male employers are more knowledgeable of the legislation than female employers. The explanation for this does not appear to lie with the composition of the workforce in the respondent's firm as these variables are also held constant in the equation. For example, the fewer the percentage of part-timers in the workforce and the higher the proportion of females, the more knowledgeable employers are of the legislation, irrespective of their gender. Employing ethnic minorities does not raise knowledge levels. As noted in other studies (Marlow, 2002), the experience of an Employment Tribunal does raise employers' knowledge levels and induces greater compliance, but although this contributes to the model, the individual relationship is not statistically significant. Finally, those respondents who stated that the legislation is a significant burden on the performance of their business are more knowledgeable of the legislation.

The overall conclusion to be drawn from this multivariate analysis is that knowledge levels of IERs are complex and vary greatly within the small business sector. The range of variables which may 'explain' awareness of the legislation, as measured by 21 factual questions on all aspects of the legislation, provides an important indication of those segments of the small business sector which require further intervention by government in terms of increasing their knowledge levels about IERs. Although the model provides some explanation of the variation in knowledge levels of IERs in the sample, the low $R^{2}$ suggests that other factors (i.e. missing variables) not included in the model are also influential.

\section{Impact of employment legislation on business performance}

Some of the most high profile studies of employment legislation have been on its constraining effects on businesses. Business owners in the survey revealed that despite a rise in legislation, 'competition' and labour markets 
were considered to be the greatest constraint on business performance over the past two years (Table 7.6). However, government legislation or regulation was mentioned by a third of all respondents as a constraint and these were cited as the second most important constraint of all the factors mentioned. Of course, this can include anything ranging, for example, from taxation to environmental laws. An examination of the responses found 'Employment laws' to be the most commonly cited followed by 'Health and Safety requirements'.

In the Department of Employment survey conducted 20 years ago (Clifton and Tatton-Brown, 1979) employment legislation was mentioned by only 2 per cent of respondents as the single most important difficulty in running the business over the past year. Even allowing for any methodological variations between the two surveys, it would be fair to deduce that employers are now more conscious of employment regulations than 20 years ago as 'regulatory capture' becomes more widespread. This 'effect' clearly needs further investigation but we would argue that this is a result of the legislation introduced over this 20-year period and particularly since 1997. However, it should be reported in this context that a formal econometric test (logistic regression) of the impact of awareness of IERs on business performance, while holding the other variables reported in Table 7.7 constant, showed no influence on whether a firm reported growth in turnover in the three years prior to the survey (i.e. 1998 to 2001).

Those business owners who stated that employment rights had signific-

Table 7.6 Constraints on business performance over last two years

\begin{tabular}{|c|c|c|c|c|}
\hline & \multicolumn{4}{|c|}{ Per cent/Weighted } \\
\hline & $\begin{array}{l}\text { Any } \\
\text { mention }^{a}\end{array}$ & $\begin{array}{l}\text { Main } \\
\text { factor }\end{array}$ & $N$ & (Unweighted $N$ ) \\
\hline Competition & 50.2 & 33.0 & 538 & $(524)$ \\
\hline Labour markets & 33.9 & 11.1 & 363 & $(465)$ \\
\hline $\begin{array}{l}\text { Government legislation or } \\
\text { regulations }\end{array}$ & 33.3 & 17.0 & 357 & (418) \\
\hline Cash flow/bad debt & 31.3 & 10.7 & 336 & $(319)$ \\
\hline Premises/rent/rates & 31.0 & 12.3 & 332 & (318) \\
\hline Interest rates/cost of finance & 21.2 & 3.3 & 227 & (187) \\
\hline High value sterling & 15.5 & 3.2 & 166 & (194) \\
\hline Access to finance & 9.6 & 1.8 & 103 & $(95)$ \\
\hline Others & 5.4 & 4.2 & 58 & $(60)$ \\
\hline Don't know/no main constraint & - & 3.4 & 32 & $(3.2)$ \\
\hline Total & - & 100.0 & 961 & $(977)$ \\
\hline$N=$ & & & 961 & (977) \\
\hline
\end{tabular}

Source: SBRC IER Survey (2000).

Note

a 'Any mention' is based on a multiple response question. 


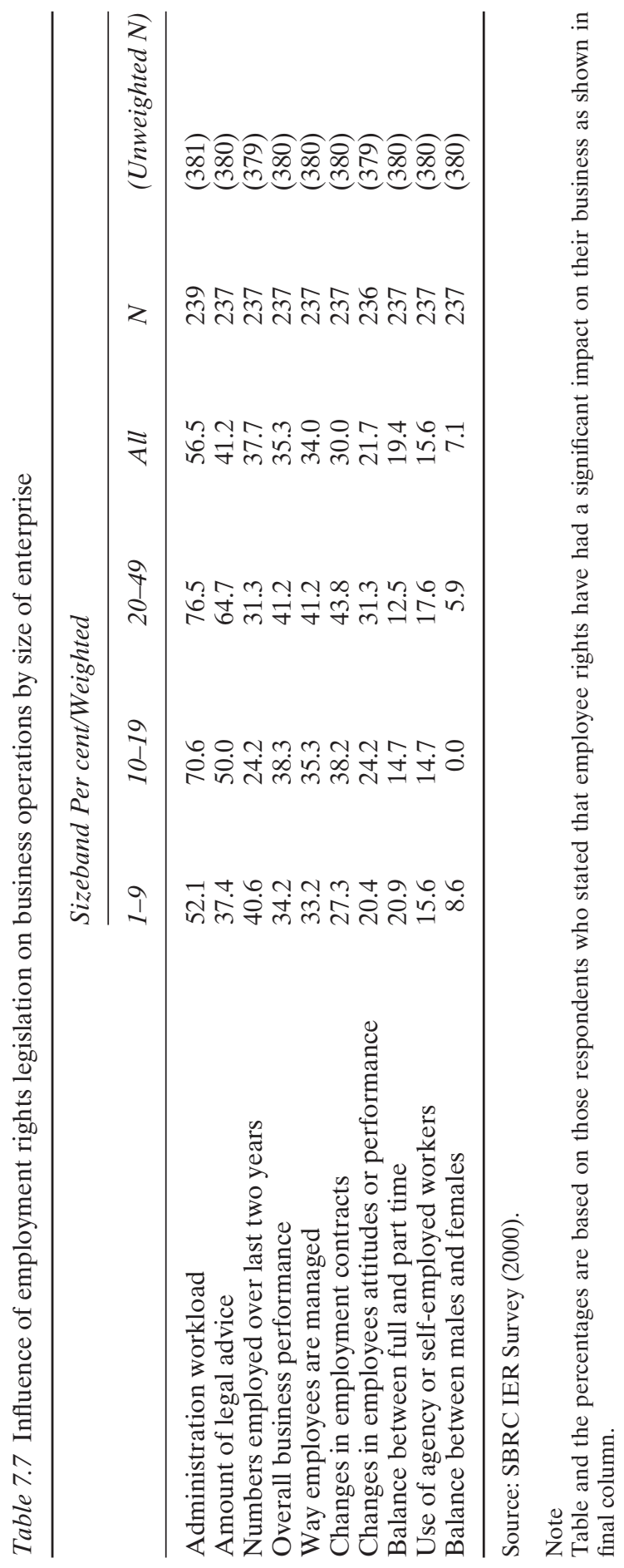


antly affected their business (i.e. a third of the sample) were asked about their impact. The biggest single effect was on 'administrative workload' followed by the 'amount of legal advice' (Table 7.7). There were also important employment and management effects. Adjustments in the numbers employed, or recruited in the past two years, the ways in which employees are managed and changes in employment contracts were all viewed as important changes in business operations by employers as a result of employment rights. It is also apparent that the effects of employment rights on the amount of administration workload and legal advice seeking are higher in the larger firms (Table 7.7) This size effect may be a result of the fact that these firms employ significant numbers of staff and thus their owners are more likely to have to come to terms with effects of employment rights. However, the smaller firms appear more likely to report an impact on the numbers employed and the balance between full and part-time employees. It may be that the perception of employment rights as a constraint on enterprise is deterring some of these micro firms from taking on staff.

This emphasis on a rise in the administrative workload as a result of employment rights should not be surprising. Other surveys have shown this to be the most immediate effect. Similarly, a rise in the amount of legal advice confirms the results of other studies (e.g. Better Regulation Task Force, 2000b: 7-8; Harris, 2000). Few employers report a shift in the balance between male and female employees or a rise in the use of agency or self-employed workers. In other words, they are not making strategic shifts in their labour force composition as consciously, or immediately, as some commentators have suggested. One possible explanation for the emphasis on the rise in administration is that in many cases it is the employer who actually deals with these matters and the immediate impact of IERs may be to actually increase their workload. Given that most employers are antithetical to bureaucracy (see Scase and Goffee, 1987) it is not surprising that this effect is recorded as the highest. ${ }^{4}$

It was anticipated that there would be some variation in the effects of different employment rights in the sample (Table 7.8) with the greatest impact coming from the National Minimum Wage (NMW) (8.2 per cent of the whole sample), followed by basic terms and conditions of employment (7.4 per cent) and then maternity rights ( 6.4 per cent). However, the numbers of employers experiencing negative effects are low overall, and with a strong positive relationship between firm size and perceived impact. On a firm size analysis, it appears that the highest negative scores were in the 20-49 size band and especially in relation to maternity rights, NMW and unfair dismissal. ${ }^{5}$

In this research, strong sector difference and labour force composition effects were expected although, hitherto, there has been little research exploring such aspects. The data confirmed our expectations of an uneven impact as shown in Table 7.8, where the number of negative responses by 


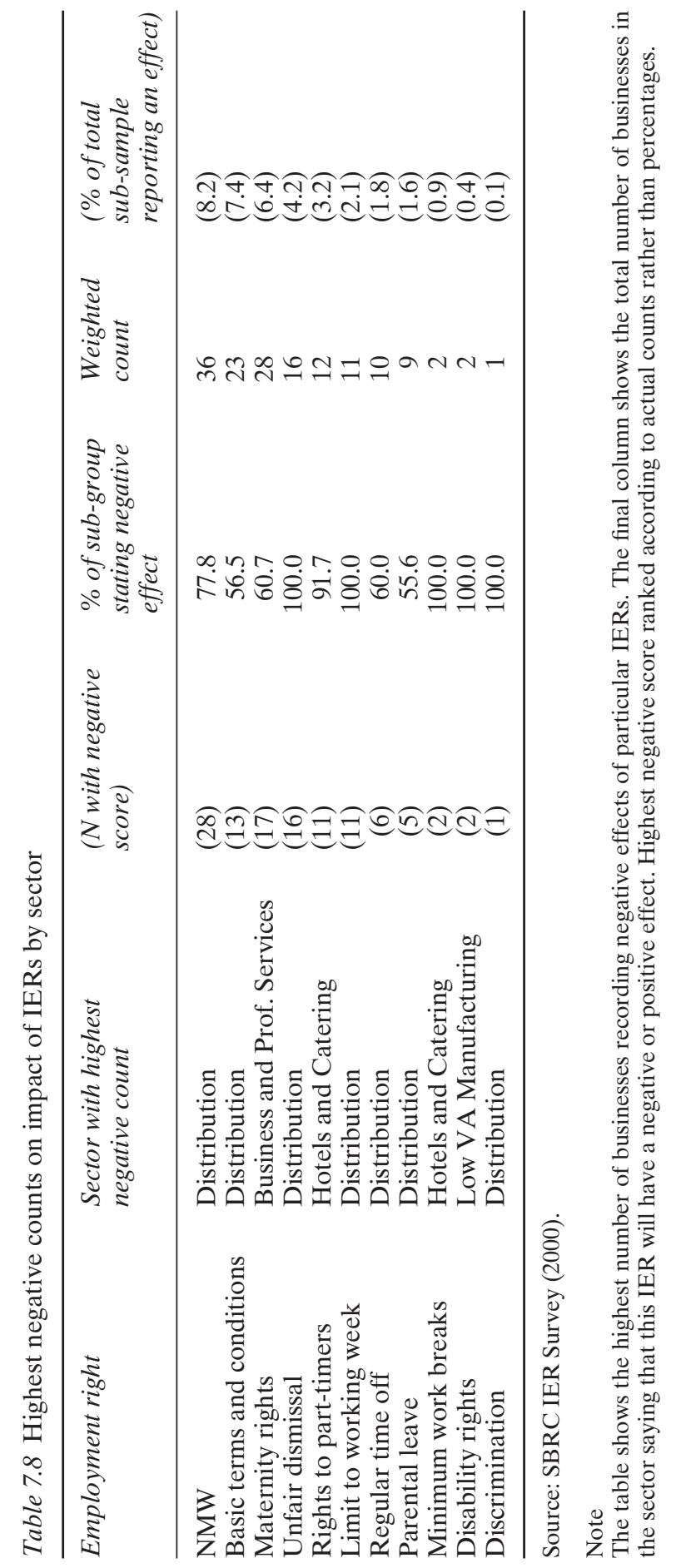


employers are classified by business sector. Employers in Distribution were especially negative about the effects of employment rights (Table 7.8). With those in Hotels and catering most negative about the extension of rights to part-timers reflecting their high dependence upon part-time labour, and minimum work breaks. Employers in Business and professional services recorded the highest number of employers expressing negativity about maternity rights. Although the precise reasons for these patterns in the data can only be covered through further qualitative research, these findings do take us away from making blanket statements regarding the effects of employment rights in small firms.

In order to explore the uneven effects of employment rights further, an analysis of employment rights according to the proportion of females in the labour force is shown in (Table 7.9). Employers with at least 75 per cent of their labour force being female were most likely to record maternity rights and the extension of rights to part-timers as having a perceived negative effect on business performance (Table 7.9). However, employers with no female workers were more likely to record perceived negative effects resulting from basic terms and conditions, limits on the working week and rights to regular time off work: that is IERs with no specific gender target. Again this analysis illuminates the varying effects of employment rights according to enterprise characteristics.

\section{Conclusions}

As the volume and complexity of legislation relating to business expands, employers' representative bodies in the UK have complained increasingly that this creates operational problems, particularly for small firms. In our investigation of the awareness and impact of Individual Employment Rights in the UK a major theme to emerge was the relative buoyancy of the enterprises in terms of turnover and employment. A self-assessment of the constraints on business performance over the past two years revealed competition in markets to be the overwhelming factor. This confirms findings of earlier studies (Clifton and Tatton-Brown, 1979; Scott et al., 1989). In other words, employment legislation was not the overriding factor in business performance. However, there was evidence to suggest that employment legislation was rising in importance as a constraint amongst small firms in the UK. Compared with earlier surveys (e.g. Clifton and Tatton-Brown, 1979; Scott et al., 1989) mention of employment legislation has risen in rank order. Employers were particularly affected by the rise in administration which IERs legislation had created for them.

Few employers provided evidence of a strategic response to the effects of individual employment rights on their enterprise. For example, employers were unlikely to report switches in the composition of their labour force as a result of the introduction of rights for part-timers. Thus, the argument that such rights may create prejudices against certain types of 


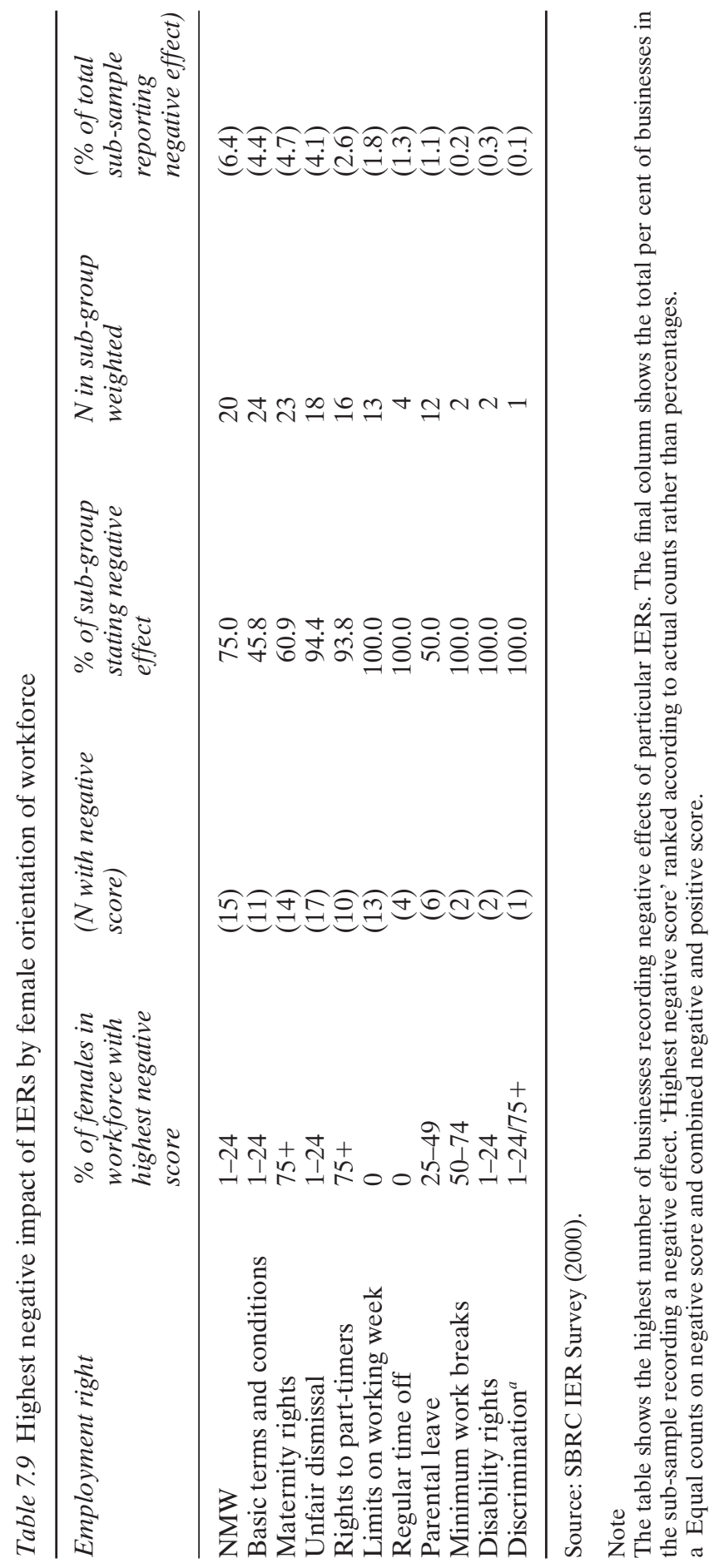


employees, by for example strategic changes in recruitment patterns, were not founded in the sample. Whether or not these fears are totally unfounded, or will take time to emerge, remains to be seen.

Our evidence found that whilst the impact of IERs on the sample was not broad, in the sense of affecting many businesses, they may be affecting specific types of enterprise at risk in terms of their size, sector and employment composition. Smaller firms in the sample were less likely to report negative effects, which fits in with the earlier findings that they were also less aware of the details of employment legislation. Moreover, the survey revealed that different types of IER were affecting different types of enterprise. For example, maternity rights were more likely to affect employers with a high proportion of females and it was these employers who were most likely to record negative effects regarding maternity rights.

The results also reveal a curious, though not illogical, pattern on assessing the effects of IERs. Although the bulk of employers tended to be vague in their knowledge of employment rights, they were prepared to be critical of the effects of this legislation on their enterprise. This suggests that the results of surveys of this kind are influenced by a negative predisposition on the effects of government intervention. Clearly, this predisposition and subsequent perception needs addressing. For example, it could be that these perceptions are rooted in the self-definitions of ownermanagers. Many owner-managers are resistant to external guidance or advice, let alone legislation, and even without knowing the detailed effects many start with a negative disposition. It may also be that perceptions of the effects of IERs on enterprise are also bound up with other government interventions such as taxation. A small number of employers were, however, supportive of the new employment rights recognising that legislation provided guidelines and clarification for them whilst increasing staff morale and security. However, the finding that almost two-thirds of employers did not record a benefit of the effect of IERs on their business does suggest that, overall, there is a very negative outlook such that when employers are 'captured' by legislation, they are more likely to be critical of it.

Methodologically the study poses some questions for other surveys of regulation and the small firm. From the results it appears that the greater the knowledge and experience employers have of employment rights, the more likely they are able to make informed assessments of the effects on their enterprise and that these assessments are more likely to be negative. Whilst we would not go so far as to argue that for the less informed employer, 'ignorance is bliss', it appears to be this group who record fewest negative effects. Undoubtedly, this is closely linked to their management style (Marlow and Strange, 2000). However, given the low levels of awareness recorded by employers on some aspects of recent employment legislation, the sweeping statements regarding the negative effects of employment legislation on small firms, as reported in some surveys, are 
open to question. Instead, it is argued that these responses are often rooted in the negative predisposition employers have on regulation and the constituency of the surveys rather than on direct experiences.

In short, the above analysis from the UK would tend to suggest that the increase in the intensity of the individual employment rights legislation in recent years may not be having the detrimental effect upon business performance as suggested. Further, there is no evidence to indicate that the employability of the more atypical worker, namely the female parttime 'flexible' worker, has been adversely affected. Consequently, one implication to be drawn from these results is that the development of a set of minimum standards in the EU labour market, which seek to safeguard many of the social aspects of the employment contract, does not appear to be an obstacle to the growth of individual SMEs.

However, neither was there any evidence to suggest that such a commitment to minimum standards has delivered greater productivity with very few owner-managers reporting any positive effects of IERs on their business. From this evidence it can be argued that at best the impact of the IER legislation has been neutral for SMEs in general. As a result EU-driven policies designed to eliminate discriminatory wage practices and safeguard traditionally low-paid groups can be introduced into the regulatory framework for the labour market in order to address the twin objectives of economic and social cohesion within the EU without damaging competitiveness and growth. In short, the European Commission's twin objectives of competitiveness and employability may not be at odds with an increase in the regulatory framework governing employment relations and employment rights across the EU.

However, more recent comparative evidence from the Lloyds TSB/SBRC (2001) European Survey of SMEs carried out in 2002 would suggest that this conclusion is perhaps too optimistic. The first point to note is that owner-managers of SMEs in the UK, France and Germany regard the balance of IER legislation to be in favour of the employee (Lloyds TSB/SBRC, 2003). Probing further on the impact of this legislation on the recruitment process, this sample of owner-managers viewed the impact of IER legislation as a burden with the French and Germans more inclined to report this view. Almost three-quarters of French and one-half of German owner-managers view the impact of the IER legislation as a constraint to employing new staff compared with two-fifths of UK owner-managers. Indeed, SMEs in France were significantly less likely to employ part-time workers than SMEs in Germany and the UK, which may reflect a very pragmatic solution on the part of French owner-managers to ensure that they do not fall within the 'footprint' of certain parts of the legislation.

While in France and Germany there was no significant difference in the results by size of firm, in the UK it was the owner-managers of larger SMEs (employing 50 or more workers) who were more likely to report 
that the IER legislation was a constraint on their ability to recruit workers. This reinforced the point made earlier from the DTI study and suggests that very small firms do not report effects (either negative or positive) because they are not aware of many aspects of the legislation. Overall, therefore, there are clear differences between the three EU Member States in this study which reflect the pace, and more importantly the intensity, of the adoption of EU directives concerning the regulation of the labour market. What emerges is that the regulatory framework for the labour market in the UK is perceived as being relatively more benign for SMEs than in France and Germany.

This then leads on to a final question which concerns the type of regulatory model for the labour market that is appropriate to achieve the objectives of competitiveness and employability within the EU, whilst adhering to the principles of economic and social cohesion. From the evidence presented above it is possible to conclude that the model currently in place in the UK may be working relatively more efficiently than those observed in France and Germany. The implementation of the 35-hour working week in France and the long-established family-friendly work environment in Germany, appear to be creating difficulties for the small business sector. The temptation, therefore, in both France and Germany is to seek to relax many aspects of the current labour market legislation and to move towards adopting the 'UK model'. However, there is, of course, a macroeconomic context to these cross-country comparisons with Germany and France at different stages of the economic cycle than the UK. The guiding principle at the core of EU social policy, which operates on the assumption that the labour market is as much a social construction as an economic one, must not, therefore, be sacrificed under the pressure of political expediency in the two major economies of the EU 15 as they seek to resolve their respective economic crises.

\section{Acknowledgements}

We would like to acknowledge the contribution of the EMARS team within the DTI to the original research study on which some of this analysis is based. We would also like to acknowledge the support of Lloyds TSB for the European Small Business Survey. The views expressed in this chapter remain those of the authors.

\section{Notes}

1 In July 2001 it was reported that only one small firm in 30 in the Provence Alpes Cotes d'Azur (PACA) region in France had introduced a 35-hour working week.

2 Only women with 2 years service and working for at least 16 hours a week (or 5 years if working less than 16 hours) qualified.

3 Hogarth et al. (2001) reported that only a modest proportion of employers 
where aware of the changes in maternity leave and parental leave regulations introduced in 1999. However, this survey was in workplaces employing five or more employees. Callender et al. (1999) provide a more detailed, though now dated, analysis. The DTI Employers' Survey on Support for Working Parents, recently conducted for the Work and Parents Review, provides more up-to-date material although is unfortunately restricted to firms with five or more employees.

4 Although the overwhelming bulk of research has reported negative views by employers on the effects of employment rights on their business performance, a minority in our survey perceived some positive effects. One in five employers stated that legislation provided them with guidelines and clarification in setting the conditions for their workers. Almost 10 per cent of employers stated that IERs raised staff morale and engendered a feeling of security.

5 The positive relationship between the size of firm and negative effects is confirmed elsewhere (Small Business Service, 2001:63-5). These results will be presented elsewhere but in this paper we wish to focus on differences between firms in different sectors.

\section{References}

Addison, J. T. and Seibert, W. S. (1979) The Market for Labor: An Analytical Treatment, California: Goodyear Publishing.

Better Regulation Task Force (2000a) Helping Small Firms Cope with Regulation Exemptions and Other Approaches, April, London: Cabinet Office.

Better Regulation Task Force (2000b) Annual Report 1999-2000, London: Cabinet Office.

Bosch, G. and Lehndorff, S. (2001) 'Working-time reduction and employment experiences in Europe and economic policy recommendations', Cambridge Journal of Economics, 25:209-43.

British Chambers of Commerce (1999) BCC Call to Compensate Small Firms on Parental Leave, Press Release, 21 July, London: BCC.

Callendar, C., Millward, N., Lissenburgh, S. and Forth, J. (1999) Maternity Rights and Benefits in Britain, 1996, DSS Research Report, No. 67, London, Stationery Office.

Clifton, R. and Tatton-Brown, C. (1979) Impact of Employment Legislation on Small Firms, Research Paper No. 6, London: Department of Employment.

Commission of the European Communities (2000) Industrial Relations in Europe 2000, COM 113 Final.

Daily Telegraph (2000) 'No hiding place from the law as parents win their rights', 15 May, p. 29.

Department of Trade and Industry (2000) 'Employment Legislation' Individual Rights of Employees; A Guide for Employers and Employees - PL 716 (Rev 7), April, London: DTI.

Employment Gazette (1979) 'The impact of employment legislation on small firms', Department of Employment Gazette, July, 652-5.

European Industrial Relations Observatory (EIRO) (2001) 'Annual review of industrial relations in Europe 2001'. http//www.eiro.eurofound.ie.

Financial Times (2001) 'Unravelling red tape: businesses are caught in a regulatory bind', 29 January, p. 18.

Forum of Private Business (2000) '58th Quarterly Survey of Small Business', The Forum of Private Business, Knutsford, September. 
Harris, L. (2000) 'Employment regulation and owner-managers in small firms: seeking support and guidance', Journal of Small Business and Enterprise Development, 7(4):352-62.

Hogarth, T., Hasluck, C., Pierre, G. with Winterbotham, M. and Vivian, D. (2001) 'Work-life balance 2000: results from the baseline study', Department for Education and Employment Research Brief, No. 249, London: DfEE.

ICAEW (2000) Smaller Businesses and Regulation, Research Report, Milton Keynes: ICAEW.

IRS (2000) 'Working Time 2000', IRS Employment Trends, 696:5-20.

Lloyds TSB/Small Business Research Centre (2003) European Small Business Survey: 2002, Kingston University.

Lloyds TSB/Small Business Research Trust (2001) Quarterly Small Business Management Report, Government and Regulations, 8(4), The Small Business Research Trust, Milton Keynes: Open University.

Low Pay Commission (2000) The National Minimum Wage, Cmnd 4571, London: Stationery Office.

Marimon, R. and Zilibotti, F. (2000) 'Employment and distributional effects of restricting working time', European Economic Review, 44:1291-326.

Marlow, S. and Strange, A. (2000) 'Regulating labour management: the effect of the Employment Relations Act upon small firms', Paper presented to the 23rd ISBA Conference, Aberdeen, November.

Marlow, S. (2002) 'Regulating labour management in small firms', Human Resource Management, 12(3):25-43.

McKay, S. (2001) 'Between flexibility and regulation: rights, equality and protection at work', British Journal of Industrial Relations, 39(2):285-303.

NatWest SBRT Survey (2000) NatWest SBRT Quarterly Survey of Small Businesses in Britain, 16(3), The Small Business Research Trust, Milton Keynes: Open University.

OECD (1998) Employment Outlook, Paris: OECD.

Rubery, J., Smith, M. and Fagan, C. (1999) Women's Employment in Europe: Trends and Prospects, London: Routledge.

Scase, R. and Goffee, R. (1987) The Real World of the Small Business Owner, 2nd edn, London: Routledge.

Scott, M., Roberts, I., Holroyd, G. and Sawbridge, D. (1989) 'Management and industrial relations in small firms', Research paper No. 70, London: Department of Employment.

Small Business Service (2001) Business Support Needs: Quantitative Research Findings Final Report, MORI Social Research for the SBS, January, Sheffield: SBS.

Solow, R. (1990) The Labour Market as a Social Institution, Oxford: Blackwell.

Stanworth, J. and Gray, C. (1991) Bolton 20 Years On, London: Paul Chapman Publishing.

Van de Horst, R., Nijsen, A. and Gulhan, S. (2000) 'Regulatory policies and their impact on SMEs in Europe: the case of administrative burdens', in Sexton, D. and Landstrom, H. (eds) The Blackwell Handbook of Entrepreneurship, Oxford: Blackwell.

Westrip, A. (1982) 'Effects of employment legislation on small firms', in Watkins, D., Stanworth, J. and Westrip, A. (eds) Stimulating Small Firms, Aldershot: Gower. 


\title{
8 Small firms and the National Minimum Wage
}

\author{
Jim Arrowsmith and Mark Gilman
}

\section{Introduction}

The Low Pay Commission (LPC) was established in July 1997 to recommend the level of a new statutory national minimum wage. This was arguably the most symbolic act of a Labour government elected, for the first time for a generation, just months before. It signalled the end of almost two decades in which labour market 'deregulation' and 'flexibility' were the primary watch-words of employment policy. In particular, the Conservative administrations of the 1980s and 1990s had been keen to distance the state from private-sector pay-setting. The Fair Wages Resolution was rescinded in 1983. For almost a century it required companies working on government contracts to observe terms and conditions of employment not less favourable than those in relevant collective agreements. A decade later the Wages Councils, first established in 1909 to set minimum pay rates and conditions for workers in certain low-paying sectors, were eventually abolished after successive restrictions in the 1980s. In this context the introduction of the NMW, alongside a raft of other significant measures (see McKay, 2001), made a clear statement that 'fairness' was a legitimate consideration underpinning the future direction of employment regulation.

The importance of this to small firms was considerable, since in many sectors rates of pay tend to be lower than those offered by large organisations (McNabb and Whitfield, 2000). Given this, and perhaps mindful of the Thatcherite legacy of 'entrepreneurialism', the case for the NMW was made on the dual grounds of fairness and efficiency. The efficiency case was well summarised in the first report of the LPC which quoted the British Chambers of Commerce view that 'a low wage policy leads to a vicious circle of low morale, low performance and low productivity', and argued that an NMW 'has the potential to encourage competitiveness based on a better skilled workforce and better quality products and services' (LPC, 1998:17). For this to occur, however, the NMW must amount to a fairly substantial 'regulatory shock'. In this chapter we assess the nature of this 'shock' on small firms in particular, based on a longitudinal 
research project conducted under the ESRC's Future of Work programme.

\section{The NMW as a 'regulatory shock' to small firms: theoretical and methodological issues}

Small firms share one obvious characteristic - their size. This underwrites two universal views of employment conditions in small firms. The first may be characterised as 'small is beautiful', and was popularised by the report of the Bolton Committee in 1971. This rests on the observation of a close physical proximity between manager and workers, so promoting a mutual 'give and take' that undermines collective organisation and conflict. Wages might be lower than in large firms, but workers willingly concede this in return for a more congenial work environment. More recently, small businesses have been seen as representing 'the ideal site for the development of a HRM approach' because of the possibility of direct communications, the directly observable contribution of each employee to organisational performance, and the more immediate ability of the owner-manager (OM) to envisage and bring about change (Bacon et al., 1996:98). One implication is that there is little pressure from employees in small firms for higher pay, especially if this would result in an elimination of either the 'slack' or 'responsiveness' in terms of patterns of supervision, work organisation or working time that they might currently enjoy.

An opposing view is that employment in small firms is likely to be harsh as a result of exposure to more competitive markets and dependence on large firms as customers (Rainnie, 1989). In some ways this resembles the atomised 'price-taking' model of firms in the tradition of neoclassical economics. Small firms not only operate in highly competitive markets, but they are incapable of influencing their environments. As such, wages might be expected to be relatively low, and the firm much more vulnerable to regulatory shocks. Orthodox economic theory predicts that regulatory interference that raises the cost of labour above market equilibrium will lead to unemployment (Bazen, 1990; Edwards and Gilman, 1999). Profitability would be adversely affected, jobs would go, and some rational actors would seek to escape regulation by resorting to illegal practices. As Milton Friedman once put it, 'minimum wage laws are about as clear a case as one can find of a measure the effects of which are precisely the opposite of those intended by the men of good will who support it' (quoted in Hirschmann, 1991:27-8).

In contrast, the institutionalist analysis of employment rejects the assumptions of neoclassical analysis as flawed. From Commons (1909) to Williamson $(1975,1985)$ institutionalists have analysed the firm not as an anonymous 'black box' but as hierarchical organisations with labour contracts that are inherently ambiguous. Notions of power and authority, efficiency wages and transaction costs have been used in institutional analysis 
to justify outside intervention to raise the 'plane of competition' (Kaufman, 1998). In other words, regulation such as a minimum wage can have positive 'efficiency' as well as 'fairness' effects in terms of eliciting, motivating and retaining labour. Though institutional analysis has been applied mainly to large firms, empirical research in small organisations shows that the relevant forces are also at work here, subject to the contingencies of product and labour market context (see e.g. Curran and Stanworth, 1981; Scott et al., 1989; Goss, 1991; Kitching, 1997). Small firms are rooted in an 'industrial subculture' shaped by factors such as the nature of the product or service itself (capital requirements; quality or quantity; high or low value-added etc.); the patterns of demand and structure of competition; the skills requirements for labour; and the structure of labour supply and patterns of engagement, including segmentation by ethnicity, sex or age (Curran and Stanworth, 1981). Employment in small firms remains a contested terrain, if one conducted less overtly than in larger organisations, which varies according to product and labour-market circumstances (Ram, 1994; Holliday, 1995; Moule, 1998). The effects of the introduction of the NMW were, therefore, likely to be indeterminate, shaped by both the universalistic features of size and the contingencies of sector and firm factors.

The NMW was introduced from April 1999 with a minimum adult hourly rate of pay of $£ 3.60$ (subsequently revised to $£ 3.70$ from October 2000, £4.10 from October 2001 and $£ 4.20$ from October 2002) and a lower youth rate for workers aged 18 to 21 inclusive of $£ 3.00$ ( $£ 3.20$ from October 2000, $£ 3.50$ from October 2001 and $£ 3.60$ from October 2002). Though the initial rate was commonly perceived to be set at the lower end of expectations, the LPC found that around 1.3 million workers received higher earnings as a result (LPC, 2001:18). The LPC also concluded that, on the whole and against the background of a strong economy, the impact on prices, jobs and competitiveness was relatively benign (LPC, 2001:101). However, as the LPC concedes, such whole economy analysis 'tell(s) us little about the processes of employer and employee reactions, which will require additional research' (LPC, 1999:29). These processes of adjustment, and their outcomes, include knock-on effects due to the restoration of pay differentials; substitution between groups in the labour market; adjustment to increased costs through changes to prices, employment levels, hours, pay structures, training, work organisation or profits; and avoidance or evasion strategies (ibid.). These were the issues that formed the basis of the research in two of the sectors most affected by the introduction of the NMW, clothing manufacturing and hotels and catering services.

Much previous research into small firms is based on individual case studies and does not examine change over time, which is important when considering the impact of new regulations. To capture this, research needs a longitudinal and comparative dimension, firmly rooted in appreciation of 
sector as well as size (Wilkinson, 1999:214). It is also important to capture an employee as well as employer view of the firm. As Scase (1995:569) remarks in reviewing the growing field of research in small firms, there remains 'a need for further detailed comparative research that will enable us to understand more adequately the diversity of employers' strategies and how these, within different contexts, are negotiated with employees to determine varying patterns of accommodation'. In examining patterns of adjustment to the NMW, two sectors were chosen, clothing manufacture and hotels and catering. The sectors, one manufacturing and one service, were selected because they are dominated by small firms and have a concentration of low pay (Bazen, 1990), but they also have different characteristics. Clothing, together with textiles, remains the ninth largest manufacturing sector in the UK, but unfavourable exchange rates and the phasing out of the protectionist Multi Fibre Agreement mean that it is officially acknowledged to be "currently facing the greatest challenges in its history' (TCSG, 2000:5). It also faces recruitment problems owing to a dependence on ethnic minority labour and 'the widely held perception that (it) is in decline, that it does not offer good career prospects and that it is poorly paid' (ibid.:26). Though fairly diverse, hotel and catering depends heavily on young and female part-time employees. The work is generally low skilled, often with relatively high levels of labour turnover. Product market problems are less acute than in clothing, though many small catering and hotel businesses face increasing competition from the 'big chains' (Lucas, 1995).

It is well known that research access to small firms is difficult (Scase, 1995:580). Managers are time-pressured because of multiple responsibilities, and are often unfamiliar with academic research. However, at the outset, publicity and concern about the NMW was at its peak. The NMW was an issue of immediate relevance and interest to small firms (Blackburn and Hart, 2002). We also used a wide range of contacts to find a range of firms to approach, including 15 business and trade associations, local councils, trade unions, banks and low pay organisations. The cases were selected to provide a range of possible circumstances rather than any statistical notion of representativeness, a form of 'theoretical sampling' (Eisenhardt, 1989:537) which is often used to minimise bias in exploratory research. The objective was to capture the rich insights into the dynamics of employment relations provided by a case study approach, but also address broader issues about paths of adjustment across a range of small firm types. It is for this reason that mixed research designs are gaining popularity in small firms research (Curran and Blackburn, 2001). The research approach involved semi-structured interviews of owner-managers and an employee in each firm prior to the introduction of the NMW, with repeat management interviews a year later. Median employment was 27 in clothing and 16 in hotel and catering. In all, 55 firms were visited, 27 in clothing and 28 in hotel and catering. 
A framework for identifying different types of regulatory effect has been provided by Hirschmann (1991), ${ }^{1}$ who points out that critics of regulation commonly allege three main negative effects. The first is perversity, that intervention exacerbates the problem under consideration. The second is futility, that the intervention makes no difference. The third refers to jeopardy, that regulation imperils other desirable states. In the case of the NMW, this might occur through increased costs, including the likely restoration of pay differentials, which would lead to unemployment and encourage working 'off the books'. Each of the three criticisms marks a strong contrast to the fairness and efficiency case advocated by the supporters of the NMW. In the following section we review some of the empirical findings of the study into the impact of the NMW on small firms. We then discuss the implications in terms of a revised form of Hirschmann's model.

\section{The impact of the NMW}

Our first round of visits found that pay in the small firms was largely opaque, individualised and unstructured. Pay setting was imprecise, with many owner-managers finding it difficult to juggle competitive pressures and employee performance. Only one company in each of the hotel and catering $(\mathrm{H} \& \mathrm{C})$ and clothing sectors was able to say that they had a formal pay scheme. Levels of pay often varied for different individuals, especially with the use of ad hoc bonuses which were usually exercised solely at the discretion of the employer. Two-thirds of companies said that there was a variation in the pay of employees carrying out the same work. Furthermore, half of the $\mathrm{H} \& \mathrm{C}$ firms and 56 per cent of clothing firms reported having no annual mechanism of pay review, and 57 per cent and 35 per cent, respectively, said that the level of any pay award would probably vary amongst employees. Employers also had very limited market information to inform any decision about increasing rates. Eleven per cent of employers in $\mathrm{H} \& \mathrm{C}$ and 7 per cent in clothing reportedly used no external sources of information about what other employers were paying, and for the rest methods were largely informal and unsystematic, relying heavily on 'word of mouth'.

Not surprisingly perhaps, 37 per cent of the employees interviewed in $\mathrm{H} \& \mathrm{C}$ and 52 per cent in clothing thought that pay increases were awarded unfairly in their firm. Over three-quarters of employees said that it was the employer unilaterally who decides how much they are paid. Furthermore, two-thirds of employees said that pay is not discussed among employees in the company. This was not only because it was frowned upon by the employer, but also because employees did not wish to divulge their earnings to other employees. Yet, as we shall see, this apparent arbitrariness and secrecy over pay, which risked sending messages of unfairness to employees, also lent employers the informal scope to adjust to the introduction of the 
NMW without impacting on employees not directly affected. In the first round of visits, immediately prior to the introduction of the NMW in the first quarter of 1999, all but eight of the $28 \mathrm{H} \& \mathrm{C}$ firms reported having employees paid under the forthcoming NMW adult hourly rate of $£ 3.60$. The average number of directly affected employees per organisation was three. In clothing, around half the firms had such low-paid workers, though some of these interviews took place just after the introduction of the NMW, and may thus reflect adjustments that had already been made. Just over a quarter ( 27 per cent) of H\&C companies and 42 per cent of the clothing firms had made changes to their pay system in anticipation of the NMW. Of the employees interviewed, 85 per cent of those in clothing and 74 per cent of $\mathrm{H} \& \mathrm{C}$ workers were aware of the NMW, and over half (58 per cent) of the former and a quarter (26 per cent) of the latter said they would personally be affected. Nearly three-quarters ( 73 per cent) of clothing workers and two in five ( 41 per cent) in $\mathrm{H} \& \mathrm{C}$ said that they expected the pay of themselves or someone else within the company to rise as a result of the NMW. In all, 18 firms reported that their lowest permanent pay was below $£ 3.60$ an hour, with a further 21 paying exactly $£ 3.60$, suggesting the rapid effect of a 'pay spike' at the minimum rate (Card and Krueger, 1995).

A significant proportion of employers expected the NMW to have at least some impact on costs - 13 per cent 'a lot' and 55 per cent 'a little' and they anticipated making a number of changes in response. For example a third (32 per cent) of the $\mathrm{H} \& \mathrm{C}$ companies and half in clothing said that they had introduced, or expected to introduce, new technology or practices designed to cut down on the cost of labour. In $\mathrm{H} \& \mathrm{C}$ new kitchen equipment or the buying in of pre-prepared foods were the most common responses, whereas in clothing it was investment in new machines, subject to available capital. Around a quarter of clothing firms expected to increase the use of sub-contracting at least partly as a result of the NMW. However, 21 per cent of $\mathrm{H} \& \mathrm{C}$ firms and 31 per cent in clothing said they felt able to pass on any cost increases through prices.

Employees were also asked whether they expected any changes as a response to their employers having to pay the NMW. In H\&C employees generally foresaw few likely changes although 28 per cent did say that they thought their employer would want more effort from them and 16 per cent said their employer would consider changes to work practices. In clothing 60 per cent of employees thought that the employer would seek to increase effort, 40 per cent changes to work practices and 28 per cent revisions to hours of work. A significant number of employees, therefore, especially in clothing, anticipated compensating changes in terms of the wage-effort bargain. However, employees also tended to report that they were already working hard and subject to tight discipline, suggesting limited space for adjustment.

In the return visits a year later, a range of adaptation was observed 
reflecting different business conditions and management practice. In clothing, a deteriorating business context meant that virtually all the firms were worse off than a year before. A few had closed and employment levels were reduced in many of the rest. This was blamed primarily on deteriorating market conditions, though the NMW was sometimes reported to have significantly increased costs. In hotel and catering, developments were more varied, reflecting greater diversity of activities and circumstances and the general picture was also less dramatic. Overall, there were three broad sets of response to the combined effects of deteriorating business conditions and the implementation of the minimum wage, which we label as 'implement', 'ignore' and 'critical event'. In the first group, comprising the majority of firms in the two sectors, implementation was generally unproblematic. The second group refers to the small number that moved into producing illegitimate goods and/or employing (some) workers 'off the books'. The third group, also small, looked to reposition themselves in the market or otherwise used the occasion of the NMW to revise existing arrangements.

\section{Implement}

Most hotel and catering firms implemented the NMW without any major difficulties, for three main reasons. First, pay was usually already around or above the level of the NMW for the majority of employees, making it easier to absorb. The number of employees paid under the NMW was usually a minority, and the fact that employees were often unaware of the dispersion in pay within the firm meant that the resultant increase did not have knock-on effects. Second, many owner-managers pointed out that there were far fewer options in small firms to offset the implementation of the NMW by introducing new technology or changes to working practices, especially in the labour-intensive service sector where most jobs involved routine tasks. Often, there was also limited scope to intensify the work to compensate for increased costs. Third, many owner-managers did not necessarily see pay as the key factor in the retention or motivation of staff. Some owner-managers admitted that low pay did make it difficult to find good staff but that qualitative factors such as a 'relaxed atmosphere', job security (including retaining workers at slack times), benefits such as meals and breaks and flexibility over working time were more important to staff retention. Their response was therefore to increase pay only to the legal minimum for those individuals affected.

In clothing, business conditions tended to be harsher, and implementation was often associated with some rationalisation. The NMW was a particular complication for firms that used piecework, prompting most to abandon it (see below). The impact of the NMW was generally less harsh in the firms that used day-rate pay systems, especially as it was set at a relatively low initial rate. Family and ethnic ties often provided a 'captured' 
labour force reluctant to move elsewhere (especially in the case of older women workers), but skilled machinists often expected to obtain pay above what they could get for alternative labour such as shop work. Rates had, therefore, been moving towards $£ 3.60$ for some time. As one ownermanager put it, 'it has not really affected us because we paid nearly the same, just 10 or 15p [less]'. In this firm employment fell over the course of the year but this was attributed less to the NMW than to lower demand and more competition from 'garages' (operators from domestic premises). Another firm, which had cut back by closing one of the two businesses at its site, blamed its hardships primarily on imports but also said that the NMW had a final effect by increasing costs and reducing pay flexibility: 'in the past when competition increased and prices reduced we could have asked workers to have less pay but we can't now, it's illegal'.

\section{Ignore}

The temptation to indulge in illegal practices was a real one, but apparently not seriously considered by most firms. Deliberate flouting of the NMW was found in only a few cases, although it may be quite common in relatively down-market operations where employees are often routinely paid on a 'cash in hand' basis (Ram et al., 2001a). The following cases can be taken as illustrative. In the first, a restaurant, the owner-manager said he was aware of the NMW but that most workers did not get it. Instead, they received $£ 15$ per shift which, if it did not surpass its scheduled five hours, worked out at $£ 3$ per hour 'cash in hand'. The owner-manager claimed that he would then 'gross it up' by paying any tax and national insurance. The workers confirmed that they picked up less than the NMW and their view of this was highly dependent on personal circumstances, what they perceived the owner was like to work for and relations with other workers and customers.

In another ethnic minority restaurant, in response to the question 'how many people do you employ?' The owner-manager replied 'do you want the official figure or the unofficial one?' Shift rates varied for employees (e.g. $£ 18, £ 20$ or $£ 25$ a night). The mechanism for reviewing pay was also very informal, helped by staff keeping information on their earnings to themselves. Pay increases were not considered by the employer unless demanded, and even then usually resisted with personal appeals and reference to the 'relaxed' work environment enjoyed by staff. In practice this meant treating staff courteously, extending them some self-regulation of activities, providing fringe benefits such as free food and transport, and flexibility over working time including keeping jobs open for staff when they made a return to the Indian sub-continent. In a third case, a clothing firm that ceased trading during the course of the research, the employment of home-workers on a cash-in-hand basis was a regular practice well before the NMW. For on-site workers, pay was based on a piece-rate that fell some way short of the NMW. The opportunity to exploit dependent 
ethnic networks reinforced the firm's position at the bottom end of the market. When this began to collapse the owner-manager experimented for a time with manufacturing 'dodgy stuff' (fake designer-label products) but still could not find enough work. The business could not compete with the fully 'underground factories', i.e. 'factories that don't exist on paper'. With the rewards dwindling, the complexity and risk of evading the new legal minimum wage was too high, and closure was the end result.

\section{Critical event}

In contrast, some clothing firms were able to respond to the pressures of deteriorating business and the NMW by making a shift to specific niche markets. In most firms the prospect of such a shift was impeded by inadequate access to capital on the one hand and a shortage of skilled staff on the other. The ability of the owner-manager is also a critical consideration in the performance of small firms, particularly if they are to shift to a higher wage-skill equilibrium through improved productivity (Mole, 2002). In one firm the owners response was to reposition the firm away from volume work to the high quality end of the market where import penetration was much lower because orders were small and customised. The transition involved significant job losses (16 staff) and substantial training investment in the remaining workforce. In order to retain staff against competition outside the sector as well as from within, minimum pay rates were pegged above the NMW at $£ 4$ per hour. In another clothing firm the owner-manager told us how they:

changed from wholesale to the corporate wear market because this is better quality and selling prices are better.... Before, say a year ago or more, this was just five per cent [of our business], then we were forced to go up-market ... The $£ 3.60$ was the major factor in the change though we were looking at it already, it was the spark to make greater efforts as soon as it came in place.

However, the shift to more profitable lines was not wholly smooth. Labour costs increased because of the NMW and variation in employee performance remained a thorny issue. This was dealt with mainly by the better performers 'balancing out' or effectively subsidising the slower workers, with some absorption of the cost increase through higher prices. At first, some efforts were made to claw back the cost increase of the NMW. However, this led to an employment tribunal case for unfair dismissal when a worker was sacked for protesting over the withdrawal of breaks. This made the owners wary of upsetting the workforce and ultimately led to important procedural change.

Many clothing firms found that implementation of the NMW was complicated by their use of piecework payment systems. As noted above, 
most firms used a mix of hourly pay and payment by results prior to the NMW, but almost all decided to switch to wholly day-rate payment in its aftermath. This was because of practical problems in reconciling average piece wages to the NMW rate but, again, the change was not solely due to the NMW. Piecework had been under general pressure for some time because of increasing variability in the volume, style and delivery requirements of customers. It was also reported that the large retail chains disapproved of piecework because of the implications for quality. However, owner-managers commonly complained that abandoning piecework, which was often blamed at least rhetorically on the NMW, led to falling productivity. Closer monitoring was, therefore, a common theme. Two businesses actually moved to new premises partly to ease supervision. In one of the firms, where the NMW increased the wage bill by around 7 per cent, the owner-manager stated that

recording and monitoring is much better in the new factory ... it [also] gives a good impression to get the work for Arcadia ... it is a good environment and facilities to keep the workers too ... we are trying hard to keep hold what staff we've got - the young generation is just not interested.

Some hotel and catering firms also asserted that the NMW provoked a rethink on pay, and not just because of the impact on costs. The manager of one of the larger firms, with several shopping-centre restaurants, explained:

I think the minimum wage and working time regulations have focused our attention on this [pay and working time arrangements] a bit more - which is an indictment of ourselves that we needed this to prompt us! When you are small you do a lot of things by the seat of your pants, there is no vast structure with people specialising [in HR].

The level of the NMW, just below established rates, brought home that pay might not be as competitive as previously thought. As a result, two new higher pay bands of $£ 4.00$ and $£ 4.20$ were introduced, linked to skills development. Crucially, the business was starting to perform particularly well, which justified the increase in costs. A similar situation prompted another independent shopping-centre restaurant to re-evaluate their pay system in the light of the NMW. Rates were increased to the NMW shortly before its introduction and subsequently by another 15p per hour in recognition of increased sales due to a new metro station opening nearby. The owner-manager said that the NMW also prompted the idea, and provided the opportunity, to introduce standardised pay rates to promote teamwork. Instead of individual variation, all staff were paid the same apart from the head chef and a cook on a higher rate. 
Occasionally, a review of pay systems reflected a more substantial NMW impact on costs. In one hotel, where some workers' pay had not increased for five years, the NMW was estimated to have taken $£ 40,000$ off annual profits. This stimulated a wider review of the pay system, including the introduction of merit pay and a grade review to encourage "multiskilling'. Formal training under department heads was extended in pursuit of Investors in People accreditation, linked to the hotel's plan to expand into the conference market. A mix of market re-evaluation, training and work intensification therefore followed in the wake of the NMW: "now we expect everyone to work twice as hard - multi-skilling. That is just the way of life now. The NMW really made the industry look at itself in a big way'.

The NMW, therefore, prompted other changes apart from pay. One cafe owner/caterer said that the introduction of the NMW encouraged him to readjust the demographic mix of staff and their contracted hours by switching from part-time school-leavers to full-time mature workers. The idea had been under consideration for some time, partly because he had run into difficulties with the authorities over the employment of minors in the kitchen, and partly because of problems of turnover and time discipline. However, the increase in wages required by the NMW allowed him to recruit better from older age groups whom he considered more reliable. Pay increased by $35 \mathrm{p}$ an hour to $£ 3.70$, reflecting a perceived need to differentiate basic pay from the bare legal minimum. In the end, therefore, the NMW was not viewed in hostile terms.

\section{Discussion and conclusions}

The above findings highlight that firms enjoy a range of indeterminacy in the setting of pay. Pay levels reflects not only economic, product and labour market factors but also the informality of internal pay structures. It is this range of indeterminacy, as well as the initially low rate of the NMW itself, which explains both the generally benign overall impact and variations in the patterns of response.

The NMW was widely expected, by opponents and proponents alike, to have significant impacts on employment outcomes in small firms, in terms of the processes of employee relations and substantively in terms of pay, hours and numbers of workers employed. This could occur because of effects on 'top-down' or 'bottom-up' expectations and behaviours. Topdown pressures refer to the increase in costs experienced by many small firms, and employers' possible range of response, from simply absorbing the cost increase to changes in the capital-labour ratio and other forms of work reorganisation. They also refer to the administration requirements of the regulations, which might have stimulated employers to modernise their systems of record keeping and possibly encourage them to introduce more systematic means of employee performance monitoring and appraisal. Bottom-up pressures refer to workers using new employment rights as a 
lever in their formal or informal negotiations with management. In the event, both sets of pressures were weak, leading to a varied pattern of response much dependent on the existing business context and management plans.

It could be argued that this was because the regulations themselves did not provide a sufficient shock to jolt employers or workers out of their customary practices and habits of employment relations. On the whole, this argument has some validity, but it is insufficient in two ways. First, the cost implications of the regulations, especially the NMW, were significant for many of the small firms in our research, particularly in the clothing sector, but also for many hotel and catering firms as well. And it was not always those firms most affected by cost hikes that chose to respond by introducing wider change. A range of responses was observed and these have to be explained in different ways. Second, the 'weak regulations' argument does not tell us much about the process of how and why firms did respond, even if in many cases this response was simply to try to observe as much continuity as possible. Stability reflected a recognition of mutual dependence and a reciprocity built on accommodation and notions of 'fairness' often underpinned by a segmentation of the labour force by ethnicity and sex.

Top-down pressure for wider change was limited by access to capital, a difficult trading environment, and the narrow scope to actually do the work differently in practice. Also significant in absorbing the impact of the regulations was the extent of individualised and personalised employment relations (which prevented, for example, the NMW having an impact on differentials); labour market pressures (which helped prevent claw-back through work intensification); and the personal idiosyncrasies and competence of owner-managers. Indeed, it was a mixture of skilful management and favourable conditions that enabled some firms to use the NMW as a 'critical incident' to introduce further change. Bottom-up pressures were defused in part by employee ignorance and de-collectivisation, but also by a common view of small-firm employment in somewhat favourable terms, especially in terms of personal relations with management. Employees also tended to appreciate the difficulties of the firm and that, though it might perhaps be easier to rock a small boat, the consequences are more likely to be dire.

In most of the small firms, labour turnover was low and average length of service high. Personal relations were, therefore, long established and characterised by some degree of mutual obligation. As one ownermanager put it, good industrial relations is 'marked by give and take', and 'a quiet ship' was preferable to confrontation: 'we have enough trouble with our customers [to want it] with our staff as well!' This is an important point in terms of understanding the dynamics of informality. In one sense informality opens possibilities for management strategy (i.e. purposeful action) and organisational change, because relationships are individualised and employees less organised than in many large firms. However, the 
small firms in the research were not only at the mercy of the product market, but were subject to more or less intense labour market pressures. Low margins helped keep pay relatively low, leaving working-time vital to recruitment and retention. This meant that there was a large variation in practices, including in wages and working time patterns, even in the same product markets and geographical areas. Certainly, a strong sector effect was not as evident as observed in larger companies where collective bargaining arrangements are well established (Arrowsmith and Sisson, 1999).

Patterns of informality and accommodation also helped to defuse 'bottom up' pressures for change, a fact helped by the clear lines of segmentation in the labour force of most of the small firms. Hotel and catering was mainly staffed by young workers and women working part-time; clothing by (older) women from ethnic minority backgrounds. These gender, age and ethnic characteristics of the workforce helped sustain the individualised and informal relations observed between workers and management. It was not simply that alternative employment opportunities were limited. The segmentation of the work force helped reinforce the 'family firm' culture of the organisation. The owner-manager represented the personification of capital and hence, had a lot of individual authority and power. Yet, he or she also worked long hours in close proximity with the workers, reinforcing the sense of mutual obligation which was exemplified by the flexibility often afforded workers over working time and the payment of ad hoc performance bonuses. Conflicts of interest tended to be resolved personally with mutual appeals to individual reasonableness rather than articulated in collective forms of dissent.

This dual context of difficult business conditions and the almost defining feature of informal employment relations mediated the procedural and substantive regulatory 'shock' of the NMW. At the outset, managers expected the introduction of the NMW to stimulate or support changes to pay, working time or work organisation, while workers suspected likely work intensification. However, informal pay arrangements meant that cost implications of the NMW could be mitigated by absorbing increases individually, without implications for differentials. Similarly, there was little sign, found elsewhere (Adam-Smith et al., 2003), of a revision to the wageeffort bargain through, for example, budgeting staff shortages into the equation. As the owner-manager of a small catering outfit explained: 'it's not like in big companies where you can cut one member of staff and get the rest to work harder. In a small firm there is no room for manoeuvre if you cut a job it wouldn't get done'. Rather, flexibility over pay and hours meant that in most cases the impact of the regulations was limited.

We can analyse the overall impact of the NMW in terms of a development of Hirschmann's framework (Table 8.1). The 'type' of response includes the three categories identified by Hirschmann, with the important addition of what we term 'achievement' that is a situation in which reform meets its goals. 'Outcome' refers to the concrete results linked to each 
type. Achievement will have fairness and efficiency implications; futility by definition entails little change; perversity means that a problem is made worse, in this case that firms are pressed to intensify work; and jeopardy means that other desirable states are endangered, here the encouragement of illegal ways of working. On 'relationship with legislation', achievement necessarily entails at least compliance, and may also involve a stimulus towards improved efficiency which can extend to market re-positioning ('niche shift'). Futility can mean compliance but no major effect, but it can also be associated with one form of evasion of the law, labelled 'business as usual': here, the law simply has little effect and such practices as working off the books continue. Under 'perversity', firms comply with legislation but may find that productivity declines (such as with some moves from incentive pay in clothing), compromising the 'efficiency' objective; or they may respond to increased costs through work intensification, which has perverse implications for the 'fairness' of the wage-effort bargain. Some people might even become unemployed as a result. Finally, the contrast between perversity and jeopardy is that firms evade the legislation and pursue a 'grey market' approach.

The first response covers cases of 'achievement', by which the NMW met the expectations of the advocates of the reform, especially in terms of 'fairness'. The pay of a number of employees rose in many clothing and hotel and catering firms as a result of the NMW. The NMW also had some implications for 'efficiency', where it prompted a rethink of existing pay systems, or encouraged a repositioning in the market as a result of increases in costs. Significantly, these firms were already considering such change, or were at least well placed to do so. Most, however, had little scope to change, were financially not equipped, or lacked the expertise and knowledge networks that could have helped them (Edwards, et al., 2003).

Second, and related, the anticipated regulatory 'shock' had few real effects for many firms. Where there is little change and compliance with the legislation, we find firms following the letter of law but doing little else. This may be termed a minimal response and placed under Hirschmann's 'futility' category, though the label is overly dismissive. This is partly because minimal does not mean zero, but more importantly because regulations can have effects in some respects and not others: even though efficiency effects were absent, the fairness effects could mean that regulations were not futile. The costs of compliance could in fact be absorbed, even by small firms, because of the 'indeterminacy' afforded by individualised pay arrangements (Gilman et al., 2002). Little change can also of course mean little impact because firms already pay above NMW levels. It can also entail simply ignoring the legislation and practising 'business as usual', as many restaurants did in terms of cash-in-hand payments, working long hours or without breaks, or providing no paid leave.

Third, the increased costs associated with the NMW helped push a few 


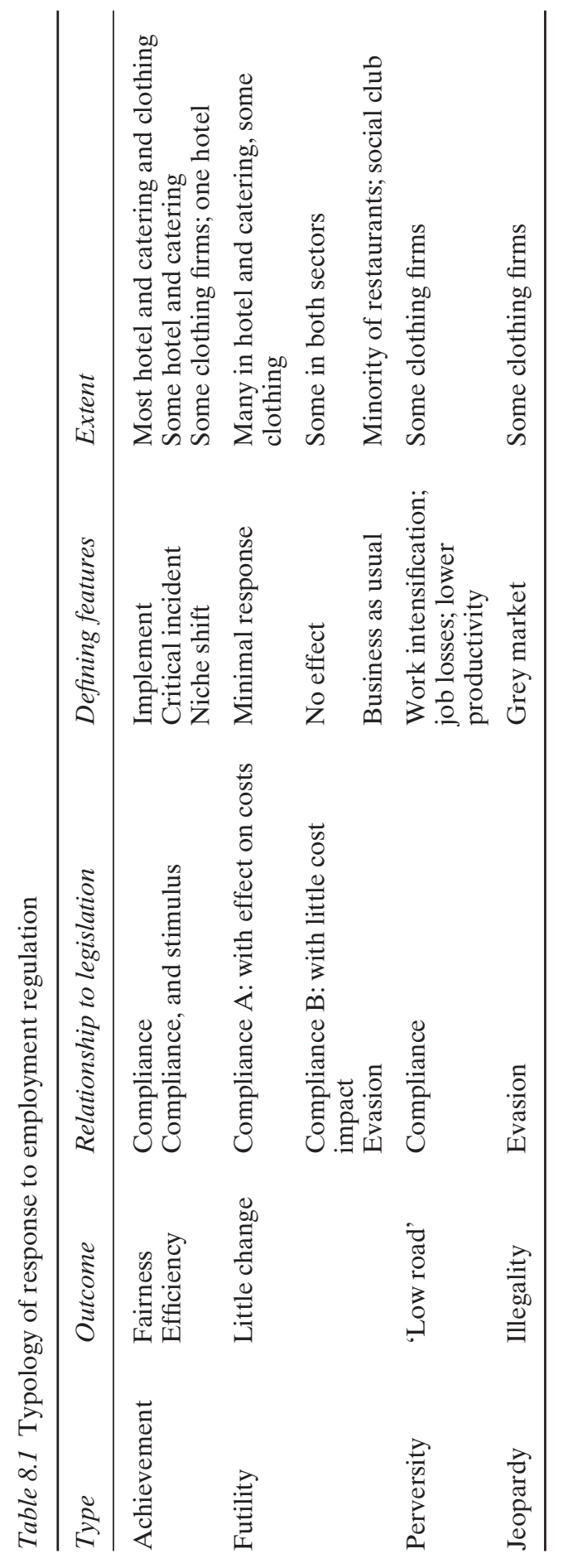


firms onto a perverse 'low road' of employment reduction and work intensification to recoup the increase in costs. This would be consistent with ideas of unbridled individualism and the expectation that the costs of the NMW will be offset through reductions in paid breaks and other fringe benefits (Simpson, 1999). However, these cases were in a minority and were often in faltering businesses that might have been moving in that direction in any case. Similarly, evasion may be associated with a move towards the illegal or quasi-legal parts of the economy and possibly closure of the firm, which we categorise as 'grey market' or 'closure' responses, and which 'jeopardise' other policy goals of legitimate employment creation.

In short, the NMW was most successful in terms of 'fairness' rather than 'efficiency'. Efficiency effects were limited because the NMW did not provide sufficient regulatory 'shock', but also because of the indeterminacy and informality of employment in the small firms which enabled the effects to be absorbed or sidestepped. The NMW did trigger some moves up- and down-market, but this might have happened in any case because of business conditions. The variation in patterns of response that we observed owes much to the external context as well as the particular characteristics of employment relations in small firms.

The findings have a number of theoretical implications, which we have explored with our colleagues more fully elsewhere (Ram et al., 2001b; Gilman et al., 2002; Arrowsmith et al., 2003). In terms of wages, Rubery (1997:338) has criticised theories of pay determination because they have 'overstressed coherence' and given insufficient weight to 'discretionary, random or opportunistic decisions'. If this is true in relation to large firms - still the focus of most academic work - it is even more likely to be true of small ones. The particular point that we would stress is that conceptions of 'fairness' (defined not just in external comparisons of pay and hours but also within the firm in terms of good personal relations and flexibility) are as important as external factors in the negotiation of this informal workplace order. Notions of 'fairness' contributed to the 'stickiness' of existing pay and working time arrangements, providing a buffer between regulatory change and outcomes so that there were relatively few direct and determinate effects. This issue is explored further in chapter 9.

On the whole, the NMW had the intended 'equity' effects of increasing (some) wages without the perversity of increased unemployment or work intensification, largely because of the individualisation and indeterminacy of pay. It was this, together with some 'Boltonesque' features reflecting the importance of mutual dependence and informal 'give and take' in shaping notions of 'fairness' in the workplace, that defused wider pressures for change. Also significant, of course, was the level at which the NMW was initially set. However, there is a more fundamental reason why the regulations largely failed to promote the secondary objective of competitiveness. This was because the impact of the employment regulations was also restricted by the inequality of bargaining power in the small firms 
(Kaufman, 1998; Freeman and Rogers, 1999). Without a link to wider regulation, such as in other EU member states where information provision and consultation requirements often extend to small firms (Biagi, 1995; Collins, 2001), the effects of the NMW were highly specific and contingent.

\section{Acknowledgements}

The research project to which this chapter refers was funded by the ESRC under its Future of Work Programme (grant L 212252031). The authors would also like to acknowledge and thank Paul Edwards and Monder Ram, and are grateful to Blackwell Publishers for permission to draw on a paper published in the September 2003 edition of the British Journal of Industrial Relations.

\section{Note}

1 Thanks to Ed Heery for alerting us to this.

\section{References}

Adam-Smith, D., Norris, G. and Williams, S. (2003) 'Continuity or change? The implications of the National Minimum Wage for work and employment in the hospitality industry', Work, Employment and Society, 17(1):29-47. British Journal of Industrial Relations, 41(3):435-56.

Arrowsmith, J. and Sisson, K. (1999) 'Pay and working time: towards organizationbased systems?', British Journal of Industrial Relations, 37(1):51-75.

Arrowsmith, J., Gilman, M., Edwards, M. and Ram, M. (2003) 'The impact of the national minimum wage in small firms', British Journal of Industrial Relations, 41(3):435-56.

Bacon, N., Ackers, P., Storey, J. and Coates, D. (1996) 'It's a small world: managing human resources in small businesses', International Journal of Human Resource Management, 7(1):82-100.

Bazen, S. (1990) 'On the employment effects of introducing a National Minimum Wage', British Journal of Industrial Relations, 28(2):215-26.

Biagi, M. (1995) 'Labour law in small and medium-sized enterprises: Flexibility or adjustment?', Comparative Labor Law Journal, 16:439-60.

Blackburn, R. and Hart, M. (2002) 'Small firms' awareness and knowledge of individual employment rights', Research Report no. 14, Department of Trade and Industry (http://www.dti.gov.uk/er/emar/errs14.pdf).

Bolton Report (1971) Report of the Committee of Enquiry on Small Firms, Cmnd. 4811, London: HMSO.

Card, D. and Krueger, A. B. (1995) Myth and Measurement: The New Economics of the Minimum Wage, Princeton: Princeton University Press.

Collins, H. (2001) 'Regulating the employment relation for competitiveness', Industrial Law Journal, 30:17-48.

Commons, J. (1909) 'American shoemakers 1648-1895: a sketch of industrial evolution', Quarterly Journal of Economics, 24:38-83. 
Curran, J. and Blackburn, R. (2001) Researching the Small Enterprise, London: Sage.

Curran, J. and Stanworth, J. (1981) 'Size of workplace and attitudes to industrial relations in the printing and electronics industries', British Journal of Industrial Relations, 19:14-25.

Edwards, P. K. and Gilman, M. (1999) 'Pay equity and the National Minimum Wage', Human Resource Management Journal, 9(1):20-38.

Edwards, P. K., Gilman, M., Ram, M. and Arrowsmith, J. (2003) 'Public policy, the performance of firms, and the "missing middle": the case of the employment regulations, and a role for local business networks', Policy Studies, 23(1):5-20.

Eisenhardt, K. M. (1989) 'Building theories from case study research', Academy of Management Review, 14:532-50.

Freeman, R. B. and Rogers, J. (1999) What Workers Want, Ithaca, New York: Cornell University Press.

Gilman, M. W., Edwards, P. K., Ram, M. and Arrowsmith, J. (2002) 'Pay determination in small firms in the UK: the case of the response to the National Minimum Wage', Industrial Relations Journal, 33:52-68.

Goss, D. (1991) 'In search of small firm industrial relations', in Burrows, R. (ed.) Deciphering the Enterprise Culture, London: Routledge.

Hirschmann, A. (1991) The Rhetoric of Reaction: Perversity, Futility, Jeopardy, Cambridge, Mass.: Harvard University Press.

Holliday, R. (1995) Small Firms: Nice Work?, London: Routledge.

Kaufman, B. E. (1998) 'Regulation of the employment relationship: the "old" instititutional perspective', Journal of Economic Behavior and Organization, 34:349-85.

Kitching, J. W. (1997) 'Labour regulation in the small service sector enterprise', unpublished $\mathrm{PhD}$ dissertation, Kingston University.

Low Pay Commission (LPC) (1998) The National Minimum Wage: First Report of the Low Pay Commission, Cmnd. 3976. London: HMSO.

Low Pay Commission (LPC) (1999) 'The National Minimum Wage: monitoring and evaluation', Labour Market Trends, 107(1):27-9.

Low Pay Commission (LPC) (2001) The National Minimum Wage: Making a Difference. Third Report of the Low Pay Commission, Vol. 1, Cmnd. 5075. London: HMSO.

Lucas, R. (1995) Managing Employee Relations in the Hotel and Catering Industry, London: Cassell.

McKay, S. (2001) 'Annual review article 2000. Between flexibility and regulation: rights, equality and protection at work', British Journal of Industrial Relations, 39:285-303.

McNabb, R. and Whitfield, K. (2000) “"Worth so appallingly little”: a workplacelevel analysis of low pay', British Journal of Industrial Relations, 38:585-610.

Mole, K. (2002) 'Augmenting productivity in SMEs: a report for the small business service'. (http://www.sbs.gov.uk/content/research/Augmenting_Productivity_ inSMEs.pdf).

Moule, C. (1998) 'The regulation of work in small firms', Work, Employment and Society, 12:635-54.

Rainnie, A. (1989) Industrial Relations in Small Firms: Small Isn't Beautiful, London: Routledge.

Ram, M. (1994) Managing to Survive, Oxford: Blackwell. 
Ram, M., Abbas, T., Sanghera, B., Barlow, G. and Jones, T. (2001a) “"Apprentice entrepreneurs"? Ethnic minority workers in the independent restaurant sector', Work, Employment and Society, 15:353-72.

Ram, M., Edwards, P. K., Gilman, M. and Arrowsmith, J. (2001b) 'The dynamics of informality: employment relations in small firms and the effects of regulatory change', Work, Employment and Society, 15(4):845-61.

Rubery, J. (1997) 'Wages and the labour market', British Journal of Industrial Relations, 35:337-62.

Scase, R. (1995) 'Employment relations in small firms', in Edwards, P. (ed.) Industrial Relations: Theory and Practice in Britain, Oxford: Blackwell.

Scott, M., Roberts, I. and Sawbridge, D. (1989) Management and Industrial Relations in Small Firms, Department of Employment Research Paper, 70, London: Department of Employment.

Simpson, B. (1999) 'A milestone in the legal regulation of pay: the National Minimum Wage Act 1998', Industrial Law Journal, 28:1-34.

Textile and Clothing Strategy Group (TCSG) (2000) A National Strategy for the UK Textile and Clothing Industry, London: DTI.

Wilkinson, A. (1999) 'Employment relations in SMEs', Employee Relations, 21(3):206-17.

Williamson, O. E. (1975) Markets and Hierarchies, New York: The Free Press.

Williamson, O. E. (1985) The Economic Institutions of Capitalism, New York: The Free Press. 


\title{
9 Managing variable pay systems in smaller workplaces
}

\author{
The significance of employee \\ perceptions of organisational justice
}

\author{
Annette Cox
}

\section{Introduction}

Over the past two decades, the debate surrounding variable pay systems has moved on from managing traditional conceptions of occupational equity and fairness in collective bargaining processes, to influencing individual employees' perceptions of their organisation. The notion of fairness has been colonised by organisational justice research operating within the psychology paradigm (Konovsky, 2000). Much work has focused on defining and classifying types of justice and explaining the antecedents and outcomes of different kinds of justice in respect of different employment practices. Remarkably few studies (Folger and Konovsky, 1989; Dulebohn and Martocchio, 1998; Lee et al., 1999) have focused on pay, thus making it particularly worthy of analysis.

Organisational context, especially in terms of organisational size, has also been ignored, since the traditions of psychology emphasise the search for universal justice perceptions rather than focusing on differences in justice perceptions between organisational and occupational groups. Employees in small and medium-sized enterprises (SMEs) have quite different experiences of work from those in larger companies; interpersonal relationships may be more significant and intense and emphasis on procedural regulation of work through formal HR policies and practitioners is likely to be reduced (Ram et al., 2001). This chapter begins with a review of organisational justice theory and highlights the areas where the empirical work reported can make a contribution. It then analyses a mixture of qualitative and quantitative data from a semi-structured face-to-face questionnaire conducted with a sample of employees from four medium-sized engineering organisations undergoing pay system change. It applies and assesses the relative importance of three kinds of justice - distributive, procedural and interactional - arguing that all were important in different ways and concludes with comments on the nature of justice perceptions in SMEs and potential implications for future research. 


\section{Organisational justice theory and employment relations in SMEs}

A burgeoning literature on employment relations in SMEs upholds the case for focusing on developing theory to explain the diversity of employment practice and employee perceptions of work rather than searching for universal truths. First, we must acknowledge the heterogeneity of workplaces which make up the sector from expanding high-value-added professional service firms (e.g. Grugulis et al., 2000) to small manufacturing sweatshops with a precarious existence (Ram, 1993; Holliday, 1994). Further diversity is found within smaller businesses in the same sector as both this chapter and previous studies (e.g. Ram et al., 2001; Gilman et al., 2002) demonstrate. Second, the varying sizes of small business, their product markets, type of ownership and nature of management-employee relations have significant implications for the range of management practices to be found within them. Employment practices are also affected by the degree of professionalisation of management and access to HR expertise, information and advice as concerns about level of education of owner-managers and absence of HR personnel may limit the development of good personnel practice. Much research is concerned with the wider socio-economic impact of the way SMEs are managed, and while recognising the policy implications of SME responses to employment legislation, for example, it is more unusual to find studies which deal directly with employee perceptions of the outcomes (see Marlow, 2002 as an exception). In terms of managing pay, we know that SMEs are more likely to pay low wages (Low Pay Commission, 2003) which may affect how fair employees perceive their pay to be. They are also less likely to use variable pay systems (Gilman et al., 2002), so it is particularly interesting to examine smaller firms which have made such innovations and consequent employee responses to them. We know remarkably little about the processes of pay system choice, design and implementation in smaller firms which, given the centrality of pay to the employment relationship, are likely to act as critical markers of the state of management-employee relations. Hence, this chapter makes a contribution to this debate by linking pay systems, small firms and notions of organisational justice.

\section{Distributive justice}

Distributive justice is concerned with the fairness of outcomes from decisions. The principles on which allocation decisions should be made are, however, subject to debate and our knowledge of how these are applied in smaller organisations is scant. Measuring distributive justice is complicated because there are multiple criteria according to which those outcomes may be judged fair or unfair. Three categories predominate in evaluating distributive justice, equality, equity and need (Cropanzano and 
Ambrose, 2001), although there is much disagreement about which principle should be used in determining pay levels. McFarlin and Sweeney (1992), operationalise distributive justice criteria as experience, effort, responsibility, performance and job stress thus, combining job characteristics, input measures and output measures.

This leads us to consider what we know about pay levels, systems and distributive justice in SMEs and from the literature, find a similar extent of variation in wage levels in small firms to that which prevails in large ones (Gilman et al., 2002). This variation underscores the need to find out how fair wage setting is perceived to be, especially when the same study found a formal pay structure was present in only a minority of organisations and the authors' calculations, based on WERS 1998 data, indicates that other methods of ensuring pay equity such as formal job evaluation or individual appraisal are similarly not widely used. Gilman et al. also refer to fairness perceptions of both employers and employees regarding what is affordable and acceptable as a key determinant of wages, but comment that for both parties these were loosely defined and so this does indeed chime with what we know of conceptions of fairness from the extant literature.

The centrality of notions of fairness and equity as principles on which decisions about pay are made and evaluated are not in doubt, but attaching precise definitions to these terms is extremely difficult (Hyman and Brough, 1975), given the problem of whether to define justice in relative or absolute terms (Rawls, 1971). The lack of research to illustrate employee views of pay (system) fairness in SMEs is clear from the discussion so far and, furthermore, with a few exceptions (e.g. Brown, 2001) we often know little about the basis for pay comparisons either within or outside the organisation being studied and to what degree firm size might impact upon this. Given the sensitivities of the subject, it is perhaps not surprising that we do not have data on employee views of pay in SMEs but nor do we know much about the allocation principles which managers apply in setting wages either, and to what extent these values are shared by employees.

\section{Procedural justice}

Procedural justice constitutes the fairness of the decision-making process by which outcomes are determined. Several theories of procedural justice exist, neatly summarised by Konovsky (2000) who suggests these include the instrumental view - that procedural justice is important in its impact on distributive justice perceptions, justice judgement theory which comprises various ways of assessing the presence or absence of procedural fairness and fairness heuristic theory which examines how distributive and procedural justice operate in relation to each other. The first of these - the instrumental view - was one of the earliest versions and in legal settings, it identified the importance of giving 'voice' to judgement recipients during 
decision-making as it enhances their perceptions of the fairness of outcomes (Thibaut and Walker, 1975).

Evidence also demonstrates the existence of a 'fair process' effect whereby people are more tolerant of outcomes, even when personally adverse, if they perceive that the processes which determined them were procedurally fair (Lind, 2001). Interestingly however, voice only appears to have an effect where employees both expect and desire it (Heller, 1998). There are several potential implications for the significance of voice in SMEs. Traditional views of the employment relations climate in small firms, have, in the past, been relatively simplistic, based upon a notion of harmony marked by an absence of manager-employee conflict as depicted in the report of the much criticised Bolton Report (1971) (see Rainnie, 1989 and Ram, 1993 for example). We know now, however, that grievance, absence and turnover rates and the incidence of claims for unfair dismissal are higher among small businesses (Cully et al., 1999). This indicates employee use of 'exit' strategies in the absence of 'voice' mechanisms (Hirschmann, 1970) and raises concerns about the prevalence of procedural justice mechanisms. Both of these perspectives oversimplify employment relations in SMEs, whose culture is usually dominated by a legacy of the founder or long established owner-manager operating through a mixture of paternalism and autocracy with decisions unfolding on the shop floor through a process of 'negotiated order' (e.g. Ram, 1993; Holliday, 1994; Storey, 1994; Moule, 1998; Ram et al., 2001). In this context then, employees may be habituated to a lack of formal or collective voice instead of finding personal solutions to this problem whilst being assured that the boss will act in every ones 'best' interest anyway.

In empirical work, procedural justice tends to be operationalised as the set of structural elements of any decision-making process. Leventhal et al. (1980) list criteria for ensuring procedural justice is seen to be done, incorporating selection of representative decision-makers, accuracy of information, consistency between persons and across time and availability of appeals processes. This is probably one of the most well known and often quoted examples, but applications of it are hard to find (one exception is Meyer, 2001). Fulfilling all of these criteria is likely to necessitate the creation of formal systems or checking procedures which are at odds with a prevalent culture of informality in SMEs and a managerial dislike of perceived bureaucracy. This raises the question of whether SMEs seek to apply procedural justice in this way and, if not, what, if any, alternatives are used. In the absence of clear procedures, the final category of justice interactional justice - may assume greater significance in such firms.

\section{Interactional justice}

As a relatively novel dimension of organisational justice, debate exists whether interactional justice is an independent construct, or simply a 
category of procedural justice (see Bies, 2001 for a review of the arguments). Bies and Moag (1986) emphasise that procedures cannot exist without being actioned and that the manner in which such procedures are followed are perceived as equally, or indeed, more important as the existence of the procedures themselves. Bies (2001) has broken down interactional justice further into two subcomponents. First, there is the sincerity with which procedures are followed; second, interpersonal sensitivity which comprises the politeness and courtesy with which an individual is treated when decisions are made or implemented, which affects the maintenance of their sense of dignity and self-worth, often referred to now as 'interpersonal justice'.

\section{Organisational justice and pay systems - interactions between justice types}

At the outset, we can note that dimensions of procedural fairness have surfaced as significant in HR/employment relations research on pay, notably the provision of employee 'voice' prior to pay system design and implementation. Evidence indicates that consultation over pay system design and implementation appear to generate better outcomes (e.g. Bowey et al., 1986; Cooper and Dyck, 1992; Kessler and Purcell, 1996; Kim, 1996; Lee et al., 1999) in terms of operational outcomes, understanding and palatability of the systems and employment relations. Participation in pay system design may offer a number of benefits, these include improved quality of decision-making, ensuring rewards offered match rewards desired, enhanced probability that employees will both accept and commit themselves to the success of the scheme and so, improved management-employee relationships (Thorpe, 2000).

Comparative analyses of distributive and procedural justice mostly concur in emphasising the particular importance of procedural justice. Much of the evidence suggests that in relation to pay, perceptions of distributive justice only predict immediate satisfaction with reward outcomes, whereas perceptions of procedural justice are associated with a broader range of attitudes. Based upon studies of pay systems in manufacturing and retail, Folger and Konovsky (1989) and McFarlin and Sweeney (1992) found that distributive justice perceptions are limited in their links only to pay and job satisfaction. Procedural justice perceptions, however, were found to be associated with levels of organisational commitment and the quality of employee relationships with immediate managers. Distributive justice had less impact on employee views when procedural justice was rated as high. This suggests that if procedures for dealing with employment issues are inadequate or absent, employee perceptions of basic distributive outcomes become much more salient. It can be dangerous however, to assume the universality of justice perceptions without considering individual circumstances. 


\section{Research evidence}

The research reported here was part of a wider study undertaken over three years into the design, implementation and outcomes of variable pay systems in small and medium-sized enterprises (SMEs) in the engineering sector. ${ }^{1}$ Three different kinds of pay system were identified and classified (after Purcell in Kessler, 1995) based on the criteria according to which employees were paid - individual output, individual input and group output. One organisation used piecework systems, one used a skills-based pay system, one used an Inland Revenue unapproved cash-based profitsharing scheme and one used a profit-related-pay (PRP) scheme. The characteristics of the case sites, the pay systems chosen and methods of implementation are shown in Table 9.1, which outlines the features of the case study firms

A series of semi-structured interviews were conducted in each of the case sites with pay system designers, line managers, wages personnel, personnel/HR managers and employee representatives (where available) to obtain data on the reasons and objectives for pay system change, design and implementation processes and scheme outcomes, supplemented by documentary evidence where this existed. Given the scarcity of studies which incorporate employee views of pay issues, this research approach offers the possibility of a more holistic view of reward systems in operation than one usually gained from managers.

These firms had a considerable degree of autonomy over personnel issues since research sites were deliberately selected for independent HR decision-making in order to examine pay systems chosen by the SMEs, rather than by large organisations. The exception to this was Heavyengco since while this organisation retained its autonomy over the majority of HR decisions, the new PRP system was implemented by the parent company, it was important to include this firm as no other small organisations could be found which had implemented a PRP system of their own volition. The firms' approaches to labour management were found to reflect the stereotypes found in the small business literature since evidence of 'good' let alone 'best' HR practice was scant and there were no existing systems of systematic communication or appraisal for example, and no formal policies on recruitment, training or pay progression. As such, the case sites represented interesting locations to investigate perceptions of organisational justice.

\section{Distributive justice in the workplace}

Employee perceptions of distributive justice took a number of forms in the data gathered. First, employees made a global assessment of the fairness of their pay; second, they assessed distributive justice in terms of perceived fairness of organisational differentials; third, they were asked to choose 


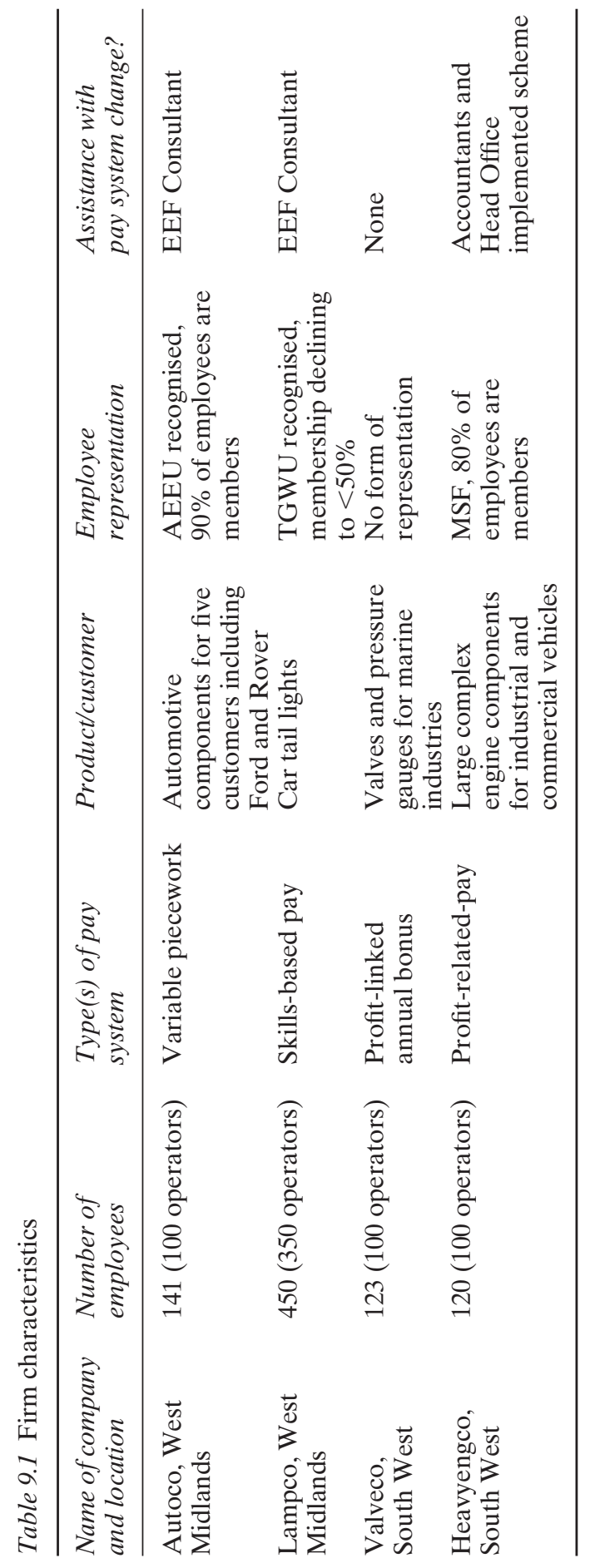


their preferred reward allocation criteria which was then compared with managerial priorities. Lastly they evaluated distributive outcomes according to perceptions of relative inputs as under equity theory. In order to check whether employee satisfaction with pay levels was related to their level of earnings relative to other workplaces, earnings for specific jobs at each case site were compared with data derived from the New Earnings Survey (ONS, 1998) and employee awareness of being under/overpaid in the labour market was assessed.

\section{Employee perception of pay level fairness}

Employees were asked whether they regarded their pay level as fair, or unfair, and to explain their response. Criteria for assessing 'fairness' were deliberately not provided, partly in order to allow employees to use their own reasoning and also because of restrictions in questionnaire length. Employee views on fairness of pay levels are shown in Table 9.2.

The tenor of response is unsurprising. As Lawler (1990) has commented, finding employee dissatisfaction with pay levels could be viewed as a non-finding. Indeed, one employee at Heavyengco echoed this sentiment, commenting wryly: 'We all always want more than we're getting, don't we?' (Driller, Heavyengco). The exceptions were employees at Valveco, who had just received a significant pay increase of around 20 per cent. Amongst the employees, the prime reason discernible for perceived unfairness with pay was dissatisfaction with basic pay rates due to a prolonged time since any pay rise. At Heavyengco too, there was some evidence of discontent with pay increases since employees strongly contested the notion that PRP constituted a pay rise and perceived it as 'simply a tax dodge' (Driller, Heavyengco). At Heavyengco two concerns predominated, first, dissatisfaction with pay rates compared both to other firms in the local area or in the nearest city and second, perceptions that the engineering industry was itself a low payer: 'it's reasonable for [town] but they get paid higher in [nearest city]' (Assembler, Heavyengco); 'engineering in general is not recognised as a skilled job for what you get paid, not compared to my friends in insurance' (Jig Borer, Heavyengco).

Pay dissatisfaction due to the lack of a recent pay rise is not a common

Table 9.2 Employee perceptions of fairness of pay level

\begin{tabular}{|c|c|c|c|c|}
\hline \multirow[t]{2}{*}{ Company } & \multicolumn{4}{|c|}{ Employee responses (\% by company) } \\
\hline & Fair & Unfair & & Don't know \\
\hline Autonco & 12 & 88 & $(n=9)$ & 0 \\
\hline Lampco & 29 & 57 & $(n=6)$ & 14 \\
\hline Valveco & 63 & 37 & $(n=8)$ & 0 \\
\hline
\end{tabular}


finding of research in this area (cf. Gilman et al., 2002:58) and this may reflect the nature of the research sites; wage restraint is likely to be more common in smaller firms in a contracting industry facing tough competitive pressures. Employees were questioned about satisfaction with their earnings compared to the earnings of others doing similar and different jobs in their organisation, but responses consistently revealed satisfaction with comparative earnings. Few employees admitted insufficient knowledge of others' earnings to respond. Given little evidence of discontent with internal pay differentials, it is worth probing two sources of perceived injustice outlined earlier: lack of weight given to personal merit as an allocation criterion and the absence of regular pay increases.

\section{Employee satisfaction with allocation criteria}

As discussed above, the allocation criteria used to determine rewards are subject to debate and may be a source of distributive (in)justice. Employees were first asked whether they agreed with the idea of variable pay in principle and the results are shown in Table 9.3.

Half of the entire sample of employees believed that pay should be varied, with considerable variation between firms. Greatest support for variable pay came from employees at Heavyengco; in contrast to employees at the other firms, they were the only group who received no element of pay at all which reflected their individual performance and their comments about the performance criteria that should be used were mostly in support of setting salaries according to skill levels. Most hostility towards variable pay came from employees at Autoco where employees received the lowest level of basic pay in the sample and to whom the variable element of pay was critical to their overall earnings, while employees at Lampco and Valveco were more evenly split between supporters and detractors. The managers at Valveco stated that support for variable pay was most evident amongst younger employees whilst older workers with mortgages found the basic rate more important. A further area of investigation, therefore, is whether employees who agreed with the principle of variable pay felt that appropriate distribution criteria were being used. Of those employees who supported variable pay, Table 9.4 shows the varying levels of support for potential reward criteria.

Table 9.3 Percentage of employees believing that pay should be variable

\begin{tabular}{ll}
\hline Company & \multicolumn{2}{c}{ Employee response $(\%)$} \\
\hline Autoco & $11 \quad(n=9)$ \\
Lampco & $57 \quad(n=7)$ \\
Valveco & $63 \quad(n=8)$ \\
Heavyengco & $70 \quad(n=10)$ \\
\hline
\end{tabular}


Table 9.4 Percentage of employees supporting each potential criterion for variable pay

\begin{tabular}{llrll}
\hline Company & \multicolumn{3}{l}{ Employee response (\%) } \\
\cline { 2 - 5 } & $\begin{array}{l}\text { Amount of work } \\
\text { produced }\end{array}$ & Skills & $\begin{array}{l}\text { Length of } \\
\text { service }\end{array}$ & Something else \\
\hline Autoco $(n=1)$ & 0 & 100 & 0 & 0 \\
Lampco $(n=4)$ & 0 & 50 & 50 & 0 \\
Valveco $(n=5)$ & 0 & 80 & 0 & 20 \\
Heavyengco $(n=7)$ & 0 & 86 & 0 & 43 \\
\hline
\end{tabular}

Notes

a $n=$ sample size of employees agreeing with principle of variable pay at each company.

b Rows may sum to $>100 \%$ where employees chose multiple criteria.

Employees gave most support to the principle of rewarding for inputs rather than outputs and defined payment according to people's skills in a variety of ways - 'whether they can use different machines' (Machinist, Valveco), 'speed and co-operation' (Machinist, Valveco), or 'how efficient they are' (Electrician, Heavyengco). Employees at Heavyengco also felt that other factors should be taken into consideration including 'quality' of work produced (Assembler, Heavyengco), 'effort' (Machinist, Heavyengco) and 'location' by an employee who alluded to London weightings (Assembler, Heavyengco). Heavyengco employees were the strongest supporters of payment for skills; this may reflect the views of a relatively highly skilled workforce which felt individual efforts were unrecognised by the PRP system. At an abstract level, although payment according to skill levels received most support from employees, it is noticeable that where this system was in place in its purest form at Lampco, employees were least supportive. At this firm morale was low and the business was struggling, reflected in labour turnover rates of around 37 per cent so it is unsurprising in this organisational context that employees felt long service should be rewarded.

Managerial perceptions of fair reward allocation criteria varied. Lampco managers favoured a skills-based pay system that emphasised behavioural inputs which went unrewarded under the previous piecework system including ability to pay attention to quality and to learn new skills. Valveco's General Manager recognised perceived inequity in the previous profit-sharing system, which only included white collar staff, and by extending it to the whole workforce supported Deutsch's (1985) principle of equality of opportunity while retaining the payout criterion of 'ability to pay'. Heavyengco managers, however, simply regarded the PRP system as a way of taking advantage of the tax system 'to give employees a pay rise without the company funding it' (Financial Controller, Heavyengco). Autoco's General Manager wanted to retain a piecework system for its 
motivationary benefits as he believed that very few staff 'had a genuine allegiance to the company' and piecework was required to ensure that the employees were productive. Managerial perceptions of appropriate criteria for distributive justice in reward allocation were centred on affordability to the organisation and stimulating appropriate employee behaviours. Given that some measure of individual merit was the preferred allocation criterion of those employees who supported variable pay in principle, it is worth asking to what extent the pay systems achieved discrimination between good and poor employees. Employees of firms using pay systems which discriminated on the basis of individual rather than group performance could be expected to agree with the statement, whereas those rewarded by company performance could be expected to disagree; Table 9.5 shows the results.

Despite the high levels of hostility to payment for output at Autoco, the company's piecework system was felt to be most effective by employees in discriminating between good and poor performers. Interestingly, half of Valveco employees felt their pay methods were effective in achieving the same objective, but from the comments made, it was clear that employees were evaluating the method which determined their basic pay and were ignoring the profit-sharing element. Under half of Lampco employees felt that their system lived up to its intention; this company experienced many problems in attaining procedural fairness of appraisals due to poorly specified performance criteria and line manager inconsistency in conducting skills gradings. Heavyengco employees felt that their pay system was least effective in distinguishing between good and poor performers as expected, since these employees' variable pay was calculated solely according to firm performance. We might expect pay rates in firms with no recent pay rises to be relatively low, this is assessed in the next section which compares employee earnings from the case sites with national pay data.

\section{Employee earnings in context}

The question of whether employees receive fair levels of pay deserves further scrutiny, since perceptions of distributive justice may be subjective rather than objective (Konovsky, 2000) and in the case of distributive

Table 9.5 Employees believing that poor performers receive less money than good performers

\begin{tabular}{ll}
\hline Company & \multicolumn{2}{c}{ Employee response $(\%)$} \\
\hline Autoco & $55 \quad(n=9)$ \\
Lampco & $43 \quad(n=7)$ \\
Valveco & $50 \quad(n=8)$ \\
Heavyengco & $10 \quad(n=10)$ \\
\hline
\end{tabular}


justice of pay, outcomes are easily comparable with objective data. Comparing the pay levels of employees at the case sites with those of people doing similar jobs as recorded in the New Earnings Survey (ONS, 1998) provides a rough guide as to whether employees' earnings from the case study firms conform to national averages. Disaggregated pay data for specific occupational categories was only available at national level, constrained by small sample sizes for some occupations, but data was matched for the year in which the employee survey took place. Small sample sizes for the occupations under analysis also meant that it was not possible to restrict the analysis to workers' earnings in SMEs; instead comparisons are made between workers' earnings in organisations of all sizes.

Table 9.6 compares the earnings of employees from case sites with national averages for the same occupational categories. It has been necessary to manipulate data from both the case sites and the New Earnings Survey to ensure that the figures are averaged for comparison purposes, e.g. bonus earnings, working time, overtime and shift pay. In order to show the effects of the variable pay systems on earnings, Table 9.6 makes an important distinction between base pay rates, shown in bold and earnings including all sources of variable pay which are shown in ordinary type.

The table usefully helps to provide some justification for employee concerns with the distributive justice of basic pay rates. Autoco and Lampco

Table 9.6 Earnings of case study company employees compared with national averages

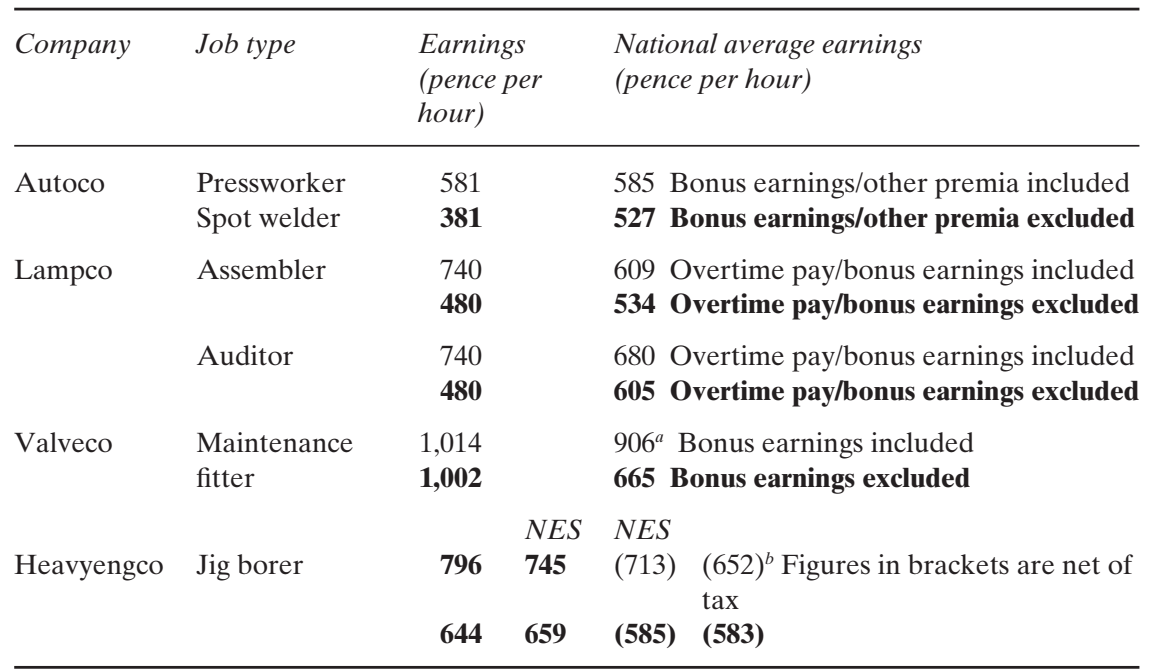

Notes

a New Earnings Survey figures for this category include shift pay, as a portion of average earnings from shift pay was consolidated into basic wages at Valveco.

b Figures in brackets based on net pay after tax so that the effects of PRP become visible. 
employees are underpaid when their basic wages are compared with national averages whilst Valveco and Heavyengco employees are comparatively well paid. At Heavyengco the effects of profit-related pay on take home pay are extremely interesting as while earnings including bonuses are higher than national averages, when net earnings excluding bonuses are considered, national base rates are higher than those of Heavyengco. However, earnings in brackets are those calculated considering the effect of profit-related pay and Heavyengco's employees take home pay rates are actually higher, albeit by a few pence, than the national average. Heavyengco employees' widespread perceptions of distributive injustice with respect to pay levels may indicate that they focus entirely on the nominal basic hourly rate, as asserted by several interviewees at managerial and employee level. Furthermore, because the PRP bonus was paid out annually, employees' wage levels appeared unchanged during the course of the year so the mechanics of the system increase its opacity.

While employees at two of the case sites were objectively underpaid according to national comparisons, this would presumably not affect their perception of distributive (in)justice unless they were aware of other firms which paid more for their work. Employee perceptions of whether they were over/underpaid in their local labour market were assessed, see Table 9.7.

Autoco employees appear to suffer from lowest comparative pay according to Table 9.7 but also to have least knowledge about this. Lampco employees' perceptions of low comparative pay are supported by New Earnings Survey data. Although only one job is shown for comparative purposes from Valveco, if this is representative of the differential between wages for other jobs within the company and what employees could expect to earn elsewhere, it seems unlikely that their expectations could be fulfilled. Heavyengco employees seem confirmed in their attachment to using the basic wage as a comparison given that such a large majority of them believed that they were underpaid, since Table 9.6 shows this is only true when all other bonuses are excluded from the wage packet.

Therefore, Table 9.7 shows mixed results with respect to the accuracy and objectivity of employees' distributive justice perceptions beyond their

Table 9.7 Employee knowledge of better paying employers in the local area (\% by company)

\begin{tabular}{llll}
\hline Company & Yes & No & Don't know \\
\hline Autoco & 33 & 33 & 33 \\
Lampco & 57 & 43 & 0 \\
Valveco & 50 & 50 & 0 \\
Heavyengco & 70 & 20 & 10 \\
\hline
\end{tabular}


organisation and reveal a persistent preoccupation among employees with basic wage levels as their criteria for evaluating distributive justice. With the exception of Autoco employees, at least half the employees surveyed in each of the other case sites knew of better paying local firms. The question of why discontented employees did not actively seek other work remains unanswered; perceived likelihood of getting another job and inconvenience or other costs associated with quitting current work may be important factors, but further analysis is beyond the scope of this chapter.

\section{Summary of employee perceptions of distributive justice}

Most employees felt that their pay level was unfair and the main source of distributive injustice was lack of a recent pay rise. The results also show that choice of appropriate allocation criteria holds importance for employees in determining their pay and that there was little overlap between managers' and employees' priorities. The employee sample broadly supported variable pay, but often not in its current form, as no employees supported the principle of pay related to firm performance. Employees with the lowest basic pay rate at Autoco were understandably most hostile to the principle of variable pay. Employees showed a marked preference for rewards for individual inputs, according to the principle of equity theory. Once in practice, however, employee support for variable pay systems, even where systems supposedly rewarded employees on an individual basis, diminished, suggesting some perceived injustice in the application of the reward criteria.

Some caveats are necessary in drawing these inferences, however. For all firms but Autoco, the amounts of variable pay were small so we cannot speculate too much on the significance of distributive injustice in relation to variable pay systems, nevertheless, the importance of ensuring positive justice perceptions of basic pay levels remains a lesson to be learned for managers. In the light of the discrepancies found between support for variable pay in theory and dissatisfaction with its application in practice, we now turn to perceptions of procedural justice to compare their relative impact.

\section{Procedural justice in the workplace}

Procedural justice in pay system change manifests itself in two stages. First, the extent to which employees receive voice in the process of pay system change was earlier identified as a key success factor for ensuring pay system palatability. Second, the procedures by which pay decisions are made may be more or less fair following Leventhal et al. (1980). The significance of procedural justice to employees in this study also appeared in two ways, first, the level of consultation experienced prior to the choice and design of the new pay systems incited strong feelings from many 
workers. Second, employees were invited to comment on and justify their perceptions of pay system fairness. This was instructive in illustrating their interpretation of procedural justice and their understanding of pay determination methods.

As critical commentators have suggested (Ram, 1993; Moule, 1998; Marlow, 2002), SMEs are associated with a lack of employee voice and an autocratic management style. This was certainly true of organisations in this study. Even in the two organisations which had fully recognised unions before the pay system changes, there were no shop stewards as employees were unwilling to take on the role and felt it was pointless since managers firmly rejected the idea of collective bargaining. At the case sites visited, there was a notable lack of consultation over pay system change which in turn had significant negative consequences, as employees subsequently resisted the unilateral imposition of new pay systems with a negative impact on production and the employment relations climate.

From the whole sample, only managers at Valveco declared that employees were not consulted, yet, from the entire sample of employees, only four (12 per cent) said they had been consulted about plans to change the pay system. Given the small numbers who could positively identify whether any consultation had taken place or not, the findings are not particularly conclusive. However, employee comments below show a strong display of dissatisfaction, the most common complaint being that consultation took a 'pseudo' form without any sincere desire from management to hear employees' views. In some cases it amounted to little more than informing the employees that the pay system was to change: 'They told us that they were going to change it ... they didn't ask what we thought of it' (Press Worker, Autoco). 'We were told we would accept it' (Spot Welder, Autoco).

Employees at Autoco felt that there was no possibility of rejecting, modifying or changing the system once it was in place: 'We said we'd give it a try but once we got it, we were stuck with it weren't we?' (Press Worker, Autoco). Lampco went through a long period of consultation lasting over a year but it seemed to make little impression on employees, this can be explained by a number of reasons; it was one of the older pay systems studied, and in the three years since its creation, employees may simply have forgotten that there was a consultation process. Furthermore, as one of the larger case study firms, employee representatives were involved with the consultation rather than all individual employees consequently, none recalled the consultancy process. One comment made by a Lampco employee again reflects a perception that decisions had already been taken before employees made their views known: 'They asked our opinion but they were going to do it anyway' (Assembler, Lampco). Heavyengco's employees similarly show an interesting response. Despite months of negotiation over the implementation of PRP, employees emphatically denied that they had experienced any true consultation over 
the system: 'It was a choice of either accept it or no pay rise - it was forced on us basically, we didn't really want it' (Grinder, Heavyengco).

Unsurprisingly, in the firms with little consultation but fundamental pay system change, employees objected vociferously with a variety of consequences. The results at Lampco were slower to emerge as the impact of the pay system was less immediate and is discussed in the next section. But both Autoco and Heavyengco experienced a significant increase in union activity and mobilisation. Heavyengco employees discovered that managers had violated the Inland Revenue's regulations for PRP schemes by not allowing sufficient consultation time when seeking employee consent to a variation in terms and conditions. Employees sought advice from a union and subsequently obtained union recognition for the first time in the firm's history. This culminated in lengthy annual pay negotiations involving full-time external representatives for the organisation and the employees and an acrimonious state of employment relations. As one employee commented: 'it's put divisions in here which weren't here before' (Supervisor and Non-Union Employee Representative).

Autoco employees initially rejected the new pay scheme and downed tools on a daily basis when sporadic supply of parts and problems with equipment threatened their opportunities to make satisfactory bonuses. Under the new scheme bonuses were calculated on a weekly instead of daily basis which made consistent production across a working week more critical to maintaining stable earnings. Problems with tools, equipment and materials supply continued, and after three months, employees requested a meeting with the General Manager and the full-time union official. After some temporary improvement, employees then conducted a six-week work to rule as they believed the job times were unfair and wanted the work study exercise repeated. Ultimately, employees became more vocal in asserting their rights and three new shop stewards were elected after a period of several years when no employees thought it worthwhile to stand for election.

At Valveco, lack of consultation about the new pay system had little impact on the recipient group of employees for two reasons. First, the amount of pay involved amounted to only three or four days' extra per year. Second, the only way the change was communicated was through a ticket in employees' pay slips, so a proportion of employees was unaware of the new scheme. However, the lack of consultation and explanation of the scheme had repercussions elsewhere. The profit-sharing scheme was created by simply making 'works' (shop floor) employees eligible for a share of the scheme already in operation for office staff. These employees were extremely angry about what they perceived as the dilution of their bonus pool and managers noticed a marked deterioration in relations between white collar and manual workers, especially reluctance to cooperate in sharing information required for production.

Lack of voice during the pay system change, therefore, had a significant 
negative impact on both production and employment relations at three of the case sites. The type of concerns employees voiced suggests a twofold aspect to perceptions of procedural justice. First, they were aggrieved at the lack of genuine voice per se which supports the view of procedural justice as an end in itself, but second, the consequences of failing to involve employees in designing the pay schemes meant that they often perceived the mechanics of the schemes as unfair or unworkable.

\section{Perceptions of pay system fairness}

Employees were asked whether they regarded the new pay systems as fair or unfair and to explain their response with criteria for assessing 'fairness' deliberately not provided, employees to use their own reasoning, these views are illustrated in Table 9.8.

The results show a mixed picture both in tenor of response and reasoning. Employee perceptions of pay system fairness tended to be founded on two criteria: first, the ground rules on which the pay system was predicated and second, on the distributive equity of the payout criteria, suggesting an overlap, at least empirically, between the concepts of distributive and procedural justice.

Autoco employees' complaints revolved around typical problems with piecework systems which have long been recognised as such. Their main criticism was of the weekly time span used for the calculation of the bonus which made their earnings more vulnerable to fluctuation. This, however, was a deliberate strategy on the part of management rather than an error in pay system design which could have been avoided through more consultation over pay system design. One employee voiced concerns about equity of outcomes from the system in expressing sympathy for a hardworking colleague who earned a smaller bonus: 'It's not done right, some pressworkers do a lot more and aren't earning as much' (Press Worker, Autoco).

Obstacles to employees reaching required performance standards were also the subject of complaint at Lampco. While the vast majority of Lampco employees felt that their pay system was fair, one had waited

Table 9.8 Employee perceptions of pay system fairness

\begin{tabular}{|c|c|c|c|c|}
\hline \multirow[t]{2}{*}{ Company } & \multicolumn{4}{|c|}{ Employee responses (\% by company) } \\
\hline & Fair & Unfair & & Don't Know \\
\hline Autoco & 22 & 78 & $(n=9)$ & 0 \\
\hline Lampco & 71 & 29 & $(n=7)$ & 0 \\
\hline Valveco & 50 & 25 & $(n=8)$ & 25 \\
\hline Heavyengco & 30 & 60 & $(n=10)$ & 10 \\
\hline
\end{tabular}


several years before being allowed to acquire new skills to upgrade, reinforcing the finding that training availability is likely to inform participants' perceptions of the fairness of skills-based pay plans (Lee et al., 1999): 'I've been on the same job for nine years, and only recently swapped round, I've got more skills the last three weeks, I've been on a sprayer for the first time' (Assembler, Lampco).

Even Valveco employees who felt the pay system was fair were unable to explain their reasons. One cause could be the recent large increase in base salaries which may have made employees likely to hold positive attitudes to the distributive and procedural elements of both the pay system which determined their base salary and the variable bonus system. This would suggest that perceived pay system fairness is associated with perceptions of both distributive and procedural justice, in contrast with the findings of Folger and Konovsky (1989) which showed that employee attitudes were unaffected by the favourability of distributive outcomes from the pay system.

The most frequent complaint amongst Valveco employees was on the basis of distributive injustice. Employees felt strongly that principles of equality should constitute reward allocation criteria given that the profitsharing is intended to promote co-operation in the interests of improving organisational performance from which all employees should benefit. In practice, because the bonus was calculated as a percentage of earnings, higher paid employees benefited more than the lower paid, as one employee put it bluntly: 'four days at my rate is a lot higher than a cleaner's' (Assembly Shop Inspector, Valveco).

\section{Summary of employee perceptions of procedural justice}

Procedural justice in designing and implementing the reward systems chosen was at best patchy and management attention to it was, in most cases, negligible. This resulted in the provision of limited information about the new pay systems masquerading as consultation. Employee discontent at the lack of opportunities to put forward their views ran high. There were consequently negative effects on employment relations and organisational performance chiefly in terms of managerial and employee time spent resolving grievances. Not only did employees often disagree with the reward allocation principles, but also once the pay systems were implemented, the lack of consultation over their design meant that the payout triggers and criteria became a frequent source of complaint.

\section{Interactional (in)justice - SMEs and the significance of interpersonal relationships}

The discussion until now has focused on the presence or absence of procedural dimensions of organisational justice. However, the quality of the 
practices and of the interpersonal relationships generated are likely to be critical to achieving the outcomes sought from them and may constitute influences on employee perceptions of interactional justice. We have noted that SMEs may be less likely to use formal procedures, in the absence of which relationships between managers and employees are likely to be more personal and more significant in influencing employees' views of their bosses and organisation (Ram et al., 2001; Marlow, 2002). Content analysis of employee comments regarding management style and conditions of employment revealed findings which map clearly onto dimensions of interactional justice. Moreover, statistical analysis of associations between employee attitudes and commitment to their employer threw up repeated connections between employee satisfaction outcomes and their relationship with their individual line manager.

At Autoco, lack of responsiveness to employee suggestions and lack of appreciation were the most frequent complaints: 'It's a pity they didn't let you know more what's going on - it gives a bit of interest, a better level of communication really. You don't see them often on the shop floor talking to workers and listening to what they say' (Press Worker, Autoco); 'It's all down to our cell manager, you ask 'im to do anything and you might as well talk to yourself, it's little things like that what niggle you' (Press Worker, Autoco); 'I don't think you're appreciated, you're just another number and there's someone always there to step in your place' (Spot Welder, Autoco).

Problems of lack of management responsiveness to employee suggestions were also widely acknowledged. One Unit Manager commented: 'I don't think we tend to communicate very well with the operators, I think we let them down a lot, we tend to make promises we can't keep, they highlight a problem and never get a permanent fix, that's what gets their goat really' (Unit Manager, Lampco). Operators similarly complained about the lack of explanation behind decision-making - informational injustice - and the way in which employees were treated as human beings - interpersonal injustice: 'I think management should make their views understood, show us proof they've looked into it and found good or bad reasons for doing something or not doing something' (Assembler, Lampco): 'Some of the team leaders treat you like shit, and the managers do too, no one listens to you' (Assembler, Lampco).

A particular problem for SMEs emerged in the form of dissatisfaction with perceived deterioration in communication levels, caused by growth and changes in the management structure at Valveco and Heavyengco: 'When I came here, it was more of a family firm, when it gets bigger and management takes over, the bosses move away from you' (Assembler/ Tester, Valveco).

Heavyengco employees were still aggrieved by the change in management style from a paternalistic one to being a small subsidiary of a larger corporate group, marked by changes in communication and depersonalisation of relationships between employees and managers: 'when it used to be 
a family firm you could talk to them, now they don't want to know, you're just here, part of the furniture' (Assembler, Heavyengco); 'Heavyengco years ago was family-owned, it was a far nicer environment, it had that personal touch from the owner, now you're just a figure in someone else's eyes' (Jig Borer, Heavyengco); 'The owner used to come down and say 'Good morning' to everyone on the shop floor' (Assembler, Heavyengco). Hence, organisational growth is likely to bring challenges in maintaining perceptions of pay fairness since managers may find it difficult to sustain employees' trust when relationships are depersonalised as new layers of management develop.

\section{Summary of employee perceptions of interactional justice}

These findings illustrate three important points about the nature of interactional justice. First, its power appears to be universal. Despite the different sizes and circumstances of all the firms, it seems remarkable that communication practices and social interaction in one form or another were a major concern and reinforces their perceived significance to employees. Second, the employee comments illustrate that, as others have argued (Bies, 2001), interactional justice appears embodied in everyday social encounters without any specific outcome attached, unlike distributive and procedural justice which are usually assessed in the context of a decision-making process. Third, contrary to Bies's most recent (2001) depiction of interactional injustice as active malice - personal insults, invasion of privacy and deception - the evidence reported here suggests that interactional justice was defined as an absence of fair treatment rather than the presence of unfair treatment. The implications for managing employee perceptions of justice go far beyond ensuring that employees suffer no slights or humiliation from colleagues or managers. Rather, actively fostering good working relationships with managers is of key significance to employees.

\section{Conclusions: comparing distributive, procedural and interactional justice perceptions in SMEs}

The chief contribution of this chapter is in moving the focus away from distributive justice of pay systems in SMEs and incorporating and highlighting the significance of procedural and interactional justice perceptions. These are especially significant in their management implications for implementing new pay systems and the resultant outcomes in the workplace. Procedural justice at the case sites was noticeable for its absence and deficiencies which, in turn, threw perceived shortcomings in interactional justice into sharp relief. The evidence supports views of procedural justice as both an end in itself, and a means to an end, as the consequences of inadequate or absent consultation discussed earlier, illustrate. 
The competence of both HR and general managers in small firms in managing pay processes is brought into question in various ways in the case studies. Employees were not involved in designing the ground rules of the pay systems which caused resistance to the systems once implemented, partly as a result of the difficulty of understanding opaque procedures. Measurable objectives were not devised and payout criteria were often subjective. In practice this often made the systems impractical or unworkable and sometimes led to avoidable modifications. However, we must recognise that these emerging problems with the pay systems are well documented in studies of large organisations with greater resources of HR expertise and, in this respect, small firms are not necessarily a special case. The outcomes of poorly managed pay system change, however, are likely to be felt much more acutely in SMEs such as the ones investigated here, given more personalised relationships between employees and line managers who may be placed in the position of having to defend ad hoc and (un)just decisions. Managerial failure to consult employees led, in some cases, to heightened demands for employee voice and a formalisation of representation mechanisms to improve procedural justice. While it is debatable how far these benefited both employees and the organisations, it illustrates the difficulty of achieving positive justice perceptions in SMEs with informal or unstructured decision-making processes.

Further research in this area, especially in the light of pending European legislation to enforce consultation mechanisms in smaller organisations, is much needed. The evidence presented offers formalising procedures as one response to perceptions of procedural injustice, but the experience of employees at Heavyengco and Valveco suggests that formalising relationships via organisational growth and ownership change ended the valued intimacy of interpersonal relationships between managers and employees. The development of formal consultation procedures then needs careful introduction to ensure that distancing between managers and employees does not occur to the detriment of interactional justice perceptions. SMEs which are growing appear to face particular challenges in managing justice perceptions as, like many elements of HRM, the effects become critical during periods of organisational change. Further research investigating managers' activities as agents of justice in SMEs and employee views of justice in expanding firms would help develop our understanding of the role of justice perceptions in these circumstances, especially given employee concerns with interactional justice which was focused on line managers as linchpins in the management structure.

Distributive justice, nevertheless, retains a role in influencing justice perceptions given the centrality of basic pay to employee concerns, especially where it is low and the amounts of variable pay on offer are relatively small. This is an especially pertinent issue for smaller firms, who may do well to concentrate on ensuring that basic pay is competitive before investing time and effort in implementing sophisticated variable pay 
systems which may offer only small extra rewards. However, it is clear from comparing employees' perceptions of distributive justice with earnings levels from the wider labour market that employee perceptions are subjective and that being underpaid does not always lead to employees quitting their jobs. This work, therefore, supports that of Ram et al. (2001) and Gilman et al. (2002) who also found a complex set of trade-offs between wage perceptions, workplace attributes and perceptions of whether alternative work was realistically available shaped employee attitudes. Further research which integrates employee perceptions of distributive justice within and beyond their workplace, their commitment to work and their organisation in the context of the local labour market would help us to understand the formation and impact of distributive justice. It would also enable us to address some of the weaknesses of treating distributive justice as if it is a-contextual. Given that the amounts of variable pay on offer were generally small, this lends support to the findings of Brockner and Wiesenfeld (1996) and McFarlin and Sweeney (1992) that when outcomes are unsatisfactory, procedures receive greater scrutiny from employees.

Given the limitation of analysing one industrial sector and changes in one facet of the employment relationship, this chapter merely scratches the surface of organisational justice perceptions in SMEs. These engineering firms represent only a tiny proportion of a heterogeneous economic sector. Highly skilled employees in the professional services industry are likely to have different expectations of and priorities for organisational justice for example. It has also only been possible to explore justice perceptions around one employment issue. However, the evidence presented by this chapter, supplemented by our knowledge that employment relations in many SMEs is often characterised by complaints of injustice, surely upholds the case for further analysis of the topic for the benefit of employment relations theory and practice.

\section{Note}

1 Funding from the Engineering Employers' Federation and the University of Bath is gratefully acknowledged.

\section{References}

Bies, R. (2001) 'Interactional (in)justice: the sacred and the profane', in Greenberg, J. and Cropanzano, R. (eds) Advances in Organizational Justice, Stanford, Calif.: Stanford University Press, pp. 89-118.

Bies, R. and Moag, J. (1986) 'Interactional justice: communication criteria for fairness', Research on Negotiation in Organizations, 1:43-55.

Bolton Commission (1971) Report of the Committee of Inquiry on Small Firms, London: HMSO.

Bowey, A., Thorpe, R. and Hellier, P. (1986) Payment Systems and Productivity, Basingstoke: Macmillan. 
Brockner, J. and Wiesenfeld, B. (1996) 'An integrative framework for explaining reactions to decisions: the interactive effects of outcomes and procedures', Psychological Bulletin, 120:189-208.

Brown, M. (2001) 'Unequal pay, unequal responses: pay referents and their implications for pay level satisfaction', Journal of Management Studies, 38(6):879-86.

Cooper, C. and Dyck, B. (1992) 'Improving the effectiveness of gainsharing: the role of fairness and participation', Administrative Science Quarterly, 37(3):471-90.

Cropanzano, R. and Ambrose, M. (2001) 'Procedural and distributive justice are more similar than you think: a monistic perspective and a research agenda', in Greenberg, J. and Cropanzano, R. (eds) Advances in Organizational Justice, Stanford, Calif.: Stanford University Press.

Cully, M., O'Reilly, A., Millward, N., Forth, J., Woodland, S., Dix, G. and Bryson, A. (1999) Britain at Work: As Depicted by the 1998 Workplace Employee Relations Survey, London: Routledge.

Deutsch, M. (1985) Distributive Justice: A Social-Psychological Perspective, London: Yale University Press.

Dulebohn, J. and Martocchio, J. (1998) 'Employee perceptions of the fairness of work group incentive plans', Journal of Management, 24(4):469-88.

Folger, R. and Konovsky, M. (1989) 'Effects of procedural and distributive justice on reactions to pay raise decisions', Academy of Management Journal, 32(1):115-30.

Gilman, M., Edwards, P., Ram, M. and Arrowsmith, J. (2002) 'Pay determination in small firms in the UK: the case of the response to the National Minimum Wage', Industrial Relations Journal, 33(1):52-67.

Grugulis, I., Dundon, T. and Wilkinson, A. (2000) 'Cultural control and the “culture manager": employment practices in a consultancy', Work, Employment and Society, 14(1):97-116.

Heller, F. (1998) 'Playing the devil's advocate: limits to influence sharing in theory and practice', in Heller, F., Pusi, E., Strauss, G. and Wilpert, B. (eds) Organizational Participation: Myth and Reality, Oxford: OUP, pp. 144-89.

Hirschmann, A. (1970) Exit, Voice and Loyalty, Cambridge, Mass.: Harvard University Press.

Holliday, R. (1994) Investigating Small Firms - Nice Work?, London: Routledge.

Hyman, R. and Brough, I. (1975) Social Values and Industrial Relations, Oxford: Blackwell.

Kessler, I. (1995) 'Reward systems', in Storey, J. (ed.) Human Resource Management: A Critical Text, London: Routledge, pp. 254-79.

Kessler, I. and Purcell, J. (1996) 'The value of joint working parties', Work, Employment and Society, 10(4):663-82.

Kim, D.-O. (1996) 'Factors influencing organizational performance in gainsharing', Industrial Relations, 35(2):227-44.

Konovsky, M. (2000) 'Understanding procedural justice and its impact on business organisations', Journal of Management, 26(3):489-511.

Lawler, E. (1990) Strategic Pay: Aligning Organizational Strategies and Pay Systems, San Francisco: Oxford Press.

Lee, C., Law, K. and Bobko, P. (1999) 'The importance of justice perceptions on pay effectiveness: a two-year study of a skill-based pay plan', Journal of Management, 25(6):851-70. 
Leventhal, G., Karuza, J. and Fry, W. (1980) 'Beyond fairness: a theory of allocation preferences', in Mikula, G. (ed.) Justice and Social Interaction, New York: Springer-Verlag, pp. 167-218.

Lind, E. (2001) 'Fairness heuristic theory: justice judgments as pivotal cognitions in organizational relations', in Greenberg, J. and Cropanzano, R. (eds) Advances in Organizational Justice, Stanford, Calif.: Stanford University Press, pp. 56-88.

Low Pay Commission (2003) The National Minimum Wage - Fourth Report of the Low Pay Commission, London: The Stationery Office.

Marlow, S. (2002) 'Regulating labour management in smaller firms', Human Resource Management Journal, 12(3):5-25.

McFarlin, D. and Sweeney, P. (1992) 'Distributive and procedural justice as predictors of satisfaction with personal and organizational outcomes', Academy of Management Journal, 35(3):626-37.

Meyer, C. (2001) 'Allocation processes in mergers and acquisitions: an organisational justice perspective', British Journal of Management, 12:47-66.

Moule, C. (1998) 'Regulation of work in small firms: a view from the inside', Work, Employment and Society, 12(4):635-53.

Office for National Statistics (1998) New Earnings Survey 1998, London: ONS.

Rainnie, A. (1989) Industrial Relations in Small Firms: Small Isn't Beautiful, London: Routledge.

Ram, M. (1993) Managing to Survive: Working Lives in Small Firms, Oxford: Blackwell.

Ram, M., Edwards, P., Gilman, M. and Arrowsmith, J. (2001) 'The dynamics of informality: employment relations in small firms and the effects of regulatory change', Work, Employment and Society, 15(4):845-61.

Rawls, J. (1971) A Theory of Justice, Cambridge, Mass.: Harvard University Press.

Storey, D. (1994) Understanding the Small Business Sector, London: Routledge.

Thibaut, J. and Walker, L. (1975) Procedural Justice: A Psychological Analysis, Hillsdale, New Jersey: Erlbaum.

Thorpe, R. (2000) 'Design and implementation of reward systems', in Thorpe, R. and Homan, G. (eds) Strategic Reward Systems, Financial Times/Prentice Hall, pp. 115-34. 


\title{
10 Representation, consultation and the smaller firm
}

\author{
Alan Ryan
}

Recent reports (TUC, 2003), suggest that there is a growing trend for people to spend more of their time in the workplace, whether this is called presentism or a long hours culture seems irrelevant in terms of the overall outcome; work is taking over ever-increasing segments of daily life (Noon and Blyton, 2002). Yet, it continues to be a key area within which people have little say in relation to what they do, how they do it, when they do it and where they do it. Employment remains, within an allegedly democratic society, an area of social interaction within which people have few opportunities for an adequate voice in decisions pertaining to a central life activity. There is, in effect, a representation gap (Towers, 1997) where few have influence over the choice of management or upon the strategic direction of the organisation for which they expend their labour and upon which they rely for their future livelihood. Freeman and Rogers (1999:39), exploring views upon this issue, found that employees wanted greater input in workplace decisions and sought greater influence in key areas such as finance, strategy, departmental goals, training, work schedules and the distribution of rewards. It was also found that, in general, the better educated the employee, the more hours (annually) they worked plus, the greater length of their permanent status with an organisation, the greater the desire for more input on such workplace decisions.

Indeed this, and other research (see for example, Cully et al., 1998; WERS, 1998), appears to indicate that there is a strong correlation between worker satisfaction and influence over those matters judged as important in the workplace setting. Moreover, dissatisfaction in this respect leads to increases in grievances lodged, turnover, absence and ultimately lower productivity (Bingham and Chachere, 1999; Freeman and Rogers, 1999; Lewin, 1999). Given that employees have indicated a desire for greater involvement but it would appear that such involvement is the exception, rather than the norm, it appears that most firms are still organised on the assumption that control can be most visibly reinforced by the centralisation of decision-making and hierarchical structures. However, that is not to say that employees are completely without voice in the contemporary organisation as trade unions, although diminished in power 
and influence during recent years (Edwards, 2003) still act to provide voice for over six million employees in the UK. Moreover, research would indicate (Cully et al., 1999) that in most large, non-unionised organisations there are varying degrees of representation and consultation processes which, even though they might be very weak mechanisms for power redistribution, do at least offer some conduit for voice. It is also apparent that with the adoption of the European Directive on consultation and information, larger organisations will be obliged to adopt mechanisms which provide for the communication of information to all employees. The extent to which such information will be provided directly to employees will, to some degree, be determined by existing procedures, however, employees will have the general right to receive classes of information (for example, relating to the economic situation, probable developments in the undertaking and proposals for the deployment of labour) for the first time. This argument moves the debate forward by challenging the simplistic nature of the theme music which indicates that, as trade unionism has been the main channel for representation, the absence of trade unions automatically results in a dearth of voice for the employees.

Since the 1980s, employee voice in larger firms in the UK has definitely weakened as union influences have been constrained and there is little evidence to indicate that any credible alternatives have emerged (Towers, 1997). Such conclusions can be drawn from the complex and sophisticated body of literature which has emerged which focuses particularly upon issues of representation, trade union activities, non-union alternatives and the growing trend towards HRM type polices of consultation and direct communication (Flood et al., 1996; Terry, 1999; Kaufman and Taras, 2000; Millward and Forth, 2000; Dundon, 2002). It is presumed, moreover, that such findings apply across the labour force with the key focus upon the representation strategies themselves. As has been argued in chapter 1, it is accepted that the effort-wage bargain is the foundation of the employment relationship in market economies, but the manner in which that is articulated will be shaped by firm context. In the case of representation, voice and influence it is again argued that these issues will be influenced by firm size. The fact that unions are not traditionally active within the small firm sector combined with the misguided (if now discredited) notion that employment relations in such firms are defined by harmony and agreement has led to the issue of voice, representation and consultation being somewhat ignored within the literature.

Recently, a growing body of literature has begun to emerge which recognises and explores the aspect of informality in the labour management processes of smaller firms and the implications of this for both employees and employers (Ram et al., 2001; Marlow, 2002). As of yet, however, there has been little attention focused specifically upon how small firms manage the process of voice and representation although it is clearly critical to policy issues regarding retention and, as Cox (chapter 9) 
indicates, perceptions of fair rewards. Of considerable importance to this debate, furthermore, is the possible impact of the forthcoming European Directive which necessitates indication of compliance with formal channels of communication and representation. To assess how smaller firms might deal with such issues, it is essential to consider current-approaches to representation, consultation and employee voice. To undertake this task, this chapter will focus on the manner in which management, as the proactive party in the employment relationship, determines strategies of participation, noting the extent to which managers in smaller firms make use of participation strategies and, therefore, the changes likely to be implemented following the enactment of the Information and Consultation Regulations. We use case study examples to highlight the mixed messages emanating from current practice within the small firm sector.

What appears, notably within small firms, to be the principal impediments to the development of mechanisms that address these issues is the lack of management willingness to relinquish power and the inability of workers to escape management hegemony over the workplace; too often, the trade-off between these is viewed as a zero-sum class struggle. The foundation stones of these problems are associated with ownership, management style, product and labour markets and, possibly more controversially, the historic absence of trade union representation within such firms. This chapter addresses these issues and examines recent proposals to tackle the effects of the influence gap in terms of legislation designed to control indirectly the practices, policies and outcomes of the employment relationship.

Despite a long history of trade union involvement in larger organisations, both pre- and post-the Bullock Report (1978), attempts to encourage employers to develop representation and consultation mechanisms in the UK are primarily seen as encouraging forms of consultation which are informational, rather than representational. More generally in smaller firms, however, the absence of trade unions has arguably led to markedly different, more informal, management styles in the area of representation and influence. In the 1980s, legislation was introduced which required larger organisations to include, within their annual company reports, a section which indicated the measures they were taking or had taken within the last twelve months, in relation to the promotion of representative arrangements within the workplace (Company Act 1985 s235). In detail, the report had to provide information that identified what measures had been undertaken to offer employees, in a systematic manner, information relevant to them as employees and provide an awareness of the economic factors affecting the performance of the company itself. Analysis by the Department of Employment (1988) on the effectiveness of this legislation indicated that many affected firms ignored the requirement ( 25 per cent), or gave an ambiguous (12 per cent), incomplete (11 per cent), or brief response ( 8 per cent). Such responses prove of limited use in understand- 
ing the current developments within larger organisations and, moreover, the rule does not apply to smaller organisations employing less than 250 people, so excluding from its ambit a large number of employees (Willey, 2003:516).

Legislative pressure to change this situation has arisen from within the European Union in terms of the Information and Consultation Directive (2002/14/EC) introduced in line with Article 136 of the Treaty of Amsterdam, an article which is designed to encourage the dialogue between management and labour. These requirements, to be implemented in the UK by means of the enactment of the Information and Consultation of Employees Regulations (currently only in Draft form), will apply to all organisations with 150 or more employees by March 2005, 100-149 by 2007 and $50-99$ by 2008 . Whilst the Directive (Article 19) indicates application to establishments with over 20 employees the UK has chosen to implement the figures as indicated above. This minimalist approach excludes many employees in smaller business units. Further, the directive turns the focus on more than just the mechanisms of delivery, but also the types of information which must be communicated and the timing of such communications. As with much new employment legislation there is a 'wait and see' element regarding the effect it may have upon employment relationships, a situation - in relation to research pertaining to the effects of legislation - which has emerged in the decades following the winding up of the Panel on the Monitoring of Labour Legislation in 1983. Current legislation on collective redundancies has been the topic of numerous comments from tribunals centring on a working, workable definition of the legal phrase 'in good time' (Trade Union and Labour Relations (Consolidation) Act, 1992 s188). Unless the new regulations make clear the timing and the issues concerned, smaller firms will be left open to litigation and may find compliance costly. Such confusing implementation may well provide evidence of what Marlow refers as 'exceptionally deleterious effects on smaller firms arising from increased regulatory burdens' (2003:535) although it is acknowledged that this effect may be perceptual rather than experiential (Blackburn and Hart, 2002).

Further, the inclusion of organisations employing as few as 50 people will extend the ambit of legislation in this area to a greater number of firms than previously envisaged and represents a further challenge to the traditional labour relationship in many small firms based upon informality and focused upon the social relations of production. The draft regulations proposed by the UK government do not specify the form that any such consultation should take (union versus non-union for example) nor does it determine what forum must be used (elected representative versus whole organisation). To a greater degree, within smaller organisations these decisions are likely to be decided by ownership and/or management style (Rainnie, 1989; Marlow, 2000) rather than the influence of pressure groups such as trade unions, given their weak influence in the sector overall. 
In response to these proposals, business leaders have suggested that the approach contained is based on the false assumption that 'one-size' fits all and as such, is misguided. They also argued that employee involvement is only one of a number of practices that can contribute to information dissemination and, therefore, the emphasis should be on direct consultation rather than consultation through representatives. Indeed, despite a growing wealth of evidence to the contrary, the CBI point to the achievement of harmonious employment relationships within small business as an example of the effectiveness of direct consultation. In arguing from this perspective they take for granted the discredited harmony thesis, which, whilst superficially attractive in this context as it supports their 'laissez faire' preferences, has more recently undergone detailed questioning leading to the realisation that it has little basis in fact (Duberley and Walley, 1995; Marlow, 2000; Burgess et al., 2001). They view this regulation as overly prescriptive and restrictive as it would limit the flexibility needed to introduce structures appropriate to their different organisation. This being the case they argue for a light touch which puts in place trigger mechanisms requiring workers to ask for consultation before there is a requirement to set up councils or committees. This would preserve the existing diversity, enable organisations to keep current mechanisms that have broad employee support and protect the legitimate business confidentiality.

The TUC argue that effective implementation of the directive is critical to the achievement of high performance and competitive advantage. It is imperative, they suggest, that the regulations need to be specific in relation to the subjects open for consultation and that any mechanisms should be permanent rather than triggered by particular incidents, requests or economic circumstances. In simple terms, it would seem that a statutory fall back arrangement, similar to the procedures relating to conflict resolution (discussed below) should be put in place and should be enforceable in relation to all organisations unwilling to implement the required procedures by agreement.

Such a statutory procedure would have major implications for smaller businesses, many of which currently operate on the basis of informality, arguably involving a regulatory shock in areas of vital importance to smaller businesses, especially when placed alongside other recent legislation (Ram et al., 2001). This regulatory shock will be further compounded by the pressures exerted by the recent enactment of legislation enforcing minimum standards and procedures in terms of organisational discipline and grievance procedures. This legislation further constrains the exercise of (un)questionable authority and imposes mechanisms on all firms (Employment Act 2002 schedule 2).

In the past decade, the number of tribunal applications has risen from some 73,346 to over 100,000; whilst recent figures show a decline from the high of 130,000 in 2001-02 there appears a line of resistance inhibiting a 
drop below 90,000 (Burgess et al., 2001). Tremlett and Banerji (1994) noted that whilst the median size of organisations involved in such cases was 35 employees, many were part of larger UK groups and over twothirds employed personnel staff. However, the smaller the firm, the more likely the jurisdiction was to be unfair dismissal, and within that area the main issues relate to disobedience/refusal to obey orders. From these results, we see a reflection of the informal nature of control within smaller organisations and the manner in which owner-managers lead their businesses. Whilst the research indicated that many of the organisations had formal discipline and grievance procedures, the application of these mechanisms was erratic. In 1998, survey evidence (DTI, 2002) indicated that small employees were less likely, on average, to be involved in discrimination cases, but significantly more likely to be involved in cases relating to redundancy payments. This is indicative of two pressures placed on smaller firms during the intervening years. The changes in legislation in this area relating to increased consultation requirements have presented owner-managers with more pitfalls to avoid, whilst the decline of manufacturing in the UK, alongside the developing use of offshore suppliers has led to increased job losses in specific sectors of the economy. If, as Blackburn and Hart (2002) noted, the knowledge of employment rights is to some extent determined by the experience of their application to the business, the regular appearance of smaller businesses is easy to explain following legislative changes. In terms of redundancy many smaller businesses experience such situations only once (closed down) or make use of managerial prerogative to remove people before redundancy becomes an issue second time around.

The government has responded to the increasing number of applications arriving at Employment Tribunal offices by putting in place statutory minima in terms of workplace dispute resolution procedures, specifically statutory dismissal, disciplinary and grievance procedures. These procedures, intended to apply to all businesses, are designed to internalise dispute resolution and restrict the number of applications to tribunals. For many smaller firms, this may prove problematic in relation to the restriction of managerial prerogative. Employees will enjoy the contractual right not to be dismissed or disciplined without the implementation of the standard three-step procedure. Where such a basic procedure is not followed the tribunal can find the dismissal automatically unfair, award a small basic award of compensation for this failure, and award an increased amount of compensation of up to an additional 50 per cent of the award, where the employee is successful. Equally, employers can require employees to adhere to a three-step grievance procedure before making any claim of constructive dismissal. For both procedures strict timetables are set out which will further limit the exercise of the traditionally accepted prerogative associated with ownership. The government figures (DTI, 2003) suggest that some 20 per cent of firms with under 200 employees currently 
have either no procedures or sub-standard procedures and that implementation for these organisations will cost, on average, $£ 171$ to $£ 190$ per case. Whilst this is well below the average cost of attendance at an Employment Tribunal, such costs on a workplace scale need to be added to the perception of lost control/authority within the organisational hierarchy. The introduction of such procedures should, therefore, generate debates within a number of smaller organisations linked to the pressures to democratise the workplace.

A central element in the outcome of this internal debate will be the management style adopted by smaller organisations. In these organisations, two other factors influence the choices made in relation to employment relations. First, we look at ownership (Scase and Goffee, 1980) divided into situations where the owner works alongside other employees undertaking routine managerial roles as employers as well as employees. In these organisations, the face-to-face nature of the employment relationship would suggest a style of representation and consultation, which is more direct and informal. In such situations, the notion of formalised meetings seems alien to the general tenor of the relationship. Whilst in other situations the employment relationship is more distant with owners acting as managing directors within less personalised organisations. It would seem that these firms are more likely to employ larger numbers of workers, have a distinctive management cadre, and operate within the less technologically advanced sectors (Lewin and Mitchell, 1992). A final strand to this debate is where the plant under consideration is part of a larger organisation and as such finds employment relationships determined by an external authority. In these organisations, it is more likely to find information and consultation mechanisms, whether unionised or otherwise, imposed on the plant, more formalised, and with an agenda set by the interests of the parent organisation.

From these arguments, it can be suggested that the style of management varies across organisations within the parameters indicated by Goss (1991) of paternalistic, fraternalistic or autocratic. Associated with each of these styles are particular forms of consultation in connection with the different objectives, organisational and individual, inherent in each. Etzioni (1961) has identified these in terms of the philosophy underlying coercive, remunerative or normative management policies. For the smaller businesses, this typology of managerial philosophy is clear and useful. Ownermanagers may choose to use the threat of dismissal as a mechanism to legitimise their decision-making power despite the negative effects this may have on personal relationships. In this respect, we see the maintenance of personal control, a lack of consultative policies, and the (re)assertion of relationships of subordination. Alternatively, some ownermanagers attempt to secure control by the application of additional rewards where service (work levels) are exceptional. It matters little whether these reward schemes are paid in cash or fringe benefits, indeed, 
in smaller firms such rewards, it is argued, may well take the form of paternalistic indulgences; smaller business managers and propagandists argue that the harmonious relationships are evidence of such a managerial style. However, claims for the school of modern management techniques, whether called Human Resource Management, High Commitment Manager or some other 'buzz' word variant, claim allegiance to a style which relies on normative assumptions. Here we are making reference to the development of organisational cultures which determine the behaviour patterns of both managerial and other staff. Such cultures in smaller businesses are generally set, developed and maintained by the owner-manager without consultation with the employees. In high skill settings, it is more likely that the culture will make some acknowledgement of the professional profile of these workers.

Here the argument is that the primacy of each philosophy will infect the way in which individual managers view the role, importance and usefulness of the various representational systems. In this respect, smaller firms are again, not merely miniature versions of larger firms, as in the latter there is less scope for personal/managerial innovation, flexibility and flair as they tend towards procedural bureaucracy. As Parker (2002) notes, 'bureaucracy is dehumanising because its dull rationality causes human beings to become morally encrusted and incapable of passion' (2002:37); a condition which stifles the individualisation of managerial systems and leads to an employment relationship which lacks the trust required from each party where both power and authority are shared.

We can concentrate on sectoral issues more directly to note that in smaller organisations, no less than in larger organisations, management information and consultation mechanisms are influenced by product markets, labour markets, technology and other institutional features (Marchington et al., 1992). Where product markets are tight or suffering short-term contractions, employers are more likely to invest in downward communications in order to offer comfort to those survivors who will not be losing their jobs; what we can refer to as 'lifeboat democracy'. Further in organisations where the application of so-called tacit skills and/or emotional labour is of greater importance, mechanisms of consultation and information appear to be more widespread, developed and central to the philosophy underlying managerial behaviour. A further factor contributing to the existence and application of these mechanisms within smaller firms appears to be the skill levels of the employees. Thus, in a small garment manufacturer we are less likely to see mechanisms designed to meet the requirements of the forthcoming legislation than in a high skill setting where the workforce is composed of knowledge-workers.

Justification for the introduction of more formalised mechanisms of consultation and information is rarely to provide employees with more power in relation to decision-making. Classically, the argument is that such schemes are introduced in a pursuit of higher performance and greater 
commitment to organisational goals (Marchington et al., 1992). So, they are systems designed to provide education and information, which will result in higher levels of employee contribution and a more efficient method of dealing with conflict (Verma, 2000). In this respect, the representation of the interests of employees is not a primary goal and management strive to retain both the power and the authority to make all decisions. Moving away from the face-to-face relationships, this style of consultation is primarily concerned with communication rather than representation of the interests of the weaker party.

In many ways, this trend towards a more formalised mechanism of consultation runs counter to the development of individualised employment relationships within UK workplaces and, notably, the familial relationships within smaller businesses. In these situations, we can speak of an individualisation, which is procedural rather than substantive. The organisational tendency within this process is predominately related to the avoidance of collective mechanisms to determine terms and conditions rather than the differentiation of the terms and conditions for individual employees. Whilst the latter may be visible in micro firms the sheer scale of the work required as firms grow make such arrangements impossible, as they are unrealistic, impractical and unworkable. In many firms, where such a process of individualisation is the predominant culture, it has meant increasing workplace expectations and difficulties arising in relation to meeting the divergent needs of both individuals and organisations; often this was driven by increased awareness of legislation (see Blackburn and Hart, 2002).

In the workplace, as a social situation, the actors' notions of the relationship vary in terms of effort level, working methods and rewards, so much remains located within the domain of custom rather than the strict legal world of contract. In smaller firms, owner-managers claim they are entitled to determine the culture or norms, which are operationalised within their organisation, for them voice as a medium to provide a protected means for employees to express collective interests which are contrary to, or in opposition with, managerial decisions is an illegitimate intrusion. For this group of managers Human Resource Management (HRM) as a policy initiative is a means of placing emphasis on the "superiority of the individualistic treatment of employees as an alternative to the eliciting of their organised collective voice' (Brown et al., 1998:11). The widespread application of representational mechanisms and formalised procedures relating to grievance are seen as counterproductive within smaller businesses.

Grievance procedures are widely regarded in one of two ways by managerial staff. They are seen either as a centrepiece of labour management relations and key elements in any process of representation or as a vehicle for whingers and moaners to cause trouble. The introduction of a statutory procedure is viewed by the government as a means of reducing the 
number of tribunal applications by (re)focusing industrial issues within the industrial realm rather than the domain of legal disputes. Such procedures are seen as being representative of the dynamics of the relationship, especially in organisations where union representation is not available to the employees. Lewin (1999:138) suggests that grievance procedures 'may represent a form of reactive conflict resolution and that alternative, preventative forms and mechanisms of workplace conflict resolution may exist and be used by labor [sic] and management'.

From this perspective, such procedures can be seen in the light of Hirschmann's exit-voice-loyalty theory (1971). Following this theoretical construct, we can suggest that workers, who file grievances because they want more say in workplace decisions, are more likely to exit where voice is denied, ignored or rejected. In this situation exit can be physical (from quitting to regular unauthorised absence) or mental (from daydreaming to working without enthusiasm). Indeed, on the surface, it would appear that grievance filing is negatively related to loyalty and positively related to intent to exit; feedback from the outcomes of cases being regularly a sound predictor of subsequent behaviour (Eaton and Keefe, 1999). Alternatively, we can argue that in order to overcome some negative effects managers could note that for Hirschmann (1971) loyalty is positively correlated with voice, so that relatively more workers that are loyal will exercise voice rather than exit the organisation. It is common for managers, especially owner-managers, to assume that workers in organisations where union, or other collective forms of representation are absent, are more likely to leave than exercise individual voice within the parameters of the grievance procedure. This is partly because those who raise grievances are generally seen to have 'significantly lower job satisfaction, more negative attitudes towards their supervisors, greater perceived pay inequality, and stronger preferences for worker participation' (Lewin, 1999:176); in short are disenchanted troublemakers who fail to fit-in with the culture of the organisation. In smaller businesses the relative closeness of management is seen to allow for the informal discussion of problems and, therefore, to negate the need for a bureaucratic mechanism of reactive conflict resolution. Marlow found that managers favoured open door policies, with 93 per cent of the sample making reference to 'informal discussion and resolution of workplace problems' (2003:540).

From this argument, we can suggest that the new legislation will mean smaller firms need to develop a more effective form of consultative management style. Toner (1987) suggests a number of elements that lead to the improvement of a consultative management style, which is founded on a strong non-union culture. Whilst some of these are out of the reach of small businesses, others appear to reflect the descriptions given of relationships within such organisations. The argument put forward is that a strong culture based on these elements will allow for the development of higher productivity levels without necessarily leading to the demand for 


\section{A. Ryan}

representation based outside the organisation. Simply the key element is one of mutuality reflected in shared goals, shared norms and visible linkages between these two (Toner, 1987). These shared elements, it is suggested, are promoted by the development of organisationally relevant symbols, a team working ethos, good interpersonal relationships and organisational pride. A consideration of these elements in relation to smaller businesses, or so much of the literature would tell us, would result in a high incidence of each being present. Further, we can argue that the adoption of a managerial style which reflects these policies, to a greater or lesser extent, will improve communication, promote a less adversarial climate, enhance levels of production, reduce barriers to flexibility, and eliminate any obvious platform for troublemakers. However, they come at the cost of higher overheads because all these meetings are time consuming, make change more problematic as such policies increase the organisational pain involved in the transformation of relationships, and may encourage the expression of trivial grievances (Flood et al., 1996). It is clear, therefore, that smaller business units, which choose to avoid formal procedures relating to consultation and dispute resolution, do not necessarily meet the worker demands for involvement nor steer clear of the costs inherent in such procedures. As Verma (2000) argues there appears to be a trade-off between equality and efficiency issues inherent in the development of more participative managerial styles.

Whilst the introduction of UK legislation, based upon the requirements of the European Union directives, is one reason for smaller organisations to look at the introduction of consultation and information mechanisms, it is by no means the only rationale for their introduction. As noted above, it would seem likely that a worker-based trigger will operate the UK legislation and some employers may seek to side-step the statutory procedures by introducing schemes of their own design. The introduction of such schemes within smaller businesses may be less widespread because the attainment of higher levels of commitment can be secured by the adoption of paternalistic, rather than autocratic managerial styles. Nevertheless, we can identify alternative rationale for the introduction of such schemes. Marchington et al. (1992) suggest that underpinning other reasons is the modern school of thought which views employee involvement (if not true participation because it lacks the element of power) as 'something of a panacea for organisational ills' (1992:x). From this perspective management, correctly or otherwise, introduce their own schemes on the grounds that it will establish direct lines of communication, enable managers to make workers aware of the market, customer, legislative and other social pressures bearing down on the firm. Such an educative function is, they argue, vital in the process of increasing the perception of mutuality where this perception encourages levels of employee contribution and commitment by introducing elements of joint problem awareness, thus eliciting the application of additional employee effort in identifying and solving the 
problems. As suggested, whether formal or informal in nature, the creation of effective information and consultation systems can be seen as an attempt at the enhancement of both problem-solving mechanisms and a means through which employees can let off steam in a managerial controlled environment which does not challenge authority structures.

The widespread use of open door rhetoric, and arguably the associated practices, within the small business sector indicates awareness that such safety vents are needed and valued. The question, which remains unanswered, relates to the extent to which such managerial styles enable greater job satisfaction rather than facilitate silent exploitation. In the main, they adopt one of two approaches to the management of employee relations based on the usual myth that, as smaller organisations are harmonious the need for formal HR management system, including consultation and information, is equally small. First, what we could call the Ostrich Approach, which denies the need for such mechanisms in the tight knit family organisation, or alternatively the Woodpecker Approach, which postulates that all they need to do is work harder at current practices in order to maintain high levels of commitment and productivity. Knowledge management, or the Owl Approach, is seen to be too expensive for implementation by these smaller units and the need for any mechanisms designed to share knowledge is seen to be negated by existing employment relationships. Alternatively, some of the innovative new wave organisations in the contemporary small business sector are free of the problems that face larger firms and those operating in older sectors of the economy, relating to the loss of human expertise and loyalty. As many of these newer firms are in high technology sectors or consultancy, they recruit skilled labour from a differentiated market that allows for the development of more personalised employment relationships, which rely on the coordinated and connected dissemination of information. Such firms, therefore, feel little pressure for formalised systems of interest representation and even less need for the involvement of trade unions.

Evidence would indicate that managers prefer to deal directly with employees, trade unions being seen as interlopers, gatecrashers who bring nothing to the party but trouble (Dundon et al., 1999). Operating on the rhetoric, if not always the reality, of a family, team or clan environment they indicate that the reason they are less confrontational and have fewer formal disputes is to a large extent due to the lack of trade union involvement. As many will have no human resource manager on site, and even fewer will have an industrial relations specialist, the absence of trade unions reflects and further strengthens a unitarist ideology within which those at the top believe themselves to be in the best place to make decisions (Wynarcyzk et al., 1993; Carter and Jones-Evans, 2000). Any union involvement, even more than managerially designed consultation mechanisms, is seen to dilute control from the owner to outside agencies. These grounds alone are sufficient to indicate that most smaller business 


\section{A. Ryan}

managers are resistant to union involvement in their organisations, what also militates against such involvement is the traditional union wage markup. From this perspective trade unions are seen as third parties that 'depend on conflict and acrimony for their survival, are driven by internal political dynamics to "milk the cow" (the company) for more, more, more at the expense of future jobs, and company well-being' (Kaufman and Taras, 2000:35).

Size of establishment, as well as age, are regularly seen to be a determinant of the propensity of the organisation to be unionised, with younger, smaller firms being far less likely to be involved with Trade Unions (Cully et al., 1999). As noted above, the legislative provisions relating to statutory recognition specifically exclude smaller firms, although some smaller units are included because of their relationship to a larger plant. Many of this latter group find their HR policies, including representational policies, influenced by previous or current links with major customers, suppliers and parent organisations. Guest and Rosenthal (1993) note that some managers deliberately keep the number of employees down in order to make the organisation unattractive to union organisers, some moving production around a number of smaller units, believing that smaller, nonunion plants reap the benefits of lower labour turnover, absence, conflict and costs. It is argued, especially in relation to smaller new wave firms, that they are characterised by flatter structures based on clan environments, high trust employment relationships, team working, open two-way communications, and very careful selection policies. In such an environment, trade unionism would appear antagonistic, a denial of the ability to fully exploit the knowledge, skills and innovation available within the workforce.

A final characteristic, which limits the effectiveness of recruitment drives by unions within the smaller business sector, is worker apathy. Cully et al. (1999) noted that whilst smaller business units (under 25 employees) reported the presence of union members within the firms in 28 per cent of instances, the figure for other organisations was 36 per cent. Whilst the points outlined above can explain some of this difference, the evidence indicates that workers in smaller business units do not feel the need for trade union involvement. Commentators (Dundon et al., 1999; Kaufman and Taras, 2000; Dundon, 2002) have argued that this may reflect greater job diversity, satisfaction with the outcomes of the wage-effort bargain and an atmosphere of supposed harmony within smaller business units. Employment relationships based on empowerment, smaller working units, open door policies and high trust are seen to compensate for lower than average wages within the sector. The opposite side of this coin is that the employees are often unskilled, temporary and part-time seeing trade union subscriptions, therefore, as an additional cost for which they receive no benefits. Moving rapidly between different employers, these 'butterfly workers' enter and leave unionised environments, never staying long 
enough in any one to view themselves as part of any collective interest groups. Union membership for this group of workers is not, unless a family tradition, of any importance nor can it be seen to offer the prospect of any improvements to their working lives.

This is not, however, the case in all smaller business units, some already operate with consultation and information mechanisms that are fully developed and attempt to address the issues of any representation gap, whilst not significantly addressing the influence gap. For these organisations consultation forms part of their day-to-day operations, is seen as a vital element of the familial culture and a required part of maintaining high performance. We can also report situations where the very idea of collective representation is seen as the antithesis of effective management. For these organisations managerial prerogative is more important than representation or consultation. The following discussion, with evidence drawn from a number of case study firms, highlights the different practices which we can find in organisations following the different ends of this spectrum. In organisations like TexCo, for example, a small multi-site textile manufacturer employing 80 mainly female staff with a major retail outlet taking some 85 per cent of available production, staff are unionised, although the branch is moribund with no elected representative on any site meaning a full-time union official provides representation. The union agreement is a policy carried over from the firms previous position as part of a much larger unionised organisation and the new management are ideologically opposed to union involvement. Formal meetings with the union are few and far between, although the managing director does give an annual address and prior to the last downsizing exercise did arrange meetings with each line; the union were not involved in these meetings and did eventually secure a number of protection awards following Employment Tribunals.

The production manager, who has little experience in employment relations, is responsible for all personnel decisions and regularly dismisses individuals without following any procedure. Neither party to the employment relationship views representation as a key issue because both view the relationship as short-term (seasonal) and employee expectations are determined by a desire to earn piecework payments rather than lose time arguing about who has the authority to make decisions. Management foster the idea that the customer knows best and will walk away if the firm fails to maintain quality and quantity at the levels they require. The union concerned manages to preserve low membership levels and has on a number of occasions sought to generate interest in membership of a branch committee. They find it difficult to sustain interest once management arrange endless meetings, which take the workers off high paying production lines and hence reduce average earnings, or workers move to alternative employment along the road at a competitor organisation which is non-union; interestingly when they switch back to this organisation they join the union again. 
In contrast to this situation TieCo, also a unionised organisation of approximately the same size and in the same area, actively encourage representation of various interest groups and union representatives are paid line averages when they are called to meetings, disciplinary hearings or pay discussions. The managing director suggests that this means they encourage better workers, who are already committed to the organisational goals to undertake the role. Membership levels are higher than average for the sector and remain consistent over time. All branch committee roles are filled and the membership regularly raise problems, which lay representatives are expected to handle. The organisation operates an open door policy but managers report they normally channel information and deal with workplace problems using the union. These two different approaches to the representation of worker interests reflect the classic problems faced by trade unions when trying to extent their influence within the smaller business sector. Clearly the new legislation will impact on each of these firms to differing degrees and in practice shine a light on involvement mechanisms. If the government adopt the trigger approach then the impact is likely to be far less on TexCo, as it will be if existing arrangements are included as acceptable application of the European directive.

Alternatively, we can note the differences between unionised and nonunion organisation operating within the same sector. GasCo is a small manufacturer of auto parts in the UK, though part of a larger European organisation. In the UK, they employ some 60 people, recognise the relevant Trade Union, and operate a European Works Council. In many respects, they are atypical in regard to smaller firms in that they have a set of well-developed formal polices and procedures. A dedicated HR manager handles all human resource and industrial relations matters; and in this case, the manager is a member of the Chartered Institute of Personnel and Development.

HeatCo manufactures auto parts for a major UK car producer, as well as providing a bespoke service direct to vintage vehicle enthusiasts and the haulage sector. Part of a larger organisation until recently, they employ some 130 workers and are, due to an ideology passed down from the larger parent organisation, a non-union organisation. The firm operated a longstanding works council arrangement in order to provide voice and representation. The management accepted that the absence of a trade union meant that the elected representatives lacked the organisational back-up and training to express the views of their constituents effectively. Recognising the counterproductive elements in this situation, they arranged training with a local provider and agreed a mechanism of confidential support and advice. A single owner recently acquired the organisation and whilst this resulted in no change in the non-union ideology, the new owner cancelled the training and advice agreement and reduced by two-thirds the number of meetings with the representatives. Some time 
before the take-over the works council had operated with two of the six worker representative places remaining unfilled. Initially, the firm held elections across the workforce for the roles and regularly secured 10 candidates and a turnout in excess of 85 per cent of the workforce, when the most recent vacancy arose following the resignation of the incumbent they could not even secure a volunteer to fill the role. When asked, workers noted that the meetings had become forums for management to make announcements, consideration of minutiae and an employer mandated 'yes' system.

We can argue from these cases that the forthcoming legislation will have varying effects on each of the organisations. For those organisations choosing the minimalist route currently, these changes threaten the introduction of more intrusive, possibly extensive, procedures. Whether the legislation requires triggers or is introduced with a standard fallback procedure, they will have to adopt procedures which are contrary to existing culture and the feeling of rule by management not committee. These changes, bearing in mind the size of each organisation, could result in more active attempts by trade unions to gain access to the organisations offering services to any employee elected/nominated to a consultation committee. We could argue that the management at HeatCo is likely to implement programmes aimed at re-invigorating the existing system in order to repel such advances, things might not be so easily solved by TexCo. However as TexCo currently recognise a trade union they may find that their current unsympathetic attitude, practice and policy can continue without challenge; the legislation does not require consultation or information procedures which are operated in good faith. Both TieCo and GasCo offer a different prism through which to view the issues. Currently, positively inclined towards involvement, if not influence, the legislation will, it appears, have little effect on their practices. However, none of the organisations operate, or would want to operate, procedures which offer influence beyond the exercise of procedural voice, which leaves untouched the key issue of power distribution. Perhaps there is no issue associated with the employment relationship which causes so much controversy as the exercise of power and authority. The granting of authority to employees by the introduction of voice mechanisms is always conditional, that which the employer gives, the employer can take away based on ownership rights. Valid representation and consultation mechanisms are an attempt to distribute intra-organisational power; they are attempts to shift the focus away from adversarial relationships and towards cooperation and mutuality. From this perspective, 'Employee representation is any organisational structure that has one or more employees in it and represents in an agency capacity the opinion and interests of other employees to management' (Kaufman and Taras, 2000:527).

For the smaller firm this twofold purpose is, supposedly, achieved through open door policies and family environments without the debilitating 
distribution of authority and power and may be thought of as targeted at securing the substitution of cooperation for antagonism. Any move towards representation and consultation will only be entered into where the project does not affect the existing system, under which it is management that 'establishes the rules and regulations that determine compensation, training, hiring and firing, and the administration of discipline' (Kaufman, 2000:55). We can argue that if it is legitimate for management to make these decisions it is equally their role to decide what, if any, form of representation and consultation mechanisms to establish. The imposition of representative forums by an outside agency, be it trade unions or government, will be resisted as the enemy of effective management. Arguments that the existence of representation and influence gaps indicate a deficit of worker trust in the ability of managers to arrive at equitable decisions about the structure of the employment exchange are dismissed as not relevant for the small firm sector. From this view, representation and consultation must be direct, management driven, and non-union based on what we might call the belief in a just management. The formality of legislative imposition brings the danger of limiting the independence of management even in relation to enterprise rights. As Marlow (2003) notes many owners of smaller business units resist the use of formal policies in order to avoid the risk of damage to the team environment, the same may be true with regard to the involvement of trade unions.

Therefore, we can argue that regarding representation, consultation and the application of voice in the employment relationship in general, evidence (Millward et al., 1992; Cully et al., 1999) would indicate that there have been some considerable shifts in recent years regarding how these concepts are articulated in the workplace. However, whilst there has been considerable debate and discussion surrounding such shifts, little consideration has been afforded to how the context of the organisation might affect such issues in the first instance. This chapter has focused more specifically upon the notion of firm size finding that this will shape and influence representation and voice. We saw that along with specific management styles, smaller organisations adopt approaches to consultation and information which reflect the preference of the dominant party within the employment relationship; be that the individual owner or the management cadre. The legacy of the thesis put forward by the Bolton Report (1971), involving the much debated harmony, continues in this area based on the use of open door policies, face-to-face communication and allemployee briefing sessions and infects the development of the debate. This chapter has considered the manner in which the introduction of legislation in the area of information and consultation will impinge upon the exercise of managerial prerogative within the small business sector. In so doing we suggested that, as with all legislation, the regulatory shock wave will, to differing degrees, interfere with traditional ownership rights depending upon existing practices. The wide range of current practice suggests that 
the costs of implementation will be unevenly distributed across the sector and that smaller firms will, therefore, choose to implement consultation mechanisms only where they can see clear cost advantages. The issue is indivisibly coupled to the development of internal (organisationally based) dispute resolution procedures, despite the fact that business organisations and pressure groups have suggested that no change will be needed. Our discussion indicates that such a position is utopian, denies the reality of the situation in the sector and perpetuates a mythical image of the employment relationship.

Following the winding up of the Panel on the Monitoring of Labour Legislation in 1983, research into the effects of regulation has been sporadic with reference to larger organisations and just beginning to emerge in relation to smaller firms. Whilst the current regime of impact assessments allows for analysis of financial implications there is a dearth of research relating to the impacts in the realm of employment relations. As the field of representation and consultation within the smaller firm sector is also a neglected area in the literature, the introduction of applicable legislation in this area will provide a stimulus for further, more detailed analysis of the current practice linked to an investigation of the organisational effects of labour legislation.

\section{References}

Bingham, L. and Chachere, D. (1999) 'Dispute resolution in employment: the need for research', in Eaton, A. and Keefe, J. (eds) Employment Dispute Resolution and Workers Rights in the Changing Workplace, Illinois: Industrial Relations Research Association.

Blackburn, R. and Hart, M. (2002) Small Firms' Awareness and Knowledge of Individual Employment Rights, Employment Relations Research Series No. 14, London: HMSO.

Bolton Report (1971) Report of the Committee of Enquiry on Small Firms, Cmnd 4811, London: HMSO.

Brown, W., Deakin, S., Hudson, M., Pratten, C. and Ryan, P. (1998) The Individualisation of Employment Contracts in Britain, Research Paper for the Department of Trade and Industry, London: HMSO.

Bullock Report (1978) Report of the Committee of Enquiry on Industrial Democracy, Cmnd 6706, London: HMSO.

Burgess, S., Propper, C. and Wilson, D. (2001) Explaining the Growth in the Number of Applications to Industrial Tribunals, 1972-1997, Employment Relations Research Series No. 10, London: HMSO.

Carter, S. and Jones-Evans, D. (2000) Enterprise and Small Business: Principles, Practice and Policy, London: Prentice Hall.

Cully, M., O'Reilly, A., Millward, N., Forth, J., Woodland, S., Dix, G. and Bryson, A. (1998) The 1998 Workplace Employee Relations Survey, London: Routledge.

Cully, M., Woodland, S., O'Reilly, A. and Dix, G. (1999) Britain at Work: As Depicted by the 1998 Workplace Employment Relations Survey, London: Routledge. 
Department of Employment (1988) 'Reporting employee participation initiatives', Employment Gazette, October, 574.

DTI (2002) Findings from the 1998 Survey of Employment Tribunal Applications, Employment Relations Research Series No. 13, London: HMSO.

DTI (2003) High Performance Workplaces - Informing and Consulting Employees: Consultation Document, DTI, London: HMSO.

Duberley, J. and Walley, P. (1995) 'Assessing the adoption of HRM by small- and medium-sized manufacturing organizations.' International Journal of Human Resource Management, 6(4):891-908.

Dundon, T. (2002) 'Employer opposition and union avoidance in the UK', Industrial Relations Journal, 33(3):234-45.

Dundon, T., Grugulis, I. and Wilkinson, A. (1999) 'Looking out of the "Black Hole": non-union relations in an SME', Employee Relations, 21(3):251-66.

Eaton, A. and Keefe, J. (eds) (1999) Employment Dispute Resolution and Worker Rights in the Changing Workplace, Illinois: Industrial Relations Research Association.

Edwards, P. (2003) Industrial Relations: Theory and Practice, 2nd edn, Oxford: Blackwell Publishing.

Etzioni, A. (1961) A Comparative Analysis of Complex Organisations, New York: Henry Holt and Co.

Flood, P., Gannon, M. and Paauwe, J. (1996) Managing Without Traditional Methods: International Innovations in Human Resource Management, Wokingham: Addison-Wesley.

Freeman, R. and Rogers, J. (1999) What Workers Want, Ithaca, New York: Cornell University Press.

Goss, D. (1991) Small Business and Society, London: Routledge.

Guest, D. and Rosenthal, P. (1993) 'Industrial relations in green field sites', in Metcalf, D. and Milner, S. (eds) New Perspectives on Industrial Disputes, London: Routledge.

Hirschmann, A. (1971) Exit, Voice, and Loyalty, Cambridge, Mass.: Harvard University Press.

Kaufman, B. and Taras, D. (eds) (2000) Non Union Employee Representation: History, Contemporary Practice, and Policy, New York: M. E. Sharpe.

Lewin, D. (1999) 'Theoretical and empirical research on the grievance procedure and arbitration: a critical review', in Eaton, A. and Keefe, J. (eds) Employment Dispute Resolution and Worker Rights in the Changing Workplace, Illinois: Industrial Relations Research Association.

Lewin, D. and Mitchell, D. (1992) 'Systems of employee voice; theoretical and empirical perspectives', California Management Review, 34(1):95-111.

Marchington, M., Goodman, J., Wilkinson, A. and Ackers, P. (1992) New Developments in Employee Involvement, Employment Department Research Series No. 2, London: HMSO.

Marlow, S. (2000) 'People and the small firm', in Carter, S. and Jones-Evans, D. (eds) Enterprises and Small Business, London: Prentice Hall.

Marlow, S. (2002) 'Regulating labour management in small firms', Human Resource Management, 12(3):25-43.

Marlow, S. (2003) 'Formality and informality in employment relations: the implications for regulatory compliance by smaller firms', Government and Policy, 21:531-47. 
Millward, N., Bryson, A. and Forth, J. (2000) All Change at Work?, London: Routledge.

Millward, N., Stevens, M., Smart, D. and Hawes, W. R. (1992) Workplace Industrial Relations in Transition: The ED/ESRC/PSI/ACAS Surveys, Aldershot: Dartmouth.

Noon, M. and Blyton, P. (2002) The Realities of Work, Basingstoke: Palgrave.

Parker, M. (2002) Against Management, Cambridge: Polity Press.

Rainnie, A. (1989) Industrial Relations in Small Firms, Small Isn't Beautiful, London: Routledge.

Ram, M., Edwards, P., Gilman, M. and Arrowsmith, J. (2001) 'The dynamics of informality: employment relations in small firms and the effects of regulatory change', Work, Employment and Society, 15(4):845-61.

Scase, R. and Goffee, R. (1980) The Real World of the Small Business Owner, London; Croom Helm.

Terry, M. (1999) 'Systems of collective employee representation in non-union firms in the UK', Industrial Relations Journal, 30(1):16-30.

Toner, W. P. (1987) 'Union or non-union: contemporary employee relations strategies in the Republic of Ireland', in Flood, P., Gannon, M. and Paauwe, J. (eds) Managing Without Traditional Methods: International Innovations in Human Resource Management, Wokingham: Addison-Wesley.

Towers, B. (1997) The Representation Gap: Change and Reform in the British and American Workplace, Oxford: Oxford University Press.

Tremlett, N. and Banerji, N. (1994) The 1992 Survey of Industrial Tribunal Applications, Employment Department Research Series No. 22, London: HMSO.

TUC (2003) 'TUC welcomes likely crackdown on long hours', TUC News, November.

Verma, A. (2000) 'Employee involvement and representation in nonunion firms: what Canadian employers do and why?', in Kaufman, B. and Taras, D. (eds) Nonunion Employee Representation: History, Contemporary Practice, and Policy, New York: M. E. Sharpe.

Willey, B. (2003) Employment Law in Context: An Introduction for HR Professionals, London: Prentice Hall.

Workplace Employment Relations Survey (1988) London.

Wynarczyk, P., Watson, R., Storey, D., Short, H. and Keasey, K. (1993) Managerial Labour Markets in Small Firms, London: Routledge. 


\section{Index}

In locator numbers, $\mathrm{n}$ is notes and $\mathrm{t}$ is table

administration of regulations 169 advantages of training 99

allocation criteria 180, 186, 188, 191

apprenticeships 96, 100

bargaining power 49, 79, 174

Bolton Report (1971) 48, 160, 181, 218

bonus 190, 193-4; variable system 195

breakout $12,110,112-13,125,127$;

location 124; proactive strategies 117; typology of $118 \mathrm{t}$

business growth 29, 27, 77-9, 124; changes in 150; reorientation 113

Business Improvement Tool for Entrepreneurs (BITE) 101, 104

business start-up 72, 126; risks 73

cash-based profit-sharing scheme 183

centralisation and decentralisation 79 , 81

CIPD (Chartered Institute for

Personnel and Development) 23, 36, $38 \mathrm{n}$

class resources 110-14, 121-2, 124, 127

client orientation of staff 73-6, 78

collective agreements 57

collective bargaining 6, 44, 54, 178, 192

collective redundancies 205

collectivism in employment 58-9

commercial trap 117

commissioning agents 72

committed staff $77,182,196,210,212$

communication 203-5, 214

comparative earnings 186

competition $13,83,110,113,119-23$, 126-7, 159, 160-1, 163, 166-7; from big chains 162 competitiveness 86-7, 97, 133, 139; effect of WTD 135

compliance burden 143

compliance costs 134, 140, 172, 205;

in small firms 13, 139

confederate structures 78-9; devolved 80

conflict at work 44, 46t, 71, 210

consultation $14,79,182,191-3,195$, 198, 203-5, 208, 210, 215;

effectiveness of 206; increased requirements 207; and information 212, 217; lack of 193; mechanisms 209, 212; trigger for 206

consultation in smaller organisations, legislation for 198

consumer markets 72

context 12, 30, 35-7, 103, 218

control and indeterminacy 26

cost of implementation of legislation 139, 208, 212, 219

cultural contexts $20,35,37,181,211$

customers $72,117,121,124$

decision-making processes $69,79-80$, 181; legitimacy of $69,79,208$

delegation, systems of 71,76

Department of Trade and Industry 60, 142

dependency relations 69-70

differentiation 68, 124

discriminatory wage practices 133 ;

elimination of 155

dispute resolution 212

distancing 198

distributive injustice 190-1, 195

distributive justice 178-80, 182, 186, 
189-90, 198; perceptions of 188, 195, 199

distributive outcomes 185

diversifying 111, 121

economic market context, variations in 48

effort and productivity, pay related 14 effort wage bargain 1-2, 8, 28, 52, 164, 171,203

embeddedness 31, 68, 110, 116; mixed 109, 125; personal networks 75; retention of 31 ; social 12,30

embeddedness and ethnicity 12 employee representation 2, 15, 53, 217 employee voice 30, 182, 191, 202-3,

216-18; demand for 198; individual

211; for judgement recipients 180 ; lack of 181,193-4; mechanisms 181, 217; in smaller firms 15, 181, 192 employees 67 ; construction of 30 employees' skills 84, 104; audit 104-5, base 83; deficiencies 91; gap identified 93; passport 103; required in current job 97; training needs 95

employers' groups 143

employers' perceptions: lost authority 208; trade unions 210, 211; voice for employees 210

employers' representative bodies 152 employers' strategies 162, 169

Employment Act (2002) 7 employment in small firms 43, 58, 161 employment issues procedures 182 employment legislation 134, 139, 143; impact on small firms 152, 179 employment levels reduced 165-6 employment protection legislation $46 \mathrm{t}$ employment regulations 7, 22, 127, 174; in smaller organisations 26,179 employment relations $28,35,44,51$, 54-5, 59, 193, 217, 219; agenda 50; literature 60-1; researchers 60-1; typologies 49

Employment Relations Act (1999) 7, 12-13, 35-6, 134, 141

employment relationships 1, 4-7, 10, 49, $125,170-1,198$; in small firms 8-9, 43-7t, 48, 51-3, 56, 58, 60-2

employment rights 148, 149t, 150-2; employers' knowledge of 141, 141t, 144,154 ; knowledge of 207; perceived impact of 143; in small firms 152 employment tribunals 7, 145, 207, 215 entrepreneurs 66, 69, 71; strategies 125 entrepreneurship literatures 59 establishments and enterprises 57 ethnic minority enterprise 109-12, 114-16, 120-1, 125-7; business trap 123

ethnic minority entrepreneurs 115,127 ethnic minority labour 12, 110, 121, 162 ethnic resources 109, 113-14, 128 European Directive 203-4, 212, 216-17 European integration 7, 138, 198

European Union 12-13, 133, 205; labour market standards 155 ; objectives 155

exit strategies 181

exploitation 2-3, 6, 74, 213; of dependent ethnic networks 166-7

external conditions 8, 49-51, 124, 126

face-to-face mechanism of direct control 69, 208, 210, 218

failure rates in small businesses 13, 67 familial culture in small businesses 31 , 51-2, 210, 215, 217

family and co-ethnic labour 109-10, $113,119-20,123,126,165$

family friendly employment regulations $13,56,140$

financial and human capital, access to 126

flexibility of work methods 72, 95, 119, 126; barriers to 212

flexible employment conditions 134-9

formal employment relations 37, 57-8

formal policies and procedures 5, 44, 94 , 216

formal training in small businesses 34 , 93; under department heads 169

friction, interpersonal 80

government bodies 53,62 ; government regulation 139-40, 143, 154 government training initiatives 60, 84, 90. 99, 100, 102, 105; awareness of 86 ; employers' attitudes to 99 grievance procedures 7, 206, 210-11, 216

growth management $73,79-80$

harmony in small firms 2, 45t, 46t, 49, 50, 191, 213; discredited 206

health and safety regulations 33,88 hierarchical authority 75, 77, 80, 160, 202 


\section{Index}

higher order sectors 112

higher wage-skill equilibrium 167

HR professional function 5-6; autonomy in 183; policies 203, 214

HRM 2, 9, 11, 21-3, 25-6, 34, 125, 210; discourse 20,36; language and ideology 36; motivational approach 24

HRM and performance 19-20, 23-5, 27-8

HRM in small businesses 9, 19-20, 24, $27-8,35-6,160$

human capital 83,89

human resource management see HRM

human resources 22,95

IER legislation 138, 144, 155; administrative workload 139, 150, 152 ; constraint to employing new staff 155; effect in small firms 155 ; impact 138, 154; knowledge levels 142, 154, 156; perception of impact 146

IERS: awareness of IERS 147-8

IiP 19, 36, 38n, 84, 99

illegal ways of working 160, 165-6, 172-4

Individual Employment Rights see IERs individualism in employment 58-9, 75, 209-10

industrial relations 52-3, 55

influence gap 204, 215, 218

informal training 93-4, 99, 101, 103; preference for 92-3; significance of 104; validity of 93; value of 92, 103; value offered 100

informal training in smaller firms see training in smaller firms

informality 6, 9, 46t, 47t, 49, 51, 58, 80, $170-1$; internal pay structures 169 ; in small firms 58, 61

information $31,79,206,213$; right to receive 203; mechanisms 215

Information and Consultation Directive $15,204-5$

information gap 37

informational injustice 196

innovative products/markets 104, 127

integration and differentiation 67, 74

interactional injustice as active malice 197

interactional justice $178,181,196-7$

internal dispute resolution procedures 219 interpersonal justice 182

Investors in People see IiP

IR (industrial relations) 18-19

justice judgement theory 180

justice perceptions critical during

organisational change 198

justice perceptions in SMEs 178

Labour government policy 7

labour management literature 60 ; in small firms 44, 49, 52; in the workplace 53

labour management practices 19-20, $23,25,31,37,183$; and performance 24

labour management strategies 9-10, 12; in market economy 1 ; in small firms 2,14

labour market 70, 161; policy 37, 133; pressures 171; regulation 12

legislation 35-6, 100, 212; awareness of 210; changes 136 ; costs for employers 140; framework 133

legislative pressure 205-6, 218

low wages $49,73,159,164,179,214$; in small firms 160, 179

management competencies 75-6

management function $67-8,77-8,80$; lack of specificity $74-5$

management practices $33,36,121,165$, 213,217 ; changes in 112 ; determinants of 81; informality in 119 management styles 3, 73-4, 79, 196, 205, 208; autocratic 49, 70, 74, 181, 192 , 208; consultative 211; informal 204 management system, formal HR 213 management training $36,95,101$; impact on firm performance 94 management-labour relations 28,182 managerial competence 32,34 managerial prerogative 6, 207, 215, 218 managerial role $21,71,74,78$ managerial strategies $11,37,66,81$ managers in smaller firms 21, 24, 35, 95 managers' resistance to structural imposition 37, 181

market conditions 1, 4-5, 50; determinism 3; environment 117 , 128n;

market position 89,121 ; reorientation 112

market saturation $117,120,127$ 
Maternity and Parental Leave

Regulations 1999141

mentoring and coaching 101

motivations to train $74,85,87-8,100$, 105

multiple business ownership 117, 120-2

multi-skilling 95, 169

mutual adjustment $68,70,76-7$

mutual dependence 4, 50, 170, 174

national collective agreement 58, 136

National Minimum Wage Agreement 1998 see NMW

negative effects of legislation 150, 195 negotiated employment relationship 9 negotiated order $47 \mathrm{t}, 181$

negotiation 4-5, 19, 50-1, 77, 162, 135

new wave firms 213-14

niches 2, 67, 71, 112-13; appropriate

121; creation of 123; exclusive 124; overpopulation of 119; shift to 167 , 172

NMW (National Minimum Wage) 7-8, $13,134,141,159$; adjusting to $162-3$; cost implications of $164,169,170-1$; effects on pay 166,168 ; effects in small firms 161; impact 14, 60, 150, 169, 171, 174; implementation 165, 167 ; regulatory shock $6,159-60$, $170-2,174$

non-union sector 54, 58, 211, 216

NVQs 84, 86, 100

off the books working 119, 163, 165, 172 on the books employment practices 125 open door policies 211, 213-14, 216-18 organisation: performance 25, 195; power relations 22; unionised 216 organisational justice 14, 178-9, 199 organisational structures 81 ; within smaller firms 96 orientation to training 97,99 overall performance of the business 77 owner: management style 125 ; perceptions of the value of training 85; preference 8 ; prerogative $2-3,7-8$ owner-manager 26-7, 49, 79; 94-5, 100,

121 ; ability of 167 ; authority and power of 171; competence of 170 ; knowledge of regulations 139,143 , 145; management style 49, 52, 140

partnerships 72-4; professional 79 part-time employees see women paternalism in labour management 4 , $49,70,74,110,113,181,208-9$

paths of adjustment 162

pay increases 186, 188, 195; compensatory 138; negotiated 135

pay levels 55; arbitrary approach 163 ; centrality to employee concerns 198; decision procedures 191; discussions 216 ; inequality, perceived 211; noncompetitive 168; performance-related 14; review $163,166,169$; setting 34 , 119, 168-9, 174, 186;

pay systems $21-2,28,33,69,172,188$, 195; cash-in-hand pay 166; change $164,168,178,191-3,198$; choice in smaller firms 179, 180; day-rate 165; design 182; discrimination 188 ; fairness, perceptions of 180, 192, 194-5; incentives 56

performance 23, 38n, 163, 167, 188, 209 , 215; appraisal 33, 56; constraints on 147-8, 148t, 150; HRM 24; monitoring 70, 76, 79-80; 168-9; regulations 143 , 146; standards 80 ; targets 34,104

personnel management 19, 22, 26, 29, 58 ; in small firms $20,23,34$ piecework 165-8, 183, 187-8, 194, 215 power and authority $217-18$ power relations 20,37; asymmetry 50; in labour management 34

Pregnant Workers Directive 141 procedural justice 178, 180-2, 188, 191, 194-5; injustice 198; mechanisms 181

procedural justice, interpretation of 192 product differentiation 117, 121-4 production manager 15 productivity 4, 94, 135-8, 155, 194 , 211-12

professional and creative small businesses $66-8,71,75-6,78,80$ professional bodies 73,75 professional intermediaries 105 profit and loss centres 79 profit-sharing 188, 193 proprietors $68-9,71,74,77,81$; selfemployed 67; styles 69-70

PRP (profit-related-pay) 183, 187, 190 psychological rewards 73 psychometric testing 24-5, 35

qualifications $86,88,92,97,99$; compulsory 100; formal 103 


\section{Index}

recruitment 21-2, 121, 126; formalised methods 31,123 ; informality 119 ; personal control 32; state regulated 30

regulation 9, 206; avoiding 126; cost implications 170; effects of 219; negative effects 163 ; specific for subject 206

regulatory burden $13,143,205$

regulatory shock 206, 218; see also NMW

relationships depersonalised 197 relocation, geographical 117, 124-5 repositioning in the market 165 representation 203-4, 209-10; collective 215; and consultation 208, 217-18 representation gap 202, 215, 218 resistance: to external advice 154; to pay systems 198; to regulation 35 responsibility 80 ; of HR managers 21 ; of local employers 70 rewards 183, 195, 208; allocation criteria 185-7, 188, 191, 195; non-pecuniary $45 \mathrm{t}$; perceptions of fairness 204 rights to reinstatement 140

sectoral context 1,3,110, 209; location 12, 126-7; skewedness 111 segmentation 99, 104, 147, 161, 171 self-employed 66-7, 72 signposting 105 size of business: distribution 57; influence of 27, 76, 96, 214 skills in the workforce $33,71,74,86$, 209, 213; interdependence of 76; shortage 167 ; specialist $72-3,77$; transferable 103

skills, management $67,71,79$

skills-based pay system 183, 187, 195

Small Business Council (SBC) 83

small businesses 26, 29, 47t, 48; changes in 165; disadvantages of 160-1; employment relations 55t; literature $43,59-61$; pressure groups $8,13-14$

small firms see small businesses

Small Firms Training Loan Scheme 91

SMEs (small and medium sized enterprises) 178-9

South Asian entrepreneurs 112, 114-15; growth in 126; response to market demands 126-8; self-employed 111 staff commitment and output 69 statutory working week 136 strategy formulation $66,77,79,91,120$

structural determinism 49-50, 52, 61

support staff, rewards for 75

survivalists 109-10, 117-20, 126

teams $68,76,168,212,214,218$

tension 32, 37; workplace 74-5, 79, 81

Trade Union Reform and Employment Rights Act (1993) 141

trade unions $34-5,52-7,136,192-3$, 203-5, 213, 215; representation 7, $38 \mathrm{n} ; 56,58,211,216-17$; resistance to 214

trainers 97,98 ; local provider 216 ; onthe-job 96; quality of 102

training $21-2,32-3,85-8,91-3,97-8$, 100, 102: appropriate 89, 99, 101; barriers to $85,89,91,98-9$; continuous 92-4; cost 88-90, 99; induction $33,75,87,92-3$; investment in $87-9,100,105,167$; opportunities 84; plans and budget 91, 96-7; take up 83-5, 98-101, 103

training in small firms $11,83-7,92-9$, 101,105 ; barriers to 88 ; needs 87 , 100

training index values 97

training initiatives 86-7, 90-2, 95, 97, 100, 102-4, 105; availability 91, 195; critical assessment 104-5; ownermanagers awareness levels 88; sectoral effect 96-7; subsidised 85; targeting 99, 100

tribunal applications 206-7, 211

trust 209, 214; deficit of 218; in employment relationships 214

unemployment $135,160,167,174$; in the ethnic community 116

unfair dismissal, protection from 141 unit labour costs 135

universality of justice perceptions 182 unskilled labour 70, 119, 214

variable pay systems $14,178,183,186$, 189, 191, 198-9

variation in pay for same work 163 vested interests, protection of 79 voice see employee voice

WERS (Workplace Employee Relations Survey) 10, 44, 53-5, 58, 61

WIRS (Workplace Industrial Relations Survey) 44, 53-4, 57-8, 62 
women and part-timers in the labour market $135,147,152,153 \mathrm{t}, 162$; in ethnic minority firms 123 work activities 73-4; project-driven 76 work intensification 169, 174 work orientation 48,66 workforce 50, 94, 148, 150, 165-6 working hours, reduction in 137-8 Working Time Directive see WTD workplace 44, 52, 56, 202, 204, 210, 216; dispute resolution 207, 211; problems WTD (Working Time Directive 1998) legislation 134-8, 140 WTD positive employment effects 138 

eBooks - at www.eBookstore.tandf.co.uk

\section{A library at your fingertips!}

eBooks are electronic versions of printed books. You can store them on your PC/laptop or browse them online.

They have advantages for anyone needing rapid access to a wide variety of published, copyright information.

eBooks can help your research by enabling you to bookmark chapters, annotate text and use instant searches to find specific words or phrases. Several eBook files would fit on even a small laptop or PDA.

NEW: Save money by eSubscribing: cheap, online access to any eBook for as long as you need it.

\section{Annual subscription packages}

We now offer special low-cost bulk subscriptions to packages of eBooks in certain subject areas. These are available to libraries or to individuals.

For more information please contact webmaster.ebooks@tandf.co.uk

We're continually developing the eBook concept, so keep up to date by visiting the website. 
